\title{
A Novel Technique for the Addition of Hydrogen to Zirconium Alloys: \\ Mechanical Hydrogen Ingress and its Applications
}

\section{by}

\author{
Curtis St. Louis \\ B.Eng. Aerospace
}

A thesis submitted to the Faculty of Graduate and Postdoctoral Affairs in partial fulfillment of the requirements for the degree of

\author{
Masters of Applied Science \\ in \\ Mechanical Engineering
}

Ottawa-Carleton Institute for Mechanical and Aerospace

Engineering

Carleton University

Ottawa, Ontario, Canada

(C) 2015, Curtis St. Louis 


\begin{abstract}
This thesis outlines the development of the Mechanical Hydrogen Ingress (MHI) technique, which is a novel method of adding hydrogen to zirconium. The method was shown to have an uncertainty of $2 \%$ of the predicted hydrogen concentration plus $1.4 \mathrm{ppm}$ (i.e. a sample with $50 \mathrm{ppm}$ would have an uncertainty of $0.02(50)+1.4=2.4 \mathrm{ppm}$ ). The MHI technique was used to add a known amount of hydrogen to a low-hydrogen zirconium sample in order to determine the initial hydrogen concentration using the differential scanning calorimetry technique, to determine the hydrogen solubility in copper, and to add hydrogen to zirconium at temperatures below $350^{\circ} \mathrm{C}$ to support life-extension experiments on irradiated ex-service CANDU pressure tubes.
\end{abstract}




\section{Acknowledgements}

I would first like to express my sincere gratitude to my supervisor, Dr. Glenn McRae, for his guidance, and financial support throughout my research. Through his guidance, and support I have gained valuable insights in science, as well as a renewed respect for the responsibilities of an engineer to society.

I owe a debt of gratitude to Kit Coleman who in concert with my supervisor aided me in my interpretations, and understanding of material science in the nuclear industry.

I would like to also thank Gabe Surrette, and Scott Langille with whom I have worked for the last few years at Carleton University. As well, I would like to thank Sean Hanlon, and Scott Read for their time, and support at Carleton University, and as employees of CNL. I would like to especially thank Jacob Schultz for his work on the clamshell oven, and thermal control system.

I can't thank Kieran Sutch enough, who as an undergraduate research assistant has aided me in my research with his tireless work, and enthusiasm. I know that he will be a great engineer in the near future.

I would also like to thank the staff of both the Mechanical and Aerospace Engineering, and Civil and Environmental Engineering departments for their help administrative, and technical support.

Lastly, I would like to thank my friends, and family who have helped me in innumerable ways and keeping me focused throughout my time here at Carleton University. Specifically my mother and father who supported me in my studies, and my brother and sister-in-law who have been the best of friends to me. 


\section{Table of Contents}

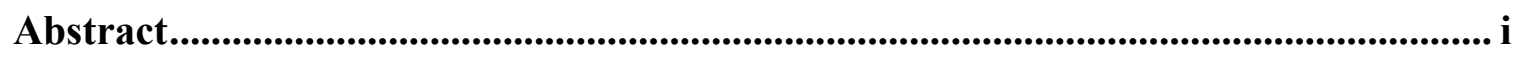

Acknowledgements ........................................................................................................................... ii

Table of Contents ......................................................................................................ii

List of Tables ................................................................................................................................ vi

List of Figures.............................................................................................................................. vii

List of Abbreviations ........................................................................................... xiv

Chapter 1: Introduction ............................................................................................................... 1

$1.1 \quad$ Zirconium and the Nuclear Industry ..................................................................

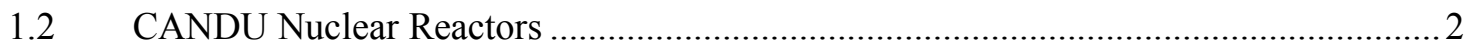

1.3 Delayed Hydride Cracking …………………………...........................................

1.4 Hydrogen Related Failures, and the Leak-Before-Break Principle ................................. 6

1.5 Techniques for the Addition of Hydrogen to Zirconium ...............................................

1.6 Research Motivation and Objectives .......................................................................

$1.7 \quad$ Thesis Organization ......................................................................................... 11

Chapter 2: Literature Review ............................................................................................. 12

$2.1 \quad$ Zirconium and Hydrogen System............................................................................ 12

2.2 Techniques of Hydriding Zirconium ....................................................................... 15

2.2.1 Electrolytic Hydriding .................................................................................. 15

2.2.2 Gaseous Hydriding .......................................................................................... 17

2.2.3 Lithium Hydroxide Corrosion ............................................................................ 18

2.3 Techniques for Measuring Hydrogen in Zirconium ...................................................2 20

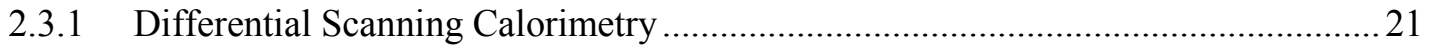

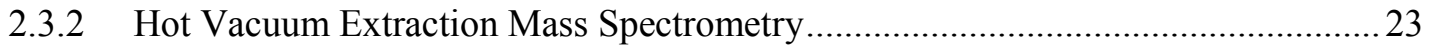


2.3.3 Inert Gas Fusion Thermal Conductivity Analysis ..............................................25

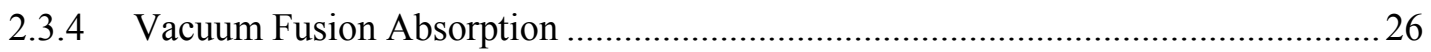

Chapter 3: Experimental....................................................................................... 28

3.1 Mechanical Hydrogen Ingress of Zirconium Experiment ..........................................28

3.1.1 Zirconium Sandwiched Hydride Experiment...................................................... 30

3.1.2 Copper-Shell Mechanical Hydrogen Ingress Experiment .......................................32

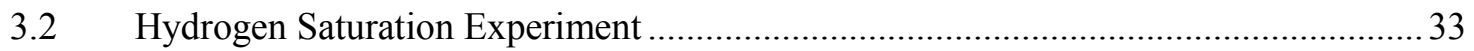

3.3 Mechanical Hydrogen Ingress - DSC Hydrogen Analysis ...................................... 33

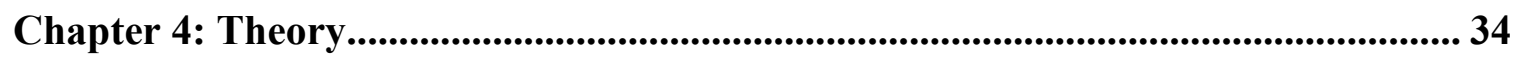

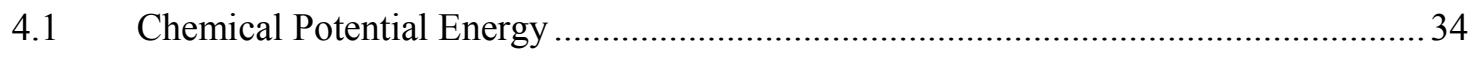

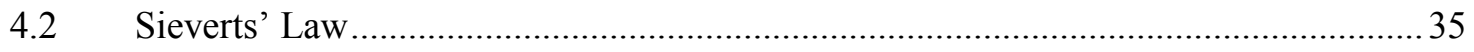

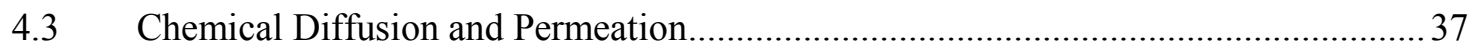

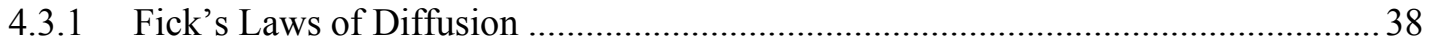

4.3.1.1 Diffusion in a Semi-Infinite Plane Sheet ........................................................... 39

4.3.2 Permeation of Hydrogen through a Zirconium ...................................................... 40

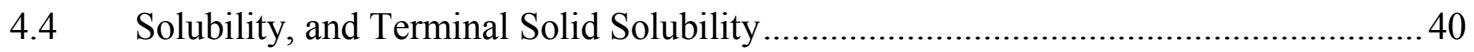

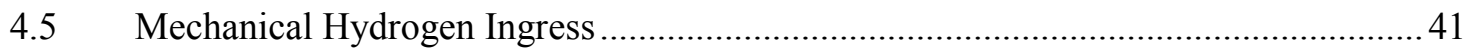

4.6 Measuring Solubility of Hydrogen in Other Metals ................................................ 48

Chapter 5: Results and Discussion .................................................................. 49

5.1.1 Zirconium Sandwiched Hydride Experiment....................................................... 49

5.1.2 Copper-Shell Mechanical Hydrogen Ingress Experiment ..................................... 52

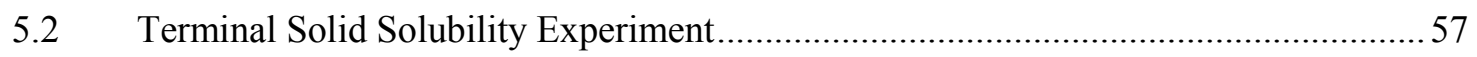

5.3 Mechanical Hydrogen Ingress to Enhance DSC at Low Concentrations .....................58

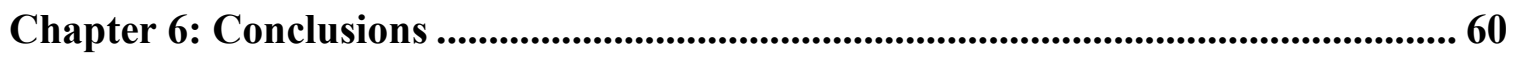

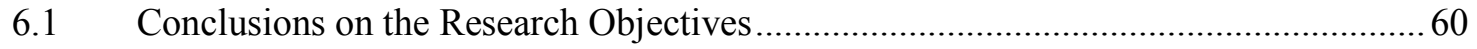


6.1.1 The Manufacture of Standards with Accurate, and Precise Concentrations of Hydrogen, and Deuterium in Zirconium

6.1.2 The Measurement of Low Hydrogen Concentrations in Zirconium .........................61

6.1.3 Determination of Hydrogen Solubility in Low Solubility Metals............................61

6.1.4 Determination of the Hydrogen Terminal Solubility Limit in Zirconium ................62

6.1.5 The Addition of End-of-Life hydrogen Concentrations to Zirconium at

Temperatures that do not Remove Irradiation Damage .62

6.2 Future Work 62

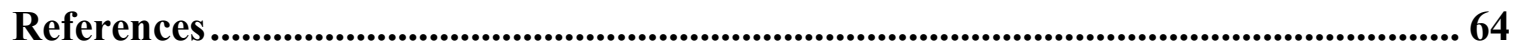

Appendices...................................................................................................................I

Appendix A Procedure for Mechanical Hydrogen Ingress......................................................

A.1 Procedure for Zirconium Sandwiched Hydride Technique........................................

A.2 Procedure for Copper-Shelled Mechanical Hydrogen Ingress Technique ................ V

Appendix B Cylindrical Clamshell Oven and Controller Design..........................................IX

B.1 Oven Controller Circuit Diagram......................................................................

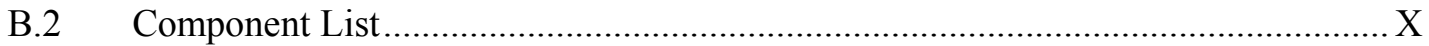

B.3 Description of Controller device …….............................................................

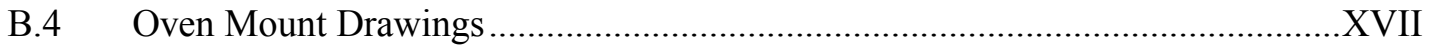

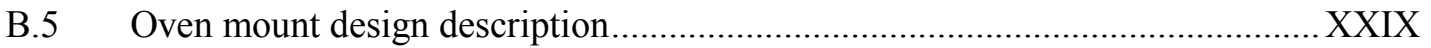

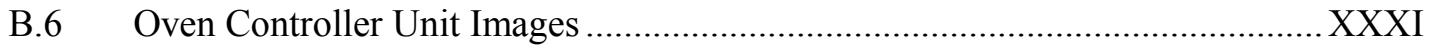

B.7 ESA Final Inspection for Certification.......................................................XXIV

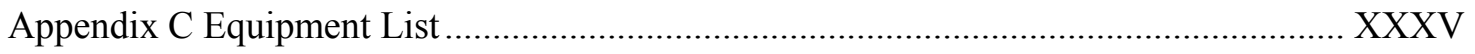

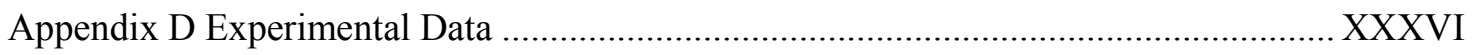

D.1 Data from Zirconium Sandwiched Hydride Experiment …........................... XXXVI

D.2 Data for Copper-Shell Mechanical Hydrogen Ingress Experiment.................... LXVI 


\section{List of Tables}

Table 1: Sample test punch description, and size

Table 2: Comparison of potential barrier materials (Red shading indicates

disqualification) [36, pp. 890-915] [14] [15] [32] [37] [38]

Table 3: Terminal Solid Solubility experimental results (MS means maximum slope, OS means onset), errors in $\mathrm{C}_{\mathrm{Zr}}$ in both predicted, and observed values are found in Appendix

E.2.

Table 4: MH-DSC determination of initial hydrogen concentration of Zircaloy-2 Sheet 59

Table 5: List of Equipment XXXV

Table 6: Zirconium Sandwiched Hydride Experimental Data LXIV

Table 7: Copper-shell mechanical hydrogen ingress experimental data XCIV 


\section{List of Figures}

Figure 1: General Layout of a CANDU PHWR Reactor [3] ........................................ 3

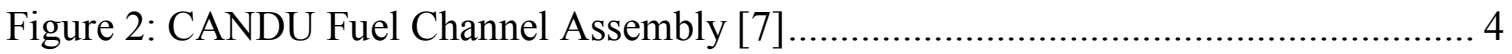

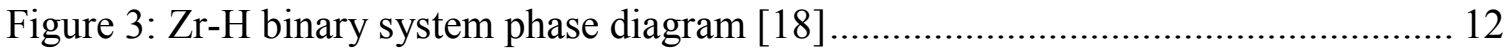

Figure 4: Terminal Solid Solubility curves for hydrogen in Zircaloy-2. The bottom (red) and top (blue) lines represent TSSP and TSSD, respectively. On the left of the curves there is both $\boldsymbol{\alpha} \mathbf{Z r}$ and hydride phases, whereas, on the right there is only $\boldsymbol{\alpha} \boldsymbol{Z} \boldsymbol{r}$ phase. The numbered points are used in-text to illustrate the standard interpretation of hysteresis in

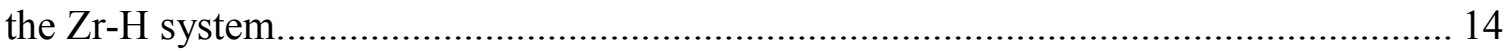

Figure 5: Hydrogen uptake rate in lithium hydroxide corrosion hydriding at $300{ }^{\circ} \mathrm{C}$ [27]

Figure 6: DSC heat flow for 126.3 ppm Zircaloy-2 sample. The TSSD maximum slope

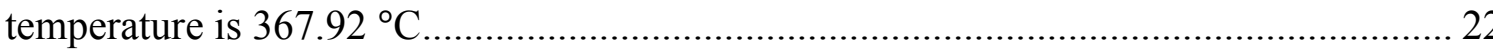

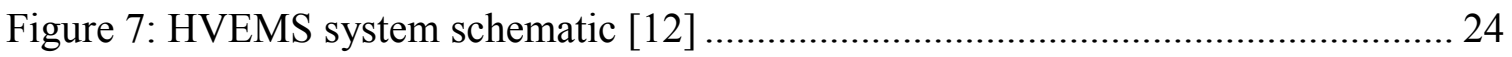

Figure 8: MTS-810 $500 \mathrm{kN}$ load frame with M42 steel platens, and clamshell oven ...... 29

Figure 9: Zirconium samples after hydrogen addition using sandwiched zirconium hydride technique. The holes are punches taken for hydrogen concentration

measurements. Refer to Table 1 for description of specimen punches. 31

Figure 10: Mechanical hydrogen ingress using a copper-shell modeled as a simple piston

Figure 11: A graphical representation of mechanical hydrogen ingress using a copper shell. The steps labeled a) through f) and are described in text 43 
Figure 12: Zirconium sandwiched hydride mechanical hydrogen ingress comparison of predicted, and measured concentration of hydrogen. The horizontal red line is TSSD maximum slope for

Figure 13: Concentration profile of sample J30-100. Black squares are bottom sheet data, and red circles are top sheet data. The predicted concentration was $113 \mathrm{ppm}$. 51

Figure 14: Copper-shell mechanical hydrogen ingress experimental results showing the predicted, and measured hydrogen concentrations. The large circle datum is not on the line because the total hydrogen concentration was insufficient to raise copper to its solubility, as described in Section 4.5

Figure 15: Solubility of Hydrogen in copper found in this study (Black Squares). The external data (unfilled data points) on the graph are recreated from [13]. 55 Figure 16: Failed copper seal on Sample Sat3-B. The dark oxide seen on the zirconium stain from the hydride powder is evidence of oxygen in the hydrogen gas pocket. 55

Figure 17: Terminal Solid Solubility Temperature for the Hydrogen Saturation

Experiment. The data follows the standard TSS trends............................................. 58

Figure 18: Oven controller, and oven circuit diagram................................................ IX

Figure 19: Thermal Control Enclosure Interior .................................................... XXXI

Figure 20: Thermal Control Enclosure Back Panel ...................................................XXXII

Figure 21: Thermal Control Enclosure Front Panel................................................XXXIII

Figure 22: DSC heating curve \#1 for sample F08-20-4T .................................... XXXVI

Figure 23: DSC heating curve \#2 for sample F08-20-4T .........................................XXXVII

Figure 24: DSC heating curve \#3 for sample F08-20-4T .....................................XXXVII

Figure 25: DSC cooling curve \#1 for sample F08-20-4T .......................................XXXVIII 
Figure 26: DSC cooling curve \#2 for sample F08-20-4T XXXVIII

Figure 27: DSC cooling curve \#3 for sample F08-20-4T XXXIX

Figure 28: DSC heating curve \#1 for sample J30-100-4T XXXIX

Figure 29: DSC heating curve \#2 for sample J30-100-4T XL

Figure 30: DSC heating curve \#3 for sample J30-100-4T XL

Figure 31: DSC cooling curve \#1 for sample J30-100-4T XLI

Figure 32: DSC cooling curve \#2 for sample J30-100-4T XLI

Figure 33: DSC cooling curve \#3 for sample J30-100-4T XLII

Figure 34: DSC heating curve \#1 for sample F09-50-4T XLII

Figure 35: DSC heating curve \#2 for sample F09-50-4T XLIII

Figure 36: DSC heating curve \#3 for sample F09-50-4T . XLIII

Figure 37: DSC cooling curve \#1 for sample F09-50-4T XLIV

Figure 38: DSC cooling curve \#2 for sample F09-50-4T. XLIV

Figure 39: DSC cooling curve \#3 for sample F09-50-4T XLV

Figure 40: DSC heating curve \#1 for sample J26-200-4T... XLV

Figure 41: DSC heating curve \#2 for sample J26-200-4T XLVI

Figure 42: DSC heating curve \#3 for sample J26-200-4T XLVI

Figure 43: DSC cooling curve \#1 for sample J26-200-4T XLVII

Figure 44: DSC cooling curve \#2 for sample J26-200-4T XLVII

Figure 45: DSC cooling curve \#3 for sample J26-200-4T XLVIII

Figure 46: DSC heating curve \#1 for sample J29-150-4T XLVIII

Figure 47: DSC heating curve \#2 for sample J29-150-4T XLIX Figure 48: DSC heating curve \#3 for sample J29-150-4T ...XLIX 
Figure 49: DSC cooling curve \#1 for sample J29-150-4T ................................................

Figure 50: DSC cooling curve \#2 for sample J29-150-4T ...............................................

Figure 51: DSC cooling curve \#3 for sample J29-150-4T ..............................................

Figure 52: DSC heating curve \#1 for sample stock material ...............................................

Figure 53: DSC heating curve \#2 for sample stock material .......................................... LII

Figure 54: DSC heating curve \#3 for sample stock material .......................................... LII

Figure 55: DSC cooling curve \#1 for sample stock material............................................. III

Figure 56: DSC cooling curve \#2 for sample stock material............................................ III

Figure 57: DSC cooling curve \#3 for sample stock material..........................................IV

Figure 58: DSC heating curve \#1 for sample J30-100-2T .............................................IV

Figure 59: DSC heating curve \#2 for sample J30-100-2T ............................................

Figure 60: DSC heating curve \#3 for sample J30-100-2T ........................................... LV

Figure 61: DSC cooling curve \#1 for sample J30-100-2T.............................................VI

Figure 62: DSC cooling curve \#2 for sample J30-100-2T ............................................VI

Figure 63: DSC cooling curve \#3 for sample J30-100-2T......................................... LVII

Figure 64: DSC heating curve \#1 for sample J30-100-1T .......................................... LVII

Figure 65: DSC heating curve \#2 for sample J30-100-1T ......................................... LIII

Figure 66: DSC heating curve \#3 for sample J30-100-1T .......................................... LVIII

Figure 67: DSC cooling curve \#1 for sample J30-100-1T...............................................X

Figure 68: DSC cooling curve \#2 for sample J30-100-1T............................................IX

Figure 69: DSC cooling curve \#3 for sample J30-100-1T.............................................. LX

Figure 70: DSC heating curve \#1 for sample J30-100-3B ...........................................

Figure 71: DSC heating curve \#2 for sample J30-100-3B..............................................XI 
Figure 72: DSC heating curve \#3 for sample J30-100-3B.............................................

Figure 73: DSC cooling curve \#1 for sample J30-100-3B .......................................... LXII

Figure 74: DSC cooling curve \#2 for sample J30-100-3B ........................................ LXII

Figure 75: DSC cooling curve \#3 for sample J30-100-3B .......................................... LXIII

Figure 76: HVEMS data from CNL Chalk River for Sandwiched Hydride experiment

LXIII

Figure 77: Heating run of a sheet of zirconium with no hydride powder. The TSSD

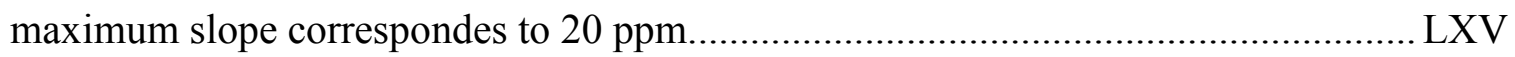

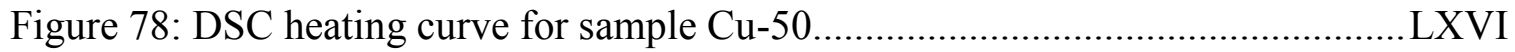

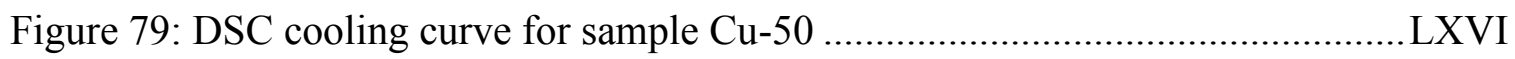

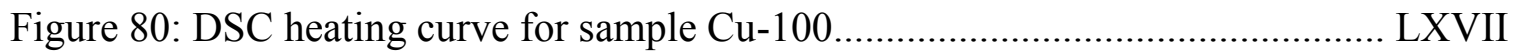

Figure 81: DSC cooling curve for sample $\mathrm{Cu}-100$............................................. LXVII

Figure 82: DSC heating curve from sample Cu-LT .............................................. LXVIII

Figure 83: DSC cooling curve for sample Cu-LT ……………………………...... LXIII

Figure 84: DSC heating curve for sample MH-DSC-1 …………………...................XIX

Figure 85: DSC cooling curve for sample MH-DSC-2 …………………………......XIX

Figure 86: DSC heating curve for sample MH-DSC-2 …………………….............XX

Figure 87: DSC cooling curve for sample MH-DSC-2 ………………….................XX

Figure 88: DSC heating curve for MH-DSC-3 ……………………………….......XXI

Figure 89: DSC cooling curve for sample MH-DSC-3 ……………...........................XXI

Figure 90: DSC heating curve of sample Sat2-B .................................................... LXXII

Figure 91: DSC cooling curve of sample Sat2-B................................................ LXXII

Figure 92: DSC heating curve of sample Sat2-M .................................................... LXXIII 
Figure 93: DSC cooling curve of sample Sat2-M............................................... LXXIII

Figure 94: DSC heating curve of sample Sat2-T ..................................................XXIV

Figure 95: DSC cooling curve for sample Sat2-T ……………………..............XXIV

Figure 96: DSC heating curve \#1 for sample A20-250-00 ......................................... LXXV

Figure 97: DSC heating curve \#2 for sample A20-250-00 ....................................... LXXV

Figure 98: DSC heating curve \#3 for sample A20-250-00 ......................................XXVI

Figure 99: DSC cooling curve \#1 for sample A20-250-00 .........................................XXVI

Figure 100: DSC cooling curve \#2 for sample A20-250-00 .....................................XXVII

Figure 101: DSC cooling curve \#3 for sample A20-250-00 ....................................XXVII

Figure 102: DSC heating curve \#1 for sample A16-200-00 ................................... LXXVIII

Figure 103: DSC heating curve \#2 for sample A16-200-00 .................................. LXXVIII

Figure 104: DSC heating curve \#3 for sample A16-200-00 .................................... LXXIX

Figure 105: DSC cooling curve \#1 for sample A16-200-00 .......................................XXIX

Figure 106: DSC cooling curve \#2 for sample A16-200-00 ...................................... LXXX

Figure 107: DSC cooling curve \#3 for sample A16-200-00 ..................................... LXXX

Figure 108: DSC heating curve \#1 for sample A29-175-00 ......................................XXXI

Figure 109: DSC heating curve \#2 for sample A29-175-00 ..................................... LXXXI

Figure 110: DSC heating curve \#3 for sample A29-175-00 .....................................XXXII

Figure 111: DSC cooling curve \#1 for sample A29-175-00 .....................................XXXII

Figure 112: DSC cooling curve \#2 for sample A29-175-00 .................................. LXXXIII

Figure 113: DSC cooling curve \#3 for sample A29-175-00 ................................... LXXXIII

Figure 114: DSC heating curve \#1 for sample A29-100-00 .................................. LXXXIV

Figure 115: DSC heating curve \#2 for sample A29-100-00 .................................... LXXXIV 
Figure 116: DSC heating curve \#3 for sample A29-100-00 ................................. LXXXV

Figure 117: DSC cooling curve \#1 for sample A29-100-00 ................................... LXXXV

Figure 118: DSC cooling curve \#2 for sample A29-100-00 .................................. LXXXVI

Figure 119: DSC cooling curve \#3 for sample A29-100-00 ....................................XXXVI

Figure 120: DSC heating curve \#1 for sample M05-010-00 ………………..........XXXVII

Figure 121: DSC heating curve \#2 for sample M05-010-00 ................................XXXVII

Figure 122: DSC heating curve \#3 for sample M05-010-00 ............................... LXXXVIII

Figure 123: DSC cooling curve \#1 for sample M05-010-00 .............................. LXXXVIII

Figure 124: DSC cooling curve \#2 for sample M05-010-00 ................................. LXXXIX

Figure 125: DSC cooling curve \#3 for sample M05-010-00 …………………...... LXXXIX

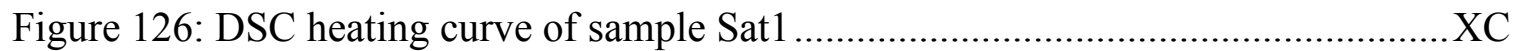

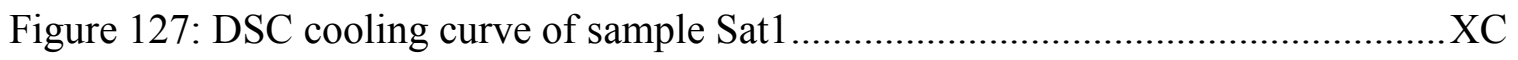

Figure 128: DSC heating curve of sample Sat3-B ................................................... XC

Figure 129: DSC cooling curve of sample Sat3-B..................................................... XCI

Figure 130: DSC heating curve of sample Sat3-M …………………….................. XCII

Figure 131: DSC cooling curve of sample Sat3-M..................................................... XCII

Figure 132: DSC heating curve of sample Sat3-T .................................................. III

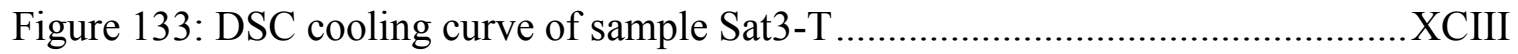




\section{List of Abbreviations}

\begin{tabular}{|c|c|}
\hline CANDU & CANadian Deuterium Uranium \\
\hline DFM & Diffusion First Model \\
\hline $\mathrm{DHC}$ & Delayed Hydride Cracking \\
\hline DSC & Differential Scanning Calorimeter \\
\hline HVEMS & Hot Vacuum Extraction Mass Spectrometry \\
\hline ID & Inner Diameter \\
\hline IGF & Inert Gas Fusion Thermal Conductivity Analysis \\
\hline MHI & Mechanical Hydrogen Ingress \\
\hline MS & Maximum Slope \\
\hline OD & Outer Diameter \\
\hline OS & Onset \\
\hline PFM & Precipitation First Model \\
\hline PHWR & Pressurized Heavy Water Reactor \\
\hline ppm & Parts per million by weight (mg of hydrogen per $\mathrm{kg}$ of zirconium) \\
\hline $\mathrm{R}$ & Universal gas constant $(8.314 \mathrm{~J} / \mathrm{K})$ \\
\hline TSS & Terminal Solid Solubility \\
\hline TSSD & Terminal Solid Solubility of Dissolution \\
\hline TSSP & Terminal Solid Solubility of Precipitation \\
\hline VFA & Vacuum Fusion Absorption \\
\hline
\end{tabular}




\section{Chapter 1: Introduction}

This thesis documents a study into an alternate technique for the addition of hydrogen to zirconium alloys, and seeks to determine the viability of this technique for use by the nuclear industry in sample preparation, and determining hydrogen concentration in low concentration samples. Chapter 1 gives an overview of zirconium alloys, their use in the nuclear industry, and discusses CANDU pressurized heavy water reactors. Delayed Hydride Cracking (DHC) is introduced as a life-limiting design consideration of CANDU reactors, and the significance of hydrogen in zirconium is discussed. The motivation for the research will be detailed and the objectives justified. The chapter will conclude with a summary of the thesis organization.

\subsection{Zirconium and the Nuclear Industry}

Construction of a nuclear reactor requires materials that are capable of withstanding internal pressures of $11 \mathrm{MPa}$ at temperatures of $310{ }^{\circ} \mathrm{C}$ in a neutron flux of $10^{14}$ neutrons per $\mathrm{cm}^{2} \mathrm{~s}$. The materials must have a low neutron absorption cross-section in order to minimize the effect on the reactor criticality. Zirconium is used in nuclear reactors due to the desirable mixture of a low thermal neutron absorption cross section $(0.4 \mathrm{~b})$ [1], a high yield stress of $475 \mathrm{MPa}$ at $310{ }^{\circ} \mathrm{C}$ (CANDU outlet temperature) [2], and corrosion resistance [3]. Zirconium has a low hydrogen solubility limit [4], which makes it susceptible to Delayed Hydride Cracking (DHC), resulting from hydrogen diffusion to regions of high hydrostatic tensile stress near a flaw, and the precipitation of a brittle metal hydride [2]. The concentration of hydrogen in the zirconium pressure tubes increases with 
time in service because of corrosion. Testing of pressure tube materials outside of reactors requires the ability to add hydrogen to end-of-life concentrations seen in service.

The ingress of hydrogen into zirconium significantly changes the material properties of the metal. The fracture toughness of the zirconium, $\mathrm{K}_{\mathrm{IC}}$, decreases significantly with the addition of hydrogen [5]. Hydrogen free zirconium has been found to have a fracture toughness of $\sim 100 \mathrm{MPa} \sqrt{\mathrm{m}}$. However, the addition of $100 \mathrm{ppm}$ (parts per million by weight) of hydrogen reduces the fracture toughness of cold worked zirconium to $20 \mathrm{MPa} \sqrt{\mathrm{m}}[5]$.

\subsection{CANDU Nuclear Reactors}

The CANadian Deuterium Uranium (CANDU) reactor grew out of the political and industrial climate of Canada, during the aftermath of the Second World War. The CANDU reactor was designed within the limitations of the Canadian heavy-industry's technological capacity of the post-WWII era. Moreover, the design exploited the experience with heavy water that Canada retained from involvement in the Manhattan Project, and took advantage of Canada's resources of high grade uranium ore developed during the war [3]. The CANDU is a Pressurized Heavy Water Reactor (PHWR) that uses heavy water to moderate, and cool the fission reaction. The pressure boundary is across the $\sim 380$ horizontal pressure tubes that lie in a Calandria vessel, at atmospheric pressure. The necessity of using pressure tubes rather than a pressure vessel stemmed from an inability to fabricate the large pressure vessel necessary for containment. By isolating the high pressure coolant within the pressure tube, and by maintaining the moderator at atmospheric 
pressures, the fabrication requirements for the Calandria vessel were within the limitations of Canadian heavy-industry.

The general layout of a CANDU reactor is shown in Figure 1. The Calandria Vessel is filled with heavy water moderator maintained at near atmospheric pressure, and $80{ }^{\circ} \mathrm{C}$. The Fuel Channels are represented by the four horizontal features in the figure. The Fuel Channels contain the heavy water coolant, and the fuel bundles [3]. The $6 \mathrm{~m}$ long horizontal fuel channels are constructed from an inner Zr2.5\% Nb alloy Pressure Tube (ID: $10.3 \mathrm{~cm}, 4.2 \mathrm{~mm}$ thick), and an outer Zircaloy-4 Calandria tube (OD: $12.9 \mathrm{~cm}, 1.4 \mathrm{~mm}$ thickness) [3]. During service, the pressure tubes sag, elongate, and expand diametrally [4]. The focus of this thesis is on the effects of hydrogen on the pressure tube.

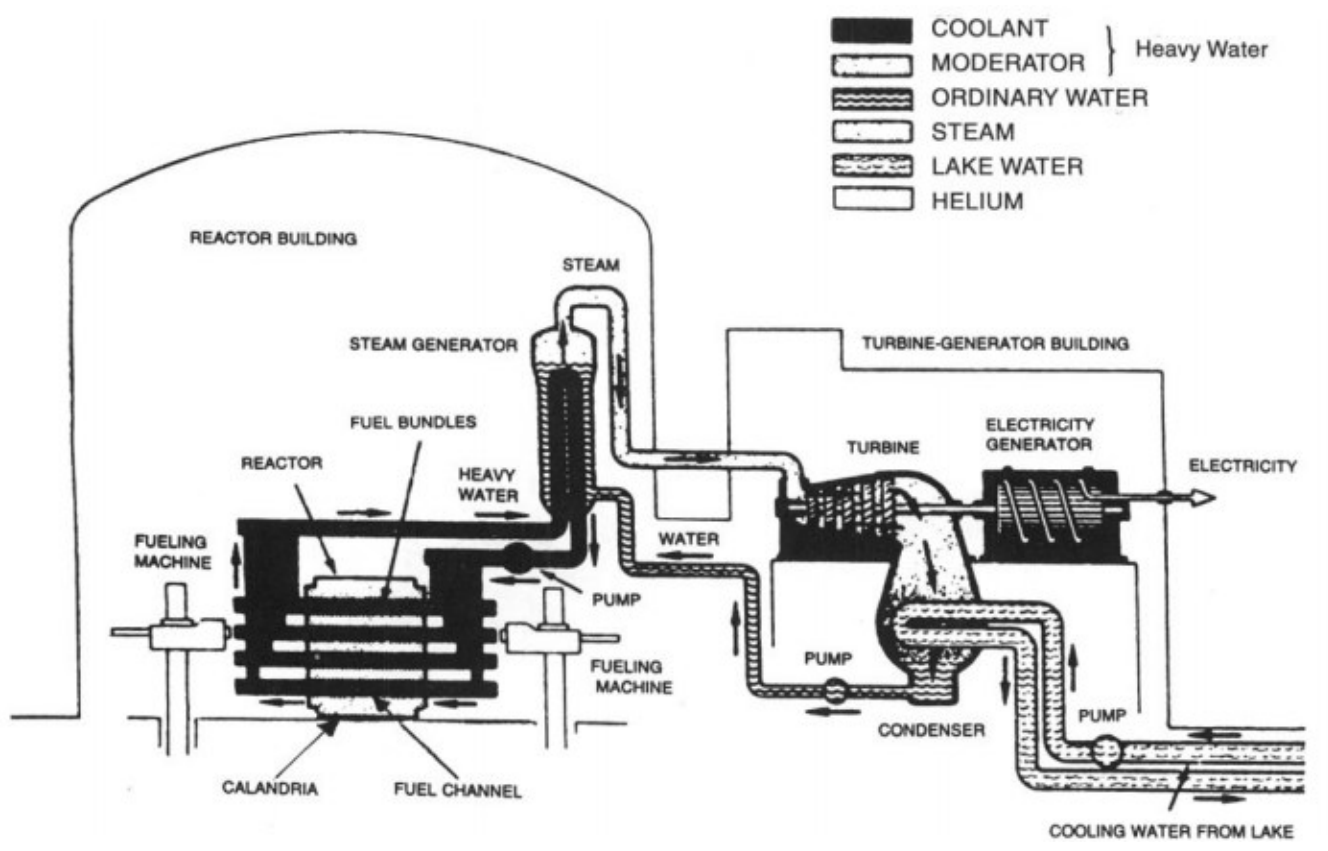

Figure 1: General Layout of a CANDU PHWR Reactor [3] 
Each pressure tube contains twelve Zircaloy-4 clad uranium oxide fuel bundles (See Figure 2) [3]. The coolant flows within each pressure tube at $20 \mathrm{~kg} / \mathrm{s}$ at temperatures between $250{ }^{\circ} \mathrm{C}$, and $310{ }^{\circ} \mathrm{C}$ at a pressure of up to $11 \mathrm{MPa}$ at the inlet [6]. The space between the Pressure Tube, and Calandria Tube is maintained by structural spacers (garter springs), and is filled with $\mathrm{CO}_{2}$ gas, which insulates the Calandria tube from the high temperature Pressure Tube [4]. The Calandria Tube is maintained at the moderator temperature. Pressure tubes are isolated during operation for on-power refuelling [3]. The fuel channel assembly is supported in the reactor by the rolled joint of the header assembly [3].

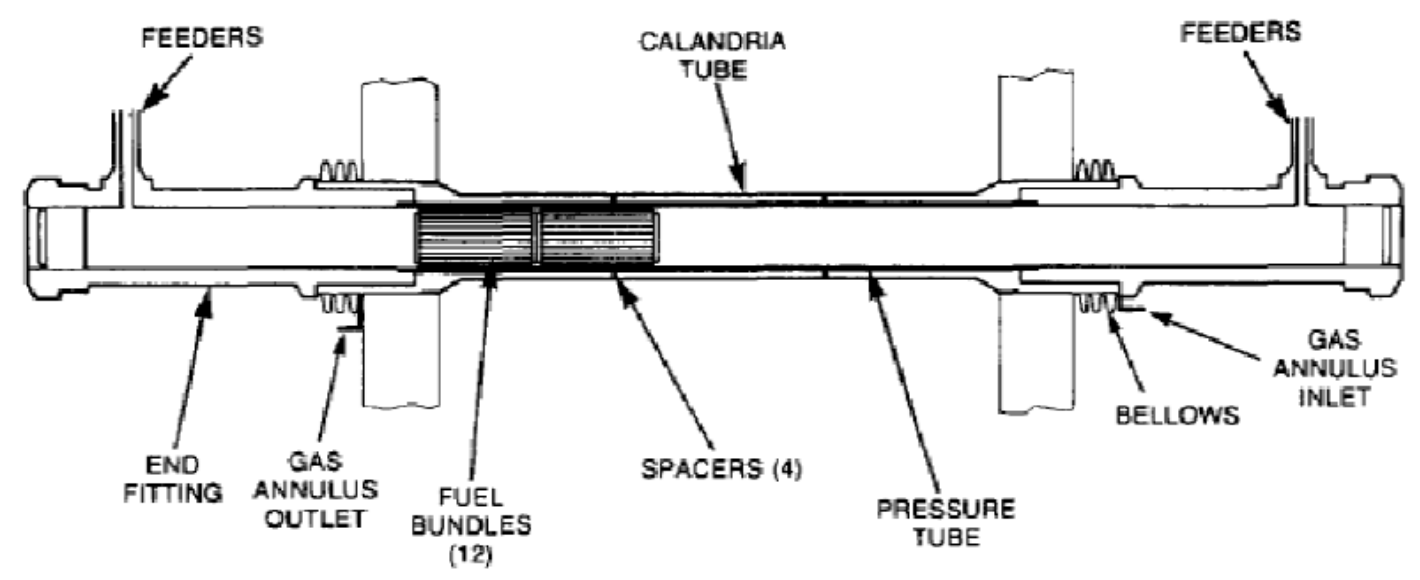

Figure 2: CANDU Fuel Channel Assembly [7]

Hydrogen enters the pressure tubes during service through the stainless steel end fittings, and through the corrosion of the zirconium tube in the heavy water [4]. The oxidation of the zirconium pressure tube in heavy water proceeds according to [2]: 
Most of the deuterium recombines to form deuterium gas; the remainder $\sim 10 \%$ enters the zirconium metal as atomic deuterium ${ }^{1}$. The atomic hydrogen diffusing to flaws under tension in the pressure tube can result in Delayed Hydride Cracking (DHC).

\subsection{Delayed Hydride Cracking}

Zirconium is susceptible to the failure mechanism known as Delayed Hydride Cracking (DHC). In DHC, a stress riser results in a localized high tensile stress region that may result in the nucleation of a hydride [2] [8] [9]. Atomic hydrogen in the zirconium will diffuse to high hydrostatic tensile stress regions, and may nucleate to form a hydride if the solubility limit is exceeded. The hydride grows, and if the stress intensity is above a limiting value, $\mathrm{K}_{\mathrm{IH}}$, the hydride can crack. The process then repeats, and the crack will grow. Zirconium hydride has been observed to crack at stress intensities of $4.5 \mathrm{MPa} \sqrt{\mathrm{m}}$ $[5]$.

There are theories regarding the mechanism of DHC that can be grouped into two categories, distinguished by the initiating event. Precipitation First Models (PFM) employ a mechanism (depending upon the model) to precipitate the hydrogen at the crack tip as a hydride resulting in a positive concentration gradient [2], the concentration gradient results in the diffusion of hydrogen towards the hydride according to Fick’s Laws. Diffusion First Models (DFM) employ a generalized diffusion equation, known as the Nernst-Einstein

\footnotetext{
${ }^{1}$ In this thesis the generic term hydrogen is used when speaking of protium, and deuterium. Similarly hydride is used generically to describe protium, and deuterium precipitates in zirconium.
} 
equation [2]. The crack tip is under a tensile stress, which causes the hydrogen in solution to diffuse to the crack tip until the solubility limit is reached whereupon a hydride may nucleate. The Diffusion First Model predicts a concentration gradient less than or equal to zero [2].

\subsection{Hydrogen Related Failures, and the Leak-Before-Break Principle}

Hydrogen ingress in zirconium components has been responsible for the failure of several components in nuclear reactors. In August of 1974, coolant was detected in the annular gas of the Pickering 3 CANDU reactor [10]. A leak had formed in one of the pressure tubes of the reactor, the first of many such failures that would occur over the next few years. The leak was found to be caused by DHC occurring near the rolled joint. In total, 16 pressure tubes developed leaks in Pickering 3, and 52 pressure tubes were replaced in Pickering 4 [10]. From an economic, and safety perspective these leaks represented a major concern.

As the DHC crack grows, the pressure tube approaches failure. The crack grows in the through-thickness, and longitudinal directions of the pressure tube at different rates [7] [11]. If the crack reaches a critical length in the longitudinal direction, the pressure tube will undergo unstable crack growth characterized by the rapid splitting of the tube in the longitudinal direction [7]. Fortunately, in CANDU reactors the through-thickness cracking penetrates the pressure tube wall before the longitudinal crack reaches the critical crack length. The through-thickness breach can be detected as moisture in the annular gas, and the reactor can be safely shut-down before failure of the pressure tube; the detection 
of leakage in time to enable safe shutdown is known as the Leak-Before-Break principle [7]. The Leak-Before-Break principle was demonstrated in 1986 at the Bruce nuclear power plant when a pressure tube breach was detected, and the reactor was safely shut down prior to pressure tube rupture [10].

\subsection{Techniques for the Addition of Hydrogen to Zirconium}

There are two commonly-used techniques to increase the concentration of hydrogen in zirconium, namely electrolytic hydriding, and gaseous diffusion. These techniques have been used for decades. In this thesis, a simple new technique with improved accuracy, and precision will be presented. In addition to the commonly used techniques, there is a technique involving the corrosion of zirconium in lithium hydroxide solution that has been used in the past. These techniques will be reviewed in Section 2.6.

\subsection{Research Motivation and Objectives}

The research detailed in this thesis is the development of a new hydrogen addition technique for zirconium. Hydrogen is added to zirconium pressure tube material beyond end-of-life values to support lifetime extension. For instance, hydrogen is added to exservice pressure tubes, which are then pressurized to failure in burst testing. The experiments conducted as part of this thesis test the possibility of mechanically driving hydrogen into zirconium using very high pressure. Specific applications include: 
1. The manufacture of standards with accurate, and precise concentrations of hydrogen, and deuterium in zirconium

Currently, the only commercially available zirconium hydrogen standard is a wire standard made by the National Institute for Standards and Technology. The standard, known as NBS-358, has a nominal concentration of $102 \mathrm{ppm}$, but due to the inhomogeneity of the concentration throughout the wire the concentration varies by \pm 4 ppm [12]. In addition, NBS-358 is a natural abundance hydrogen standard, with a negligible amount of deuterium, meaning that isotopic effects are difficult to study using this standard. The mechanical hydrogen ingress technique developed in this thesis provides a technique to make standards with variable isotopic concentrations. Current methods of hydrogen addition have an uncertainty of $10 \%$; the target uncertainty for the mechanical hydrogen ingress technique is less than $10 \%$. An objective of this research is to reliably manufacture zirconium samples with a specific hydrogen concentration.

\section{The measurement of low hydrogen concentrations in zirconium}

The measurement of hydrogen in zirconium at concentrations between 5 ppm, and $20 \mathrm{ppm}$ presents a challenge to researchers who only have access to Differential Scanning Calorimetry (DSC). Hot Vacuum Extraction Mass Spectrometry (HVEMS), and Inert Gas Fusion thermal conductivity analysis (IGF) are capable of reliably determining the hydrogen concentration in zirconium 
samples in this range, and lower; however, these techniques are relatively expensive compared with DSC. An objective of this research is to investigate whether mechanical hydrogen ingress techniques can be used to add a precise amount of hydrogen to a low concentration sample, in order to raise the total hydrogen concentration to values where the DSC performs well, and Terminal Solid Solubility (TSS) calibration curves are well determined.

3. Determining the solubility of hydrogen in metals with low hydrogen solubilities

In metals with low solubilities of hydrogen, it can be difficult to determine experimentally these solubilities. Solubilities determined for hydrogen in copper can vary by an order of magnitude [13]. Solubilities determined for hydrogen in gold lead to a value for partial excess entropy that is inconsistent with similar metals, suggesting that the solubilities are in error [14]. For aluminum, the solubility of hydrogen varies by six orders of magnitude when extrapolated to room temperature [15]. An objective of this thesis is to investigate whether the mechanical hydrogen ingress technique can be used to determine the solubility of hydrogen in low-hydrogen-solubility metals.

\section{Determining the solubility limit of hydrogen in zirconium}

The Terminal Solid Solubility (TSS) of hydrogen in zirconium has an apparent temperature hysteresis when heating, and cooling: hydrides dissolve at 
temperatures $60{ }^{\circ} \mathrm{C}$ higher than the temperatures at which they precipitate. The concentration, and dissolution temperature are defined by the experimentally determined Terminal Solid Solubility of Dissolution (TSSD) relation, and likewise Terminal Solid Solubility of Precipitation (TSSP) is defined for cooling [2]. These two solvi relations are defined by the direction of approach: TSSD is only defined on heating, and TSSP is only defined on cooling [16]. Generally a solvus is defined as an equilibrium state independent of direction of approach. In addition, competing models of DHC use the "solvus" differently: McRae et al use TSSP as the solvus in their diffusion first model [2], whereas Dutton et al use both solvi [16] [17], and Kim uses TSSD [9]. An objective of this thesis is to investigate whether the technique of mechanical hydrogen ingress can be used to shed light on the apparent hysteresis of TSS.

5. The addition of end-of-life hydrogen concentrations to zirconium at temperatures that do not remove irradiation damage

During service in reactors the properties of pressure tubes change because of deuterium ingress, and irradiation at operating temperatures. Irradiation damage, and deuterium ingress both affect fracture toughness; deuterium ingress can lead to DHC. Support for continuing safe reactor operations requires testing of pressure tubes under deuterium, and irradiation conditions expected in the future [6]. Thus, hydrogen is added to ex-service pressure tubes to increase concentrations to values expected in the future, without affecting the irradiation damage. Work is currently 
underway in the industry to develop techniques to raise hydrogen concentrations to $140 \mathrm{ppm}$ in $\mathrm{Zr} 2.5 \% \mathrm{Nb}$ pressure tubes, without exceeding $350{ }^{\circ} \mathrm{C}^{2}$. An objective of this thesis is to investigate whether the mechanical hydrogen ingress technique is capable of adding hydrogen to end-of-life concentrations, at a temperature that will not remove irradiation damage.

\subsection{Thesis Organization}

The thesis has been organized into six chapters. After the Introduction chapter, the second chapter provides a Literature Review of the zirconium-hydrogen system. This is followed by a review of current techniques of adding hydrogen to zirconium, and a discussion of techniques for measuring hydrogen in zirconium. The Experimental chapter shows the steps taken that led to the mechanical hydrogen ingress technique. The Theory chapter discusses chemical potentials, Sieverts' Law, diffusion, solubility, and solubility limits. The equation to predict hydrogen concentration in zirconium treated with the mechanical hydrogen ingress technique is derived in the Theory chapter. The Results and Discussion chapter follows. The Conclusions chapter discusses the findings in terms of the thesis goals described in Section 1.6.

\footnotetext{
${ }^{2}$ Personal communication with Sean Hanlon of CNL Chalk River.
} 


\section{Chapter 2: Literature Review}

This chapter contains an overview of the zirconium-hydrogen system, followed by a review of current techniques of adding hydrogen to zirconium, and techniques for measuring hydrogen concentrations in zirconium.

\subsection{Zirconium and Hydrogen System}

The phase diagram for the binary zirconium-hydrogen system is shown in Figure

3. The area of interest for this thesis is the region between $10 \mathrm{ppm}(0.001 \mathrm{wt} . \%)$ to 350 ppm (0.035 wt. \%) [18].

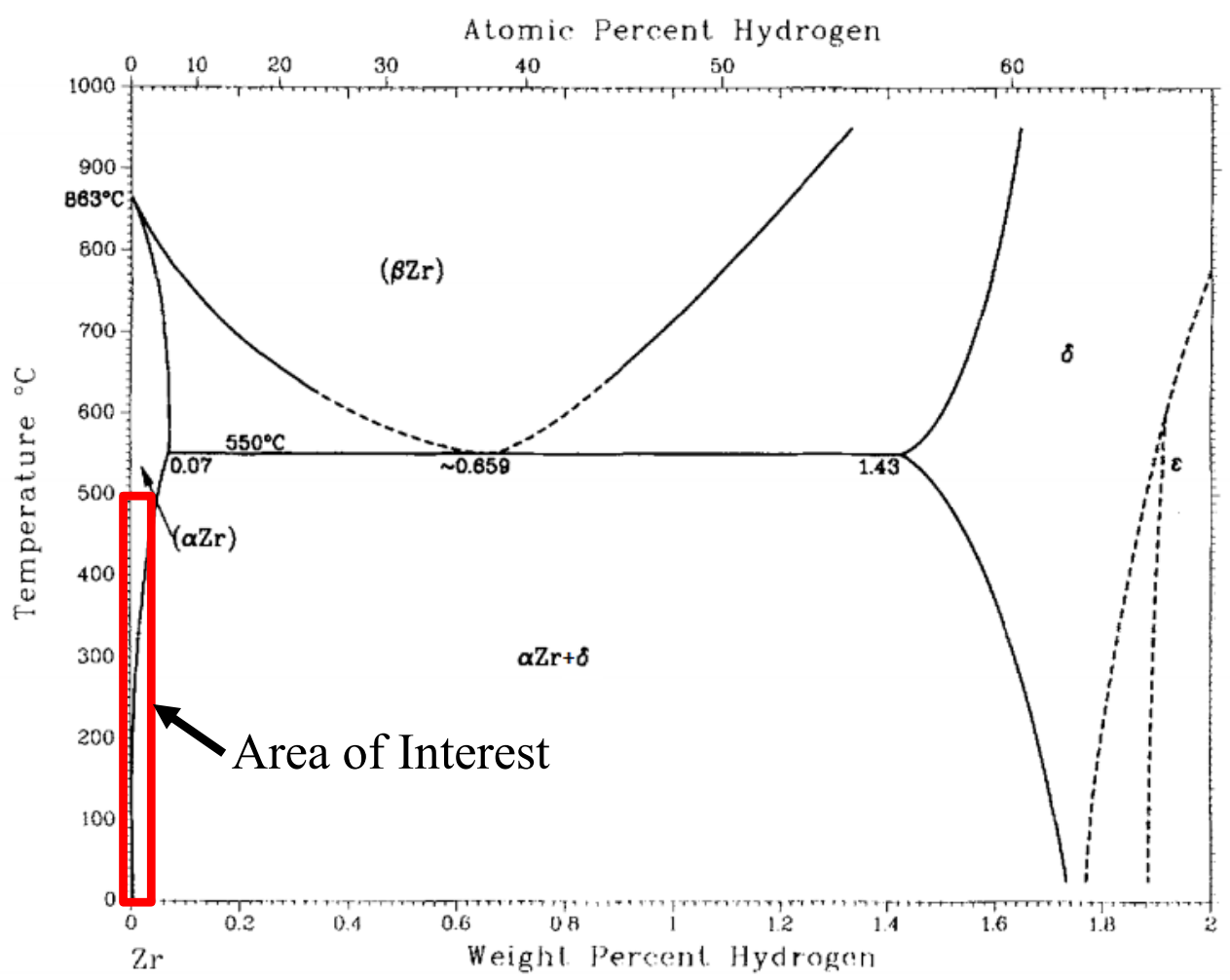

Figure 3: Zr-H binary system phase diagram [18] 
Zirconium hydrides can nucleate, and precipitate if the solubility limit has been exceeded [19]. The size of a hydride formed by cooling a sample is highly dependent on the rate of cooling. Quenching the sample will cause the nucleation of many small hydrides, whereas, a slow cooling will result in nucleation of a smaller number of larger hydrides [19]. The cooling rate dependence of hydride size is caused by the diffusion time available during the precipitation of the hydrides; the short cooling time of a quench limits the range from which dissolved hydrogen can diffuse to form a metal hydride resulting in small hydrides.

In Figure 3, all the lines between phases are single lines for a specific phase change, however, operationally two curves are used, as shown in Figure 4, for the $\alpha \leftrightarrow \alpha+$ hydride phase change. The bottom (red) line is the so-called precipitation solvus (TSSP), and the top (blue) line is the corresponding dissolution curve (TSSD). The region between these lines is the apparent 'hysteresis' zone [20,2]. In the standard interpretation, TSSD does not appear on cool-down, and TSSP does not appear on heat-up. Operationally, the standard interpretation is used because these temperatures are associated with max-slope endothermic, and exothermic heat flow features observed during DSC measurements calibrated to HVEMS [21]. 


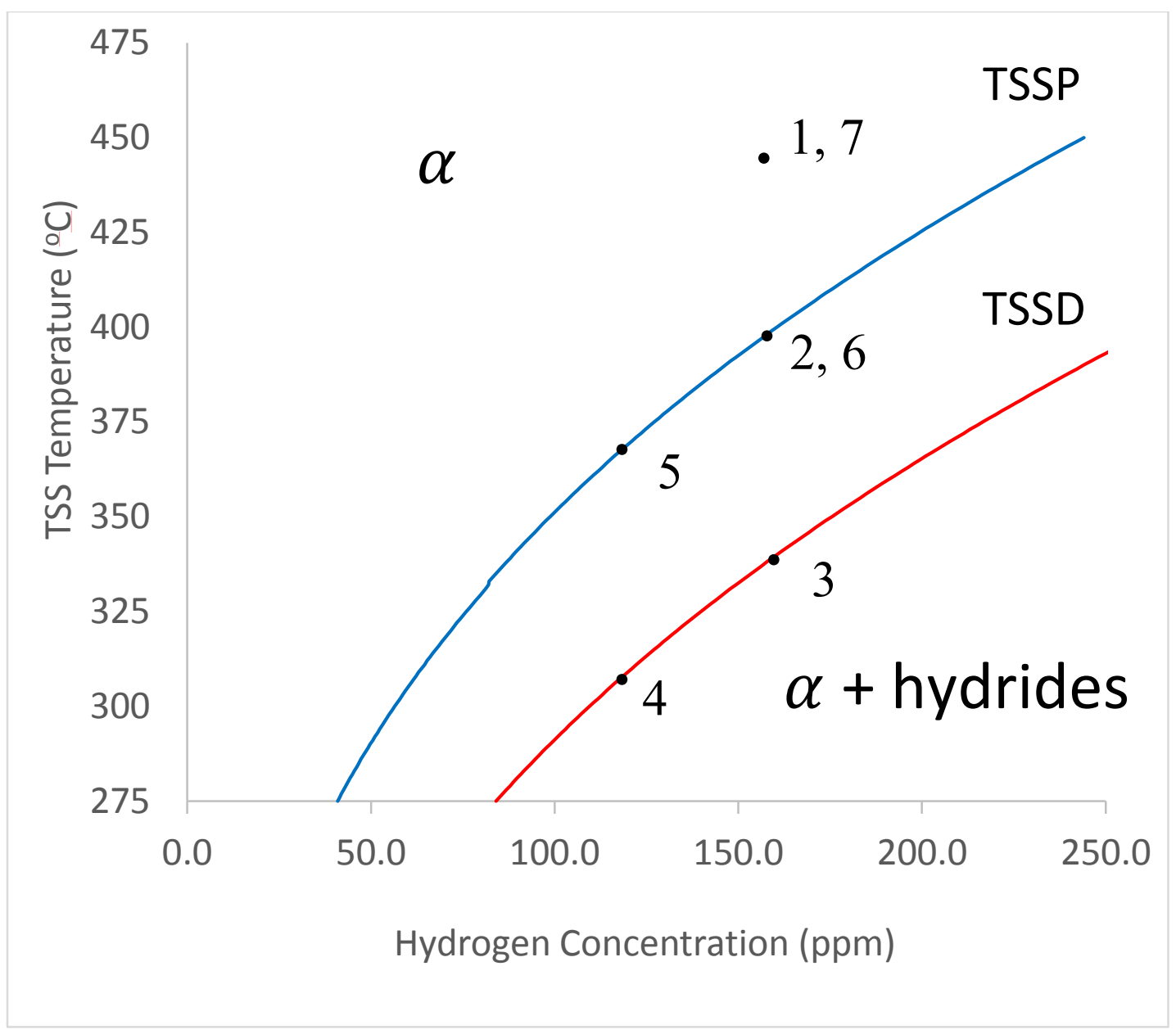

Figure 4: Terminal Solid Solubility curves for hydrogen in Zircaloy-2. The bottom (red) and top (blue) lines represent TSSP and TSSD, respectively. On the left of the curves there is both $\alpha Z r$ and hydride phases, whereas, on the right there is only $\alpha \mathrm{Zr}$ phase. The numbered points are used in-text to illustrate the standard interpretation of hysteresis in the $\mathrm{Zr}-\mathrm{H}$ system.

As an example of the standard interpretation, imagine zirconium with a hydrogen concentration is heated to point 1 on Figure 4 where the hydrogen is all in solution. As the zirconium is cooled it passes TSSD at point 2 without precipitating hydrides. The zirconium will continue to cool without forming hydrides until point 3 , when it reaches TSSP, below which hydrides can nucleate. The concentration of hydrogen in solution decreases as the zirconium cools, following the TSSP curve until cooling stops at point 4. 
If the zirconium is now heated the hydrogen in solution remains constant until TSSD is reached at point 5 , and hydrides begin to dissolve into solution. The hydrogen in solution at point 5 is less than the hydrogen in solution at point 3 , despite being at the same temperature. The hydrogen concentration in solution will then follow TSSD until point 6 is reached where all hydrogen is now once again in solution, and the concentration remains constant as the temperature is raised to the starting temperature at point 7 .

\subsection{Techniques of Hydriding Zirconium}

The common techniques of adding hydrogen to zirconium are electrolytic hydriding, and gaseous diffusion hydriding. Hydriding by lithium hydroxide corrosion has not been used since 1967. This section includes a description of these techniques. The current techniques of adding hydrogen to zirconium all use an excess of hydrogen, which limits the predictability of the final concentration.

\subsubsection{Electrolytic Hydriding}

Electrolytic hydriding involves an electrochemical cell in which the zirconium is the cathode, a DC current source, and an anode typically made of lead. There are standard procedures for electrolytic hydriding of zirconium. For example, following the procedure in [22], the zirconium sample is first prepared by progressively smoothing the sample surface with emery paper, from 120 grit to 1200 grit, to minimize the oxide on the surface. The sample is then pickled for a minute in a solution of 5\% $\mathrm{HF}, 45 \% \mathrm{HNO}_{3}$, and $50 \% \mathrm{H}_{2} \mathrm{O}$. Finally, the sample is placed in a large beaker containing a solution of $0.05 \mathrm{M}$ sulphuric acid, which is the electrolyte. The beaker interior is covered with a thin lead sheet, which 
acts as an anode. The zirconium sample, which is the cathode, and the anode sheet are attached to electric leads, and a current is run through the sample at a DC current density of $100 \frac{\mathrm{mA}}{\mathrm{cm}^{2}}$ to $200 \frac{\mathrm{mA}}{\mathrm{cm}^{2}}$. The electrolyte is maintained at a temperature of $65^{\circ} \mathrm{C}$. The thickness layer can be predicted from the current density, and the time [22].

Following the electrolytic hydriding, the sample is heated to the TSS temperature corresponding to the desired concentration, given TSS curves like those in Figure 4. The time required for hydrogen to diffuse from the surface hydride into the sample is estimated with the solution of Fick's Second Law for a semi-infinite plane sheet found in Section 4.3.1.1. The sample is hydrided on all sides because the anode surrounds it. Thus, the time required to reach the desired concentration is calculated using half the thickness for a planar geometry [22]. Following the heating, the remaining hydride layer is ground off the surface of the sample.

The advantages of electrolytic hydriding include [22]:

- Relatively simple, and inexpensive equipment

- Standard electrolysis DC current source capable of outputting a few amps at a few volts

- Capability to hydride using either protium, or deuterium

- Deuterium is possible, but requires fully deuterated sulphuric acid, and heavy water.

- Hydriding rate is predictable

$\circ \pm 10 \%$ is achievable. 
The disadvantages include:

- Existence of oxide layer on sample may result in uneven hydrogen uptake

- Uses sulphuric acid, which is corrosive

\subsubsection{Gaseous Hydriding}

Gaseous Hydriding deposits a hydride layer on zirconium at high temperature from hydrogen gas. The zirconium is first placed in a quartz glass tube that is then evacuated to $10^{-5}$ Torr [22]. The tube is supplied with hydrogen from an external source, typically a hydrogen gas reservoir or zirconium hydride heated to release hydrogen [22] [23]. The zirconium, and the hydrogen are isolated once the pressure of hydrogen gas reaches a predetermined pressure, typically $\mathrm{mPa}$, calculated with Sieverts' Law as discussed in Section 4.2. The zirconium is then heated to a temperature between $350{ }^{\circ} \mathrm{C}$ and $400{ }^{\circ} \mathrm{C}$, which allows the zirconium to absorb hydrogen once its oxide layer has been absorbed into the metal. The hydrogen concentration in the metal is determined using the pressure change, and assuming ideal gas behaviour [22], which is a valid assumption for the pressures, and temperatures typical of gaseous hydriding [24]. The time required for the hydrogen to diffuse from the surface throughout the sample is estimated with the semiinfinite plane solution to Fick's Law in Section 4.3.1.1.

The solubility of hydrogen in zirconium depends on the pressure of hydrogen in the surrounding gas according to Sieverts' Law [23] [25]:

$$
C_{H}=k \sqrt{P}=1.21 \cdot 10^{-3} e^{\frac{49728}{R T}} \sqrt{P} \text { at. \% }
$$


Where $P$ is the hydrogen partial pressure in $P a, R$ is the universal gas constant $(8.314 \mathrm{~J} / \mathrm{K})$, and $T$ is the temperature in Kelvin. Sieverts' Law is explained in detail in Section 4.2. Sieverts' Law gives the solubility of hydrogen in solution until the TSS is reached (see Figure 4). Gaseous diffusion can add hydrogen to zirconium 'beyond' the terminal solid solubility using a technique known as thermal ratcheting [26].

The advantages of gaseous hydriding include [22] [23]:

- Capability to hydride 'beyond' TSS

- Capability to hydride using any combination of protium, and deuterium The disadvantages include:

- $\pm 10 \%$ of predicted value

- Existence of oxide layer on the sample may result in uneven hydrogen uptake

\subsubsection{Lithium Hydroxide Corrosion}

The corrosion of zirconium in a solution of lithium hydroxide can be used to increase the hydrogen concentration to high levels in Zircaloy-2 pressure tubes. Pressure tubes were prepared by minimizing surface oxides, using grit blasting, and pickling the samples in the same solution employed in the electrolytic hydriding technique described previously in Section 2.2.1 [27]. The tubes were then washed, dried, and massed before being placed in an autoclave containing a solution of lithium hydroxide (10 g/L to $72 \mathrm{~g} / \mathrm{L})$ [27]. The autoclave was heated to $300{ }^{\circ} \mathrm{C}$, and maintained at this temperature for several 
hours. The rate of hydriding was dependent on the solution concentration, Figure 5 shows the hydrogen uptake rate rapidly increased between $10 \mathrm{~g} / \mathrm{L}$ and $30 \mathrm{~g} / \mathrm{L}$.

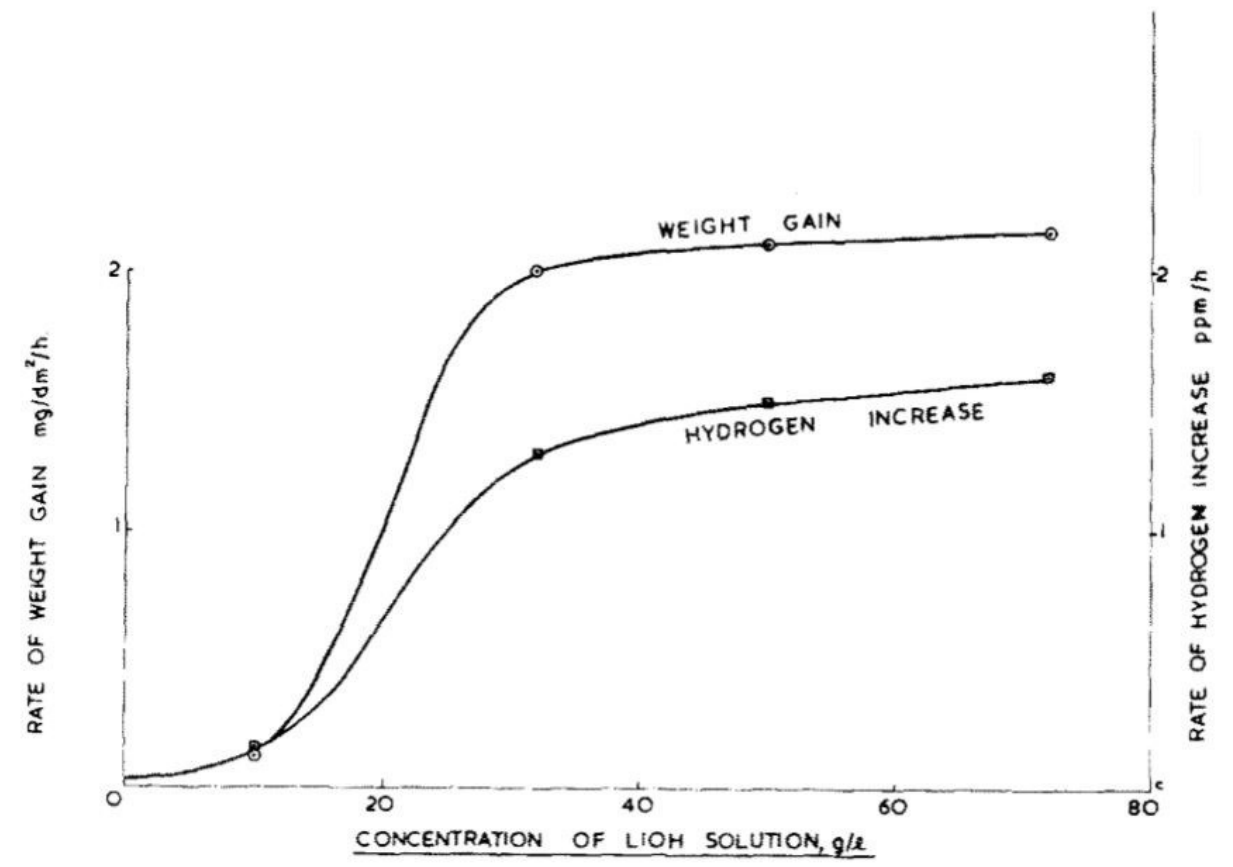

Figure 5: Hydrogen uptake rate in lithium hydroxide corrosion hydriding at $300{ }^{\circ} \mathrm{C}$ [27]

The choice of solution concentration is important, as the hydriding rate below $10 \mathrm{~g} / \mathrm{L}$ was negligible, and the rapid increase for lithium hydroxide concentrations between $10 \mathrm{~g} / \mathrm{L}$ and $30 \mathrm{~g} / \mathrm{L}$ made the hydrogen uptake difficult to predict. The hydrogen uptake rate typically used was between $0.2 \mathrm{ppm} / \mathrm{h}$ and $1.8 \mathrm{ppm} / \mathrm{h}$ leading to long hydriding times between 300 hours, and 30 hours, respectively, for a hydrogen concentration of $60 \mathrm{ppm}$. Nonhomogeneous hydrogen distributions were found in the metal when the hydrogen uptake rate was fast. The results were confounded by lithium substitution into the zirconium oxide, and crevices. 
The advantages of lithium hydroxide corrosion hydriding include [27]:

- Capability to hydride 'beyond' TSS using a low hydrogen addition rate, and thermal ratcheting

- Predictable hydriding rate

- Simple inexpensive equipment

The disadvantages include:

- Lithium ingress changes oxide chemistry at the surface

- Technique has an uncertainty of $\pm 20 \%$

- Uneven hydrogen uptake

- Long times

\subsection{Techniques for Measuring Hydrogen in Zirconium}

Hydrogen concentrations in zirconium reactor components is monitored carefully, because of the detrimental effect hydrogen has on the material properties of zirconium, for instance the reduction of fracture toughness, and the potential for DHC. Hydrogen concentrations can be monitored with a variety of techniques. Indirect measurement techniques include Differential Scanning Calorimetry (DSC), and Inert gas Fusion thermal conductivity analysis (IGF). Direct measurement techniques include Hot Vacuum Extraction Mass Spectrometry (HVEMS), and Vacuum Fusion Absorption (VFA). These techniques are described below. 


\subsubsection{Differential Scanning Calorimetry}

Differential Scanning Calorimetry (DSC) is a thermal-analysis technique that measures changes in the difference of the heat flux to a sample, and a reference sample, which is required to maintain both at the same temperature, as a temperature range is scanned. In a power compensation DSC the heat difference is measured as the difference in power usage by the sample, and reference ovens. In a heat flux DSC the sample, and reference are in the same oven; the temperature of the sample and reference are measured using two thermocouples, and the required heat flux to maintain the samples is inferred from the thermal conductivity resistance between the two thermocouples.

When there is a change in the heat capacity of the sample (in this case zirconium + hydrogen), that is not present in the reference (hydrogen-free zirconium), the change requires a differential heat flux to maintain the sample, and reference at the same temperature. The differential change in the heat capacity accompanies precipitation, and dissolution of hydrides. The dissolution of hydrides upon heating is observed in DSC as an endothermic phase change, whereby the sample requires a larger heat flux to maintain the same temperature as the reference (Figure 6). The precipitation of hydrides upon cooling is observed as an exothermic phase change [28], whereby the reference requires a higher heat flux to maintain the same temperature as the sample. 


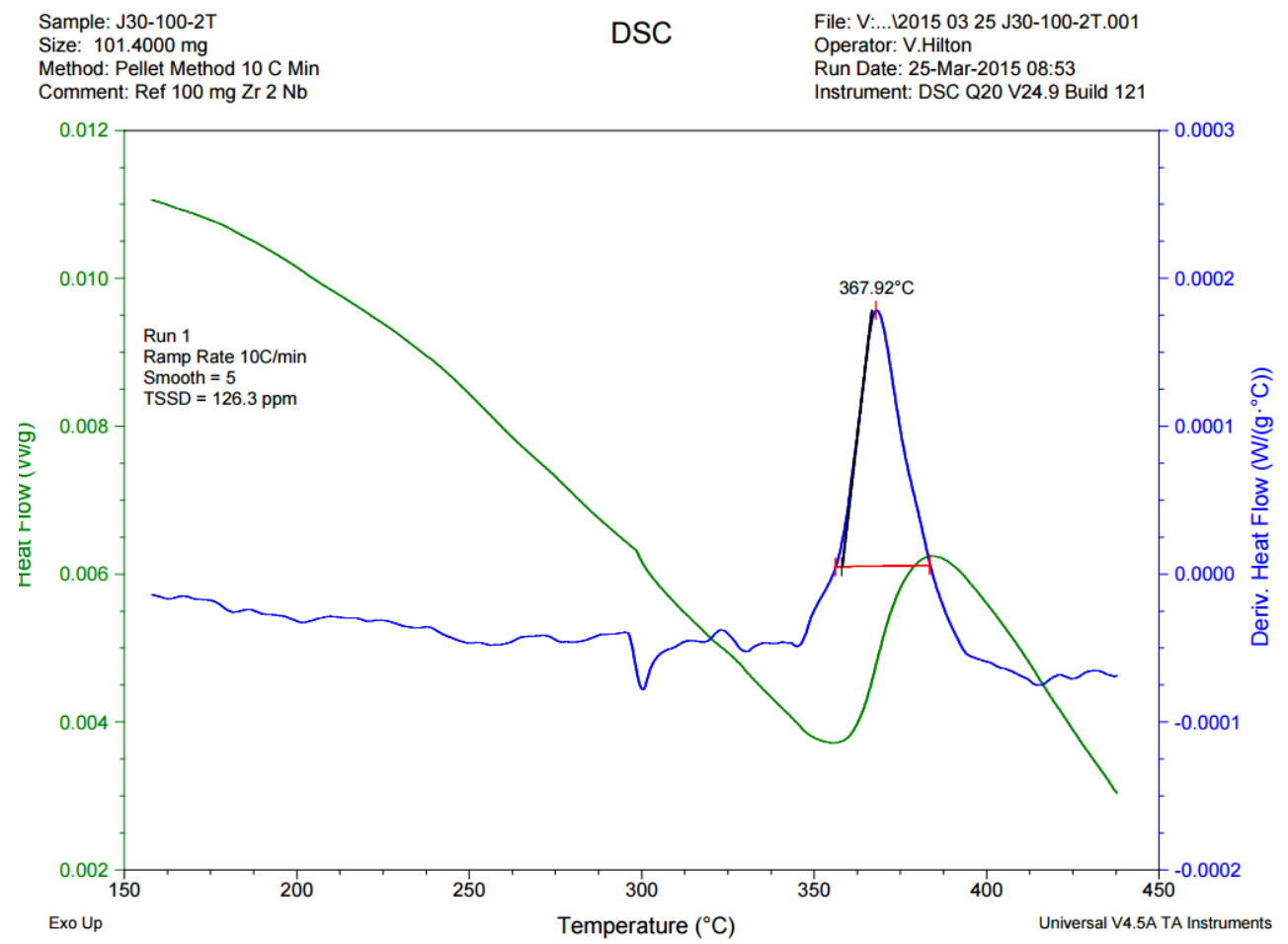

Figure 6: DSC heat flow for $126.3 \mathrm{ppm}$ Zircaloy-2 sample. The TSSD maximum slope temperature is $367.92{ }^{\circ} \mathrm{C}$

Features in the DSC heat flux vs temperature curves can be used to estimate the hydrogen concentration using the TSSD, or TSSP curves in Figure 4, which are calibrated with HVEMS [28]. Figure 6 shows the heat flux (flow), and its first derivative with respect to temperature. The maximum slope in the heat flow, or the peak of the first derivative, is used to calibrate the TSS curves. The maximum slope temperature is chosen over the peak temperature because it is insensitive to linear baselines in the DSC measurement.

Advantages of DSC hydrogen determination include [28]:

- Low cost, commercially available equipment

- Hydrogen remains in sample, allowing for repeat tests 
Disadvantages of DSC hydrogen determination include [28]:

- Hydrogen concentrations below 20 ppm are difficult to measure

- Indirect measurement of hydrogen, requires calibration curve

- Sample cold work, and irradiation complicates interpretations

- Incapable of detecting isotopic concentrations

\subsubsection{Hot Vacuum Extraction Mass Spectrometry}

Hot Vacuum Extraction Mass Spectrometry (HVEMS) is a technique to determine the hydrogen concentration directly. The samples of zirconium containing hydrogen are transferred to a quartz glass tube, and heated under vacuum to release hydrogen as hydrogen gas. The gas is transferred to the collection chamber of a quadrupole mass spectrometer using a turbomolecular pump, where it is then spiked with a known amount of deuterium, deuterium-protium, or protium gas. Figure 7 shows a schematic diagram of the HVEMS system used in this thesis [12]. 


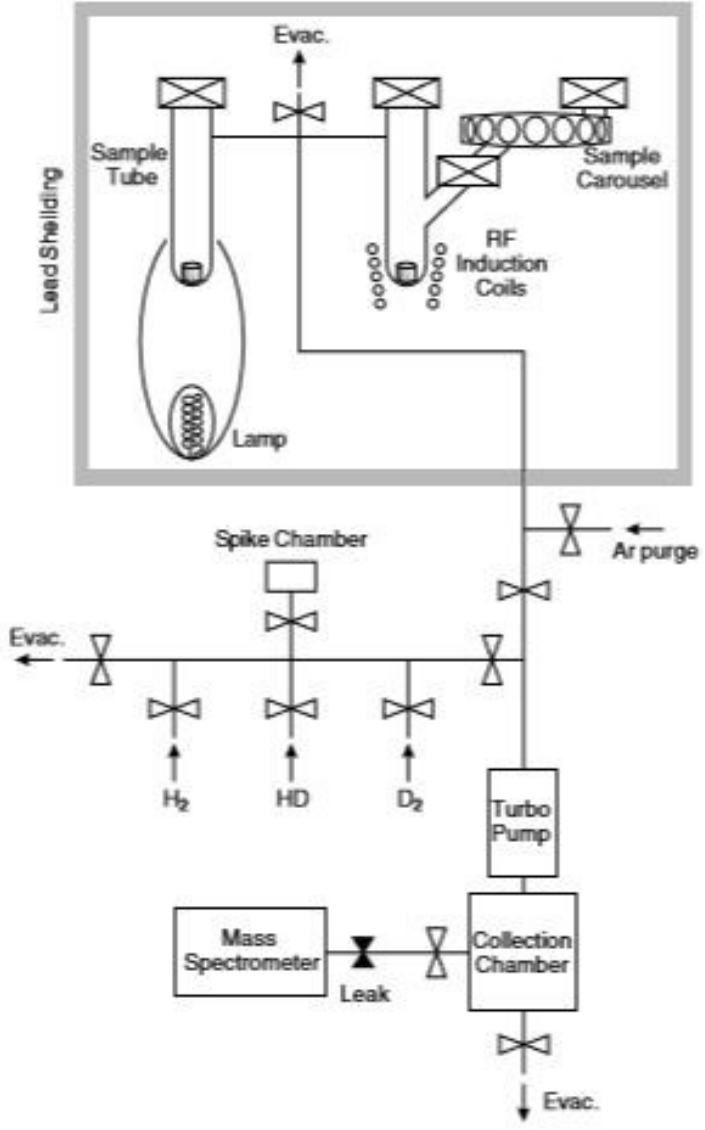

Figure 7: HVEMS system schematic [12]

After the hydrogen is spiked, it is ionized, and the ions are accelerated through a magnetic quadrupole, which separates the constituents depending on their charge-to-mass ratios [12]. The mass spectrometer determines the amount of $\mathrm{H}_{2}{ }^{+}, \mathrm{HD}^{+}$, and $\mathrm{D}_{2}{ }^{+}$by measuring the ion currents [12]. HVEMS is currently the state-of-the-art for determination of hydrogen isotopes in zirconium.

The advantages of HVEMS are [12]:

- Direct determination of hydrogen

- Capability to determine isotopic concentrations 
- Low uncertainty on the order of $\pm\left[0.6+2 \% C_{\text {measured }}\right]$ ppm of protium in a $300 \mathrm{mg}$ sample; $\pm\left[0.2+1 \% C_{\text {measured }}\right] \mathrm{ppm}$ of deuterium in a $300 \mathrm{mg}$ sample.

- Capability to measure low protium concentrations (as low as $3 \mathrm{ppm}$ ), and even lower deuterium concentrations (as low as $0.04 \mathrm{ppm}$ )

The disadvantages of HVEMS are [12]:

- Expensive

- Destructive test procedure, cannot repeat measurements

\subsubsection{Inert Gas Fusion Thermal Conductivity Analysis}

Inert Gas Fusion hydrogen analysis exploits the dependence of electrical properties of resistors on temperature in order to measure hydrogen concentration in a metal. A sample of zirconium is cut or punched from the component, and is placed in an oxygenfree crucible [29]. The crucible is placed in a pressure vessel that is evacuated, and backfilled with high purity carrier gas (typically $99.9999 \%$ Ar). The sample is then melted at $2000{ }^{\circ} \mathrm{C}$ to extract the hydrogen, and other gasses such as oxygen, and nitrogen [29]. The oxygen reacts with the crucible, and an oxidizing agent to form carbon dioxide which is removed from the gas stream with molecular sieves. The remaining gas is comprised of hydrogen, nitrogen, and argon [29].

The gas is then passed over half of the resistors in a balanced bridge circuit, while the pure carrier gas is passed over the other half of the bridge resistors [29]. The difference in thermal conductivity of the gasses changes the relative temperatures of the resistors, and unbalances the bridge, which creates a potential difference proportional to hydrogen 
concentration [29]. The nitrogen in the sample gas does not contribute to the measurement because its thermal conductivity is negligibly different from argon.

The advantages of using IGF to determine hydrogen concentration include [29]:

- Moderate uncertainty, $\pm 5 \%$ of reading

- Capability of measuring hydrogen concentrations between 1 and $150 \mathrm{ppm}$. The upper limit is based on sample size, smaller samples can be used for higher concentrations to avoid sensor saturation.

The disadvantages of using inert gas fusion analysis include [29]:

- Cannot determine isotopic concentrations

- Destructive

- Thermal conductivity sensor saturation results in maximum reading, regardless of actual concentration

- Requires hydrogen standards for calibration

\subsubsection{Vacuum Fusion Absorption}

Vacuum Fusion Absorption (VFA) analysis is an industrial process to determine hydrogen, and other gas forming elements in metals. Similar to HVEMS, and IGF the zirconium is placed into a crucible in a pressure vessel, which is then evacuated to at least $10^{-5}$ Torr, and then heated to $1100{ }^{\circ} \mathrm{C}$. The evolved gas is then passed through a series of solid absorbents of known mass. The hydrogen reacts with cupric oxide to become water (Equation 2.2), which is recovered, and massed to determine the hydrogen concentration [30]. 


$$
\mathrm{CuO}+\mathrm{H}_{2} \rightarrow \mathrm{H}_{2} \mathrm{O}+\mathrm{Cu}
$$

The VFA technique is not suitable for hydrogen determination in zirconium because it lacks sufficient sensitivity. As an example, for a zirconium sample with a mass of $60 \mathrm{~g}$, an uncertainty of $0.1 \mathrm{mg}$ in the mass of recovered water is equivalent to an uncertainty of $200 \mathrm{ppm}$ in the concentration of hydrogen in zirconium [30]. Thus, the technique is inappropriate for use with zirconium, where the range of interest for hydrogen concentration is between $1 \mathrm{ppm}$ and $200 \mathrm{ppm}$. 


\section{Chapter 3: Experimental}

The mechanical hydrogen ingress technique was developed with accuracy, precision, and simplicity in mind. All experiments in this thesis were done using a $0.9 \mathrm{~mm}$ thick sheet of Zircaloy- $2^{3}$ cladding material, with an initial hydrogen concentration reported to be $6 \mathrm{ppm}^{4}$. The procedure for operating the MTS- 810 load frame and the thermal control unit used in the following experiments can be found in Appendix A. The design schematics for the custom-built Thermal Control Unit, and Clamshell Oven can be found in Appendix B. Appendix C is a list of all equipment used in this thesis, including manufacturer, model number, and serial numbers.

\subsection{Mechanical Hydrogen Ingress of Zirconium Experiment}

The mechanical hydrogen ingress experiments were performed using an MTS-810 $500 \mathrm{kN}$ load frame. A clamshell oven, and thermal control unit were built, and certified to heat samples in situ. Figure 8 shows the MTS load frame, and the clamshell oven setup. Two variants of the mechanical hydrogen ingress technique were used to increase the hydrogen in Zircaloy-2 to various concentrations. The first variant technique involved compressing a layer of zirconium hydride powder between two sheets of Zircaloy-2. The second variant technique was a modification of the original technique, using C110 copper plates as a shell around a single sheet of Zircaloy-2. The modifications were necessary to

\footnotetext{
${ }^{3}$ Zircaloy-2 composition: $98.5 \% \mathrm{Zr}, 1.4 \% \mathrm{Sn}, 0.12 \%$ O, $0.050 \% \mathrm{Ni}, 0.10 \% \mathrm{Fe}, 0.1 \% \mathrm{Cr}$

${ }^{4}$ This concentration was from Wah Chang Corporation's QA testing done in 1965, prior to shipping to CNL Chalk River. Subsequent testing by CNL Chalk River found the initial concentration to be $14 \mathrm{ppm} \pm$ 1 ppm (See CNL ACQA \#147829 in Figure 74).
} 
rectify problems with the initial procedure; reasons for the modifications are discussed in the Results and Discussion chapter.

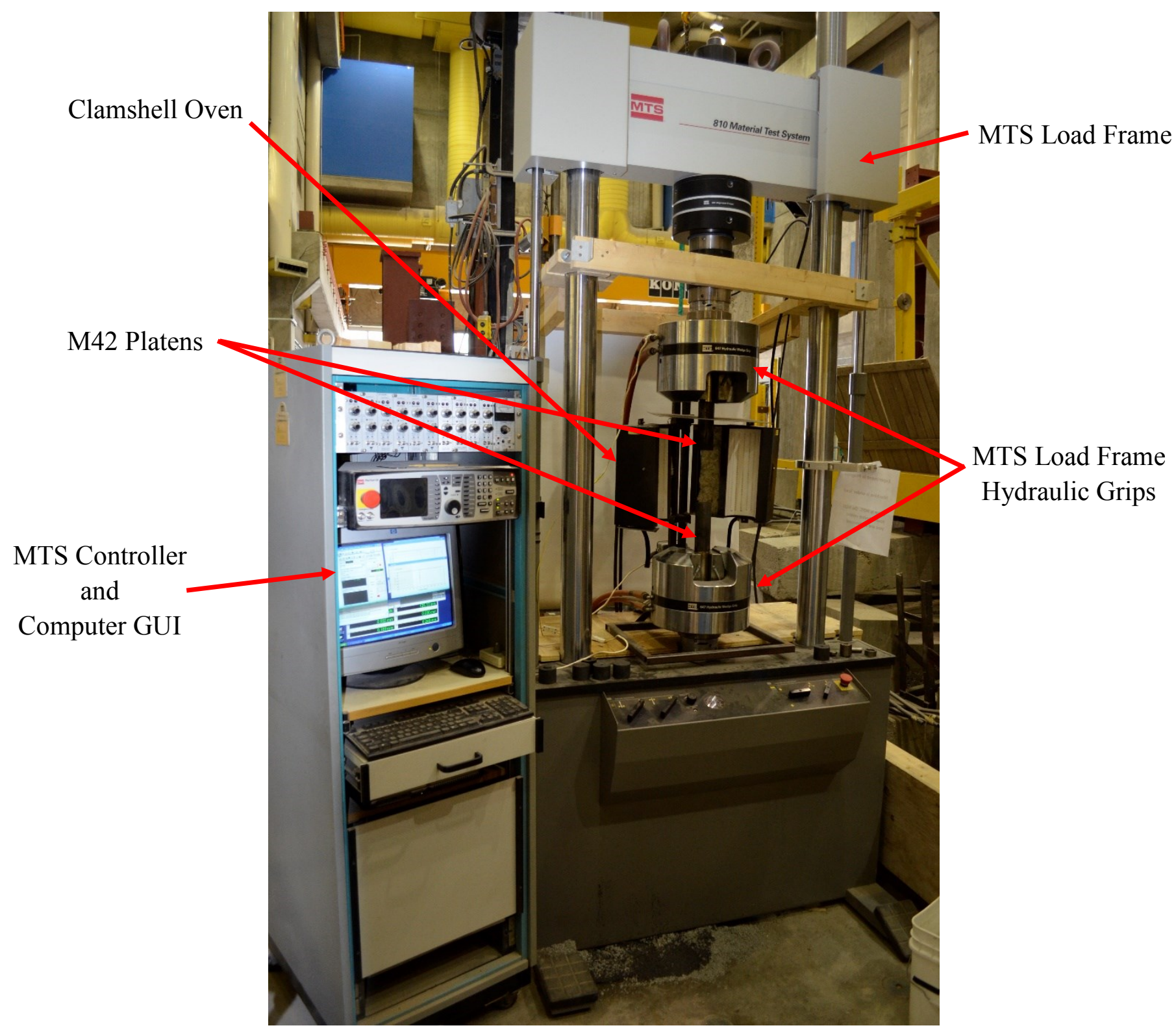

Figure 8: MTS-810 $500 \mathrm{kN}$ load frame with M42 steel platens, and clamshell oven 


\subsubsection{Zirconium Sandwiched Hydride Experiment}

The initial experiments into mechanical hydrogen ingress were done by compressing a layer of zirconium hydride powder between two $38 \mathrm{~mm}$ square sheets of Zircaloy- 2 at a temperature of $425^{\circ} \mathrm{C}$. A compressive force of $400 \mathrm{kN}$, which resulted in a stress of $275 \mathrm{MPa}$, was used in this experiment. The procedure for the addition of hydrogen to zirconium using this technique can be found in Appendix A.1.

Following the addition of hydrogen, five test punches were made using a Heinrichco model \#5 deep throat bench punch. Table 1, and Figure 9 provide information on the positions, and size of the test punches ${ }^{5}$.

Table 1: Sample test punch description, and size

\begin{tabular}{|c|l|c|c|}
\hline $\begin{array}{c}\text { Specimen } \\
\text { Designation }\end{array}$ & \multicolumn{1}{|c|}{ Specimen Description } & $\begin{array}{c}\text { Punch } \\
\text { Diameter } \\
\text { (inches) }\end{array}$ & $\begin{array}{c}\text { Punch } \\
\text { Label in } \\
\text { Figure 9 }\end{array}$ \\
\hline 1T & Top sheet centre DSC specimen & $1 / 8$ & $\mathrm{a}$ \\
\hline 2T & Top sheet side DSC specimen & $1 / 8$ & $\mathrm{~b}$ \\
\hline 3B & $\begin{array}{l}\text { Bottom sheet centre DSC } \\
\text { specimen }\end{array}$ & $1 / 8$ & $\mathrm{c}$ \\
\hline 4T & $\begin{array}{l}\text { Top sheet adjacent to 1T HVEMS } \\
\text { specimen }\end{array}$ & $3 / 16$ & $\mathrm{~d}$ \\
\hline 5B & $\begin{array}{l}\text { Bottom sheet adjacent to 3B } \\
\text { HVEMS specimen }\end{array}$ & $3 / 16$ & $\mathrm{e}$ \\
\hline
\end{tabular}

The test punches were annealed at $500{ }^{\circ} \mathrm{C}$ for an hour to remove cold work introduced from the punching ${ }^{6}$. The measurements of hydrogen concentrations in these test punches were

\footnotetext{
${ }^{5}$ Imperial units are presented in Table 1 in accord with the machine sizing. DSC sample sizes were determined by the requirements of the DSC instruments. HVEMS samples were made to meet the recommended $300 \mathrm{mg}$ mass for measurement.

${ }^{6}$ Without annealing, the DSC max-slope temperature was a few degrees lower.
} 
made at CNL Chalk River using a TI Q20 Power Compensation DSC, and calibration curves for Zircaloy that include thermal lag corrections, or HVEMS [12].

\section{Bottom Top}

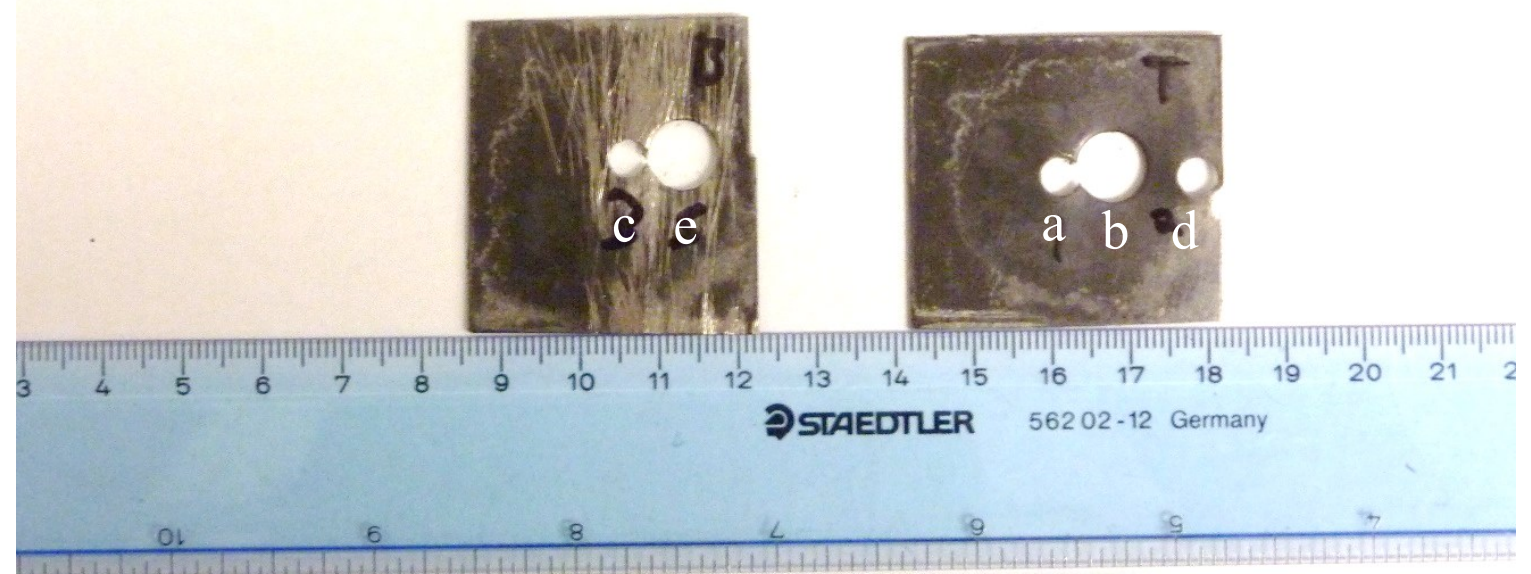

Figure 9: Zirconium samples after hydrogen addition using sandwiched zirconium hydride technique. The holes are punches taken for hydrogen concentration measurements. Refer to Table 1 for description of specimen punches. 


\subsubsection{Copper-Shell Mechanical Hydrogen Ingress Experiment}

Mechanical hydrogen ingress into zirconium was also done by compressing $25 \mathrm{~mm}$ square sheets of Zircaloy-2, and hydride powder, between copper plates (3.2 $\mathrm{mm}$ thick, $\mathrm{C} 110^{7}$ ) measuring $28.6 \mathrm{~mm} \times 28.6 \mathrm{~mm}$ at temperatures between $322{ }^{\circ} \mathrm{C}$, and $500{ }^{\circ} \mathrm{C}$. The $0.9 \mathrm{~mm}$ thick zirconium was cut using a corner-shear punch, and the copper was cut using a fine tooth band-saw. A compressive force between $75 \mathrm{kN}$ corresponding to $90 \mathrm{MPa}$, and $120 \mathrm{kN}$ corresponding to $145 \mathrm{MPa}$, was used in this experiment. These loads were always greater than the yield stress for the $\mathrm{C} 110$ at the test temperature. The procedure can be found in Appendix A.2.

Following the addition of hydrogen, half of the samples were sent to CNL Chalk River for analysis. Specimens were cut from these samples using a slow speed diamond saw at CNL. Specimens were cut from the centre of the zirconium sheet, and an additional specimen was made from sample A20-100 ${ }^{8}$ to show hydrogen homogeneity. These specimens were analysed for hydrogen concentration using a TI Q20 Power Compensation DSC, and calibration curves for Zircaloy that include thermal lag corrections. The other half of the samples were analysed using a Netzsch Pegasus 404C Heat Flux DSC with a 6.235.4-63.9.00+S measurement head. These samples were punched, and annealed at $500{ }^{\circ} \mathrm{C}$ for one hour.

\footnotetext{
${ }^{7} \mathrm{C} 110$ copper composition: $\geq 99.9 \% \mathrm{Cu}, \leq 0.05 \% \mathrm{O}$
}

${ }^{8}$ Sample data are found in Appendix D.2. 


\subsection{Hydrogen Saturation Experiment}

An experiment to determine the true TSS solvus was devised by modifying the copper-shell mechanical hydrogen ingress technique. Sheets of zirconium, and copper plates were cut as described in Section 3.1.2. The experiment followed the procedure in Appendix A.2 up to step 15, with a load of $140 \mathrm{MPa}$, and an oven temperature of $350{ }^{\circ} \mathrm{C}$. The samples were not homogenized at $500^{\circ} \mathrm{C}$. Instead the copper-shells were broken open, and the zirconium samples removed, punched, and the punches were annealed for 24 hours at $350{ }^{\circ} \mathrm{C}$. The hydrogen concentration of the samples was determined with the DSC method using a Pegasus 404C DSC, and the maximum slope TSSD, maximum slope TSSP, and onset TSSP temperatures were recorded. The true TSS temperature should not be greater than $350{ }^{\circ} \mathrm{C}$, if the TSS is a true terminal solubility.

\subsection{Mechanical Hydrogen Ingress - DSC Hydrogen Analysis}

An experiment to determine the initial hydrogen concentration in the Zircaloy-2 stock material using the copper-shell technique was devised. Zirconium samples, and C110 copper plates were manufactured as per Section 3.1.2, and sufficient zirconium hydride powder was used to add $\sim 60 \mathrm{ppm}$ of hydrogen to the samples. The experiment followed the procedure laid out in Appendix A.2, with $120 \mathrm{MPa}$, and an oven temperature of $425^{\circ} \mathrm{C}$. 


\section{Chapter 4: Theory}

This chapter presents analysis of the underlying theory of mechanical hydrogen ingress. The chapter begins with a description of chemical potential energy, Sieverts' Law, and chemical diffusion. A comment on the difference between solubility, and solubility limits is presented. The chapter concludes with a mathematical derivation of the equations governing the mechanical hydrogen ingress technique.

\subsection{Chemical Potential Energy}

Chemical potential energy is the partial derivative of the free energy with respect to the amount of a chemical species [31]. The chemical potential of hydrogen in solid solution is given by:

$$
\mu_{H}=\mu_{H}^{0}+R T \ln \left(a_{H}\right)
$$

Where $a_{H}$ is the activity of hydrogen, $\mu_{H}^{0}$ is the chemical potential of the standard reference state when the activity is unity. For dilute solid solutions the activity can be taken as the concentration, $C_{H}$. For hydrogen in the gas phase, the activity is equal to the fugacity, which is taken as the gas pressure in this thesis [25]. At equilibrium, the chemical potentials for hydrogen are equal everywhere. 


\subsection{Sieverts' Law}

Sieverts' Law relates the pressure of a diatomic gas to the monatomic solubility in a metal. The law is named after Adolf Sieverts, whom first derived it in 1929 from Henry's Law [25]. From the equilibrium equation,

$$
H_{2,(g)} \leftrightarrow 2 H_{(d)}
$$

where (g) stands for gas, and (d) stands for dissolved in the metal, the equilibrium constant in terms of activities is given by:

$$
k_{e q}=\frac{a_{H,(d)}^{2}}{a_{H_{2,(g)}}}
$$

The activity of the dissolved hydrogen is squared because of its stoichiometric coefficient in Equation 4.2. The activity of hydrogen gas is given by the fugacity of the hydrogen gas. At moderate pressures, the fugacity of the hydrogen gas can be approximated by the product of the partial pressure of the hydrogen gas, and the fugacity constant as [25]:

$$
f_{H}=\phi P_{H}
$$

Where $\phi$ is the fugacity coefficient, which is a function of temperature. The activity of the 
dissolved hydrogen is given by Henry's Law as the product of the activity coefficient of hydrogen dissolved in the metal, and the concentration of the hydrogen:

$$
a_{H,(d)}=k_{H,(d)} C_{H}
$$

Where $k_{H,(d)}$ is the activity coefficient, and $C_{H}$ is the concentration of the dissolved hydrogen. By substituting Equation 4.4 into Equation 4.3 as the activity of hydrogen gas, and substituting Equation 4.5 as the activity of hydrogen dissolved in the metal, a prediction of the solubility of hydrogen in the metal is given as:

$$
C_{H}=\frac{\sqrt{\phi P_{H} k_{e q}}}{k_{H,(d)}}=K_{H} \sqrt{P_{H_{2}}}
$$

The coefficient $K_{H}$, known as the Sieverts constant has a temperature dependence, and is specific to the metal in question. The implication of Sieverts' Law is that the solubility of monatomic hydrogen in metals is proportional to the square root of the partial pressure of the surrounding hydrogen gas. The proportionality typically has an Arrhenius form temperature dependence:

$$
K_{H}(T)=A e^{-\frac{Q}{R T}}
$$

A Sieverts apparatus is used to determine the Sieverts' constant at various temperatures [14]. The apparatus consists of a pressure vessel attached to a vacuum pump, 
a hydrogen gas supply, and a radiant heater. The metal is placed in a crucible within the pressure vessel with a thermocouple attached. The vessel is evacuated, hydrogen is added to the appropriate pressure, and heated. The apparatus is maintained in this state until the hydrogen has sufficient time to reach solubility. The metal is then quenched, and the hydrogen concentration determined. Zirconium, and copper have been shown to follow Sieverts' law experimentally [14] [32].

\subsection{Chemical Diffusion and Permeation}

Diffusion is the stepwise mass transport of a species under the action of a force derived from a chemical potential gradient. In the absence of external forces, the flux determined from the chemical potential gradient shows that species will move from regions of high concentration, to regions of low concentration [33]. The first formulation of the equations governing diffusion were in 1855 by Adolf Fick in what are now known as Fick's Laws of Diffusion [33]. When external forces are present, Fick's Law no longer applies. For instance, hydrogen can move because of stress gradients as well as concentration gradients [2].

Permeation is another formulation of stepwise mass transport of particles derived from a chemical potential gradient. Although diffusion is a more generalized formulation of the same problem, permeation is often used in cases of fluid transport through a membrane. The equations are similar to Fick's Laws with different parameters. 


\subsubsection{Fick's Laws of Diffusion}

In 1855, Adolf Fick published his theory of diffusion, based on a study of the movement of salt dissolved in water between regions of high, and low concentrations [33]. Fick's First Law describes the dependence of the solute flux on the concentration gradient:

$$
\vec{J}=-D \nabla C
$$

Where $\vec{J}$ is the solute flux (particles/length ${ }^{2} /$ time), $^{\mathrm{D}}$ is the diffusivity (length ${ }^{2} /$ time, and $C$ is the concentration (particles/length ${ }^{3}$ ). Fick's Second Law is derived with the continuity equation (conservation of mass):

$$
\frac{\partial C}{\partial t}+\nabla \cdot \vec{J}=0
$$

Where $\nabla \cdot \vec{J}$ is the divergence of the flux vector field. By substituting Equation 4.8 into 4.9 the time dependence of concentration is given as:

$$
\frac{\partial C}{\partial t}=\nabla \cdot(D \nabla C)
$$

At low concentrations the diffusivity is independent of position, hence [34]:

$$
\frac{\partial C}{\partial t}=D \nabla^{2} C
$$


Where $\nabla^{2}$ is the Laplace operator representing the divergence of the gradient. Fick's Laws are used extensively in engineering, chemistry, and physics to describe chemical diffusion in solids, liquids, and gasses.

\subsubsection{Diffusion in a Semi-Infinite Plane Sheet}

The experiments in this thesis were performed with zirconium sheets with a thickness of $0.9 \mathrm{~mm}$. To calculate the diffusion time through the sample for homogenization, the sheet is modelled as a semi-infinite plane. The initial conditions are:

$$
\begin{gathered}
C(l, t \geq 0)=C_{s} \\
C(0 \leq x<l, t=0)=C_{0}
\end{gathered}
$$

Where $l$ is the thickness, $C_{0}$ is the initial concentration of hydrogen in solid solution in the sheet, $C_{S}$ is the concentration of hydrogen in solid solution at the surface of the sheet at $x=l$. Solving Equation 4.11 using the initial conditions yields a series solution of [34]:

$$
\frac{C(x)-C_{0}}{C_{s}-C_{0}}=1-\frac{4}{\pi} \sum_{n=0}^{\infty} \frac{(-1)^{n}}{2 n+1} e^{-\frac{D(2 n+1)^{2} \pi^{2} t}{4 l^{2}}} \cos \frac{(2 n+1) \pi x}{2 l}
$$


At $t=\infty$ the summation term in Equation 4.12 goes to zero, and $C(x)=C_{s}$. A nondimensional time parameter can be defined:

$$
T=\frac{D t}{l^{2}}
$$

When $T=1.5$, Equation 4.12 goes to 0.98 at $x=0$, which is interpreted as $98 \%$ completion. The times for different levels of completion are determined using Equation 4.13 for different values of $T$. As an example, the time for diffusion to $98 \%$ completion is $1.5 l^{2} / D$.

\subsubsection{Permeation of Hydrogen through a Zirconium}

The permeation of a gas through metal can be derived from Fick's First Law by substituting Sieverts' expression for the solubility for the concentration [34]:

$$
\vec{J}=-D K_{\text {Sieverts }} \nabla \sqrt{P}
$$

The product of $D$, and $K_{\text {Sieverts }}$ is the permeability constant. The permeation of hydrogen through zirconium is therefore dependent on the gradient of the square root of partial pressure.

\subsection{Solubility, and Terminal Solid Solubility}

An important distinction exists between solubility, and the terminal solid solubility.

For hydrogen in zirconium, the solubility can be determined using Sieverts' Law: the solubility increases with the square root of pressure, and decreases with temperature 
(Section 4.2). This solubility is the amount of hydrogen in solid solution in equilibrium with hydrogen gas. However, this solubility is limited by the terminal solid solubility. Therefore, the solubility is equal to the lesser of the Sieverts value, or the TSS concentration.

The solubility has a pressure dependence, whereas the TSS does not have a significant pressure dependence [16]. This distinction is used in hot vacuum extraction of hydrogen. At low external pressures the hydrogen comes out of solution even though the terminal solid solubility is higher at higher temperatures. The amount of hydrogen that remains in the zirconium is given by Sieverts' Law at low pressures.

\subsection{Mechanical Hydrogen Ingress}

This section shows the derivation of the equation used to predict final hydrogen concentrations in zirconium using mechanical hydrogen ingress techniques. The source of hydrogen is zirconium hydride powder, which thermally decomposes at $310{ }^{\circ} \mathrm{C}$ to zirconium powder, and hydrogen gas [35]. The hydrogen gas is contained within a 'shell' comprised of zirconium, or copper. The oxides on the metals surfaces inside the shell are presumed to be dissolved into the metal. The hydrogen gas then partitions to the various metals according to Sieverts' Law, and TSS of zirconium; TSS does not apply to copper, because it does not form hydrides at the temperatures, and pressures used in this thesis. The rate is dependent on permeability, which can be made large with an applied load because of the square root dependence on gas pressure [34]. 
The hydrogen gas pressure is maintained by the decomposing zirconium hydride until it is all but depleted. At this point the volume for hydrogen decreases as the shell deforms under the applied load acting in a similar manner to a piston (Figure 10).

\section{$\sigma_{\text {Load Frame }}$}

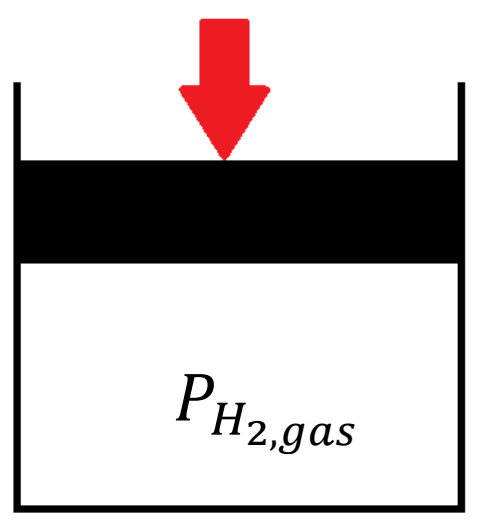

Figure 10: Mechanical hydrogen ingress using a copper-shell modeled as a simple piston

Eventually the gas volume goes to zero, and the movement of hydrogen between the shell, and the zirconium no longer depends on permeability. The movement of hydrogen in the metal-metal couple is now diffusion limited. The implication of this is that when the gas volume goes to zero the hydrogen concentrations are 'frozen' because the diffusivity rate is much lower than the permeability rate for the temperatures, and pressures used.

Figure 11 shows a step-by-step graphical representation of mechanical hydrogen ingress in a copper shell. In step a) the zirconium sheet is placed on top of a copper plate, and zirconium hydride powder is spread evenly over the zirconium. A second copper plate is placed over top of the zirconium hydride. In step b) a small load is applied to the copper 
shell, and zirconium. At this point the oven is set to the experimental temperature between $310{ }^{\circ} \mathrm{C}$ and $500{ }^{\circ} \mathrm{C}$. The load is increased to a value between the yield stress of the shell material, and the zirconium. As the load and temperature increase the shell will deform around the zirconium, forming the seal seen in c). When the temperature passes $310{ }^{\circ} \mathrm{C}$ the zirconium hydride powder thermally decomposes into zirconium powder, and hydrogen gas. The hydrogen forms the gas pocket seen in d). The internal oxides dissolve into the metals, as shown in e), exposing the metal to the hydrogen gas pocket. Finally in f) the hydrogen gas pocket collapses as the load pushes the hydrogen into the zirconium, and copper by permeation.

a)

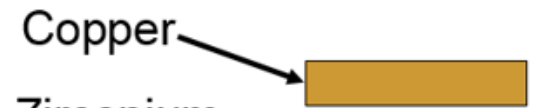

Zirconium

b)
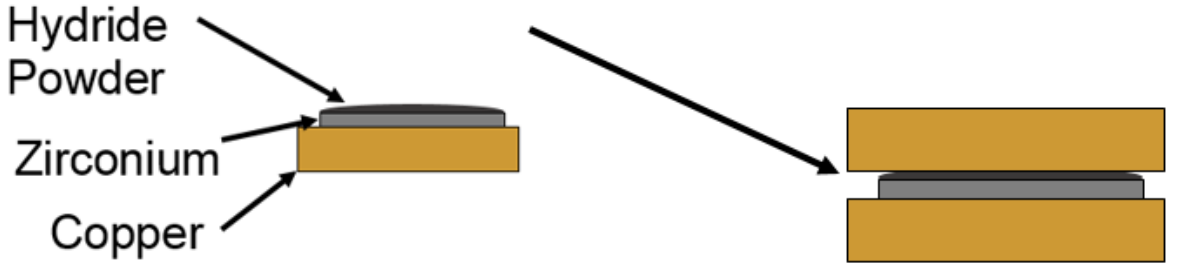

e)

d)

c)

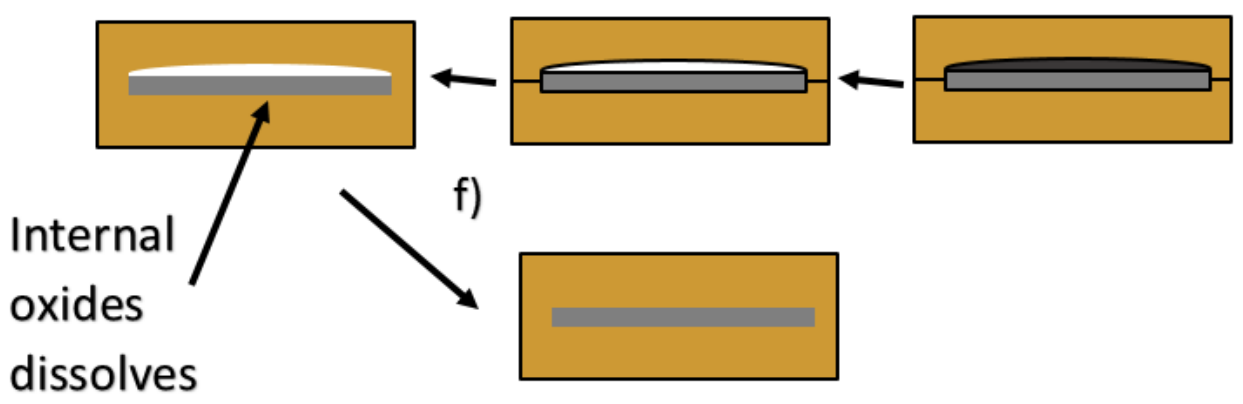

Figure 11: A graphical representation of mechanical hydrogen ingress using a copper shell. The steps labeled a) through $\mathrm{f}$ ) and are described in text. 
Copper makes a good shell metal because of a favourable combination of yield strength, hydrogen permeability, hydrogen solubility, melting temperature, and cost when compared with other potential shell metals such as steel, nickel, gold, and aluminium.

The shell metal must yield under the applied load, so that the pressure of the hydrogen gas from the thermal decomposition of the hydride powder is equal to the pressure delivered by the load frame. In addition, to avoid cold work on the zirconium, the yield stress of the shell must be lower. Table 2 shows a relative comparison of yield stress for potential shell metals. Steel, and nickel were disqualified because their yield stresses are comparable to or greater than that of zirconium.

The shell metal must have a high permeability so that equilibrium is quickly established. The remaining metals in Table 2 are not distinguished by their hydrogen permeability. The metal shell must ultimately act as a barrier, gold was eliminated because it does not form an oxide, which is assumed to be the barrier.

The melting temperature of the shell metal should not be comparable to the maximum experimental temperature of $500{ }^{\circ} \mathrm{C}$. Thus, aluminium with a melting temperature of $660^{\circ} \mathrm{C}$ was eliminated.

The shell metal should have a lower hydrogen solubility than zirconium, so that the hydrogen uptake by the shell is low, which means that a greater amount of the hydrogen will end up in the zirconium. Aluminium was eliminated a second time because its 
hydrogen solubility is low, but not well known, which ultimately means that an accurate hydrogen in zirconium prediction could not be made.

Cost of the shell metal eliminated gold, and nickel. Copper was chosen for the shell metal.

Table 2: Comparison of potential barrier materials (Red shading indicates disqualification) [36, pp. 890-915] [14] [15] [32] [37] [38]

\begin{tabular}{|c|c|c|c|c|c|c|}
\hline & Copper & Steel & Nickel & Gold & Aluminum & Zirconium \\
\hline $\begin{array}{l}\text { Yield stress } \\
\text { relative to } \\
\text { Zirconium }\end{array}$ & Lower & $\begin{array}{l}\text { Equal or } \\
\text { much } \\
\text { higher }\end{array}$ & Equal & Lower & Lower & Equal \\
\hline $\begin{array}{l}\text { Hydrogen } \\
\text { Permeability } \\
\left(\mathrm{mol} \mathrm{m}^{-1} \mathrm{~Pa}^{-}\right. \\
\left.\mathbf{1 / 2} \mathrm{s}^{-1}\right)\end{array}$ & $8 \times 10^{-12}$ & $7 \times 10^{-10}$ & $\begin{array}{c}1 \times 10^{-} \\
10\end{array}$ & $<10^{-12}$ & $1 \times 10^{-12}$ & $1 \times 10^{-11}$ \\
\hline $\begin{array}{l}\text { Melting } \\
\text { Temperature } \\
\left({ }^{\circ} \mathrm{C}\right) \\
\end{array}$ & 1084 & $\begin{array}{c}1425- \\
1540\end{array}$ & 1435 & 1063 & 660 & 1855 \\
\hline $\begin{array}{l}\text { Hydrogen } \\
\text { Solubility } \\
\text { (ppm@425 } \\
\left.{ }^{\circ} \mathrm{C}\right)\end{array}$ & 2.2 & 2 & 5 & $<2$ & $\begin{array}{l}\text { Literature } \\
\text { varies by } \\
\text { six orders of } \\
\text { magnitude }\end{array}$ & 200 \\
\hline $\begin{array}{l}\text { Forms an } \\
\text { Oxide }\end{array}$ & Yes & Yes & Yes & No & Yes & Yes \\
\hline $\begin{array}{l}\text { Relative Cost } \\
\text { to mild Steel } \\
\text { by mass }\end{array}$ & 7.9 & $1.0-4.0$ & 31.5 & 14100 & 7.6 & 66.1 \\
\hline
\end{tabular}

The equation used to predict the amount of hydrogen in zirconium is derived from the conservation of mass of hydrogen before, and after the mechanical hydrogen ingress 
process. The total mass of hydrogen before the temperature, and pressure are applied is given by:

$$
m_{H, i}=m_{Z r} C_{0}+F_{H} m_{Z r H_{2}}
$$

Where $C_{0}$ is the initial concentration of hydrogen in zirconium, $m_{Z r}$ is the zirconium mass, $m_{\mathrm{ZrH}_{2}}$ is the mass of zirconium hydride powder, and $F_{H}$ is the mass fraction of hydrogen in zirconium hydride: 0.02162 .

After the mechanical hydrogen ingress procedure, the hydrogen is partitioned into the zirconium metal, the remaining zirconium metal from the decomposition of the hydride, and the copper-shell (if used):

$$
m_{H, f}=C_{Z r}\left(F_{Z r} m_{Z r H_{2}}+m_{Z r}\right)+m_{C u} S_{C u}
$$

Where $F_{Z r}$ is the mass fraction of zirconium in zirconium hydride, equal to $1-F_{H}=$ 0.97838. The mass of copper is given by $m_{C u}$, and the solubility of hydrogen by weight in copper is given by $S_{C u}$ which is given by Sieverts' Law [13]:

$$
S_{C u}=9.5 e^{-\frac{19300}{R T}} \frac{\mathrm{mol} \mathrm{H}_{2}}{\mathrm{~m}^{3} \mathrm{MPa}^{-0.5}}
$$


Equating Equations 4.15, and 4.16 because of conservation of mass, and solving for $C_{Z r}$ yields the equation used to predict final hydrogen concentration:

$$
C_{Z r}=\frac{F_{H} m_{Z r H_{2}}+m_{Z r} C_{0}-m_{C u} S_{C u}}{m_{Z r}+F_{Z r} m_{Z r H_{2}}}
$$

The assumption leading to Equation 4.18 was that there was sufficient hydrogen available, so that the solubility of hydrogen in copper could be reached. If this assumption is not valid, then the equilibrium concentration ratio of hydrogen in zirconium, and copper is determined by equating the chemical potentials for hydrogen in each metal. The chemical potential of hydrogen in zirconium is given as:

$$
\mu_{H, Z r}=\mu_{H, Z r}^{0}+R T \ln \left(C_{Z r}\right)
$$

The chemical potential of hydrogen in copper is given by:

$$
\mu_{H, C u}=\mu_{H, C u}^{0}+R T \ln \left(C_{C u}\right)
$$

Where $\mu_{H, C u}^{0}$ is the standard state potential of hydrogen in copper. Equating the chemical potentials yields:

$$
C_{C u}=C_{Z r} e^{\frac{\Delta \mu^{0}}{R T}}
$$


Where $\Delta \mu^{0}$ is the difference of the standard state chemical potentials of hydrogen in zirconium, and copper. Substituting Equation 4.21 into Equation 4.18 yields:

$$
C_{Z r}=\frac{F_{H} m_{Z r H_{2}}+m_{Z r} C_{0}}{m_{C u} e^{\frac{\Delta \mu^{0}}{R T}}+m_{Z r}+F_{Z r} m_{Z r H_{2}}} \quad\left\{e^{\frac{\Delta \mu^{0}}{R T}} C_{Z r}<S_{C u}\right\}
$$

\subsection{Measuring Solubility of Hydrogen in Other Metals}

The use of the copper-shell allows for the determination of the solubility of hydrogen in copper from measurements of hydrogen in the zirconium. The solubility of hydrogen in the copper can be calculated by rearranging Equation 4.18:

$$
S_{C u}=\frac{F_{H} m_{Z r H_{2}}+m_{Z r} C_{0}-C_{Z r}\left(m_{Z r}+F_{Z r} m_{Z r H_{2}}\right)}{m_{C u}}
$$

Similar equations can be written for other metals with low solubilities of hydrogen, such as aluminium, silver, and gold. A previous study to determine hydrogen solubility in these metals used large samples ( 120 g) in a Sieverts' apparatus [14]. The method developed in this thesis uses smaller samples ( $40 \mathrm{~g}$ ), and is only limited by the accuracy of measuring hydrogen concentrations in zirconium. 


\section{Chapter 5: Results and Discussion}

The chapter begins with an analysis of the zirconium sandwiched hydride experiment results, and the reasoning for modifying the procedure for the subsequent copper-shell experiments, which are then presented ${ }^{9}$. The zirconium-hydrogen TSS experiment is then presented. Finally, the experimental measurement of a low hydrogen concentration using a combination of mechanical hydrogen ingress, and DSC is presented.

\subsubsection{Zirconium Sandwiched Hydride Experiment}

Two zirconium sheets were pressed together at a temperature of $425^{\circ} \mathrm{C}$ with a layer of zirconium hydride powder between the two sheets. Hydrogen was successfully introduced into the zirconium metal using the procedure in Appendix A.1, and was detected using both DSC, and HVEMS. These data, and a summary, can be found in Appendix D.1. Figure 12 shows a combined graph of the DSC, and HVEMS data. The accuracy of the measured values can vary by up to $30 \%$ for the same prediction, which is insufficient for the objectives of this thesis in Section 1.6.

\footnotetext{
${ }^{9}$ All DSC hydrogen determinations use the Kearns TSSD max-slope relationship that includes thermal lag. The curve is given by: $C=69000 e^{-\frac{33900}{R T}}$.
} 


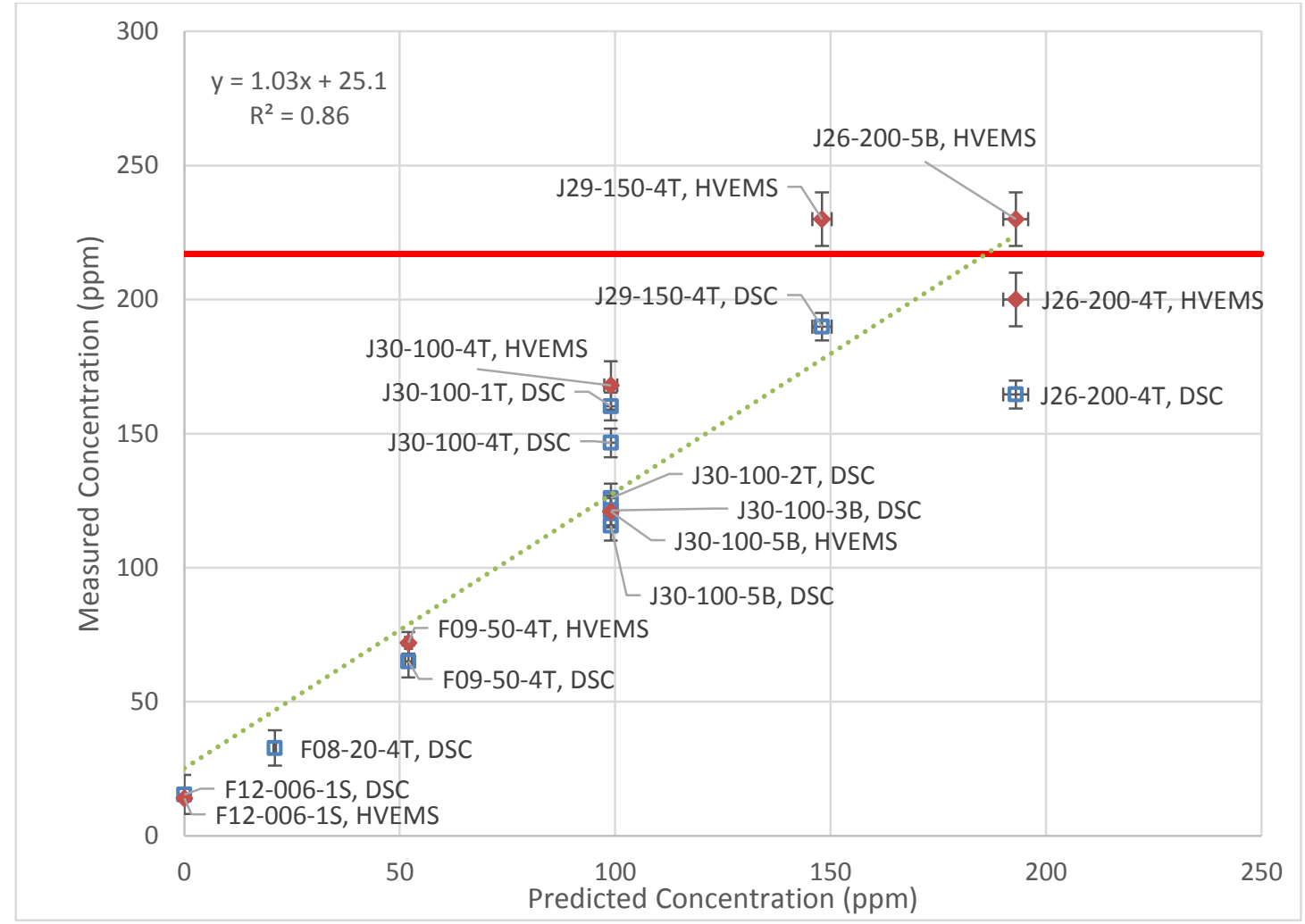

Figure 12: Zirconium sandwiched hydride mechanical hydrogen ingress comparison of predicted, and measured concentration of hydrogen. The horizontal red line is TSSD maximum slope for $425^{\circ} \mathrm{C}$ determined with DSC.

In addition, the distribution of hydrogen throughout the samples was not homogeneous. Sample J30-100 was predicted to have $113 \mathrm{ppm} \pm 5 \mathrm{ppm}$. Figure 13 shows the results. The centre of the top zirconium sheet was found to have a hydrogen concentration of $162 \mathrm{ppm}$ $\pm 6 \mathrm{ppm}$, whereas the bottom sheet was found to have $121 \mathrm{ppm} \pm 4 \mathrm{ppm}$ at the centre. The bottom sheet was relatively homogenous with concentrations of $121 \mathrm{ppm} \pm 4 \mathrm{ppm}$, and $116 \mathrm{ppm} \pm 4 \mathrm{ppm}$. The top sheet concentrations were not as homogeneous:

$162 \mathrm{ppm} \pm 5 \mathrm{ppm}, 147 \mathrm{ppm} \pm 5 \mathrm{ppm}$, and $125 \mathrm{ppm} \pm 5 \mathrm{ppm}$. The measured concentrations well above the predicted value of 113 ppm (i.e., 162 ppm, 147 ppm) suggest hydrogen was entering the zirconium from a source other than the decomposing zirconium hydride at the 
centre of the sandwich. Hydrogen ingress through steel into zirconium has been observed at the rolled joint in CANDU reactors, presumably, when the protective metal oxides are not present [39]. In this case, it is believed that hydrogen ingress was happening through the steel-zirconium interface. This hypothesis is supported by the observation of a shiny finish on the M42 steel where it was in contact with the zirconium. In addition, an experiment performed with no hydride powder on a single Zircaloy sheet found that the hydrogen concentration had increased to $20 \mathrm{ppm} \pm 3 \mathrm{ppm}$ further supporting the hypothesis. This hydrogen ingress through the steel makes the zirconium sandwich inappropriate for quantitative hydrogen addition. Thus, in the next section a copper-shell is introduced around the zirconium.

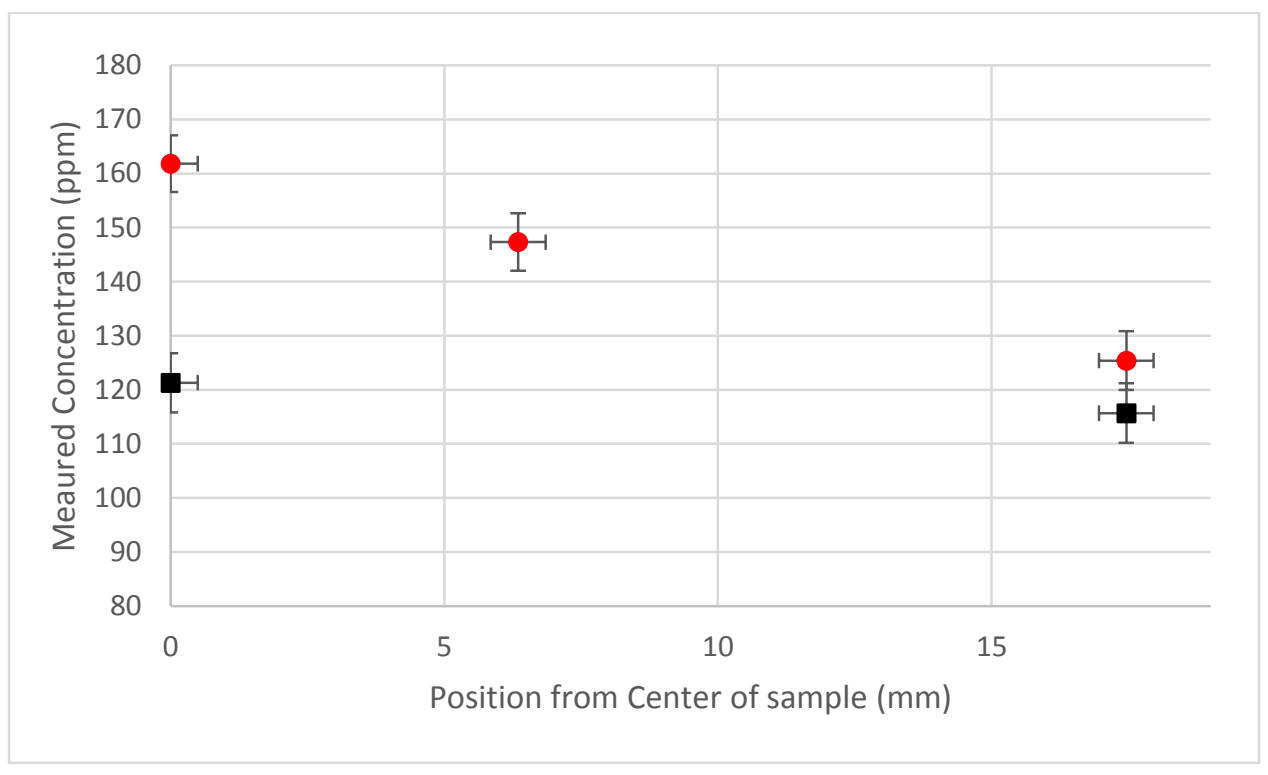

Figure 13: Concentration profile of sample J30-100. Black squares are bottom sheet data, and red circles are top sheet data. The predicted concentration was $113 \mathbf{p p m}$. 


\subsubsection{Copper-Shell Mechanical Hydrogen Ingress Experiment}

Hydrogen was successfully introduced into zirconium in quantitative measure using a copper-shell, and the procedure in Appendix A.2. Figure 14 shows the relationship between the concentrations predicted with Equation 4.18, and measured concentrations of hydrogen in the copper-shell mechanical hydrogen ingress experiments. The predicted values were made with pressures between $90 \mathrm{MPa}$, and $140 \mathrm{MPa}$, oven temperatures between $322{ }^{\circ} \mathrm{C}$ and $500{ }^{\circ} \mathrm{C}$, zirconium hydride masses between $1 \mathrm{mg}$ and $35 \mathrm{mg}$, copper masses between $40 \mathrm{~g}$ and $200 \mathrm{~g}$, and zirconium masses between $1 \mathrm{~g}$ and $4 \mathrm{~g}$. All of these different initial conditions resulted in predictions that were validated by the observations, with one exception. The datum represented by the large circle does not fit the line because there was insufficient hydrogen for copper to reach its solubility, as described in Section 4.5. From this datum, $\Delta \mu^{0}$ can be estimated to be $-14000 \mathrm{~J} / \mathrm{K}$ using Equation 4.22 . These data, and a summary can be found in Appendix D.2.

The accuracy, and precision of the copper-shell mechanical hydrogen ingress technique is demonstrated by the linear relation in Figure 14, when there is sufficient hydrogen to reach the hydrogen solubility in copper. The equation for the line in Figure 14 is:

$$
C_{\text {measured }}=(0.98 \pm 0.02) C_{\text {Predicted }}+2.4 \pm 1.4
$$

where the uncertainties are 1-sigma values. 


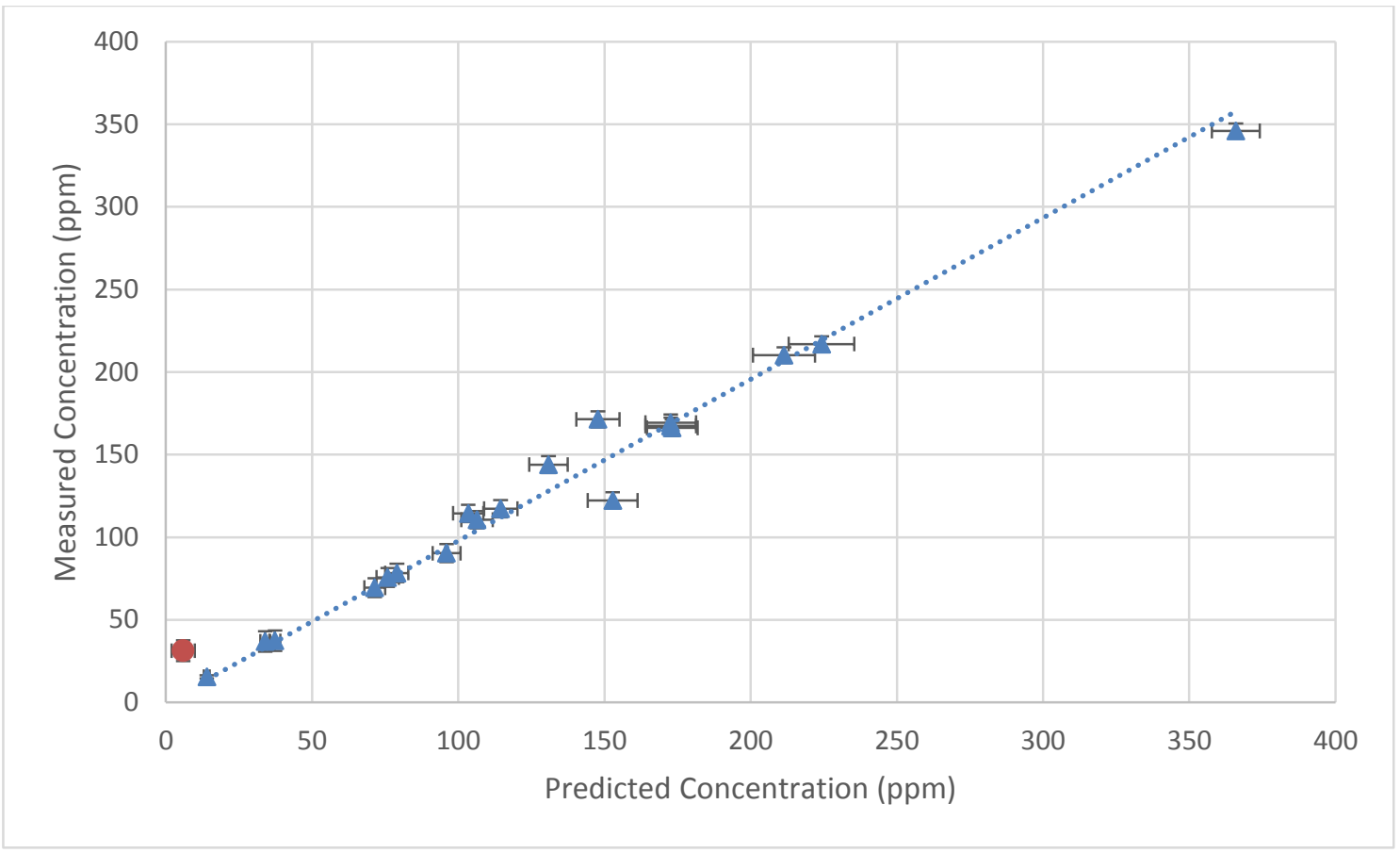

Figure 14: Copper-shell mechanical hydrogen ingress experimental results showing the predicted, and measured hydrogen concentrations. The large circle datum is not on the line because the total hydrogen concentration was insufficient to raise copper to its solubility, as described in Section 4.5.

The slope of the line is unity within the $95 \%$ confidence interval, and the intercept of the line is null within the $95 \%$ confidence interval. The line can thus be considered to be a one-to-one plot of measured values with the predictions of Equation 4.18, with an uncertainty on the measured concentration given by:

$$
\delta_{C, \text { measured }}=0.02 C_{\text {predicted }}+1.4
$$

The uncertainty of the measurement is comparable to that of HVEMS (See Section 2.3.2), against which the DSC method used is ultimately calibrated. The predictions rely on the 
relationship for hydrogen solubility in copper that is given in [13]; improving this relationship will improve the accuracy, and precision of the predictions.

The homogeneity of the hydrogen in sample A20-100 was determined with DSC by measuring the TSSD maximum-slope temperatures of hydrogen in specimens cut from the side, and the centre of the sample. The corresponding concentration of the side-cut specimen was $167.4 \mathrm{ppm} \pm 7 \mathrm{ppm}$, and the centre-cut was $169.4 \pm 7 \mathrm{ppm}$. These measurements show that the sample was homogenous within the uncertainty of the DSC measurement. The homogeneity is also inferred from the agreement of the predicted, and measured concentrations.

The solubility of hydrogen in C110 copper can be determined with Equation 4.22 as described in Section 4.6 from the measurements of the hydrogen in the zirconium; the results are shown in Figure 15 given the data in Appendix D.2. The experimental solubilities are consistent with the solubility relationship, and data found in [13]. One outlier datum for $350^{\circ} \mathrm{C}$ was significantly lower than expected; the probable cause for this is the failed copper shell seal shown in Figure 16. 


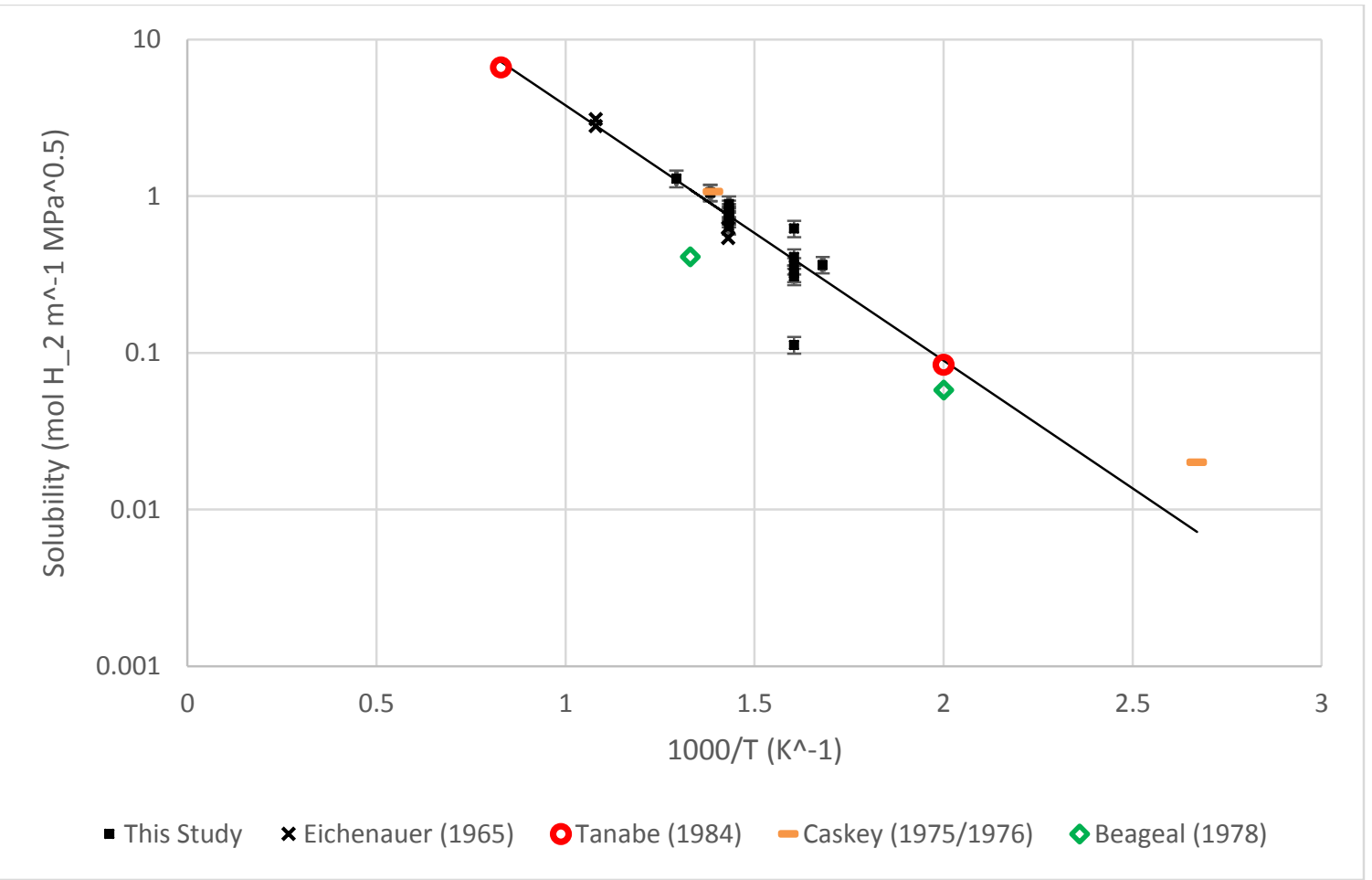

Figure 15: Solubility of Hydrogen in copper found in this study (Black Squares). The external data (unfilled data points) on the graph are recreated from [13].

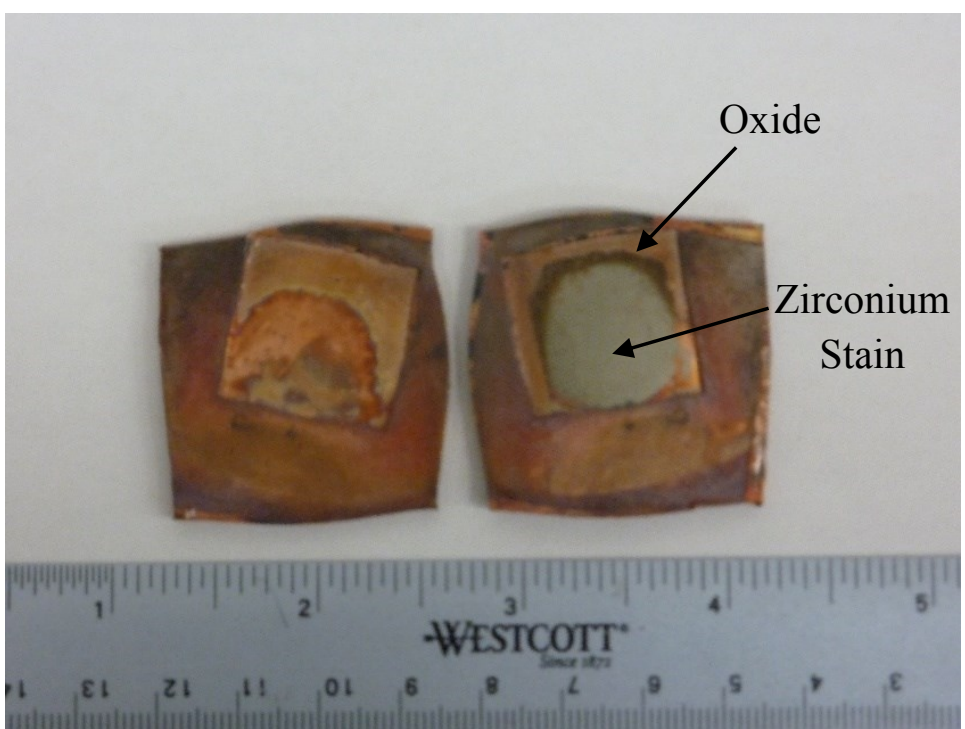

Figure 16: Failed copper seal on Sample Sat3-B. The dark oxide seen on the zirconium stain from the hydride powder is evidence of oxygen in the hydrogen gas pocket. 
During service in reactors, the properties of pressure tubes change because of deuterium ingress, and irradiation at operating temperatures. Irradiation damage, and deuterium ingress both affect fracture toughness; deuterium ingress can lead to DHC. Support for continuing safe reactor operations requires testing of pressure tubes, under deuterium, and irradiation conditions expected in the future. Thus, hydrogen is added to ex-service pressure tubes to increase concentrations to values expected in the future, without affecting the irradiation damage. Work is currently underway in the industry to develop techniques to raise hydrogen concentrations to $140 \mathrm{ppm}$ in $\mathrm{Zr} 2.5 \% \mathrm{Nb}$ pressure tubes, without exceeding $350^{\circ} \mathrm{C}$. The equivalent concentration in Zircaloy-2 is $110 \mathrm{ppm}$.

An objective of this thesis was to investigate whether the mechanical hydrogen ingress technique is capable of adding hydrogen to end-of-life concentrations, at a temperature that will not remove irradiation damage. Specifically, the objective was to raise hydrogen concentrations to $110 \mathrm{ppm}$, without exceeding $350{ }^{\circ} \mathrm{C}$. Experiments performed at temperatures of $322{ }^{\circ} \mathrm{C}$ (sample CU-LT) reached a hydrogen concentration of $90.3 \mathrm{ppm} \pm 5.5 \mathrm{ppm}$.

The results for the $350{ }^{\circ} \mathrm{C}$ tests (samples labeled with the prefix Sat2, and Sat 3 in Appendix D.2) showed that hydrogen concentrations of up to $210.2 \mathrm{ppm} \pm 4.9 \mathrm{ppm}$ can be reached, using mechanical hydrogen ingress. These results show that it is possible to reach concentrations of $210.2 \mathrm{ppm}$ in Zircaloy without exceeding $350^{\circ} \mathrm{C}$. Similar results are expected for $\mathrm{Zr} 2.5 \% \mathrm{Nb}$ pressure tubes. 


\subsection{Terminal Solid Solubility Experiment}

An objective of this research was to determine the true terminal solid solubility.

The terminal solid solubility experiment results are shown in Table 3. It was hypothesized that at the true TSS solvus, the hydrogen ingress into the zirconium would end, and any remnant hydrogen would be distributed in equilibrium between the hydride powder, and gaseous states. The results, however, show that this was not true (Figure 17). Each of the observed TSS temperatures for sample Sat3-M were significantly higher than the observed oven temperature of $350^{\circ} \mathrm{C}$.

Table 3: Terminal Solid Solubility experimental results (MS means maximum slope, OS means onset), errors in $\mathrm{Czr}$ in both predicted, and observed values are found in Appendix E.2.

\begin{tabular}{|c|c|c|c|c|c|c|}
\hline $\begin{array}{c}\text { Sample } \\
\#\end{array}$ & $\begin{array}{c}\text { Toven } \\
\left({ }^{\circ} \mathbf{C}\right)\end{array}$ & $\begin{array}{c}\text { Predicted } \\
\mathbf{C z r}(\mathbf{p p m})\end{array}$ & $\begin{array}{c}\text { Observed } \\
\mathbf{C z r}(\mathbf{p p m})\end{array}$ & $\begin{array}{c}\text { TSSDMs } \\
\left({ }^{\circ} \mathbf{C}\right)\end{array}$ & $\begin{array}{c}\text { TSSPMs } \\
\left({ }^{\circ} \mathbf{C}\right)\end{array}$ & $\begin{array}{c}\text { TSSPos } \\
\left({ }^{\circ} \mathbf{C}\right)\end{array}$ \\
\hline Sat-1 & 500 & 365.9 & 346.0 & $497.7 \pm 1.8$ & $444.8 \pm 1.7$ & $\begin{array}{c}\text { Not } \\
\text { Observed }\end{array}$ \\
\hline Sat-2T & 350 & 140.0 & 143.9 & $393.7 \pm 1.6$ & $323.2 \pm 1.4$ & $330.4 \pm 1.5$ \\
\hline Sat-2M & 350 & 117.9 & 114.5 & $360.8 \pm 1.4$ & $294.2 \pm 1.3$ & $307.2 \pm 1.4$ \\
\hline Sat-2B & 350 & 106.5 & 110.5 & $359.0 \pm 1.4$ & $290.5 \pm 1.3$ & $301.0 \pm 1.3$ \\
\hline Sat-3T & 350 & 122.2 & 152.8 & $371.3 \pm 1.5$ & $297.4 \pm 1.3$ & $303.5 \pm 1.4$ \\
\hline Sat-3M & 350 & 211.4 & 210.2 & $431.8 \pm 1.7$ & $368.9 \pm 1.5$ & $373.9 \pm 1.5$ \\
\hline Sat-3B & 350 & 147.8 & 171.3 & $407.3 \pm 1.7$ & $340.6 \pm 1.4$ & $347.1 \pm 1.4$ \\
\hline
\end{tabular}

The homogeneity of hydrogen in sample Sat3-M is inferred as the datum fits the prediction line in Section 5.1.2. All the TSS temperatures for sample Sat3-M are well above the test temperature of $350{ }^{\circ} \mathrm{C}$. This suggests that the test temperature was not the temperature of the solubility limit, and at the pressures used in the experiment, the TSS concentration is higher than the TSS concentration found at atmospheric pressures. The experiment was 
unable to determine the true solvus of hydrogen in zirconium. However, the results suggest that there might be a significant pressure dependency for the TSS contrary to [40].

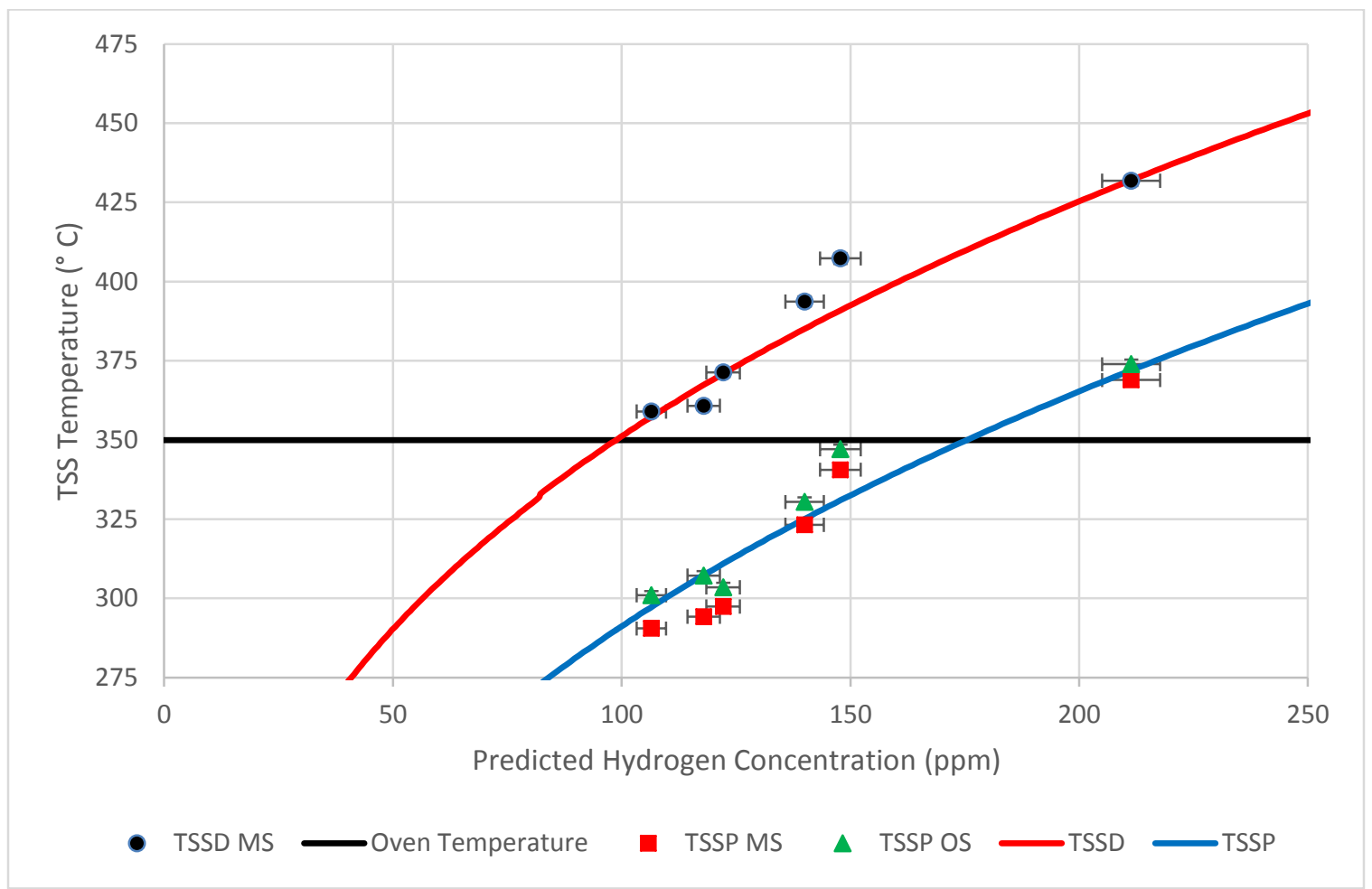

Figure 17: Terminal Solid Solubility Temperature for the Hydrogen Saturation Experiment. The data follows the standard TSS trends.

\subsection{Mechanical Hydrogen Ingress to Enhance DSC at Low Concentrations}

An objective of this thesis was to investigate whether mechanical hydrogen ingress techniques can be used to add a precise amount of hydrogen to a low concentration sample to raise the total hydrogen concentration to values where the DSC performs well, and Terminal Solid Solubility (TSS) calibration curves are well determined. 
The as-received zirconium contained $14 \mathrm{ppm} \pm 1 \mathrm{ppm}^{10}$, which corresponds to a TSSD maximum slope temperature of $206^{\circ} \mathrm{C}$. Hydrogen concentrations at these levels are difficult to measure with DSC. A precise amount of hydrogen was added to raise the concentration by $60 \mathrm{ppm}$. Table 4 below shows the results. The initial concentration in the as-received material was determined using Equation 4.18. The average of three determinations was $13.0 \mathrm{ppm} \pm 2.3 \mathrm{ppm}$, which agrees with the HVEMS measurement of $14 \mathrm{ppm} \pm 1 \mathrm{ppm}$. The use of the mechanical hydrogen ingress technique to spike low hydrogen concentration samples expands the range where DSC can be used.

Table 4: MH-DSC determination of initial hydrogen concentration of Zircaloy-2 Sheet

\begin{tabular}{|c|c|c|c|}
\hline Sample \# & $\begin{array}{c}\text { Hydrogen } \\
\text { Added } \\
\text { (ppm) }\end{array}$ & $\begin{array}{c}\text { Hydrogen } \\
\text { Measured } \\
\text { (ppm) }\end{array}$ & $\begin{array}{c}\text { Difference } \\
\text { (ppm) }\end{array}$ \\
\hline $\begin{array}{c}\text { MH- } \\
\text { DSC-1 }\end{array}$ & $57.5 \pm 1.5$ & $69.4 \pm 5.2$ & $12.0 \pm 5.4$ \\
\hline $\begin{array}{c}\text { MH- } \\
\text { DSC-2 }\end{array}$ & $65.1 \pm 1.5$ & $78.3 \pm 5.1$ & $13.3 \pm 5.4$ \\
\hline $\begin{array}{c}\text { MH- } \\
\text { DSC-3 }\end{array}$ & $61.9 \pm 1.5$ & $75.6 \pm 5.1$ & $13.7 \pm 5.4$ \\
\hline
\end{tabular}

\begin{tabular}{|c|c|}
\hline $\begin{array}{c}\text { MH-DSC } \\
\text { Average } \\
\text { (ppm) }\end{array}$ & $13.0 \pm 2.3$ \\
\hline $\begin{array}{c}\text { HVEMS } \\
\text { (ppm) }\end{array}$ & $14 \pm 1$ \\
\hline
\end{tabular}

\footnotetext{
${ }^{10}$ Appendix D1, AQSA\# 147829 in Figure 76.
} 


\section{Chapter 6: Conclusions}

This chapter contains conclusions for each of the thesis objectives. Following these conclusions, recommendations for future work are presented.

\subsection{Conclusions on the Research Objectives}

The thesis objectives outlined in Section 1.6 were:

- The manufacture of standards with accurate, and precise concentrations of hydrogen, and deuterium in zirconium

- The measurement of low hydrogen concentrations in zirconium

- Determining the solubility of hydrogen in metals with low hydrogen solubilities

- Determining the solubility limit of hydrogen in zirconium

- The addition of end-of-life hydrogen concentrations to zirconium at temperatures that do not remove irradiation damage

\subsubsection{The Manufacture of Standards with Accurate, and Precise Concentrations of}

\section{Hydrogen, and Deuterium in Zirconium}

Hydrogen can be accurately added to zirconium with precisions based on the accuracy, and precision of the relationship for the solubility of hydrogen in copper, and the precision, and accuracy of the mass balance used to mass the zirconium, zirconium hydride, and the copper shell. The uncertainty of the final concentration is comparable to the capability of HVEMS to measure hydrogen concentration. These values can be improved 
through a better determination of the solubility of hydrogen in copper, and a better mass balance.

\subsubsection{The Measurement of Low Hydrogen Concentrations in Zirconium}

The concentration of hydrogen in as-received zirconium was determined to be $13.0 \mathrm{ppm} \pm 2.3 \mathrm{ppm}$ using a combination of the copper-shell mechanical hydrogen ingress technique, and differential scanning calorimetry. This concentration is below the current measurement limit of typical DSC instruments. The measurement was verified by HVEMS: $14 \mathrm{ppm} \pm 1 \mathrm{ppm}$. The combined use of the mechanical hydrogen ingress, and differential scanning calorimetry techniques allows for the use of DSC measurement of transition temperatures to determine hydrogen concentrations below current measurement limits.

\subsubsection{Determination of Hydrogen Solubility in Low Solubility Metals}

Using the copper-shell technique the solubility of hydrogen in C110 copper was determined over a temperature range of $322{ }^{\circ} \mathrm{C}$ to $500{ }^{\circ} \mathrm{C}$. The determined values agreed with those of previous studies, but the precision was improved. It was suggested this technique could be used to determine the hydrogen solubility in gold, aluminum, and silver, etc. 


\subsubsection{Determination of the Hydrogen Terminal Solubility Limit in Zirconium}

The determination of the hydrogen TSS in zirconium was unsuccessful. The results of the TSS experiment show that at the pressures used in the experiment, hydrogen could be added beyond the standard TSS concentrations.

\subsubsection{The Addition of End-of-Life hydrogen Concentrations to Zirconium at Temperatures that do not Remove Irradiation Damage}

The addition of hydrogen to end-of-life concentrations at temperatures below which significant annealing of irradiation damage occurs was successful. The goal was to be able to add hydrogen to a final concentration of $140 \mathrm{ppm}$ in $\mathrm{Zr} 2.5 \% \mathrm{Nb}$ pressure tubes, the solubility limits in Zircaloy-2 are lower so that the equivalent goal in Zircaloy-2 is $110 \mathrm{ppm}$. The hydrogen concentration in Zircaloy-2 was increased from $14 \mathrm{ppm}$ to $210 \mathrm{ppm}$ at a temperature of $350{ }^{\circ} \mathrm{C}$, using the mechanical hydrogen ingress technique. Furthermore, the technique was successfully demonstrated at temperatures as low as $322^{\circ} \mathrm{C}$.

\subsection{Future Work}

The natural evolution of the work in this thesis on flat Zircaloy sheet is to adapt the mechanical hydrogen ingress technique for cylindrical CANDU pressure tubes. One possibility is to impregnate the outside surface of a copper tube with zirconium hydride; the copper tube would have an OD slightly less than the ID of the pressure tube. The copper tube would be fitted inside the pressure tube. The inside of the composite tube could be filled with water, the ends sealed, and the apparatus heated. The outside of the composite tube could be reinforced to withstand high hoop stress from the pressure. 
Future work should include an investigation of why hydrogen could be added to zirconium at concentrations beyond the TSS.

Future work should also include determining the hydrogen solubilities in lowsolubility metals such as gold, aluminum, and silver. In addition more experiments on copper would provide an improved solubility relationship to improve the accuracy, and precision of the mechanical hydrogen ingress technique. 


\section{References}

[1] J. Lilley, Nuclear Physics: Principles and Applications, West Sussex, UK: John Wiley \& Sons, 2001.

[2] G. A. McRae, C. E. Coleman and B. Leitch, "The First Step in Delayed Hydride Cracking in Zirconium Alloys," Journal of Nuclear Materials, pp. 130-143, January 2010.

[3] H. K. Rae, "CANDU and Its Evolution," in Canada enters the nuclear age: a technical history of Atomic Energy of Canada Limited, Montreal, Quebec, McGillQueens University Press, 1997, pp. 191-214.

[4] M. P. Puls, "Assesment of aging of $\mathrm{Zr} 2.5 \% \mathrm{Nb}$ pressure tubes in CANDU reactors," Nuclear Engineering and Design, vol. 171, no. 1-3, pp. 137-148, 1997.

[5] C. E. Coleman, "Cracking of Hydride-forming Metals and Alloys," Atomic Energy of Canada Limited, Chalk River, 2011.

[6] C. E. Coleman and L. A. Simpson, "Evaluation of a Leaking Crack in an Irradiated CANDU Pressure Tube," Atomic Energy Canada Limited, Chalk River, Ontario, 1988.

[7] G. D. Moan, C. E. Coleman, E. G. Price, D. K. Rodgers and S. Sagat, "LeakBefore-Break in pressure tubes of CANDU reactors," Int. J. Pres. Ves. \& Piping, vol. 43, pp. 1-21, 1990.

[8] S. Q. Shi, G. K. Shek and M. P. Puls, "Hydrogen concentration limit and critical temperatures for delayed hydride cracking in zirconium alloys," Journal ofNuclear Materials, vol. 218, pp. 189-201, 1995. 
[9] Y. S. Kim, "Driving Force for Delayed Hydride Cracking of Zirconium Alloys," Metals and Materials International, vol. II, no. 2, pp. 29-38, 2005.

[10] C. E. Ells, "Fuel Channels," in Canada Enters the Nuclear Age, Chalk River, Atomic Energy of Canada Limited, 1997, pp. 233-253.

[11] S. Hanlon, "The Effect of Testing Direction on DHC Growth Rate using Zr-2.5Nb Plate," Masters Thesis, 2013.

[12] G. A. Bickel, L. W. Green, M. W. D. James, T. G. Lamarche, P. K. Leeson and H. Michel, "The determination of hydrogen and deuterium in $\mathrm{Zr}-2.5 \mathrm{Nb}$ material by hot vacumm extraction mass spectrometry," Journal of Nuclear Materials, vol. 306, pp. 21-29, 2002.

[13] C. S. Marchi, "Technical Reference on Hydrogen Compatibility of Materials: Copper Alloy; Pure Copper (4001)," Sandia National Labs, Livermore, 2006.

[14] R. B. McLellan, "Solid Solutions of Hydrogen in Gold, Silver, and Copper," Journal of Physical Chemical Solids, vol. 34, pp. 1137-1141, 1973.

[15] C. S. Marchi, "Technical Reference on Hydrogen Compatibility of Materials: Pure Aluminium (Code 3101)," Sandia National Labs, Livermore, 2007.

[16] M. P. Puls, "Elastic and Plastic Accommodation Effects on Metal-Hydride Solubility," Acta Metallurgical, vol. 32, no. 8, pp. 1259-1269, 1984.

[17] R. W. C. H. Dutton, L. A. Nuttall, L. A. Simpson and M. P. Puls, Hydrogen in Metals, Oxford: Pergamon Press, 1978. 
[18] E. Zuzek, J. P. Abriata, A. San-Martin and F. D. Manchester, "The H-Zr (Hydrogen-Zirconium) System," Bulletin of Alloy Phase Diagrams, vol. II, no. 4, pp. 385-395, 1990.

[19] C. E. Ells, "Hydride precipitates in zirconium alloys (A review)," Journal of Nuclear Materials, vol. 28, no. 2, pp. 129-151, 1968.

[20] W. H. Erickson and D. Hardie, "The Influence of Alloying Elements on the Terminal Solubility of Hydrogen in a-Zirconium," Journal of Nuclear Materials, vol. 13, no. 2, pp. 254-262, 1964.

[21] G. A. McRae and C. E. Coleman, To be Published, 2015.

[22] R. N. Singh, R. Kishore, S. Mukherjee, S. Roychowdhury, D. Srivastava, T. K. Sinha, P. E. De, S. Banerjee, R. Kameswaran, S. S. Sheelvantra and B. Gopalan, "Hydrogen charging, hydrogen content analysis, and metallographic examination of hydride in zirconium alloys (BARC-2003/E/034)," Bhaba Atomic Research Center, Mumbai, 2003.

[23] J. H. Huang and S. P. Huang, "Hydriding of zirconium alloys in hydrogen gas," Materials Science and Engineering, vol. A161, pp. 247-253, 1993.

[24] H. Callen, Thermodynamics and an Intoduction to Thermostatistics, New York, USA: John Wiley \& Sons, 1985, pp. 181-202.

[25] Y. K. Rao, Stoichiometry and Thermodynamics of Metallurgical Processes, Melbourne: Cambridge University Press, 1985.

[26] M. P. Puls, The Effect of Hydrogen and Hydrides on the Integrity of Zirconium Alloy Components, New York: Springer-Verlag London, 2012. 
[27] R. A. Murgatroyd and J. Winston, "Hydriding Zircaloy-2 in Lithium Hydroxide Solutions," Journal of Nuclear Materials, vol. 23, pp. 249-256, 1967.

[28] P. Vizcaino, R. O. Rios and A. D. Banchik, "Hydrogen determinations in a zirconium based alloy with a DSC," Thermochimica Acta, vol. 429, no. 1, pp. 7-11, 2005.

[29] J. Akhtar, M. Ahmed, B. Mohammad, S. Jan and F. Waqar, "Determination of hydrogen in zirconium and its alloys by melt extraction under carrier gas flow using thermal conductivity cell as detector," Pakistan Institute of Nuclear Science and Technology, Islamabad, 1987.

[30] L. Jordan and J. R. Eckman, "Determination of Oxygen and Hydrogen in Metals by Fusion in Vacuum," vol. 18, no. 3, pp. 279-282, 1926.

[31] J. W. Gibbs, "On the Equilibrium of heterogeneous substances," Trans. Connecticut Academy, vol. 3, pp. 108-248, 1875.

[32] J. J. Kearns, "Terminal solubility and partitioning of hydrogen in the alpha phase of zirconium, Zircaloy-2, and Zircaloy-4," Journal of Nuclear Materials, vol. 22, no. 3, pp. 292-303, 1967.

[33] A. Fick, "Ueber Diffusion," Annalen der Physik, vol. 170, no. 1, pp. 59-86, 1855.

[34] J. Crank, The Mathematics of Diffusion, New York: Oxford University Press, 1975.

[35] A. Roth, Vacuum Sealing Techniques, New York: American Institute of Physics, 1994.

[36] W. D. J. Callister and R. D. G., Materials Science and Engineering: An Introduction, New Jersey: John Wiley and Sons Inc., 2014. 
[37] C. S. Marchi, "Technical Reference on Hydrogen Compatibility of Materials: Austenitic Stainless Steels Type 316 (Code2103)," Sandia National Labs, Livermore, 2005.

[38] S. W. Stafford and R. B. McLellan, "The permeability of hydrogen in nickel," Scripta Metallurgica, vol. 9, no. 11, pp. 1195-1199, 1975.

[39] V. F. Urbanic, B. D. Warr, A. Manolescu, C. K. Chow and M. W. Shanahan, "Oxidation and Deuterium Uptake of Zr-2.5Nb Pressure Tubes in CANDU-PHW Reactors," in Zirconium in the Nuclear Industry: Eighth International Symposium, San Diego, 1989.

[40] M. P. Puls, "The Effect of Misfit and External Stresses on Terminal Solid Solubility in Hydride-Forming Metals," Acta Metallurgica, vol. 29, no. 12, pp. 1961-1968, 1981. 


\section{Appendices}

\section{Appendix A Procedure for Mechanical Hydrogen Ingress}

\section{A.1 Procedure for Zirconium Sandwiched Hydride Technique}

1. The zirconium samples are cut to size using a corner shear punch. The metallic surface of the sample is cleaned using $\# 0000$ steel wool to clean off excessive surface oxide.

2. The sample is massed using an Acculab mass balance with a precision of \pm 0.0001 g. The appropriate amount of zirconium hydride powder (See Section 3.2.3) is massed out into a $10 \mathrm{~mL}$ Pyrex beaker.

3. The hydraulic feed pump, and MTS-810 load frame are turned on, and the load control software is loaded on the control computer. The M42 hardened platens are loaded into the load frame grips by placing them into position, and turning the appropriate toggle on the main console. The left toggle controls the bottom grip, and the right toggle controls the top grip.

Note: The stainless steel thermal shroud must be placed on the top platen to disperse the convective heat transfer around the top MTS hydraulic grip, and the load cell. This prevents the grip, and load cell from exceeding their maximum safe operating temperature of $85^{\circ} \mathrm{C}$.

4. The appropriate load for the experiment is programed into the software by clicking the lock program button into the unlocked position, and then right clicking the step titled "Load," and selecting "open". The load can be changed by typing the loading 
into the box labeled "Force" as the negative of the desired force. The negative force is used as the MTS-810 is capable of compressive or tensile loading, and compressive forces are deemed negative loads. When changing the force it is important that the force text box not be active (i.e. the text curser is not flashing within the box) when the save button is pressed, as this results in the force not changing.

5. The bottom steel die is placed on the bottom platen. It is necessary to use dies as the platens are insufficiently long to clear the oven on their own. This is a design feature, allowing different stress profiles to be applied to the samples using differently shaped dies. In these experiments the dies are simple flat surfaces giving a uniform stress profile.

6. The sample, and bottom zirconium sheet are placed on the hardened M42 steel die, and the hydride powder is spread evenly over the sample. The top zirconium sheet is placed over the sample, and the upper steel die placed on top.

7. The MTS software is then locked by pressing the padlock button. The sample name is then input into the "Test Name" text box, and the play button is clicked. The program step button will become activated, and read "Close". The close button should be clicked once. Allow the MTS load frame to close together the two platens (with the dies, and sample in between). The frame is only closed when the frame reads $2 \mathrm{kN}$.

8. Ensure that the "Stop" button is depressed on the Laboratory Thermal Control Unit, and then power up the device by switching the main disconnect on the right hand side of the controller to the "on" position. The CN7223 controller is automatically 
powered up, however, the DP1001AM thermocouple scanner must be powered up manually using the power button on the interface.

9. Set the test temperature using the up, and down arrows on the CN7223 device. The temperature is set by using the enter key on the far left of the controller. Place the controller thermocouple such that it is fed in through the bottom of the oven unit, and touches the sample's edge. Close the clamshell oven around the sample, and latch the oven shut.

10. Place the primary heat shroud on top of the oven such that they block convection through the top hole of the oven unit. Without these the oven cannot reach temperatures above $350{ }^{\circ} \mathrm{C}$.

11. Ensure that the DP1001AM thermocouples are placed on appropriate components of the load frame, and oven (upper grip jaw, upper hydraulic lines, load cell, oven cage electrical utility box, controller enclosure interior, and a second thermocouple on the sample). The appropriate maximum temperatures with a $20{ }^{\circ} \mathrm{C}$ safety factor are programmed into the DP1001AM by depressing the "function B" button for 5 seconds. Depressing the button again allows setting of the various alarm state parameters.

12. The MTS can now be loaded to the test load by pressing the "Start/Load" button. Ensure that the oven thermocouple has not been displaced by the loading. The oven stop can now be released by twisting the button clockwise.

13. The oven is heated to the test temperature of $425^{\circ} \mathrm{C}$ for one hour.

14. To unload the sample depress the oven stop button, click the unload button on the MTS controller. Open the oven, and remove the sample thermocouples. Click the 
open button on the MTS controller, wait until the MTS frame stops moving, and remove the sample by gripping the bottom die in tongs, and quenching the metal in still water. Once the boiling has stopped remove the dies from the water to prevent corrosion. The sample can be retrieved by softly tapping the die with a ball pein hammer.

15. The sample is now hydrided to the desired concentration, and can be tested after cutting specimens from the sample. 


\section{A.2 Procedure for Copper-Shelled Mechanical Hydrogen Ingress Technique}

1. The zirconium sample is cut to size using a corner shear punch. An appropriately sized copper-shell is cut using a fine tooth band saw. The metallic surface of both the sample, and shell are cleaned using \#0000 steel wool to clean off excessive surface oxide.

2. The sample, and copper-shell are massed using an Acculab mass balance with a precision of $\pm 0.0001 \mathrm{~g}$. The appropriate amount of zirconium hydride powder (See Section 3.2.3) is massed out into a $10 \mathrm{~mL}$ Pyrex beaker.

3. The hydraulic feed pump, and MTS-810 load frame are turned on, and the load control software is loaded on the control computer. The M42 hardened platens are loaded into the load frame grips by placing them into position, and turning the appropriate toggle on the main console. The left toggle controls the bottom grip, and the right toggle controls the top grip.

Note: The stainless steel thermal shroud must be placed on the top platen to disperse the convective heat transfer around the top MTS hydraulic grip, and the load cell. This prevents the grip, and load cell from exceeding their maximum safe operating temperature of $85^{\circ} \mathrm{C}$.

4. The appropriate load for the experiment is programed into the software by clicking the lock program button into the unlocked position, and then right clicking the step titled "Load," and selecting "open". The load can be changed by typing the loading 
into the box labeled "Force" as the negative of the desired force. The negative force is used as the MTS-810 is capable of compressive or tensile loading, and compressive forces are deemed negative loads. When changing the force it is important that the force text box not be active (i.e. the text curser is not flashing within the box) when the save button is pressed, as this results in the loading not changing.

5. The bottom steel die is placed on the bottom platen. It is necessary to use dies as the platens are insufficiently long to clear the oven on their own. This is a design feature, allowing different stress profiles to be applied to the samples using differently shaped dies. In these experiments the dies are simple flat surfaces giving a uniform stress profile.

6. The sample, and bottom copper-shell are placed on the hardened M42 steel die, and the hydride powder is spread evenly over the sample. The top copper-shell is placed over the sample, and the upper steel die placed on top.

7. The MTS software is then locked by pressing the padlock button. The sample name is then input into the "Test Name" text box, and the play button is clicked. The program step button will become activated, and read "Close". The close button should be clicked once, and then allow the MTS load frame to close together the two platens (with the dies, and sample in between). The frame is only closed when the frame reads $2 \mathrm{kN}$.

8. Ensure that the "Stop" button is depressed on the Laboratory Thermal Control Unit, and then power up the device by switching the main disconnect on the right hand side of the controller to the "on" position. The CN7223 controller is automatically 
powered up, however, the DP1001AM thermocouple scanner must be powered up manually using the power button on the interface.

9. Set the test temperature using the up, and down arrows on the CN7223 device. The temperature is set by using the enter key on the far left of the controller. Place the controller thermocouple such that it is fed in through the bottom of the oven unit, and touches the sample's edge. Close the clamshell oven around the sample, and latch the oven shut.

10. Place the primary heat shroud on top of the oven such that they block convection through the top hole of the oven unit. Without these the oven cannot reach temperatures above $350{ }^{\circ} \mathrm{C}$.

11. Ensure that the DP1001AM thermocouples are placed on appropriate components of the load frame, and oven (upper grip jaw, upper hydraulic lines, load cell, oven cage electrical utility box, controller enclosure interior, and a second thermocouple on the sample). The appropriate maximum temperatures with a $20^{\circ} \mathrm{C}$ safety factor are programmed into the DP1001AM by depressing the "function B" button for 5 seconds. Depressing the button again allows setting of the various alarm state parameters.

12. The MTS can now be loaded to the test load by pressing the "Start/Load" button. Ensure that the oven thermocouple has not been displaced by the loading. The oven stop can now be released by twisting the button clockwise.

13. The sample can now be left for the test duration, with occasional inspections to ensure the load, and temperature have been maintained. While not strictly 
necessary for safety reasons, the inspections ensure that no alarm states have terminated the test on the MTS controller, or oven controller.

The test duration is scaled from 24 hours at a temperature of $425^{\circ} \mathrm{C}$ by the ratio of the hydrogen diffusivity of zirconium.

$$
t=24 h \frac{D_{\text {test }}}{D_{425^{\circ} \mathrm{C}}}
$$

14. To unload the sample depress the oven stop button, click the unload button on the MTS controller. Open the oven, and remove the sample thermocouples. Click the open button on the MTS controller, wait until the MTS frame stops moving, and remove the sample by gripping the bottom die in tongs, and quenching the metal in still water. Once the boiling has stopped remove the dies from the water to prevent corrosion. The sample can be retrieved by softly tapping the sample with a ball pein hammer.

15. The sample is removed from the copper-shell using a ball pein hammer and chisel, and the sample is placed in an oven for 24 hours at $500{ }^{\circ} \mathrm{C}$ to homogenize the sample concentration.

16. The sample is now hydrided to the desired concentration, and can be tested after cutting specimens from the sample. 


\section{Appendix B Cylindrical Clamshell Oven and Controller Design}

\section{B.1 Oven Controller Circuit Diagram}

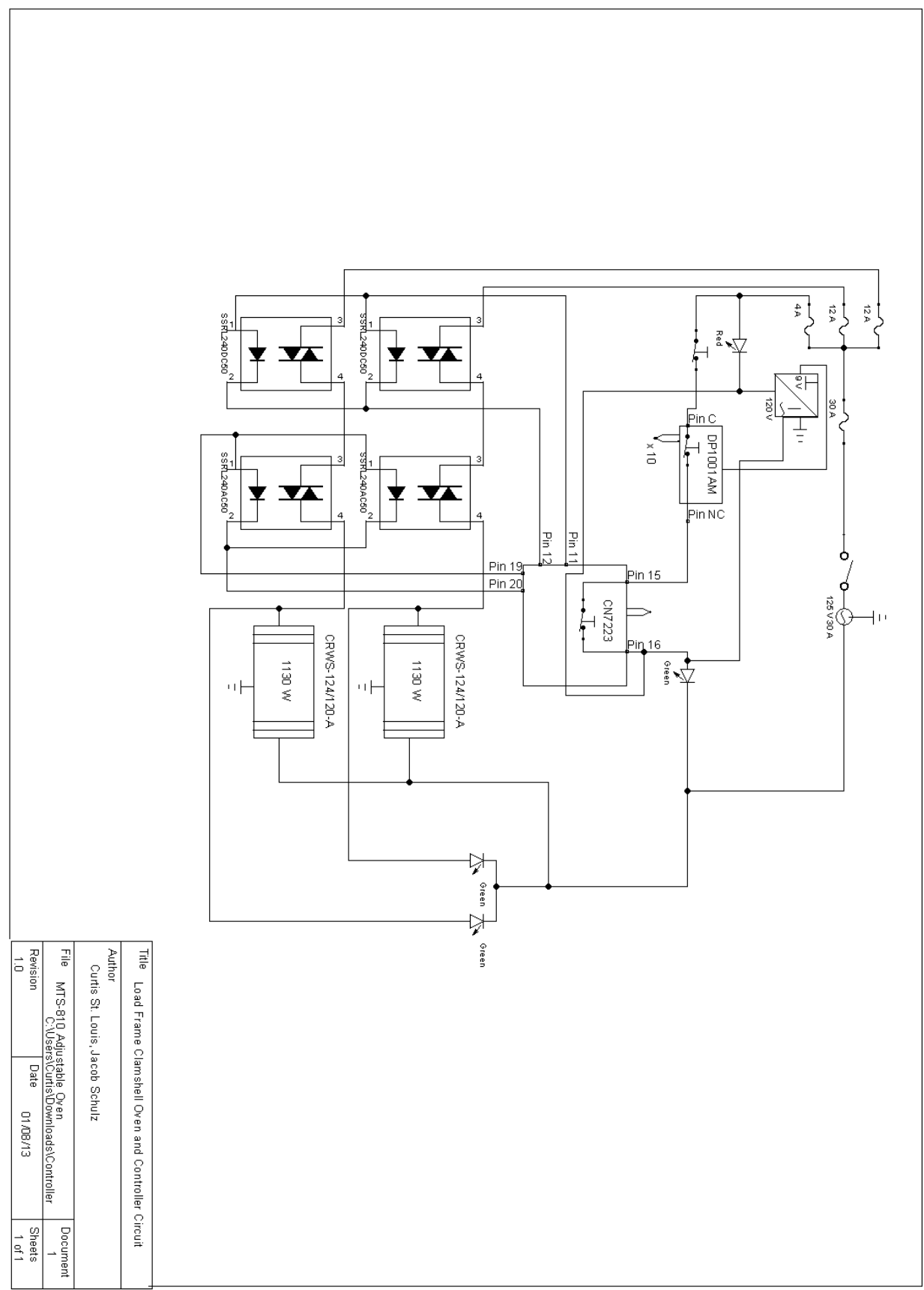

Figure 18: Oven controller, and oven circuit diagram. 


\section{B.2 Component List}

\begin{tabular}{|c|c|c|c|}
\hline Part \# & Manufacturer & $\#$ & Description \\
\hline CN7223 & Omega & 1 & $\begin{array}{l}1 / 4 \text { DIN PID controller with ramp soak } \\
\text { capability, and an NC alarm setting for } \\
\text { overheating. NC alarm acts as the primary } \\
\text { safety device. } \\
\text { The CN7223 was chosen for its simple } \\
\text { interface, and ability to self-optimize the PID } \\
\text { control parameters, and self-calibration feature. } \\
\text { As well the controller's thermal cycle } \\
\text { programming was a highly desirable option for } \\
\text { automation. }\end{array}$ \\
\hline DP1001AM & Omega & 1 & $\begin{array}{l}10 \text { Channel thermocouple scanner with } \\
\text { individual NC alarms, acting as secondary } \\
\text { safeties. Each NC alarm has a thermocouple } \\
\text { attached to critical load frame components. } \\
\text { The DP1001AM was chosen for the ability of } \\
\text { the device to set ten alarm channels, and self- } \\
\text { calibration feature. As well the ability to output } \\
\text { to a computer using a RS } 232 \text { serial connection } \\
\text { could be implemented in the future. }\end{array}$ \\
\hline SSRL240DC50 & Omega & 2 & $\begin{array}{l}\text { DC solid state relay rated up to } 240 \mathrm{~V} \text { at } 50 \mathrm{~A} \text {. } \\
\text { The CN7223 DC control circuit attaches to } \\
\text { each device's switching circuit in parallel. } \\
\text { Each DC SSR is attached to a } 12 \text { A feed line, } \\
\text { and runs into the AC SSR to control oven } \\
\text { output. }\end{array}$ \\
\hline SSRL240AC50 & Omega & 2 & $\begin{array}{l}\text { AC solid state relay rated up to } 240 \mathrm{~V} \text { at } 50 \mathrm{~A} \text {. } \\
\text { The CN7223 AC control circuit attaches to } \\
\text { each device's switching circuit in parallel. } \\
\text { Each AC SSR is attached to the DC SSR's } \\
\text { output line. }\end{array}$ \\
\hline FHS-2 & Omega & 4 & $\begin{array}{l}\text { Finned heat sinks for SSRs. The larger FHS-2 } \\
\text { was selected for the larger surface area, and } \\
\text { negligible cost difference. SSRs are mounted }\end{array}$ \\
\hline
\end{tabular}




\begin{tabular}{|c|c|c|c|}
\hline & & & $\begin{array}{l}\text { on the heat sinks with two screws. Thermal } \\
\text { paste ensures thermal contact. }\end{array}$ \\
\hline $\begin{array}{l}\text { CRWS- } \\
124 / 120-A\end{array}$ & Omega & 2 & $\begin{array}{l}\text { Semi cylindrical radiant heater rated to } 1130 \\
\text { W, to a maximum of } 980^{\circ} \mathrm{C} \text {. Each oven draws } \\
\text { a maximum of } 9.5 \text { A. The ovens have an ID of } \\
4 \text { ", an OD of 6", and are } 12 \text { " in height. The } \\
\text { ovens are set into the oven cage component of } \\
\text { the mount. }\end{array}$ \\
\hline $\begin{array}{l}\text { SCE- } \\
16 \mathrm{C} 16 \mathrm{EJL}\end{array}$ & Omega & 1 & $\begin{array}{l}\text { Electrical console enclosure used to mount, } \\
\text { and house components safely. }\end{array}$ \\
\hline SCE-16P14 & Omega & 1 & $\begin{array}{l}\text { Electrical enclosure subpanel for mounting. } \\
\text { All high power components are mounted to } \\
\text { this grounded sub panel for safety. }\end{array}$ \\
\hline $\begin{array}{l}\text { HTMG-1CU- } \\
312 \mathrm{~S} / \mathrm{C}\end{array}$ & Omega & 1 & $\begin{array}{l}25 \mathrm{ft} \text { of high temperature wire for wiring near } \\
\text { oven device. }\end{array}$ \\
\hline $30103 \mathrm{D}$ & $\begin{array}{l}\text { Automation } \\
\text { Direct }\end{array}$ & 1 & $\begin{array}{l}3 \text { pole main disconnect, mounted to side of } \\
\text { enclosure. } 125 \mathrm{~V} 30 \text { A power feed runs into } \\
\text { the disconnect device through the bottom with } \\
\text { a } 15 \mathrm{~m} \text { long } 10 \text { ga three wire cable. }\end{array}$ \\
\hline HBL9309 & Hubble & 1 & $\begin{array}{l}\text { Single phase NEMA } 30 \mathrm{~A}, 125 \mathrm{~V} \text { male plug } \\
\text { used for primary power feed. }\end{array}$ \\
\hline MJP1-12-K & Omega & 1 & $\begin{array}{l}12 \text { channel } \mathrm{k} \text { type thermocouple input for } \\
\text { controller enclosure. Used to pass external } \\
\text { thermocouple wiring to the internal } \\
\text { components. Accepts sub-mini } \mathrm{k} \text { type } \\
\text { thermocouple connections. Connections } 1-10 \\
\text { are connected to the DP1001AM thermocouple } \\
\text { scanner, connection } 11 \text { is the controller } \\
\text { thermocouple. }\end{array}$ \\
\hline FB-1 & Omega & 1 & Fuse block for a KAX-30 type fuse. \\
\hline KAX-30 & Omega & 1 & $\begin{array}{l}30 \text { amp fast blow fuse, used as the main line } \\
\text { fuse. }\end{array}$ \\
\hline RLNI-12 & Omega & 4 & $\begin{array}{l}\text { High temperature ring terminals for oven } \\
\text { connections. }\end{array}$ \\
\hline EXTT-K-20-50 & Omega & 2 & $\begin{array}{l}100 \mathrm{ft} \text { of standard } \mathrm{K} \text { type thermocouple wire, } \\
\text { insulated in plastic. Used for the low } \\
\text { temperature zones. }\end{array}$ \\
\hline $\mathrm{XC}-24-\mathrm{K}-24$ & Omega & 6 & $\begin{array}{l}\text { Nextel braided ceramic thermocouples for high } \\
\text { temperature regions. }\end{array}$ \\
\hline
\end{tabular}




\begin{tabular}{|c|c|c|c|}
\hline $\begin{array}{l}\text { GCX1232- } \\
120 \mathrm{~L}\end{array}$ & $\begin{array}{l}\text { Automation } \\
\text { Direct }\end{array}$ & 3 & $\begin{array}{l}\text { Green LEDs, used as power indicators for } \\
\text { main power supply, and the each oven power } \\
\text { line to indicate when the oven is heating. In } \\
\text { operation the oven power indicators blink on, } \\
\text { and off in accordance with controller signal. }\end{array}$ \\
\hline GCX1226-120 & $\begin{array}{l}\text { Automation } \\
\text { Direct }\end{array}$ & 1 & $\begin{array}{l}\text { NC emergency stop device, when depressed } \\
\text { the control device retains power, but }\end{array}$ \\
\hline $\begin{array}{l}\text { HTMG-1CU- } \\
312 \mathrm{~S} / \mathrm{C}\end{array}$ & Omega & 1 & $\begin{array}{l}25 \mathrm{ft} \text { of high temperature insulated wire for } \\
\text { wiring the oven, and components near to the } \\
\text { ovens. }\end{array}$ \\
\hline $93493 \mathrm{~A} 233$ & $\begin{array}{l}\text { McMaster- } \\
\text { Carr }\end{array}$ & 16 & $\begin{array}{l}\text { Fiberglass insulating washers used as a thermal } \\
\text { break between the oven mounting brackets, } \\
\text { and the oven mounting cage components of the } \\
\text { oven mount. Two washers are used on each } \\
\text { side of a bracket bolt hole to act as a thermal } \\
\text { break. }\end{array}$ \\
\hline $9332 \mathrm{~K} 65$ & $\begin{array}{l}\text { McMaster- } \\
\text { Carr }\end{array}$ & 1 & $\begin{array}{l}\text { Very high temperature mineral wool insulation } \\
\text { rated to } 430^{\circ} \mathrm{C} \text {. The mineral wool is } \\
\text { smokeless, and fire proof making it ideal for } \\
\text { insulating a heating device. Used to thermally } \\
\text { insulate the oven cage assembly. }\end{array}$ \\
\hline $2592 \mathrm{~K} 61$ & $\begin{array}{l}\text { McMaster- } \\
\text { Carr }\end{array}$ & 1 & $\begin{array}{l}25 \mathrm{ft} 3 / 8 \text { " ID fiberglass sleeving used to } \\
\text { insulate wires in areas close to the ovens. Two } \\
\text { small pieces were also used to wrap the oven } \\
\text { mounting bracket } 1 / 8 \text { " bolts to supplement the } \\
\text { thermal breaking. }\end{array}$ \\
\hline $\begin{array}{l}12 \mathrm{~A} 5 \times 20 \mathrm{~mm} \\
\text { ceramic } 120 \mathrm{~V} \\
\text { fast acting fuse }\end{array}$ & & 2 & $\begin{array}{l}\text { Fuses for oven lines, each fuse is wired to the } \\
\text { primary } 30 \text { A fuse with } 10 \text { ga wire. The wiring } \\
\text { following the fuse is } 12 \text { ga wire, due to the } \\
\text { lowered requirement for a maximum of } 12 \mathrm{~A} \text {. }\end{array}$ \\
\hline $\begin{array}{l}4 \mathrm{~A} 5 \times 20 \mathrm{~mm} \\
\text { ceramic } 120 \mathrm{~V} \\
\text { fast acting fuse }\end{array}$ & & 1 & $\begin{array}{l}\text { Fuse for peripheral power, fuse is wired to the } \\
\text { primary } 30 \text { A fuse with } 10 \text { ga wire. The wiring } \\
\text { following the fuse is } 12 \text { ga wire, due to the } \\
\text { lowered requirement for a maximum of } 4 \mathrm{~A} \text {. }\end{array}$ \\
\hline $\begin{array}{l}4 \text { slot } 5 \times 20 \mathrm{~mm} \\
\text { fuse holder }\end{array}$ & & 1 & $\begin{array}{l}\text { Used to hold the three } 5 \times 20 \mathrm{~mm} \text { fuses used for } \\
\text { the peripheral power line }(1 \times 4 \mathrm{~A}) \text {, and oven } \\
\text { power lines }(2 \times 12 \mathrm{~A}) \text {. }\end{array}$ \\
\hline
\end{tabular}




\begin{tabular}{|c|c|c|}
\hline $\begin{array}{l}1110 \text { Utility } \\
\text { Box (Steel), } \\
\text { and covers }\end{array}$ & 4 & $\begin{array}{l}\text { Two are used to feed in high temperature } \\
\text { power lines from the clamshell ovens to lower } \\
\text { temperature power lines. } \\
\text { A third acts as a junction, switching the lower } \\
\text { temperature power lines into BX cable wires. } \\
\text { The fourth junctions the BX cable wires into } \\
\text { standard } 3 \text { wire } 12 \text { ga cable. }\end{array}$ \\
\hline 12 ga wire & & $\begin{array}{l}25 \mathrm{ft} \text { each in green (ground), black (negative), } \\
\text { and white (positive) insulation. }\end{array}$ \\
\hline $\begin{array}{l}\text { BX Cable } 3 \\
\text { wire, } 12 \mathrm{ga}\end{array}$ & & $\begin{array}{l}10 \mathrm{ft} \text { of cable. The original wires are removed, } \\
\text { and replaced with two wires of high } \\
\text { temperature wire, and a bare copper wire for } \\
\text { grounding. }\end{array}$ \\
\hline $\begin{array}{l}3 \text { wire cable, } \\
12 \text { ga }\end{array}$ & & $\begin{array}{l}2 \times 15 \mathrm{ft} \text { of cable for wiring from back end of } \\
\text { oven. }\end{array}$ \\
\hline $\begin{array}{l}10 \text { ga three } \\
\text { wire cable }\end{array}$ & & $15 \mathrm{~m}$ of cable for the main power supply \\
\hline 18 ga wire & & $\begin{array}{l}2 \mathrm{ft} \text { in black, and white insulation for control } \\
\text { signal wiring. }\end{array}$ \\
\hline $\begin{array}{l}\text { Wire strain } \\
\text { reliefs }\end{array}$ & & $\begin{array}{l}\text { Wire strain reliefs must be installed into every } \\
\text { junction box to prevent disconnections. }\end{array}$ \\
\hline $\begin{array}{l}\text { Female } 120 \mathrm{~V} \\
12 \text { A NEMA } \\
\text { receptacle }\end{array}$ & 2 & Used to plug oven into controller device. \\
\hline $\begin{array}{l}\text { Grommets 1" } \\
\text { diameter }\end{array}$ & 2 & $\begin{array}{l}\text { Used on holes cut into the electrical enclosure } \\
\text { to prevent wire fraying on exposed metal. }\end{array}$ \\
\hline Marettes & & $\begin{array}{l}\text { Used to junction wires. Need } 4 \text { copper screw } \\
\text { marettes for use near oven; standard plastic } \\
\text { marettes of various sizes needed within the } \\
\text { control enclosure }\end{array}$ \\
\hline $\begin{array}{l}\text { Ring terminals, } \\
\text { and slot } \\
\text { terminals }\end{array}$ & & $\begin{array}{l}\text { Used to join wires to various components, } \\
\text { sized based on wire ga required. }\end{array}$ \\
\hline
\end{tabular}




\section{B.3 Description of Controller device}

The controller device was designed to be a compact, and simple to use device capable of working in the Civil Engineering high bay lab. The device would thus have access to $120 \mathrm{~V}$ service from a 12 A, 20 A, or 30 A plugs. The necessary ovens for heating the system were calculated to be two $1130 \mathrm{~W}$ heaters rated at $120 \mathrm{~V}$, thus the combined power draw at $120 \mathrm{~V}$ would be nearly $19 \mathrm{~A}$, necessitating a continuous draw rating for the 20 A service for the ovens. The peripherals, such as the controller or thermocouple scanner draw about $3 \mathrm{~A}$; it was thus decided that the use of 30 A service would be more appropriate to the design. The main power is taken into the unit through the bottom of the three pole disconnect device from a $15 \mathrm{~m}$ long, $10 \mathrm{ga}, 3$ wire cable. The disconnect device is rated up to $600 \mathrm{~V}$, at $50 \mathrm{~A}$, and is thus quite rugged for the application.

The main power feeds from the disconnect device into a 30 A fuse, which is a fast blow type fuse. The $30 \mathrm{amp}$ fuse protects the device from power surges above the service rating, and it feeds into three service lines within the device. The three service lines are fused at $12 \mathrm{~A}, 12 \mathrm{~A}$, and $4 \mathrm{~A}$; the two $12 \mathrm{~A}$ lines feed power to the ovens, and are designed to blow if an oven ever surges above the maximum power rating of $1130 \mathrm{~W}$, the $4 \mathrm{~A}$ feed line powers all the peripheral components of the unit such LEDs, the controller, and thermocouple scanner device. The controller signal power supply is wired into a solid state NC switch, which acts as an emergency stop (technically this is not an "emergency stop", which must be an analog device rather than a solid state device). This wiring prevents the controller from sending a control signal to the solid state relays, thus leaving them stuck in the open position. The power for the control signal continues from the stop device to the 
DP1001AM thermocouple scanner, and attaches to the NC alarm input slot. The DP1001AM acts as the secondary thermal safety device, which when it detects an overtemperature state, an alarm is triggered shutting preventing control signal power from continuing to the controller device. The DP1001AM was selected for the option of attaching up to 10 channels of input for alarm states. The controller device is a CN7223 PID controller from Omega, it acts as the primary safety device for the oven controlling the temperature using a $\mathrm{K}$ type thermocouple as the input device. The controller will trip an alarm state if an over-temperature event is detected, preventing the control signal from reaching the SSR devices.

The solid state relays that control power flow from the two $12 \mathrm{~A}$ lines are attached to finned heat sinks to dissipate the heat generated by the switching circuits. The SSRs are attached in a series from the DC SSR to the AC SSR, controlled from the PID's DC, and AC control signals, respectively. The SSRs selected were rated up to $240 \mathrm{~V}$ at $50 \mathrm{~A}$, which ensures that they will operate for a long duration without failure. The power from the SSRs attaches to two female NEMA plug receptacles on the back of the device rated to $15 \mathrm{~A}$ at $120 \mathrm{~V}$. The power from the ovens terminates at the main disconnect, after a wire junction connecting to the power return from the peripherals.

The power for the CN7223, and DP1001AM is drawn from the peripheral power line. The power splits to the CN7223, and an 1110 utility box with a standard NEMA 120 V, 15 A receptacle face cover. The power for the DP1001AM is supplied by an AC adaptor plugged into the 1110 utility box. 
A sub mini $\mathrm{K}$ type thermocouple junction with twelve channels is attached to the back of the enclosure. This junction allows external thermocouples to pass into the enclosure safely. The first ten channels are attached to the DP1001AM device for thermocouples used to measure temperatures on the load frame, and trip an alarm state in the case of an overheating; the eleventh channel is wired to the controller device, and acts as the primary measurement for the CN7223 controller, and safety device. K type thermocouples were chosen for their low cost, and reasonable accuracy. The thermocouples used were wired into ceramic sub mini thermocouple plugs for high temperature zones, and plastic sub-mini thermocouple plugs for low temperature zones. The thermocouple wire used for low temperature zones was standard grade K-type thermocouple wire insulated in plastic. The thermocouple wire used for high temperature zones were 24" Nextel braided ceramic insulated thermocouple wires from Omega. 


\section{B.4 Oven Mount Drawings}

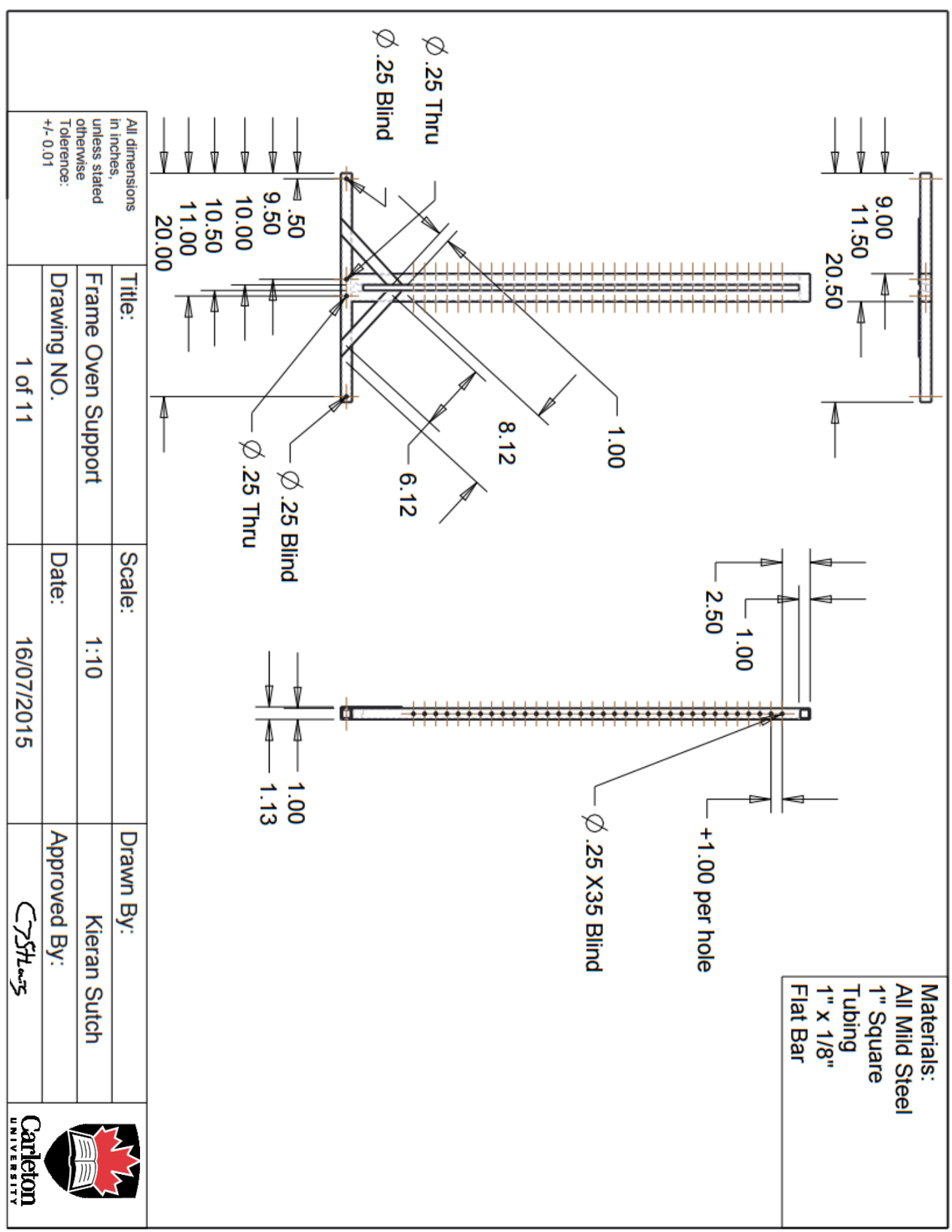




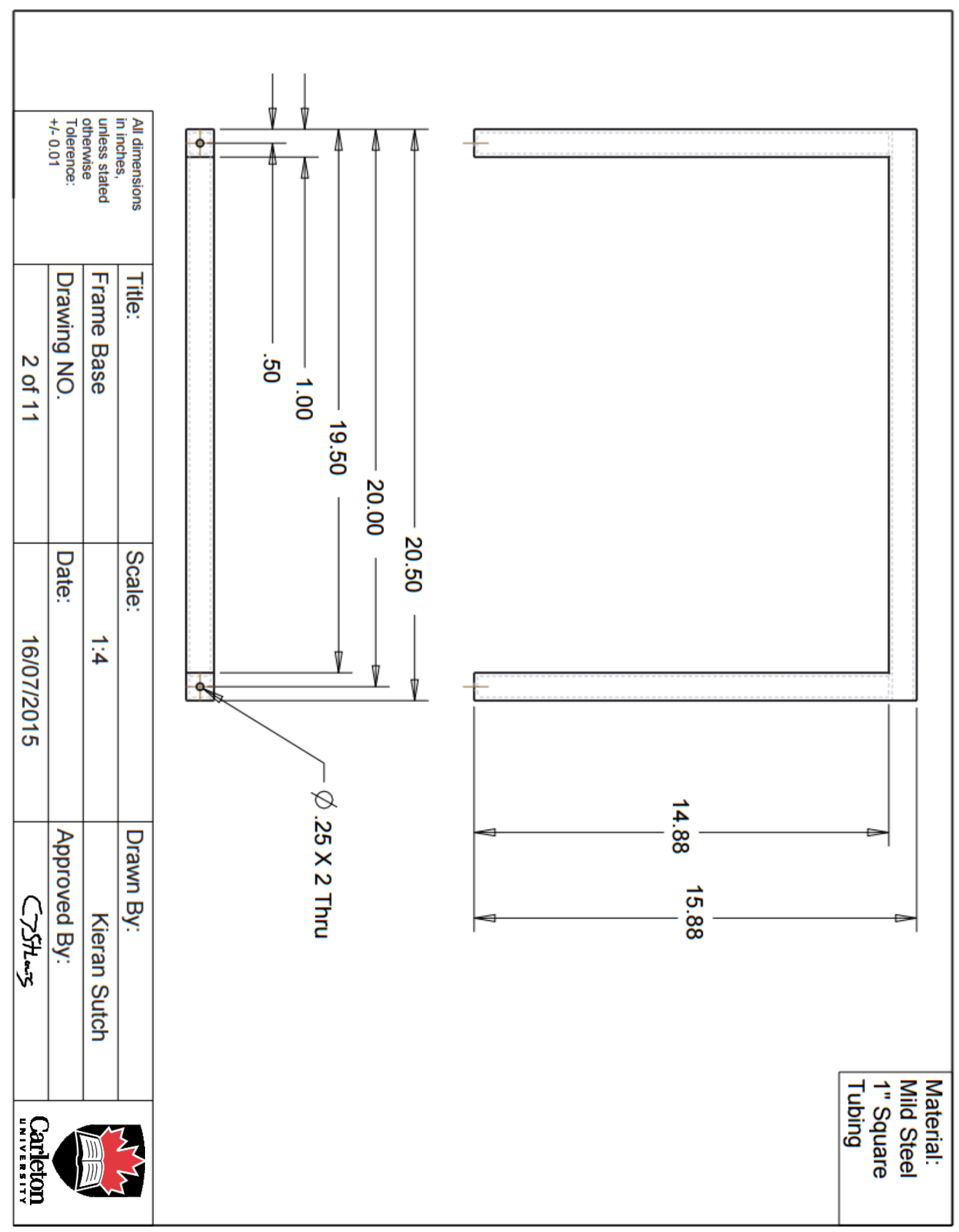

XVIII 


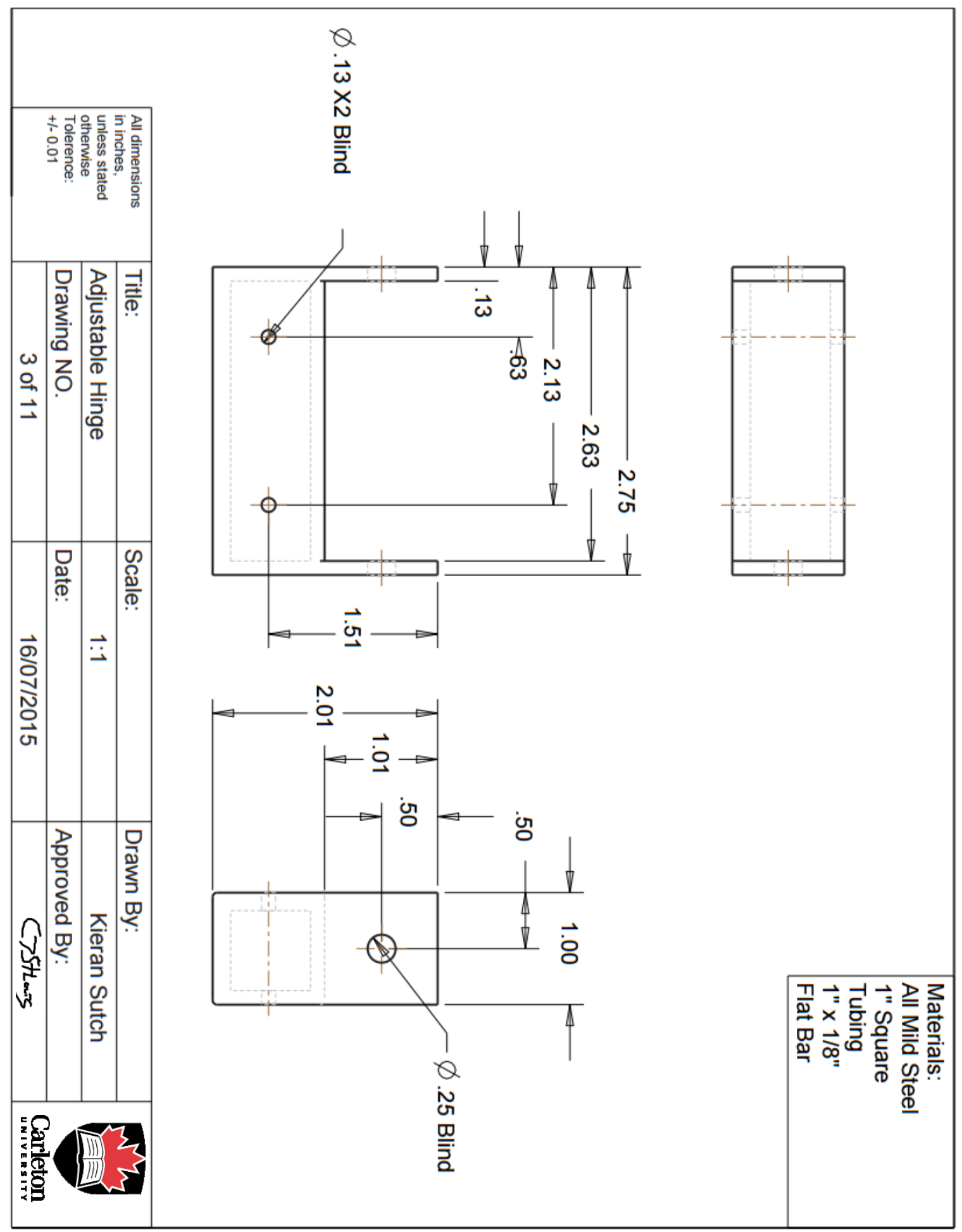




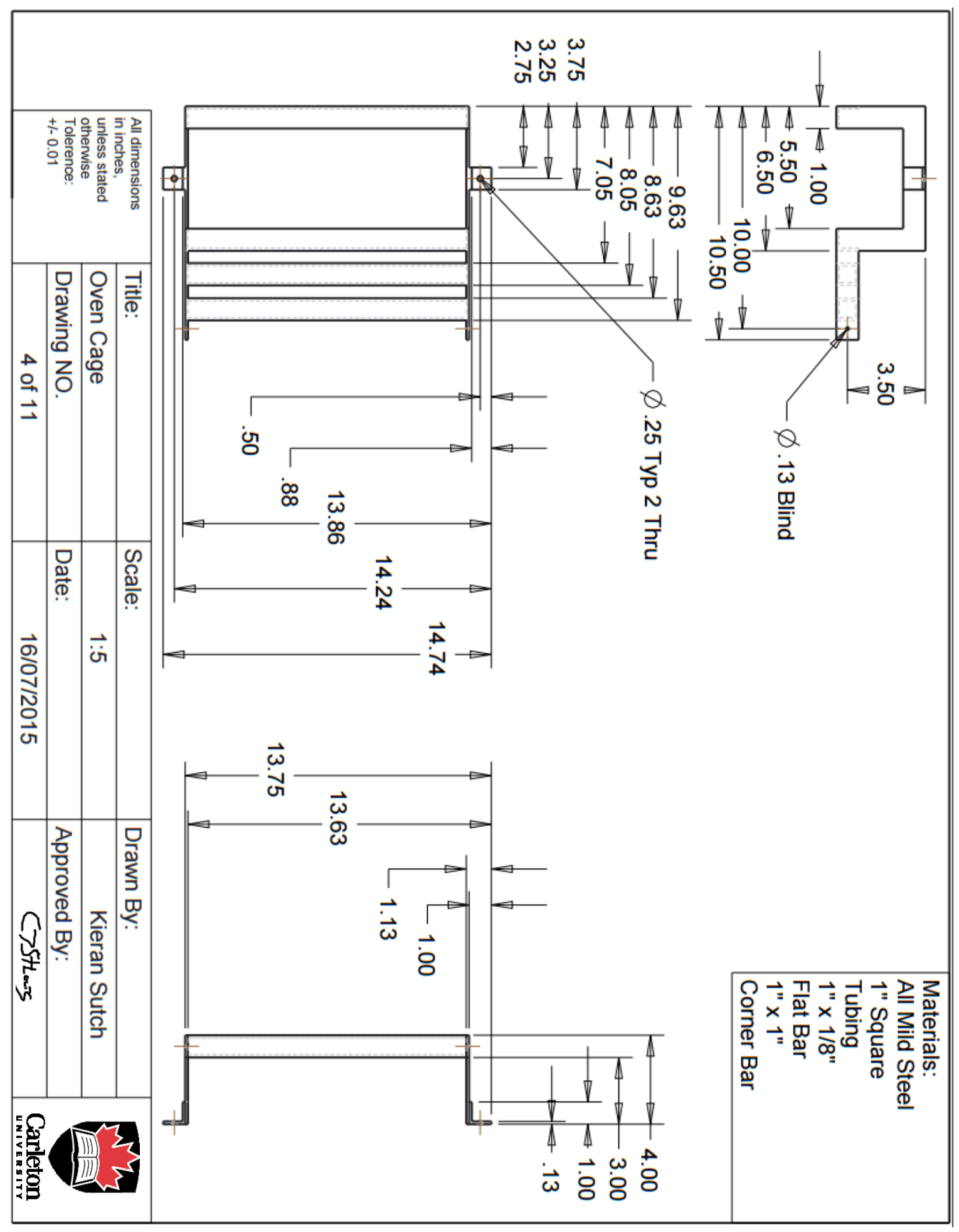




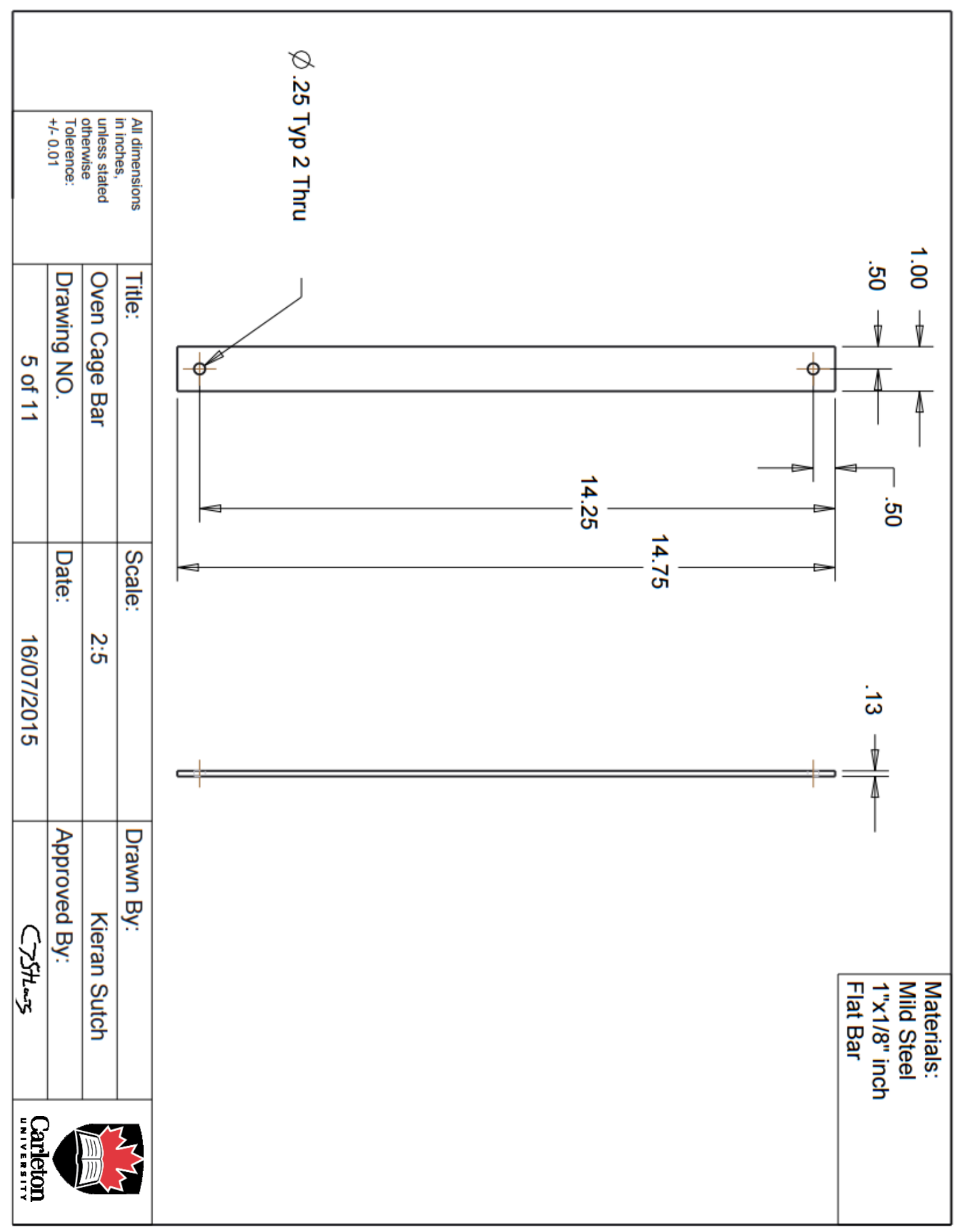




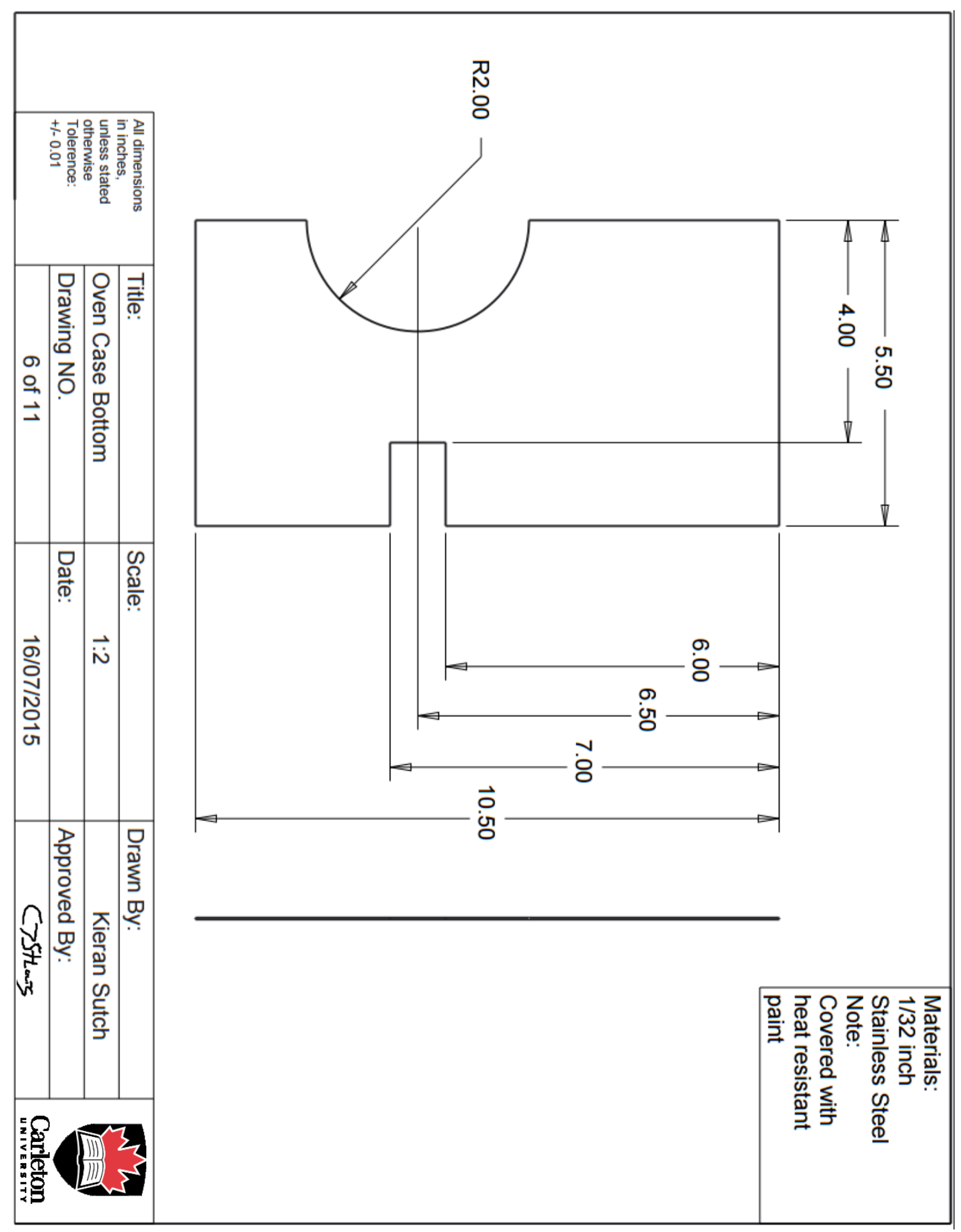

XXII 


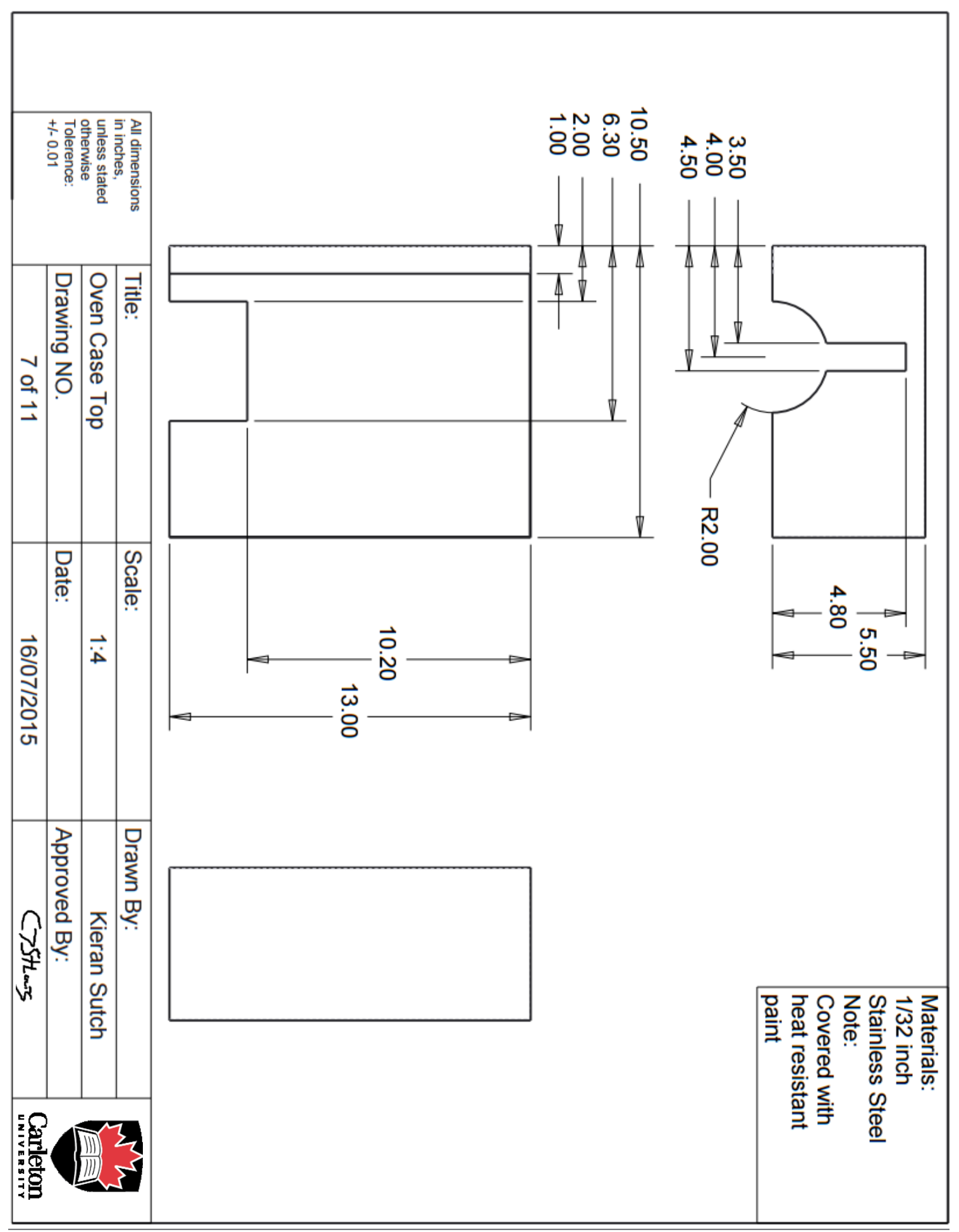




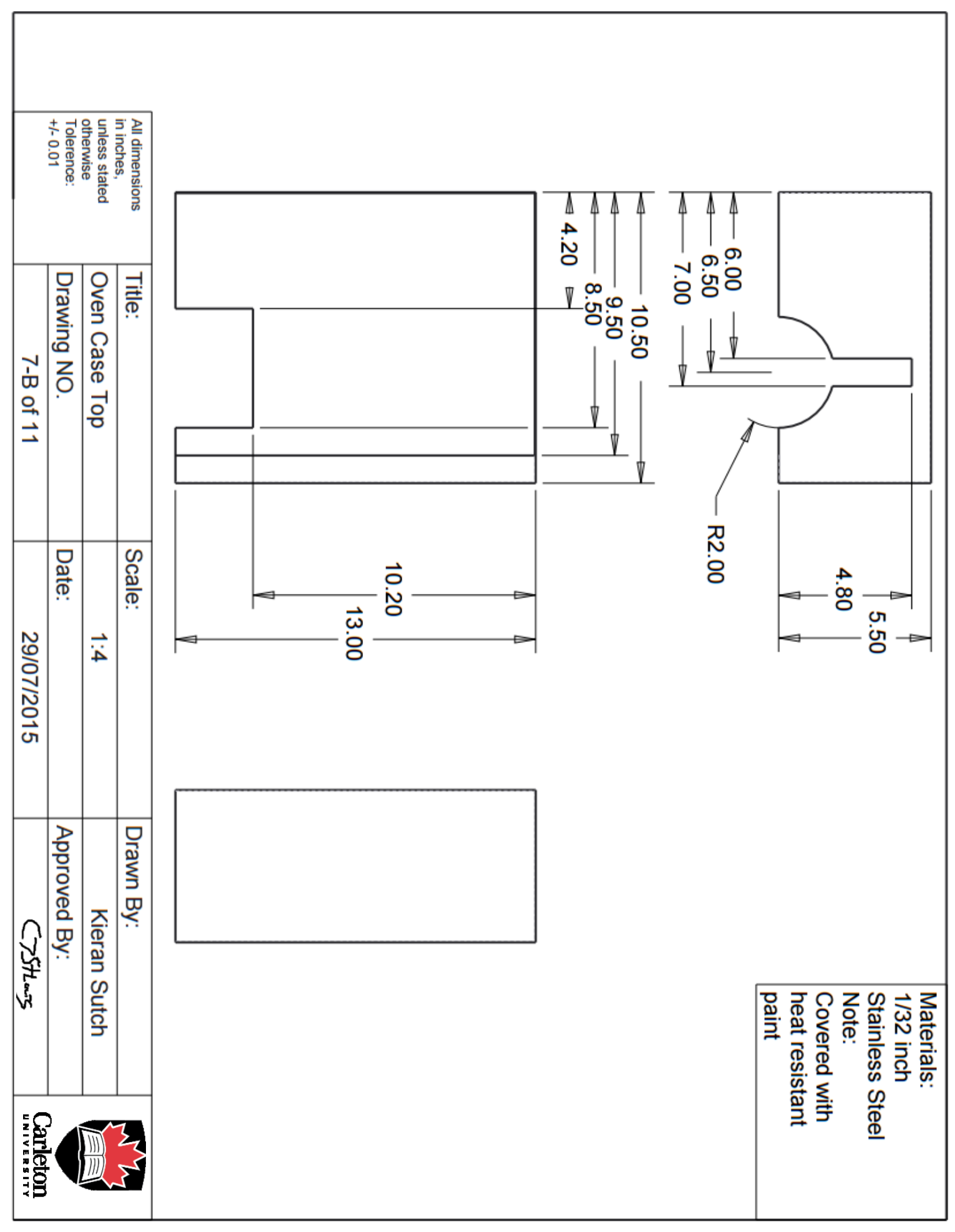

XXIV 


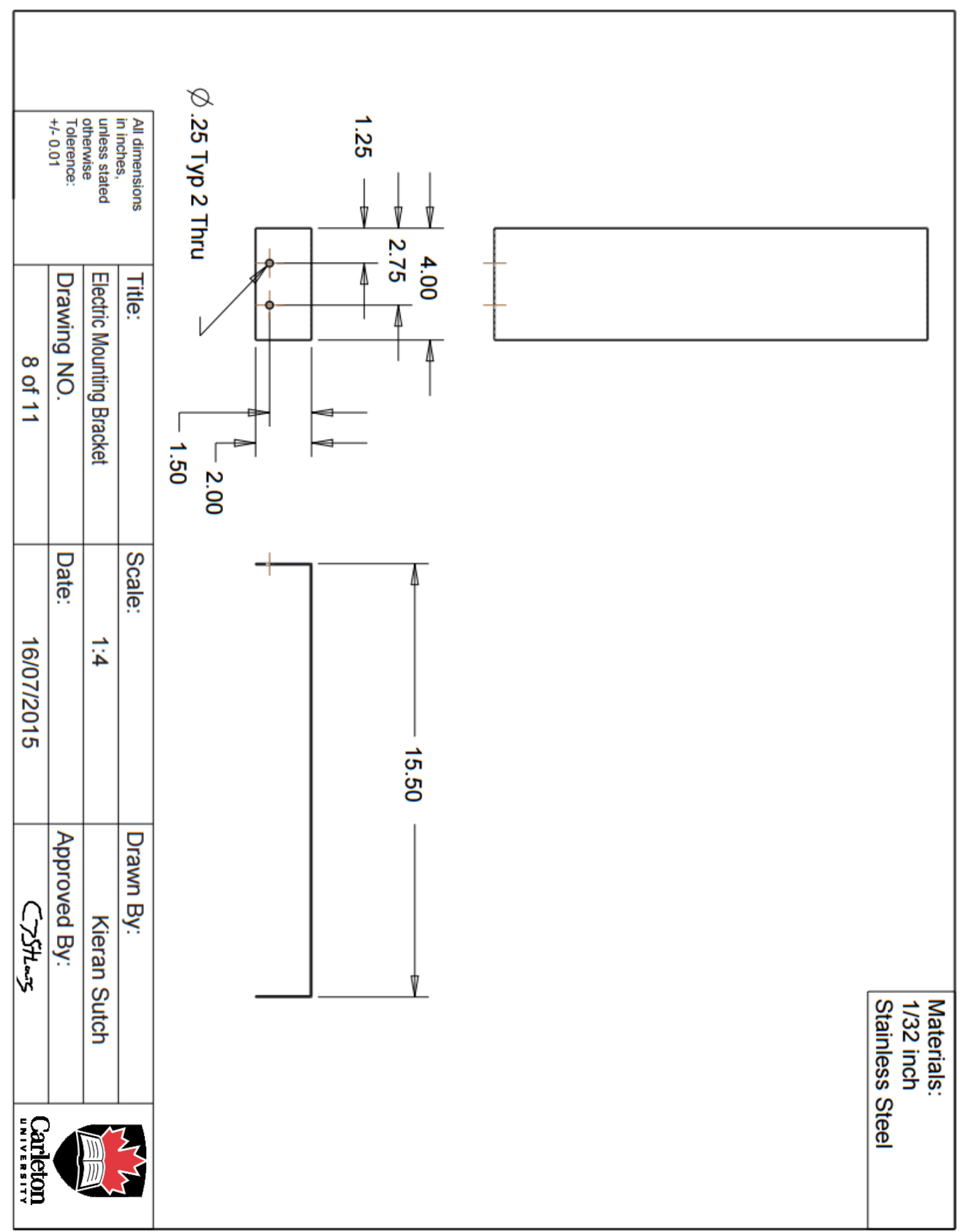




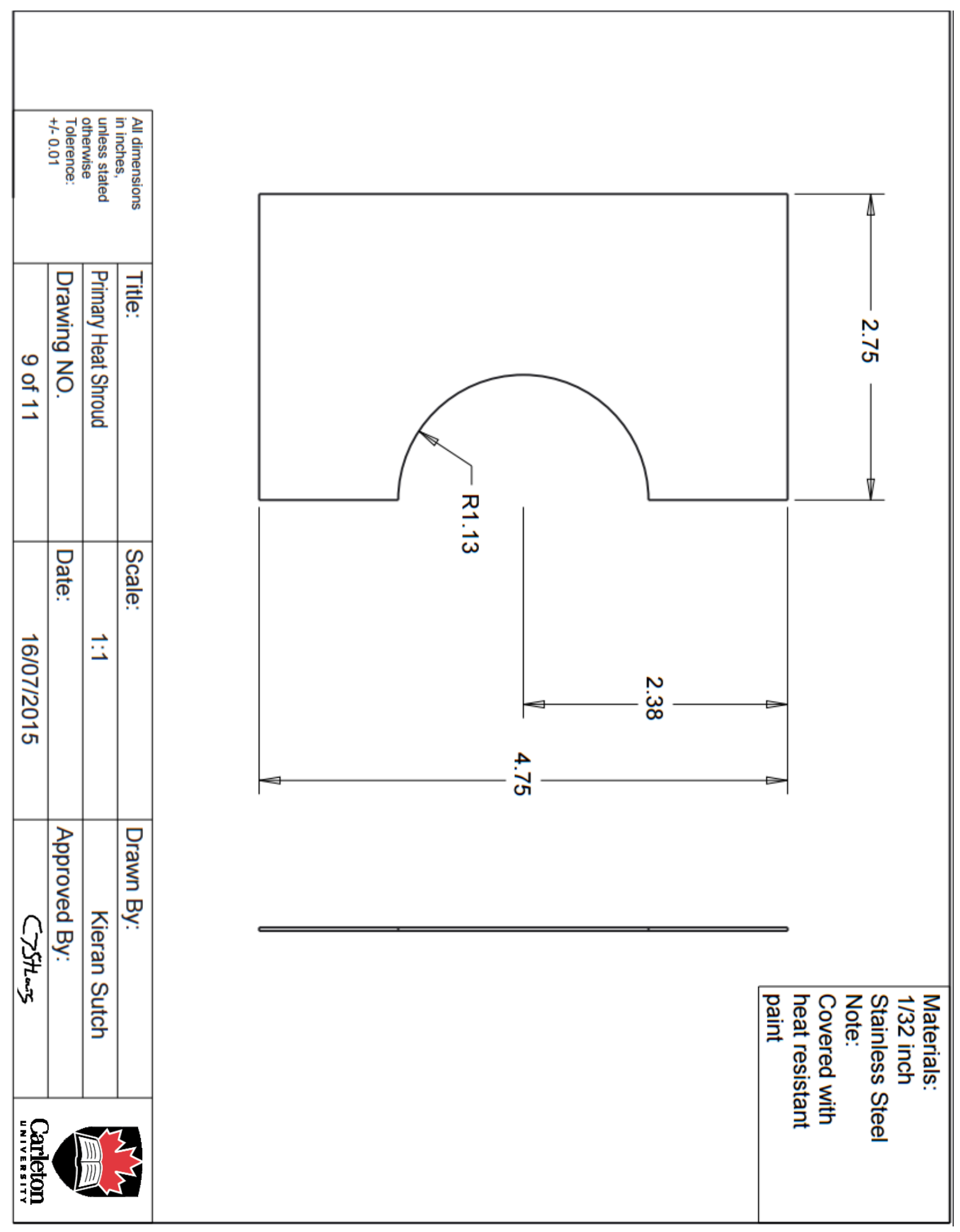

XXVI 


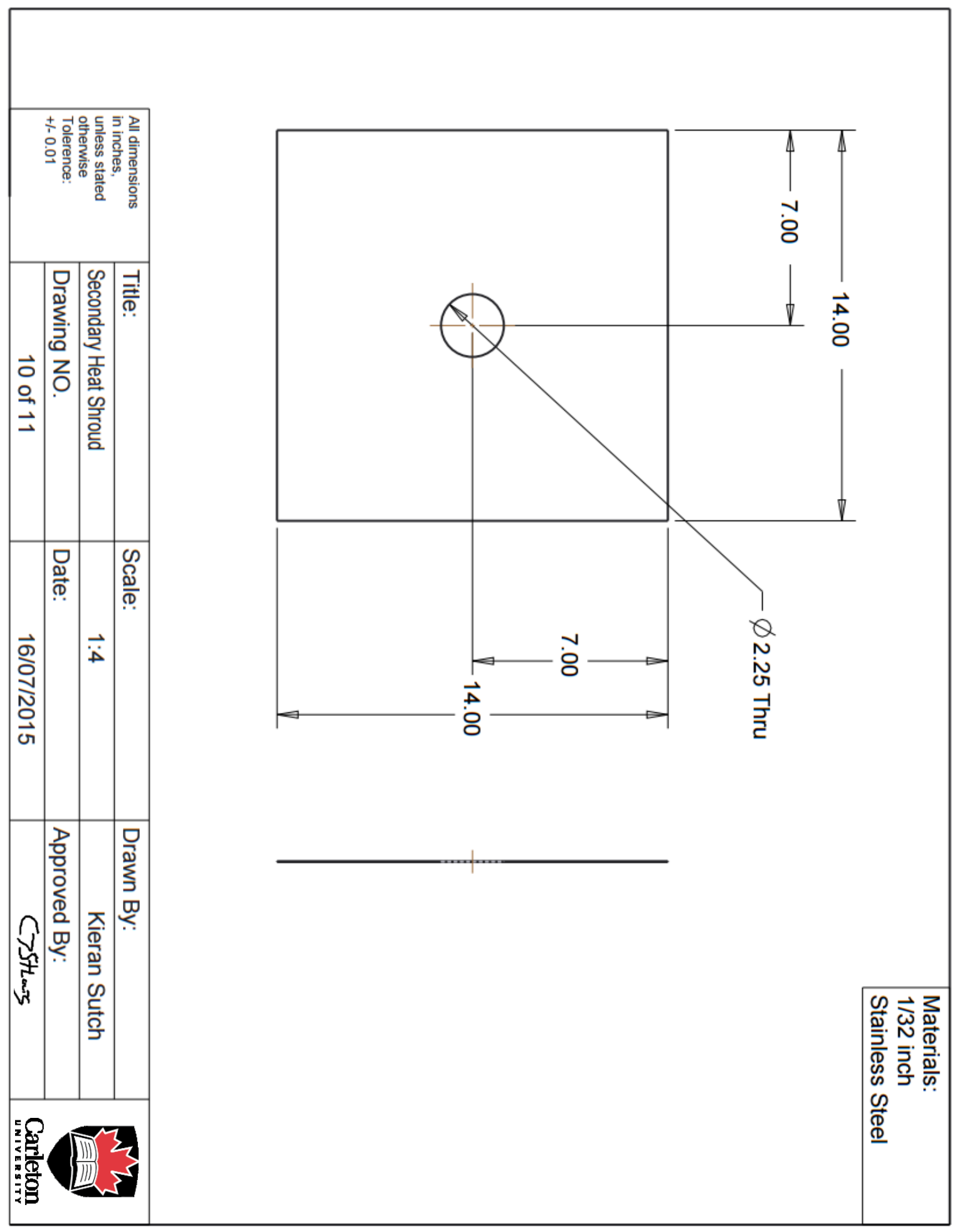

XXVII 


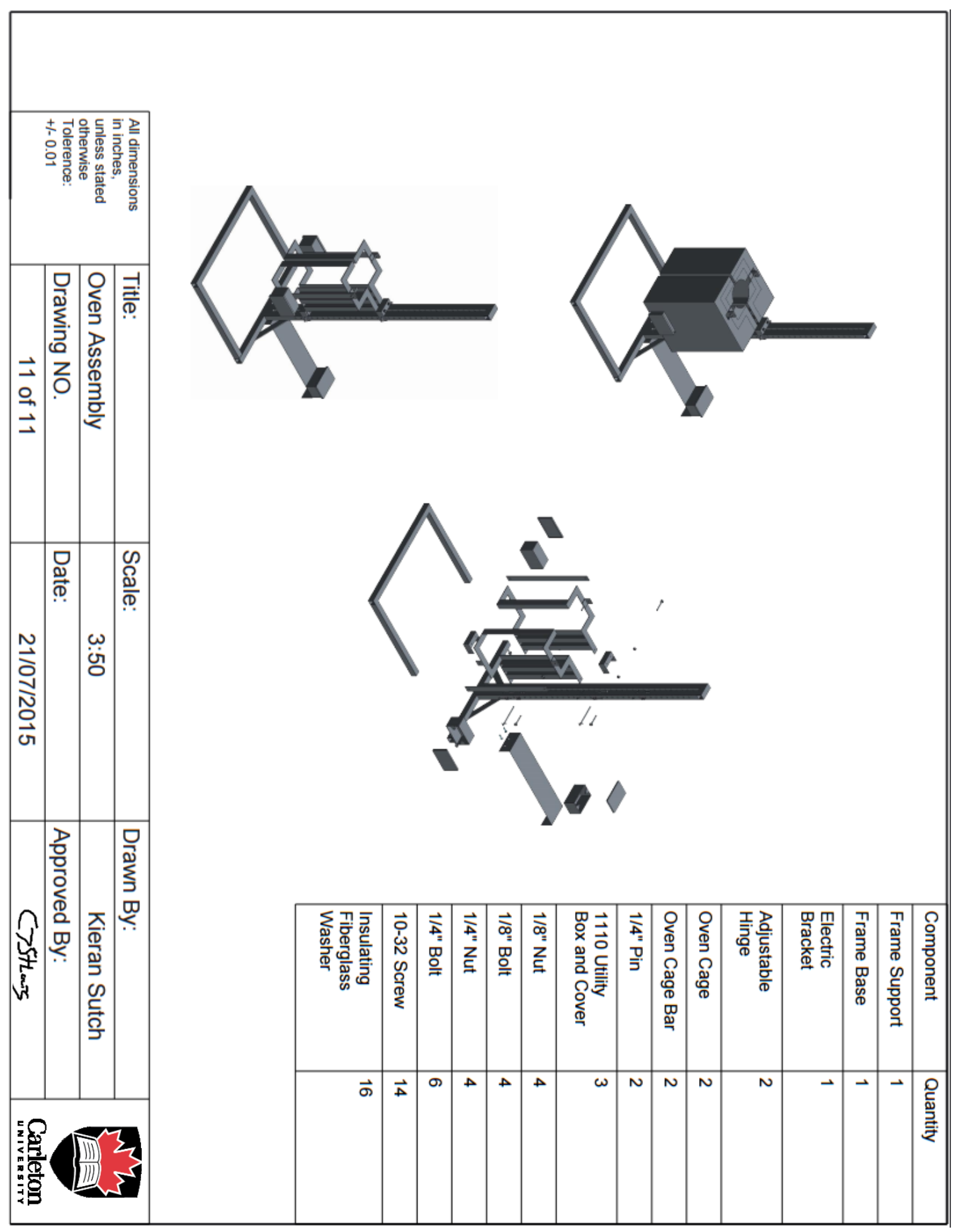

XXVIII 


\section{B.5 Oven mount design description}

The oven mount for the load frame was designed to be simple, rugged, and adjustable for the oven position. The frame base fits around the bottom hydraulic press. The frame base attaches to the frame oven support piece with two bolts at the back of the frame base. This two bolt system allows the easy removal of the oven from the load frame. Attached with two screws to the back of the oven support component is the electrical box u-bracket. The frame oven support has a series of $1 / 4$ " holes drilled through the vertical arm that allow the oven cage position to be changed to accommodate the loaded position of the load frame's grips. The oven mounting brackets are attached to the vertical arm of the frame oven support with a simple steel cotter pin. The mounting brackets are attached to the oven cage with a $1 / 8$ " bolt wrapped in fiberglass mesh insulation and a nut. Two fiberglass washers are placed on the top, and bottom of the bolt that connects the oven cage, and mounting bracket, acting as a thermal break between the oven cage, and the oven mount base components. The CRWS-124/120-A semi-cylindrical ovens are placed in the oven cage, and locked into position with the cage bar using two screws.

The oven wires are insulated in high temperature fiberglass sheathing, and fed into an 1110 utility box on the back of the cage bar. Inside the utility box the oven wires are attached to the high temperature wire, which is fed through the bottom of the utility box. The high temperature wires are encased in fiberglass insulating sheath to an 1110 utility box at the base of the oven mount. Within the base's utility box the wires from each oven feed into two custom BX cable containing high temperature wire. The BX cable runs down the frame support to a final 1110 box on the electrical box u-bracket. Within the utility 
box the high temperature wire is connected to two standard 12 ga three wire cables, which terminates at a standard NEMA $120 \mathrm{~V}, 15 \mathrm{~A}$ service plugs. The two plugs are plugged into the control enclosure at the back when in operation.

The oven cage is enclosed within a sheet metal enclosure composed of a base piece that screws into the oven cage, and a top enclosure that slides into place. The top enclosure is screwed into the oven cage for grounding continuity. Within the oven cage enclosure is high temperature, smokeless, flame-proof mineral wool insulation. The mineral wool thermally insulates the oven, frame, and electrical components. To operate the device the two oven cages swing open allowing access to the interior of the oven; the device is held closed during heating with a simple mild steel latch. 


\section{B.6 Oven Controller Unit Images}

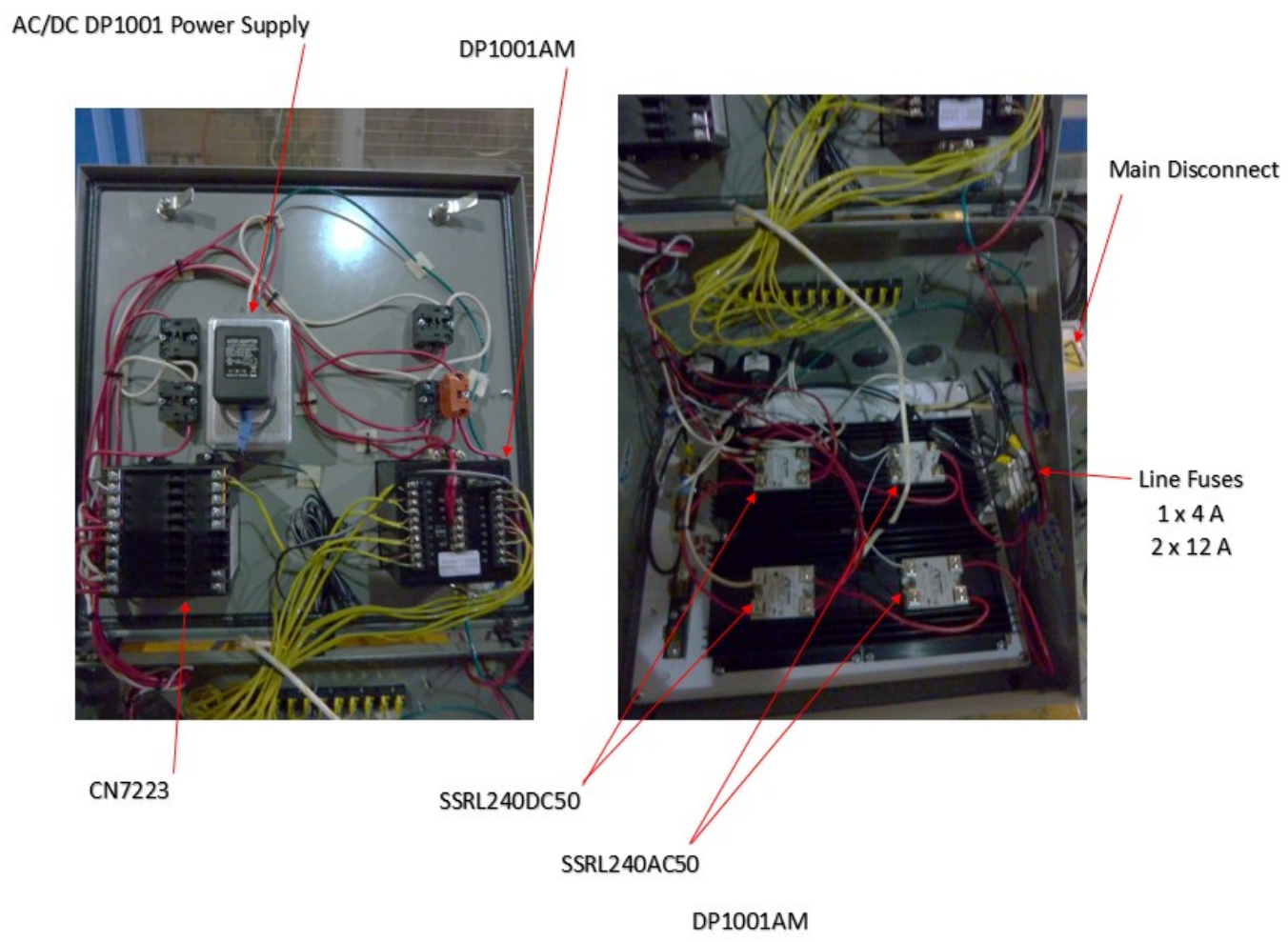

Figure 19: Thermal Control Enclosure Interior 


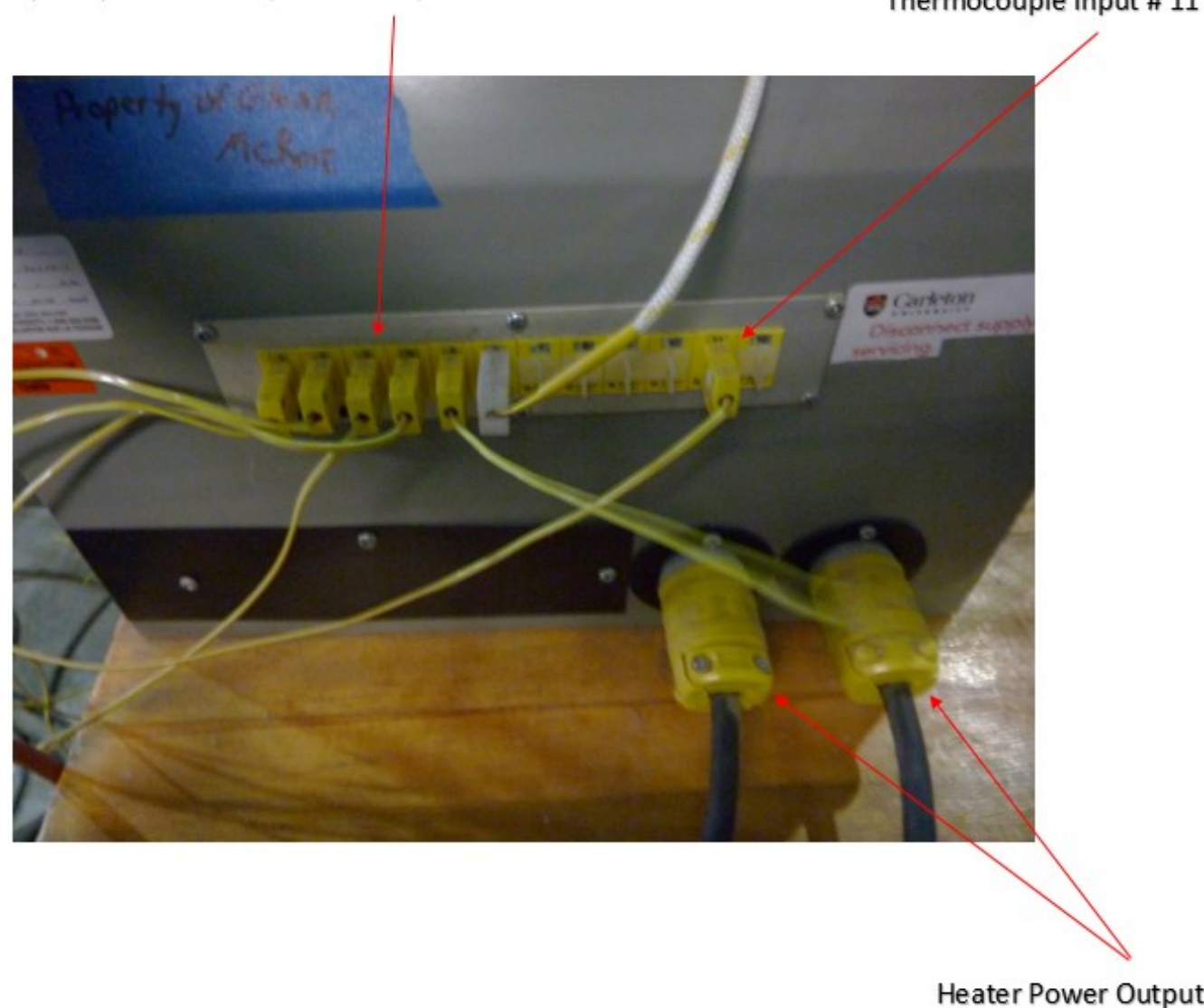

Figure 20: Thermal Control Enclosure Back Panel 


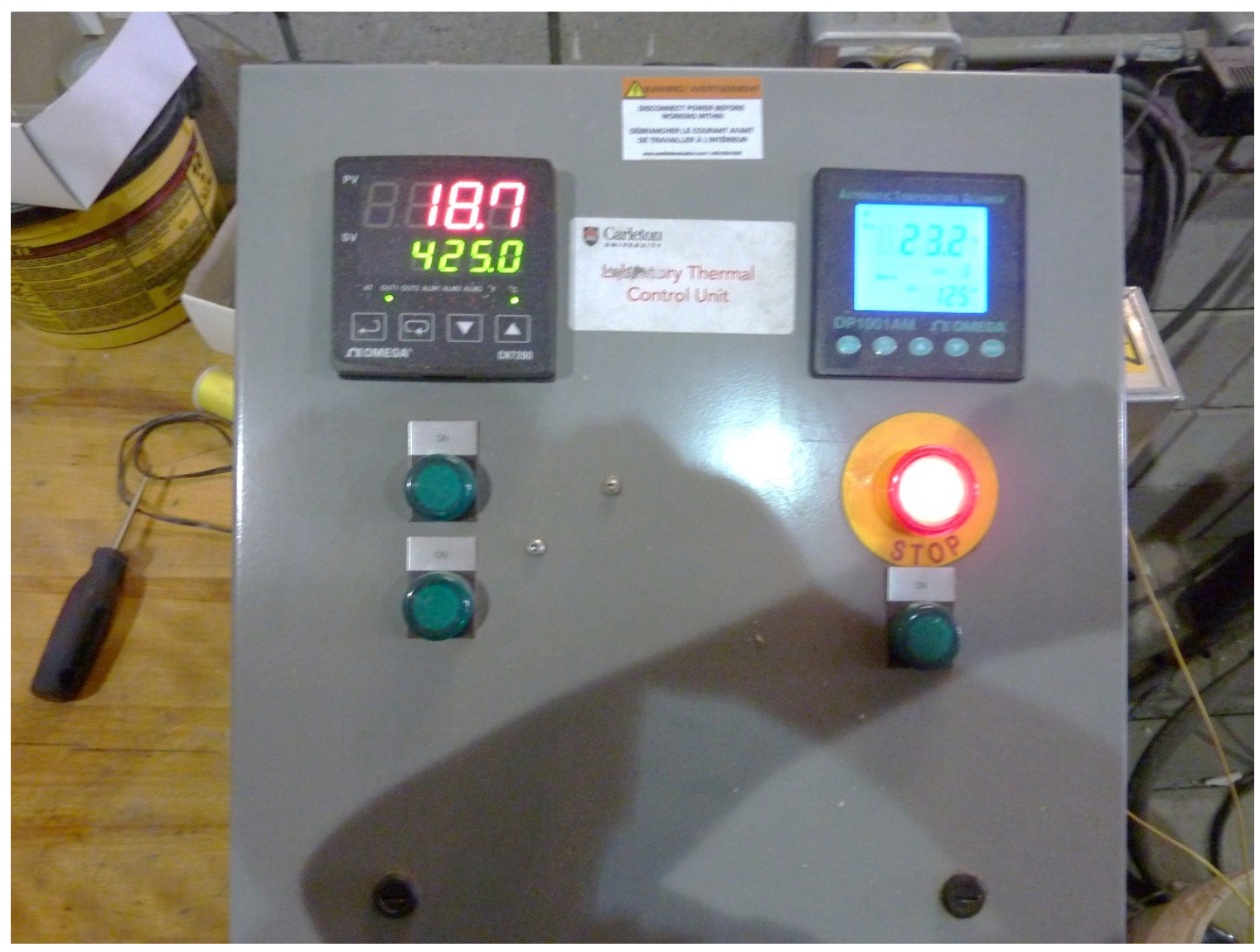

Figure 21: Thermal Control Enclosure Front Panel 


\section{B.7 ESA Final Inspection for Certification}

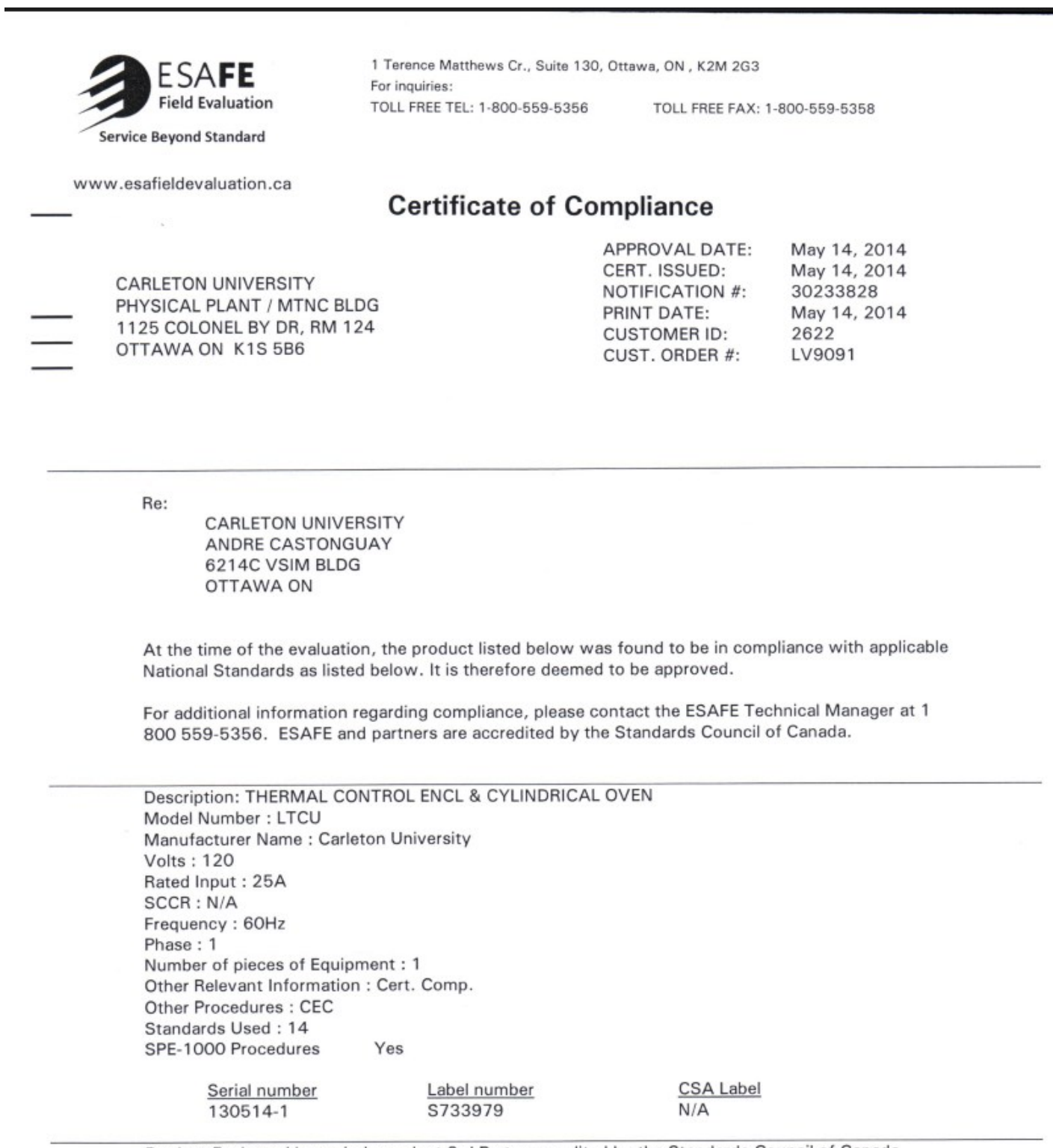

Product Evaluated by an independent 3rd Party accredited by the Standards Council of Canada 


\section{Appendix C Equipment List}

Table 5: List of Equipment

\begin{tabular}{|l|l|l|l|}
\hline Equipment Name & Manufacturer & Model \# & Serial Number \\
\hline $\begin{array}{l}\text { Clamshell Oven, } \\
\text { and Thermal } \\
\text { Control Unit }\end{array}$ & $\begin{array}{l}\text { Carleton University } \\
\text { MAAE } \\
\text { Zirconium } \\
\text { Research Group }\end{array}$ & LTCU & $130514-1$ \\
\hline $\begin{array}{l}\text { MTS-810 500 kN } \\
\text { load frame }\end{array}$ & MTS & 318.508 & 10183091 \\
\hline $\begin{array}{l}\text { MTS 500 kN load } \\
\text { cell }\end{array}$ & MTS & 661 & $23 \mathrm{E}-01$ \\
\hline $\begin{array}{l}\text { MTS FlexTest SE } \\
\text { Controller }\end{array}$ & MTS & V3.5C & 1817 \\
\hline Mass balance & Acculab & ALC-110.4 & 25850241 \\
\hline $\begin{array}{l}\text { Pegasus } \\
\text { Differential } \\
\text { Scanning } \\
\text { Calorimeter } \\
\text { with 6.235.4- } \\
\text { 63.9.00+S } \\
\text { measurement head }\end{array}$ & Analysis & $404 \mathrm{C}$ & 23540746 \\
\hline
\end{tabular}




\section{Appendix D Experimental Data}

\section{D.1 Data from Zirconium Sandwiched Hydride Experiment ${ }^{11}$}

The left-hand vertical axis is a measurement of the difference of heat flow to the sample (zirconium + hydrogen), and a reference sample (hydrogen free zirconium). The right hand vertical axis is the temperature derivative of the differential heat flow. The horizontal axis is the temperature of the specimen, and reference.

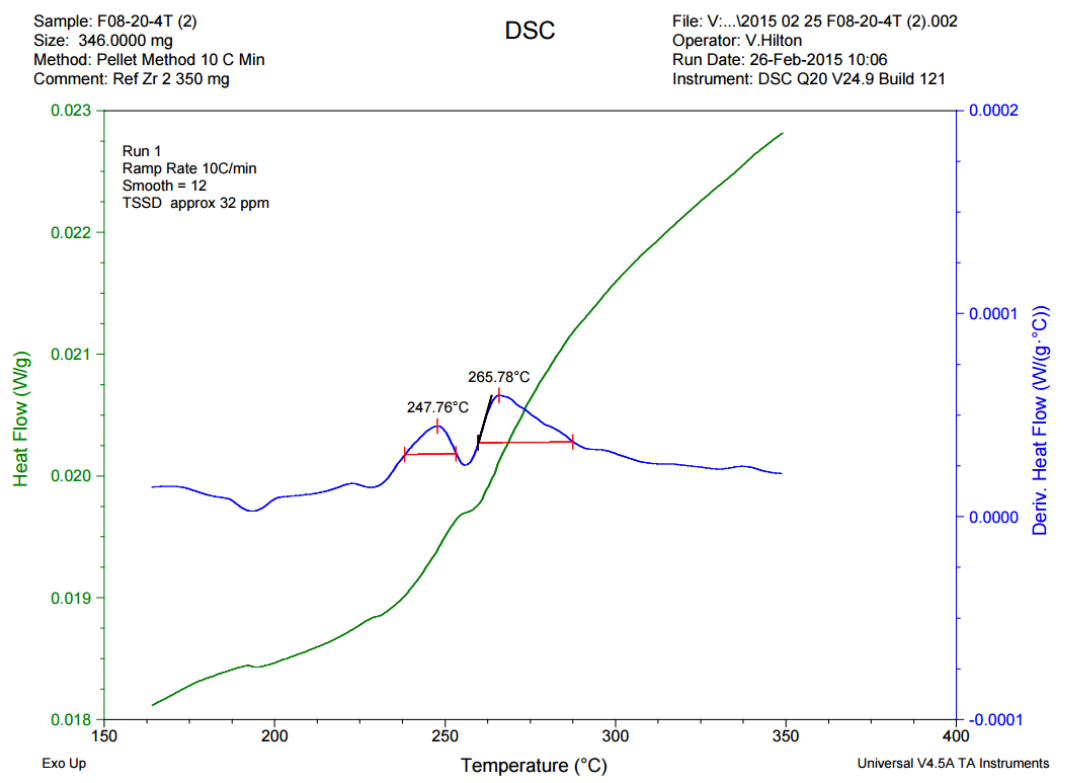

Figure 22: DSC heating curve \#1 for sample F08-20-4T

${ }^{11}$ The value for concentration on some of the DSC curves from CNL Chalk River using the DSC Q20 from TA Instruments was incorrect. The lab technician mistakenly used the wrong TSSD equation, and the data was subsequently corrected for in the concentrations reported in Table 6. 


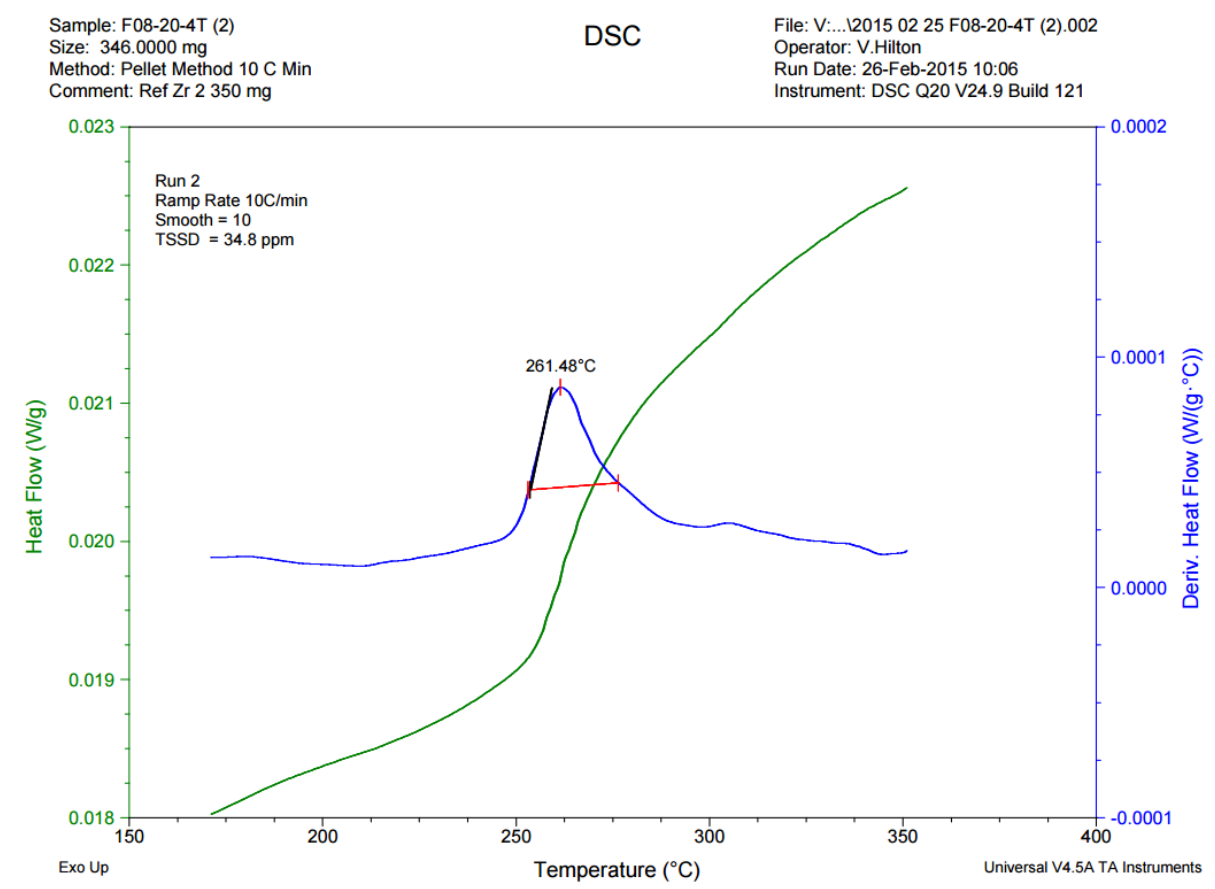

Figure 23: DSC heating curve \#2 for sample F08-20-4T

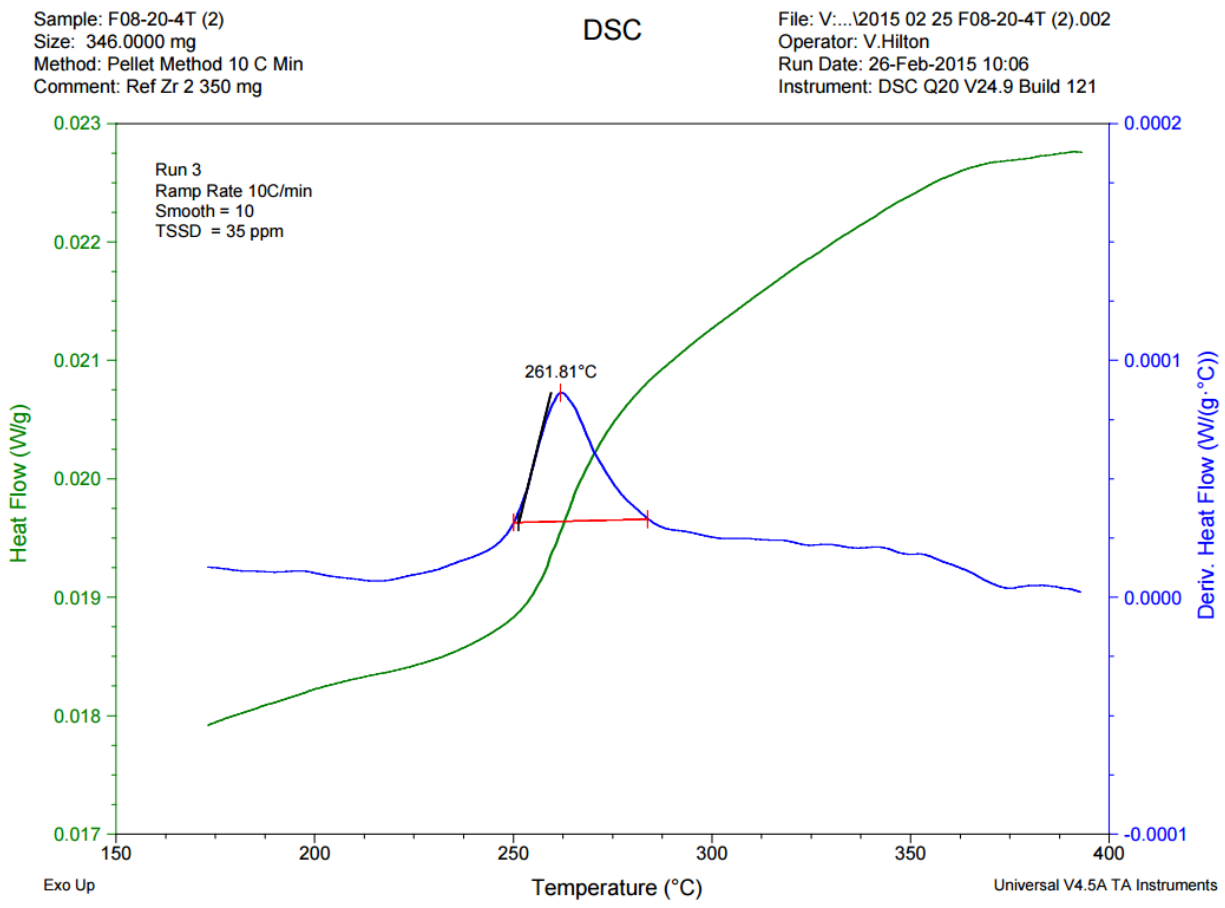

Figure 24: DSC heating curve \#3 for sample F08-20-4T 


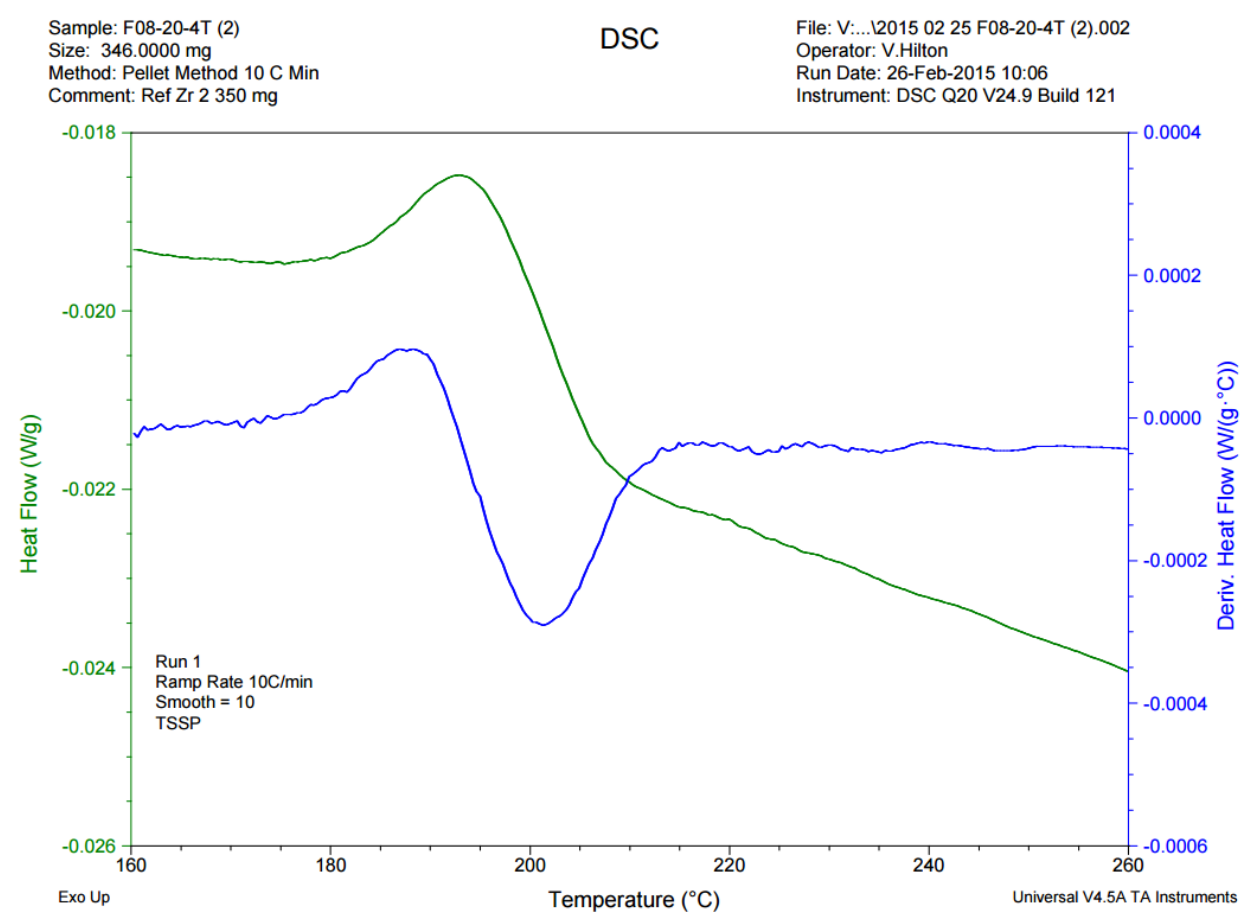

Figure 25: DSC cooling curve \#1 for sample F08-20-4T

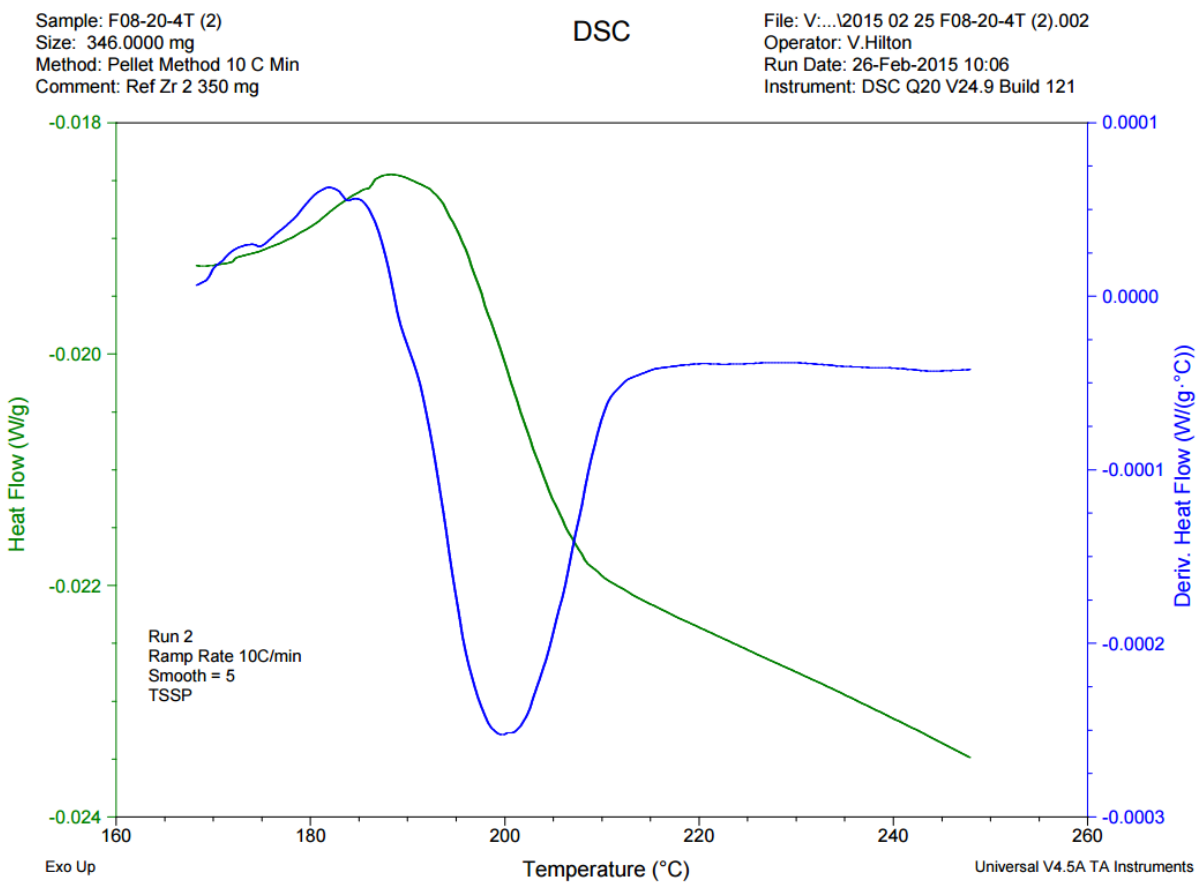

Figure 26: DSC cooling curve \#2 for sample F08-20-4T 


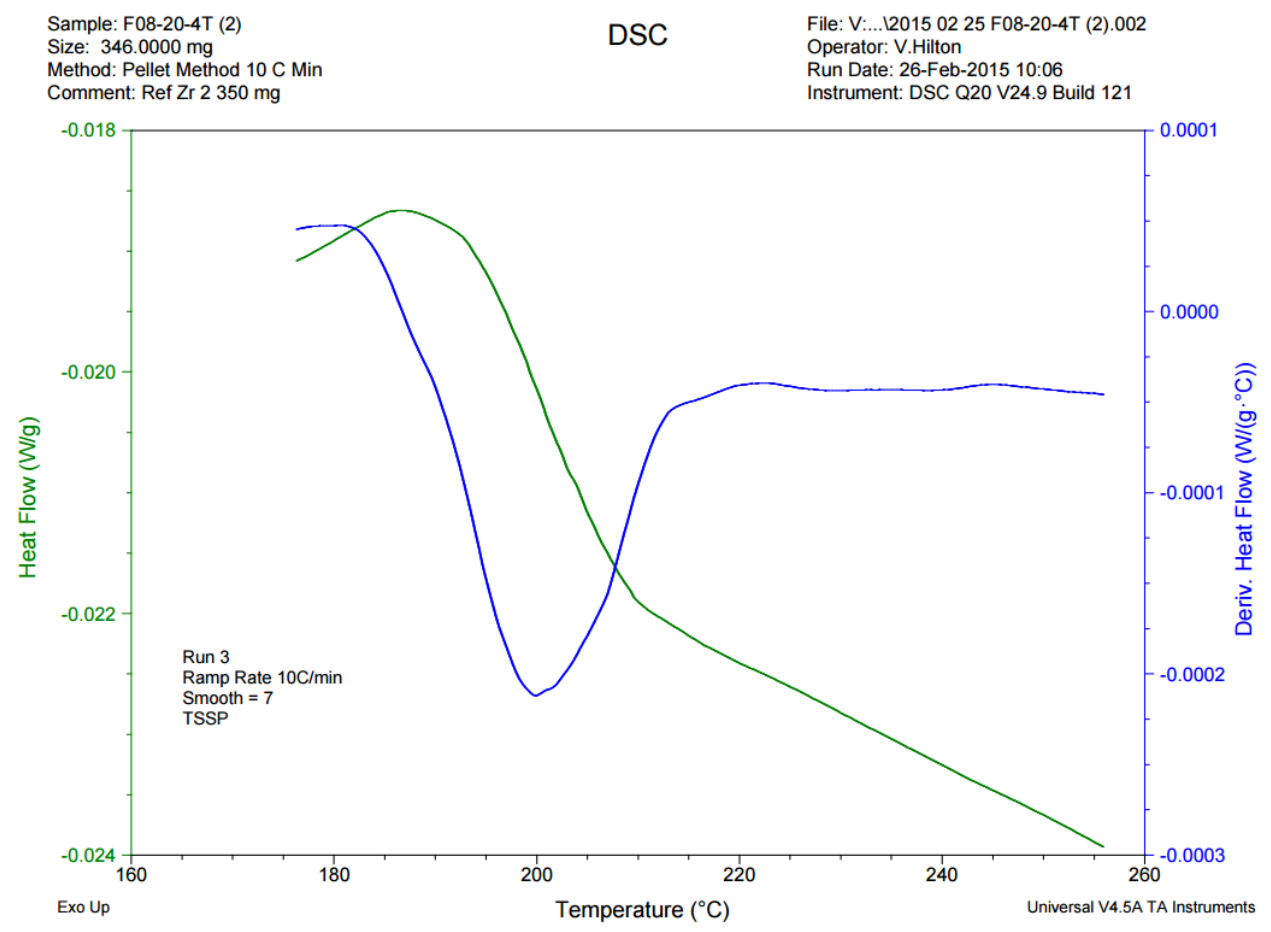

Figure 27: DSC cooling curve \#3 for sample F08-20-4T

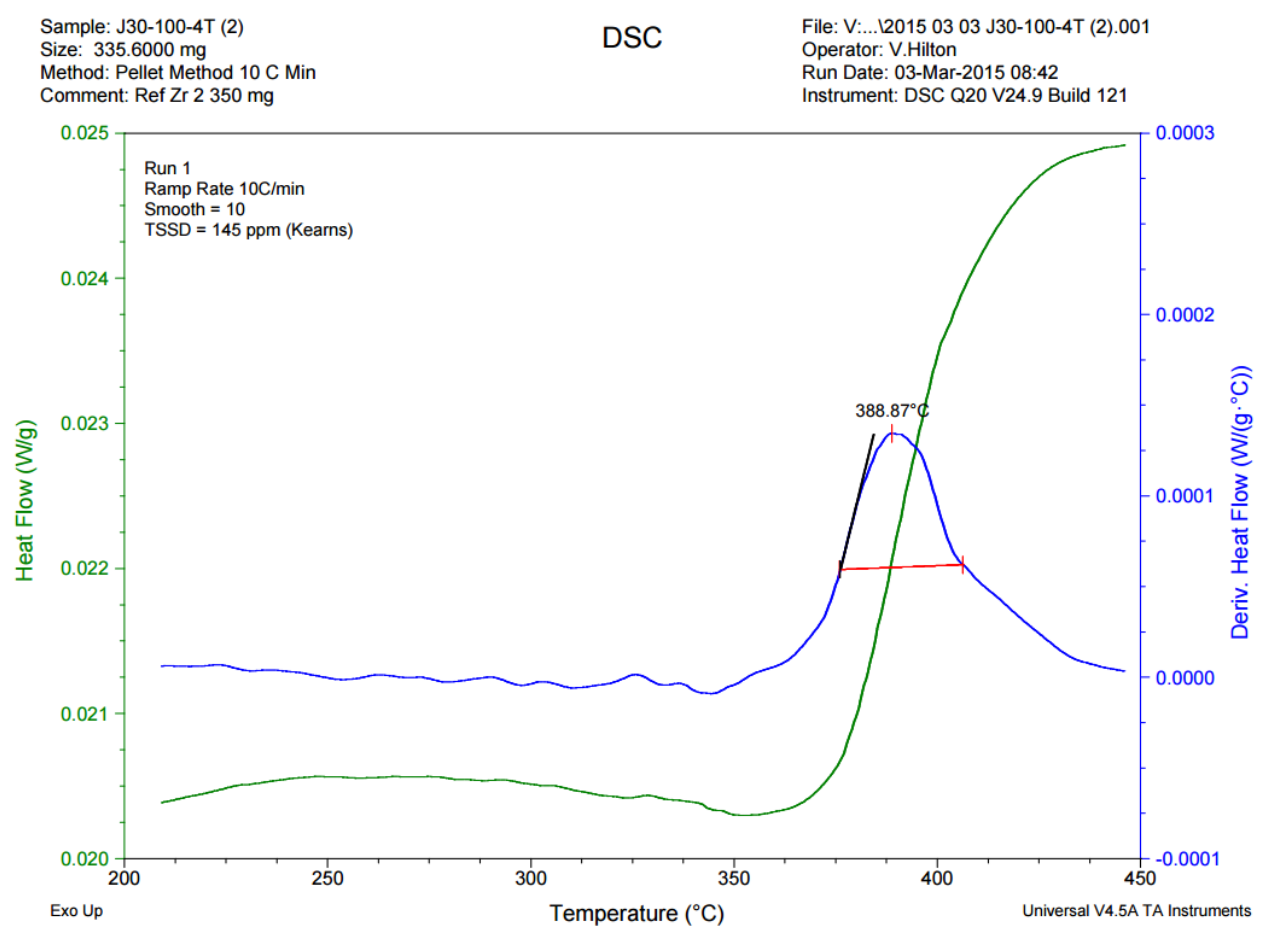

Figure 28: DSC heating curve \#1 for sample J30-100-4T 


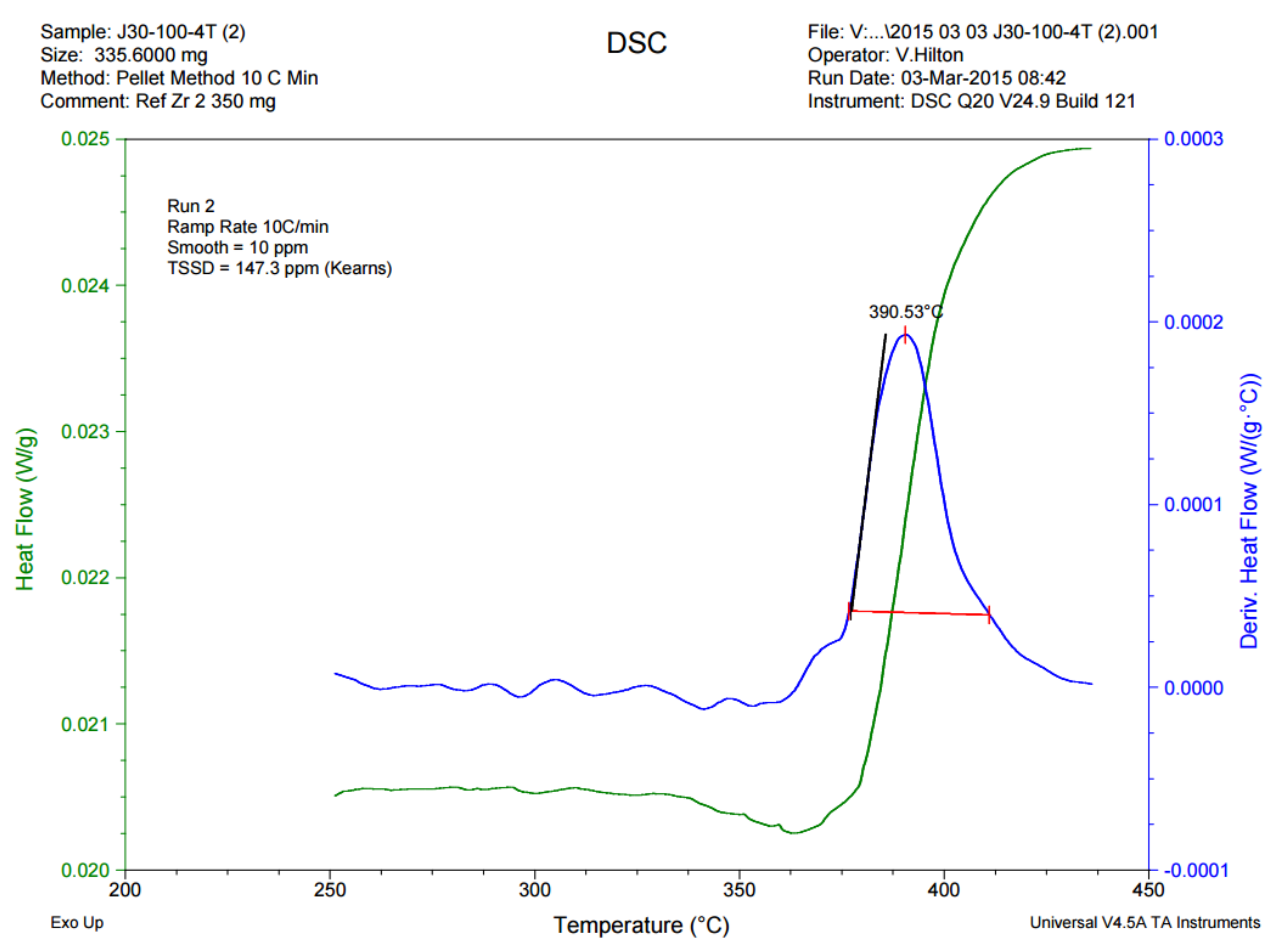

Figure 29: DSC heating curve \#2 for sample J30-100-4T

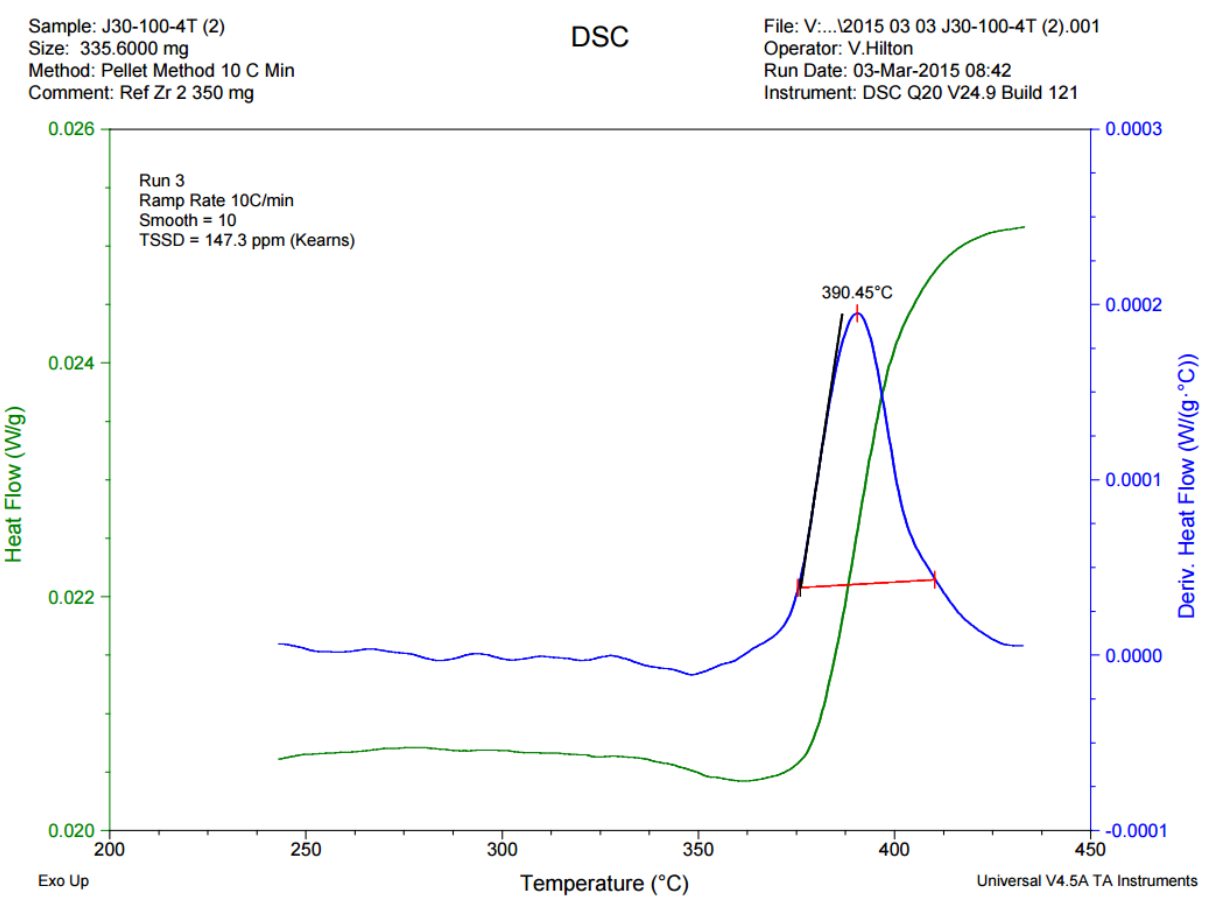

Figure 30: DSC heating curve \#3 for sample J30-100-4T 


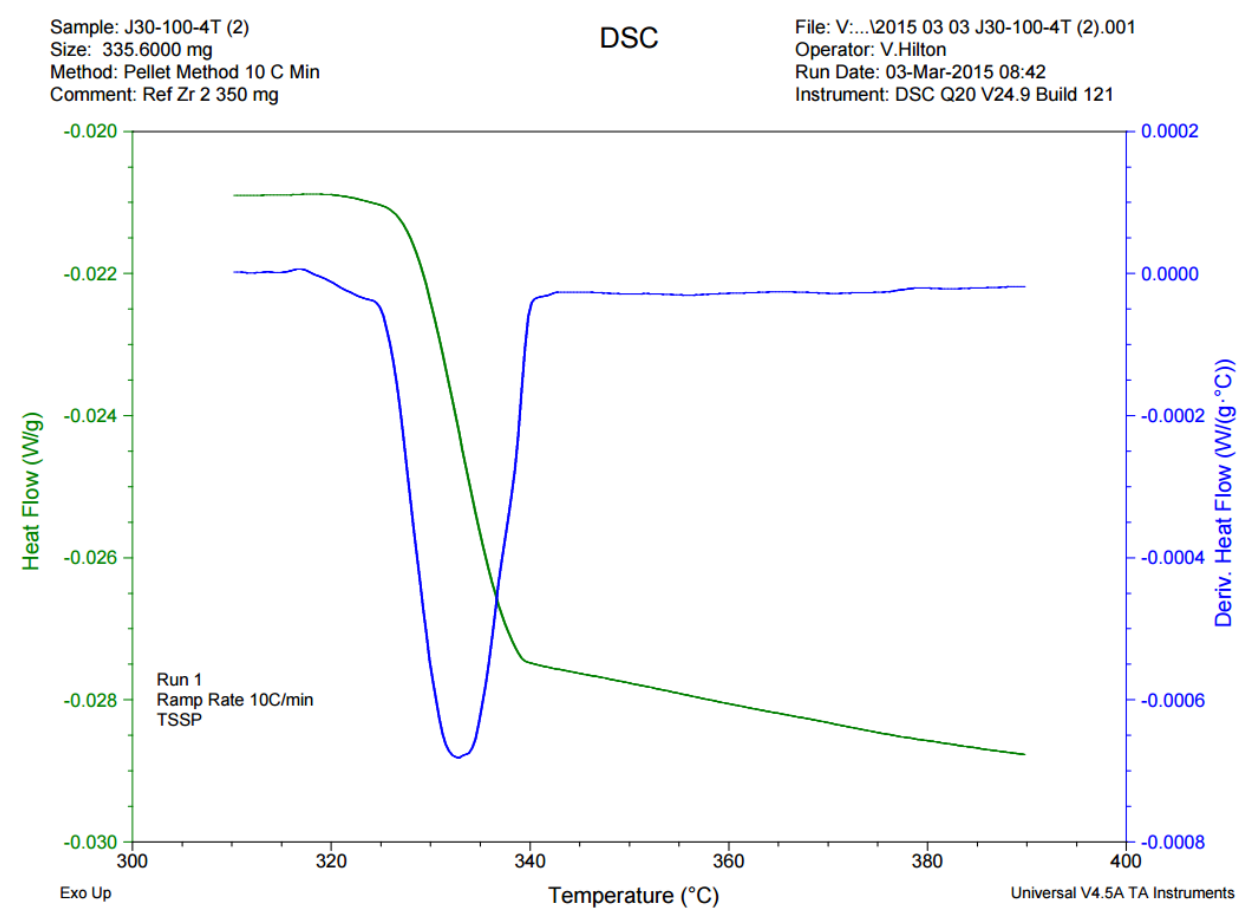

Figure 31: DSC cooling curve \#1 for sample J30-100-4T

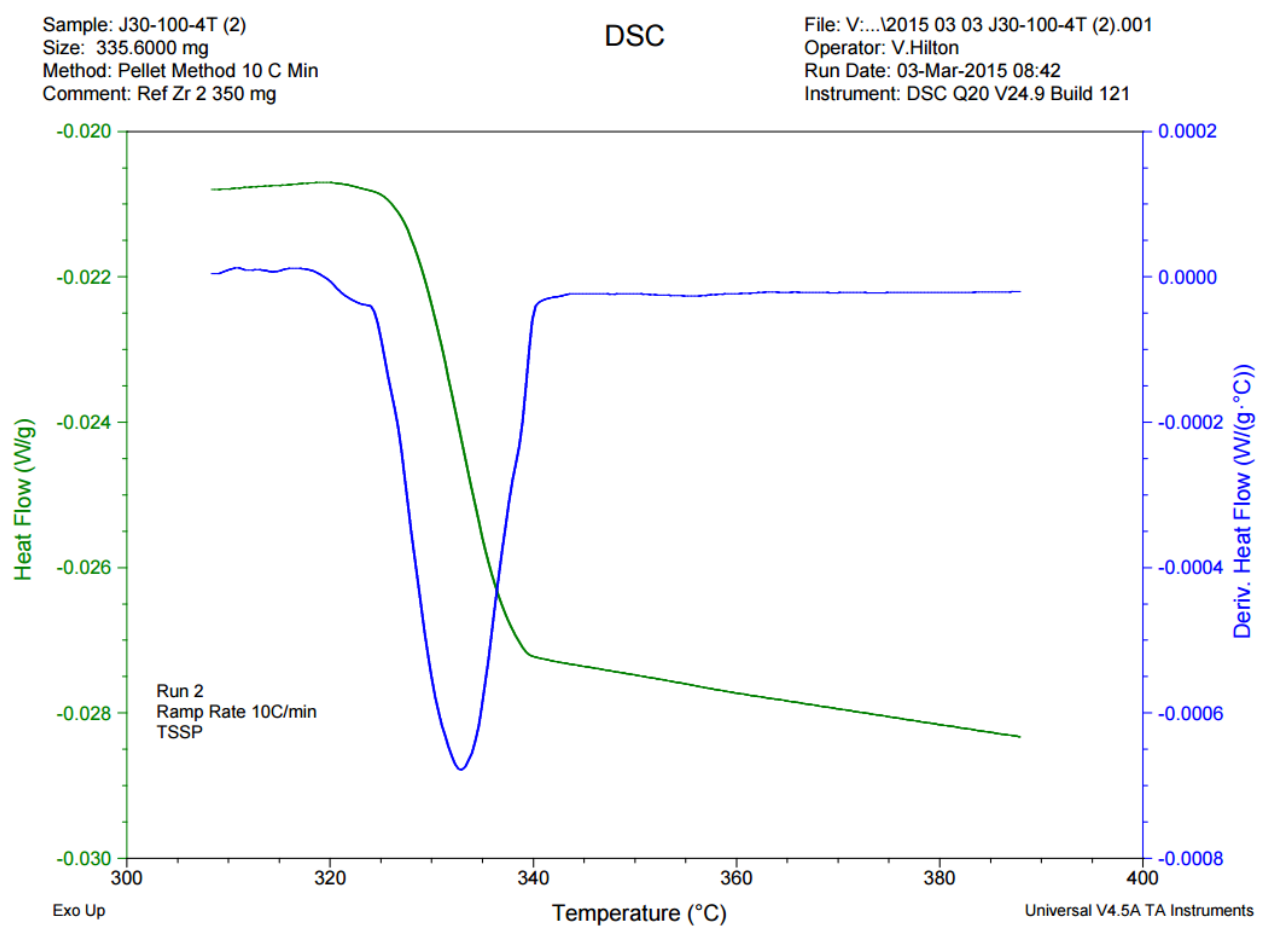

Figure 32: DSC cooling curve \#2 for sample J30-100-4T 


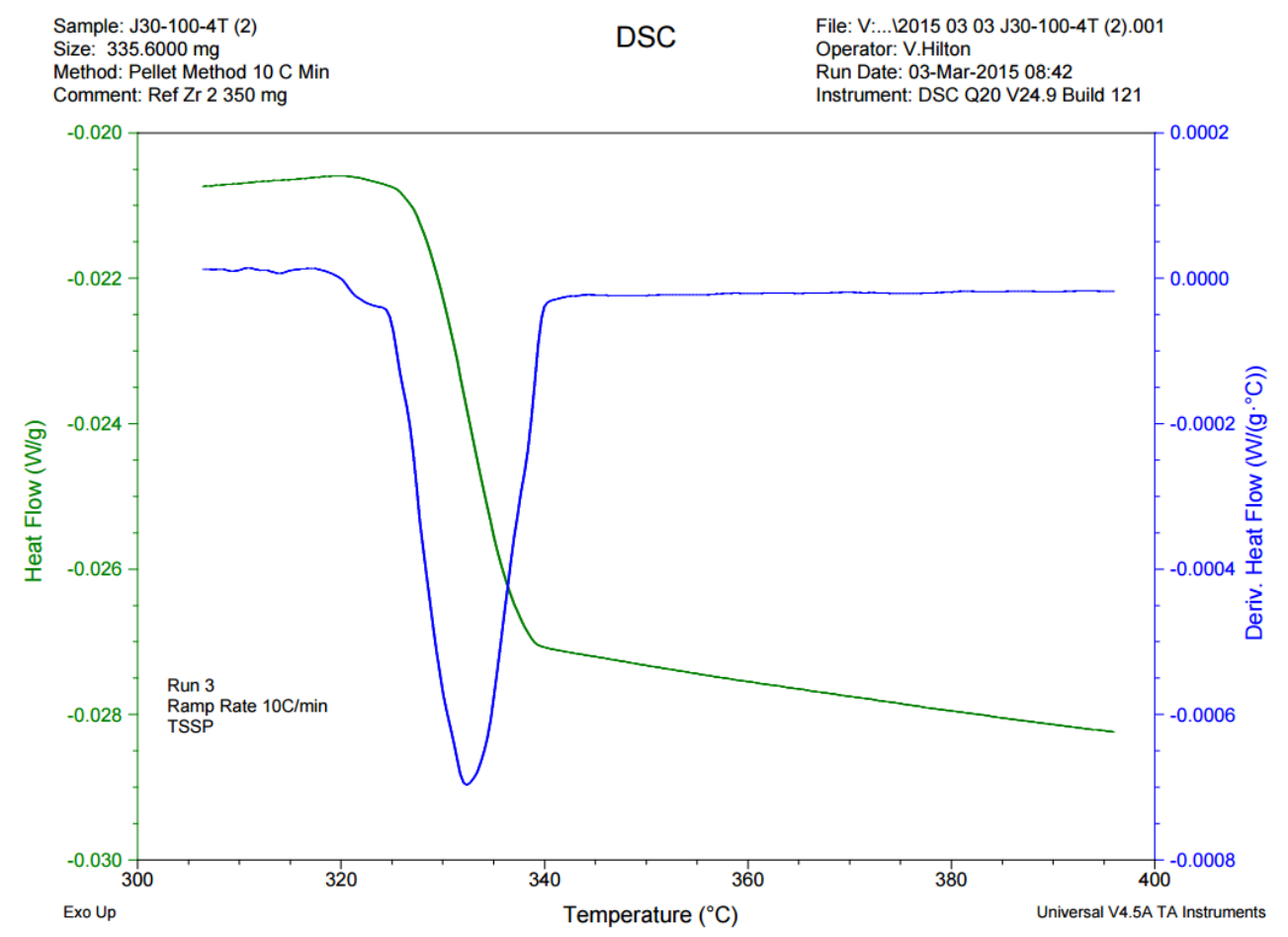

Figure 33: DSC cooling curve \#3 for sample J30-100-4T

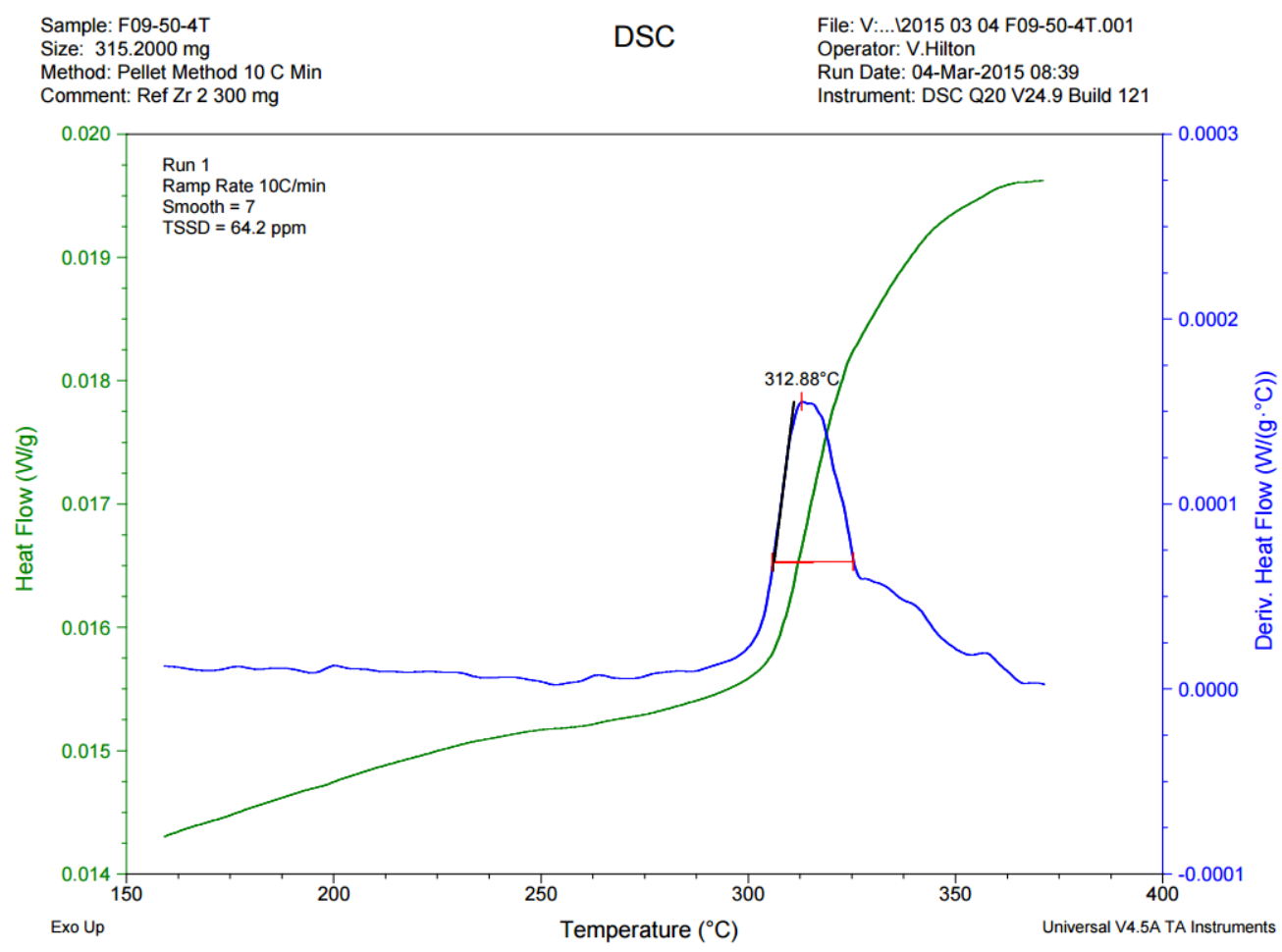

Figure 34: DSC heating curve \#1 for sample F09-50-4T 


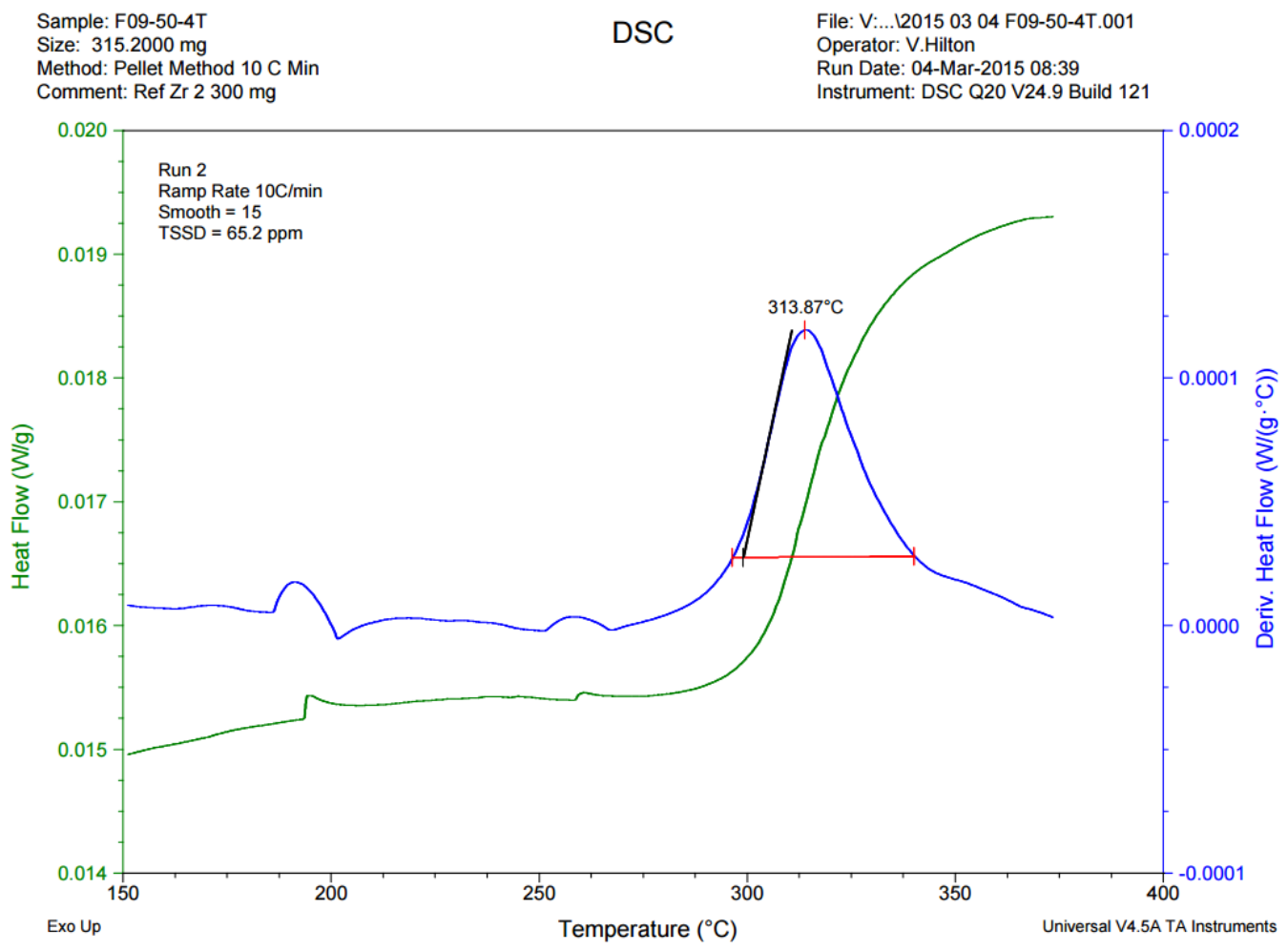

Figure 35: DSC heating curve \#2 for sample F09-50-4T

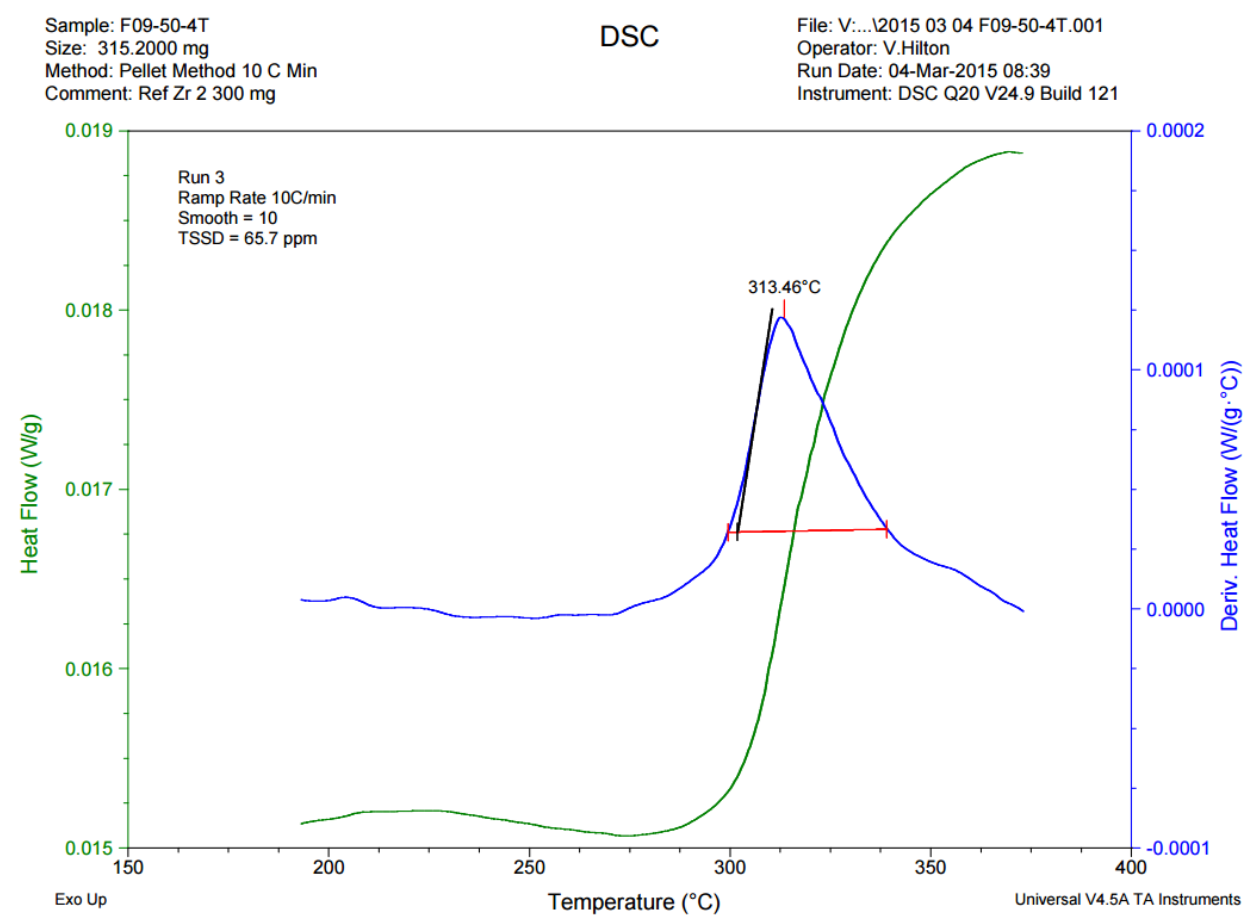

Figure 36: DSC heating curve \#3 for sample F09-50-4T 


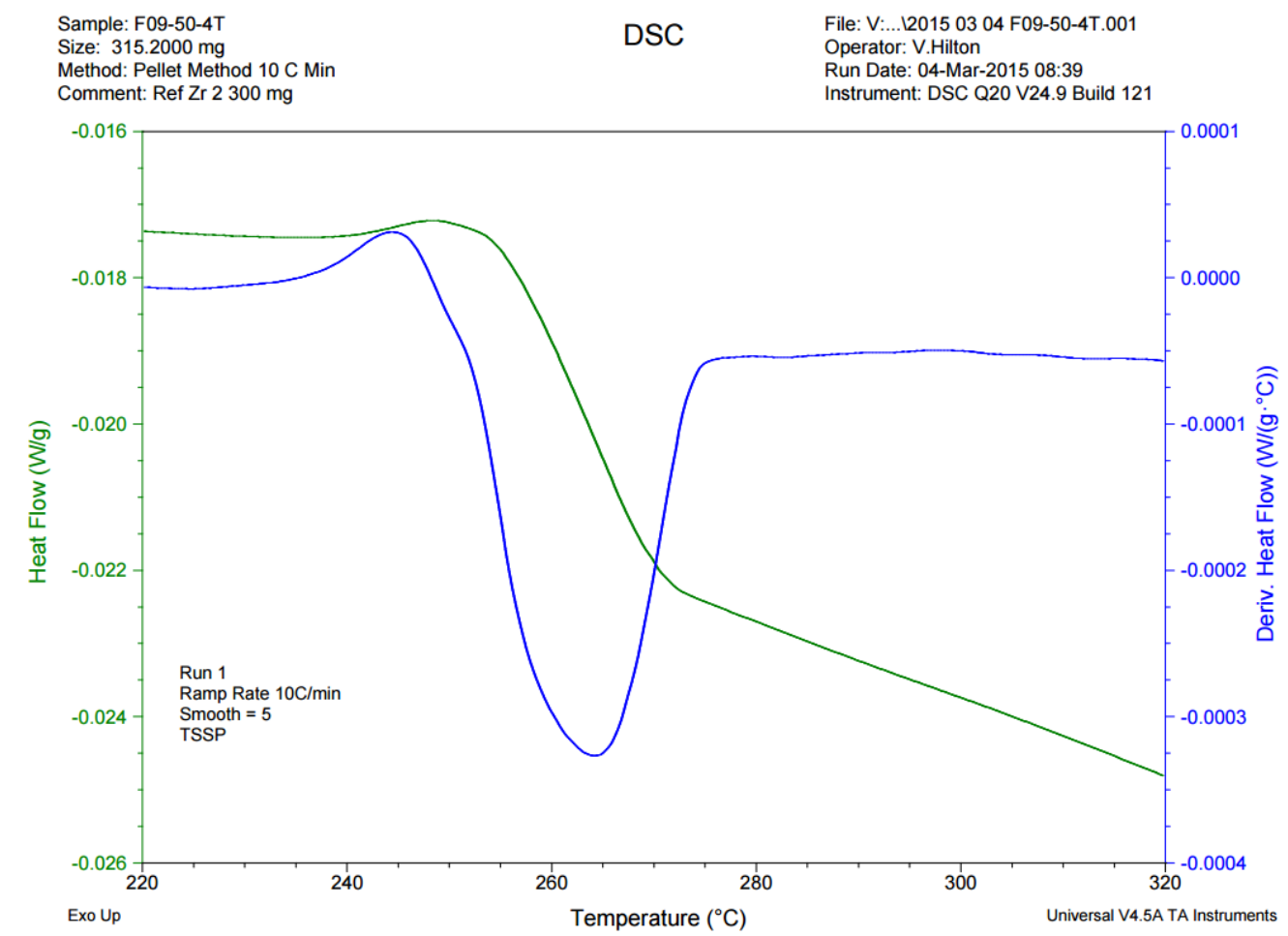

Figure 37: DSC cooling curve \#1 for sample F09-50-4T

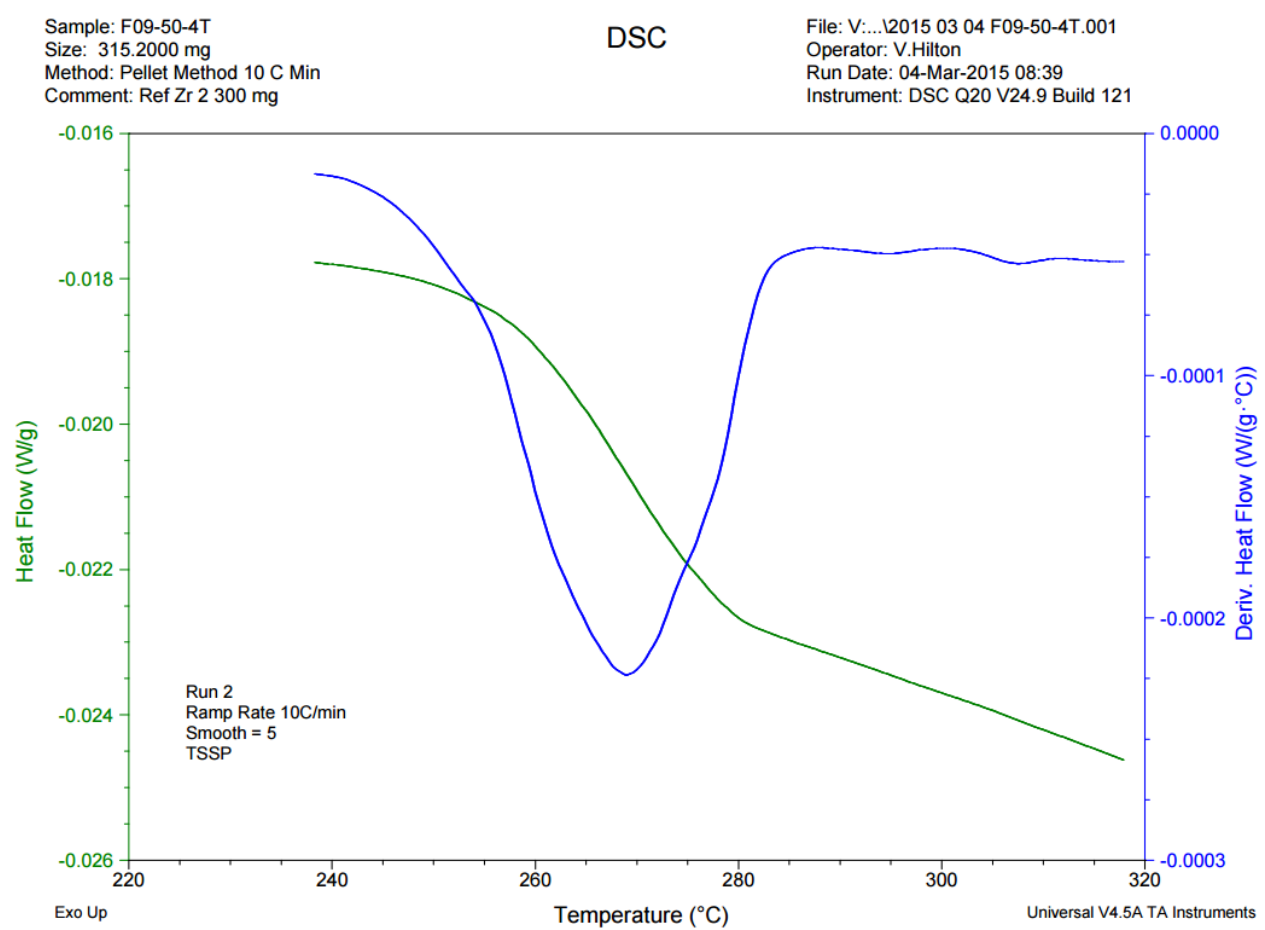

Figure 38: DSC cooling curve \#2 for sample F09-50-4T 


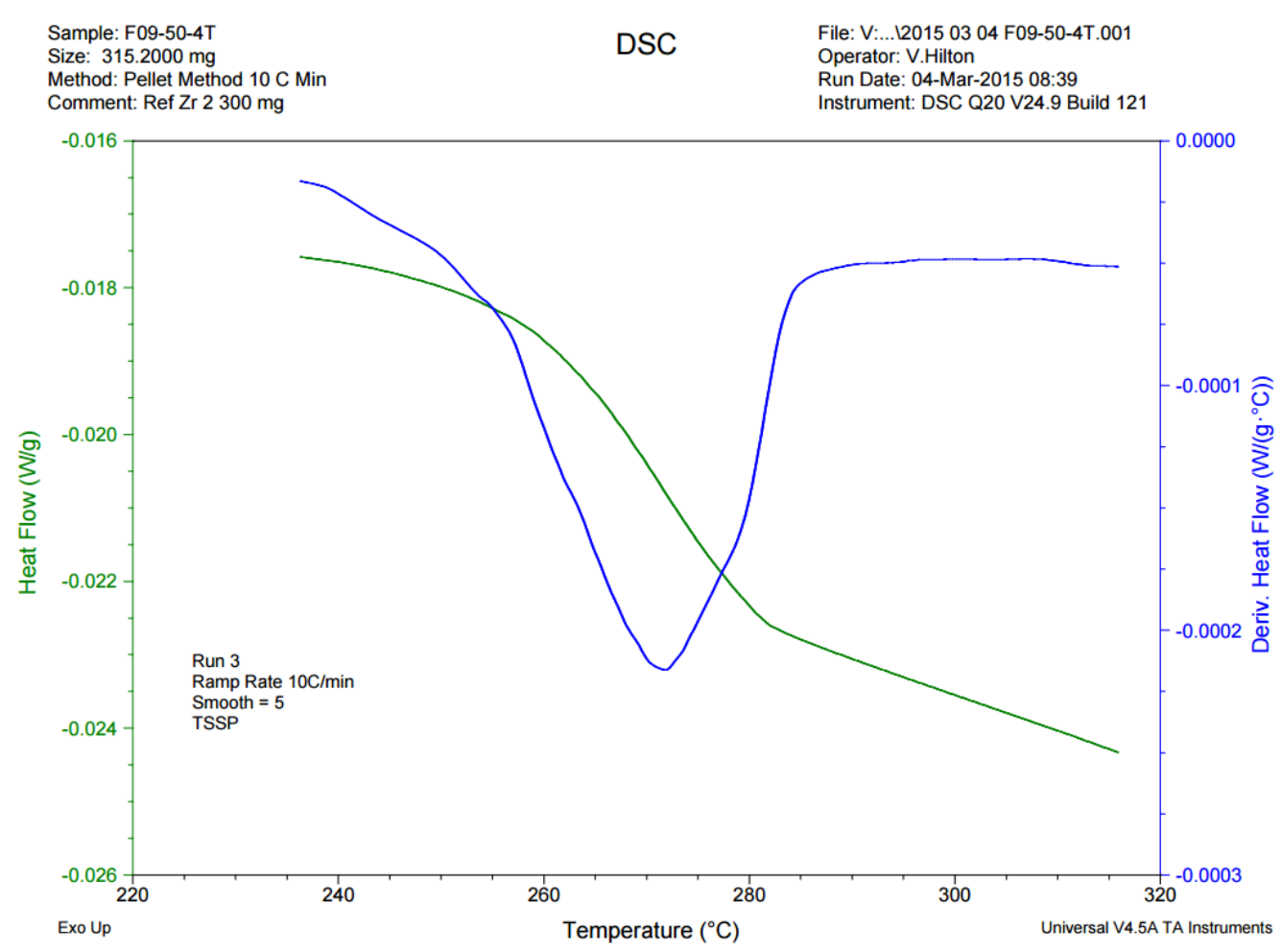

Figure 39: DSC cooling curve \#3 for sample F09-50-4T

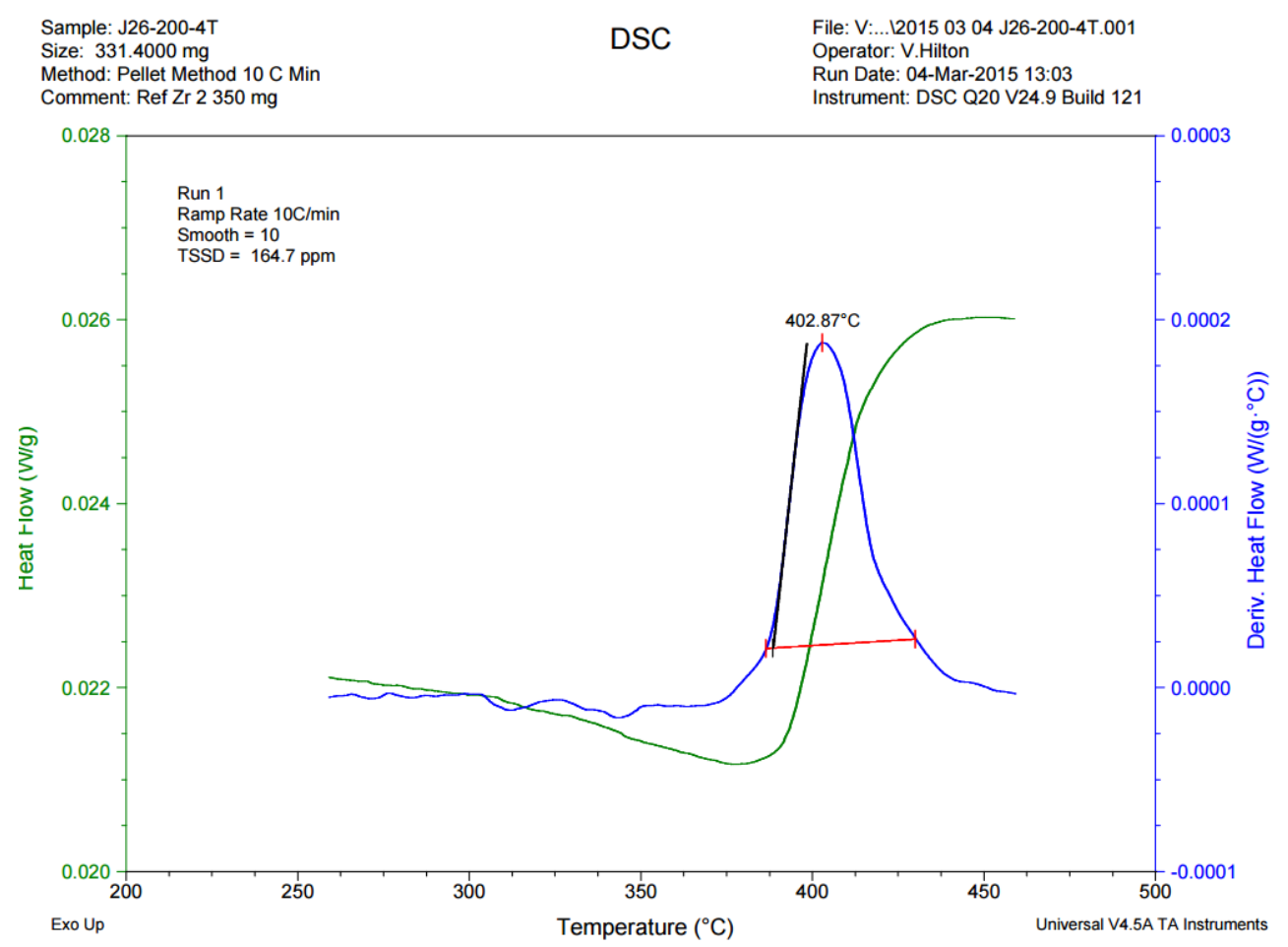

Figure 40: DSC heating curve \#1 for sample J26-200-4T 


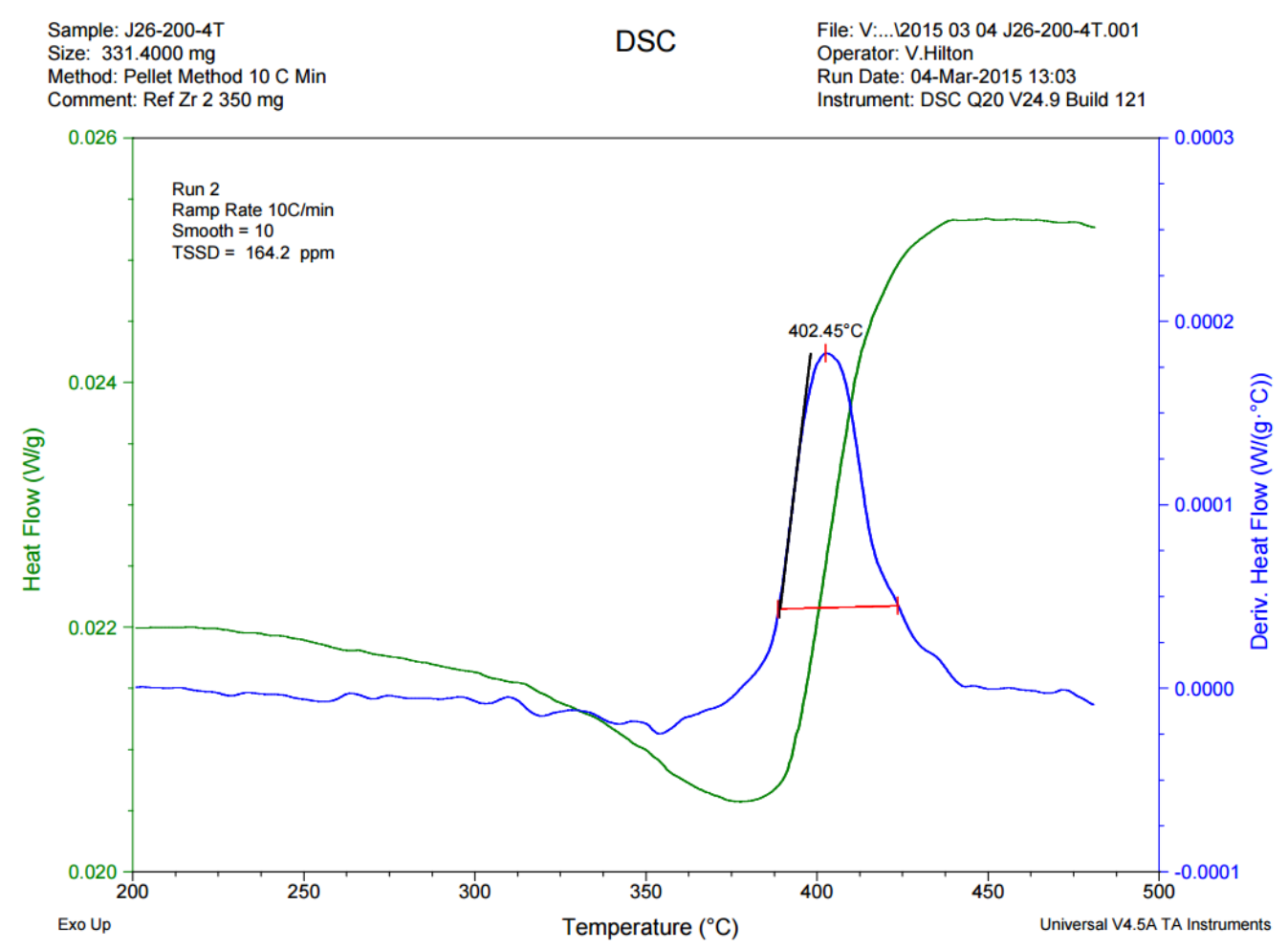

Figure 41: DSC heating curve \#2 for sample J26-200-4T

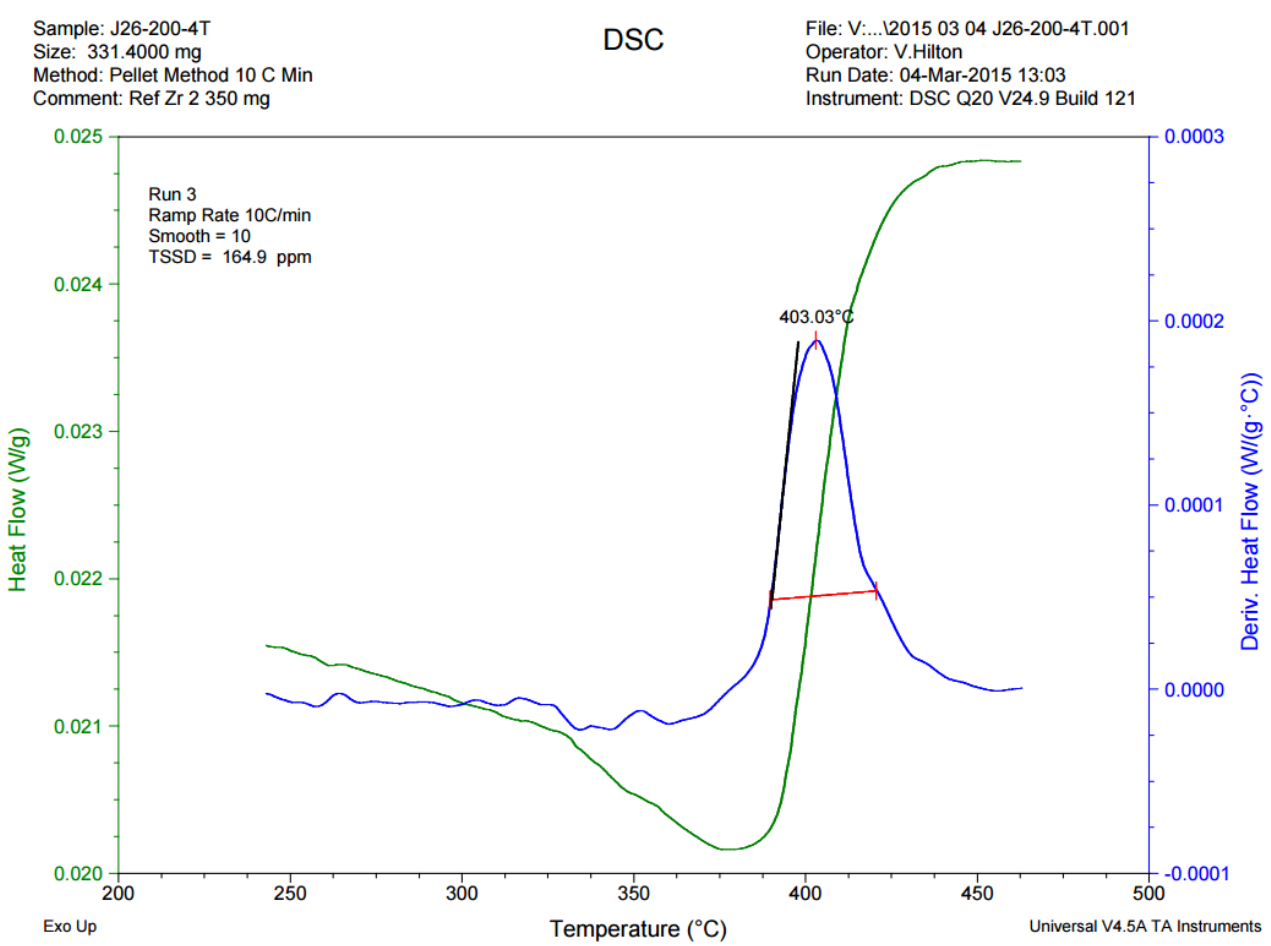

Figure 42: DSC heating curve \#3 for sample J26-200-4T 


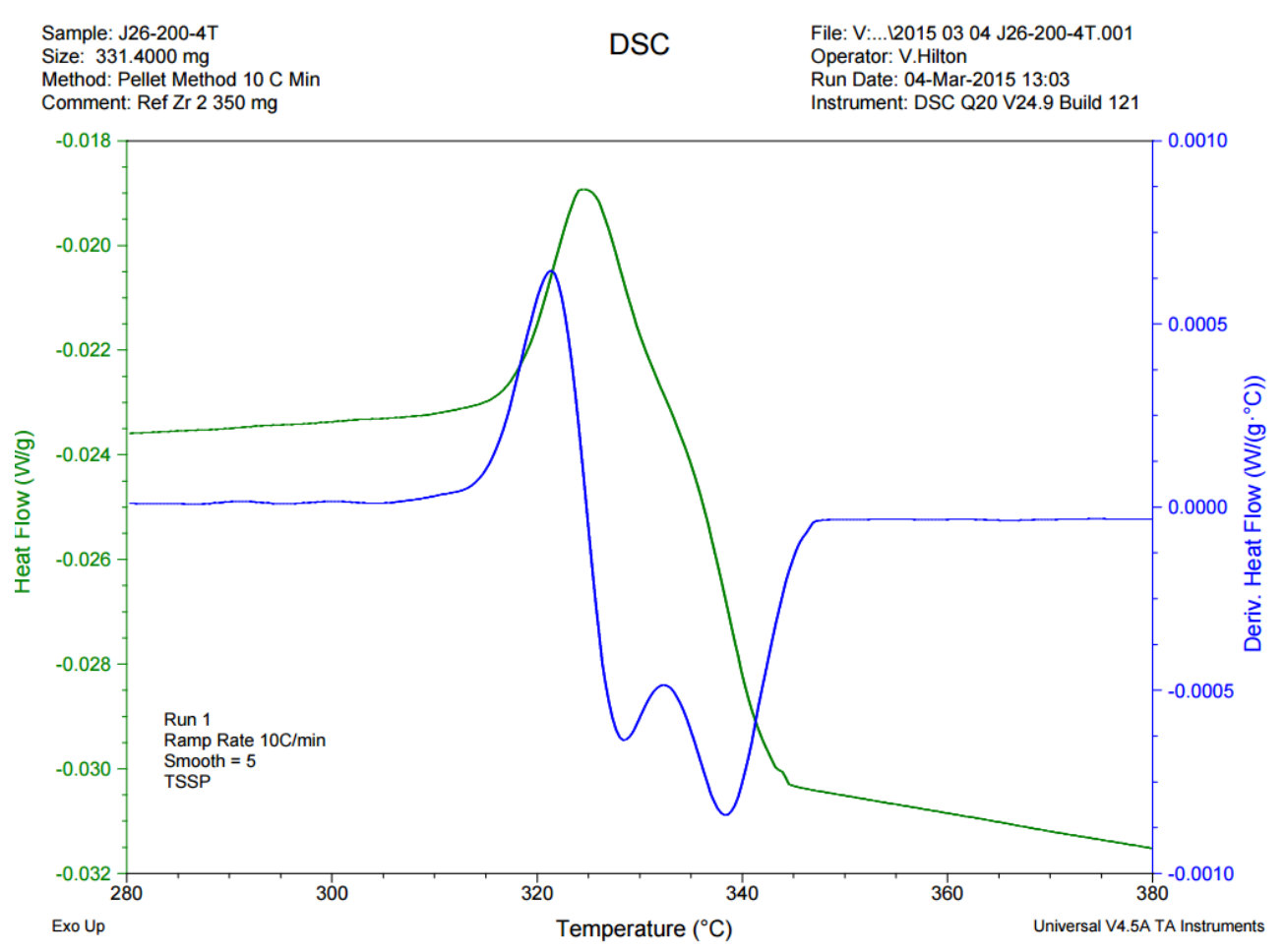

Figure 43: DSC cooling curve \#1 for sample J26-200-4T

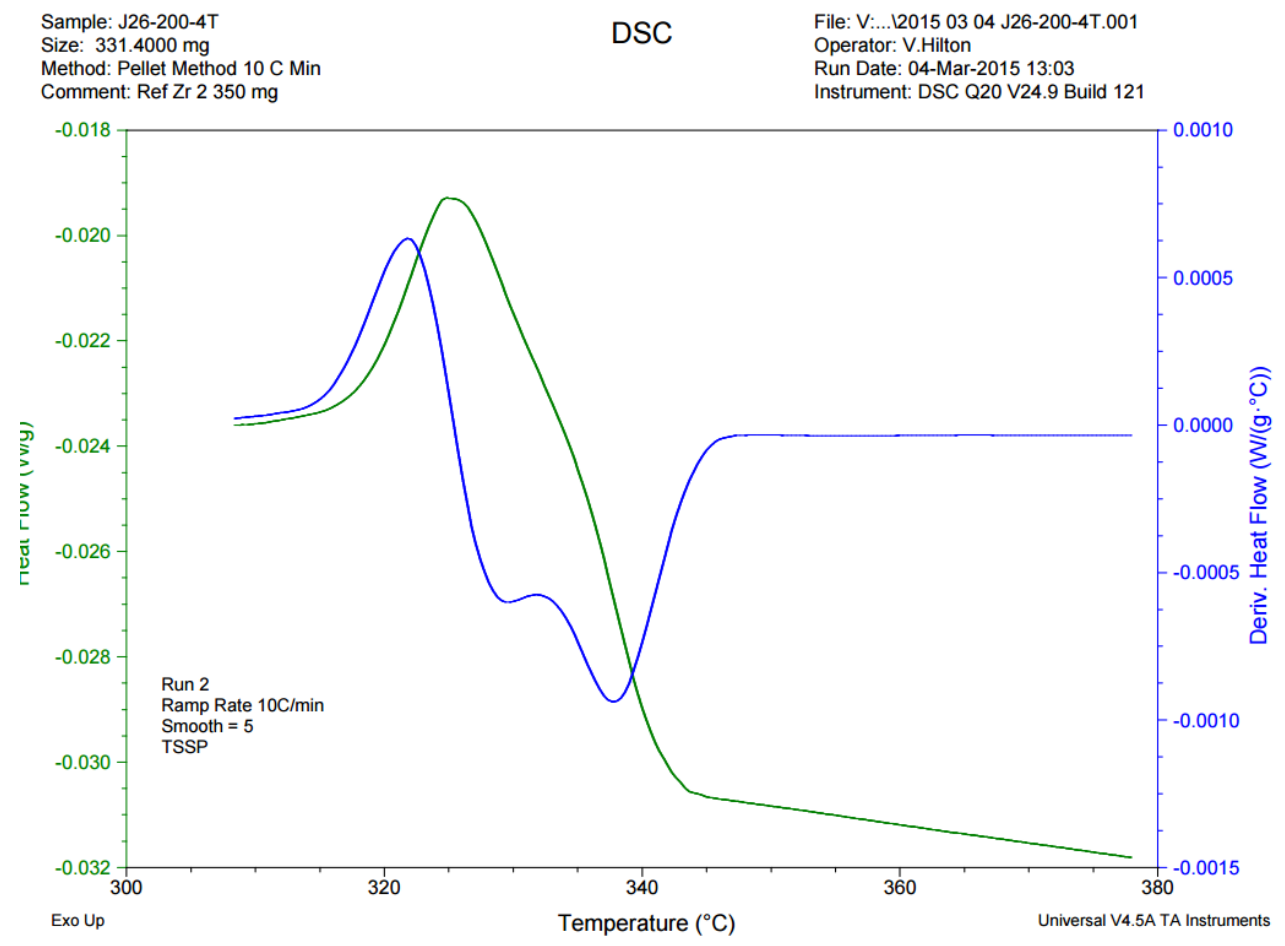

Figure 44: DSC cooling curve \#2 for sample J26-200-4T 


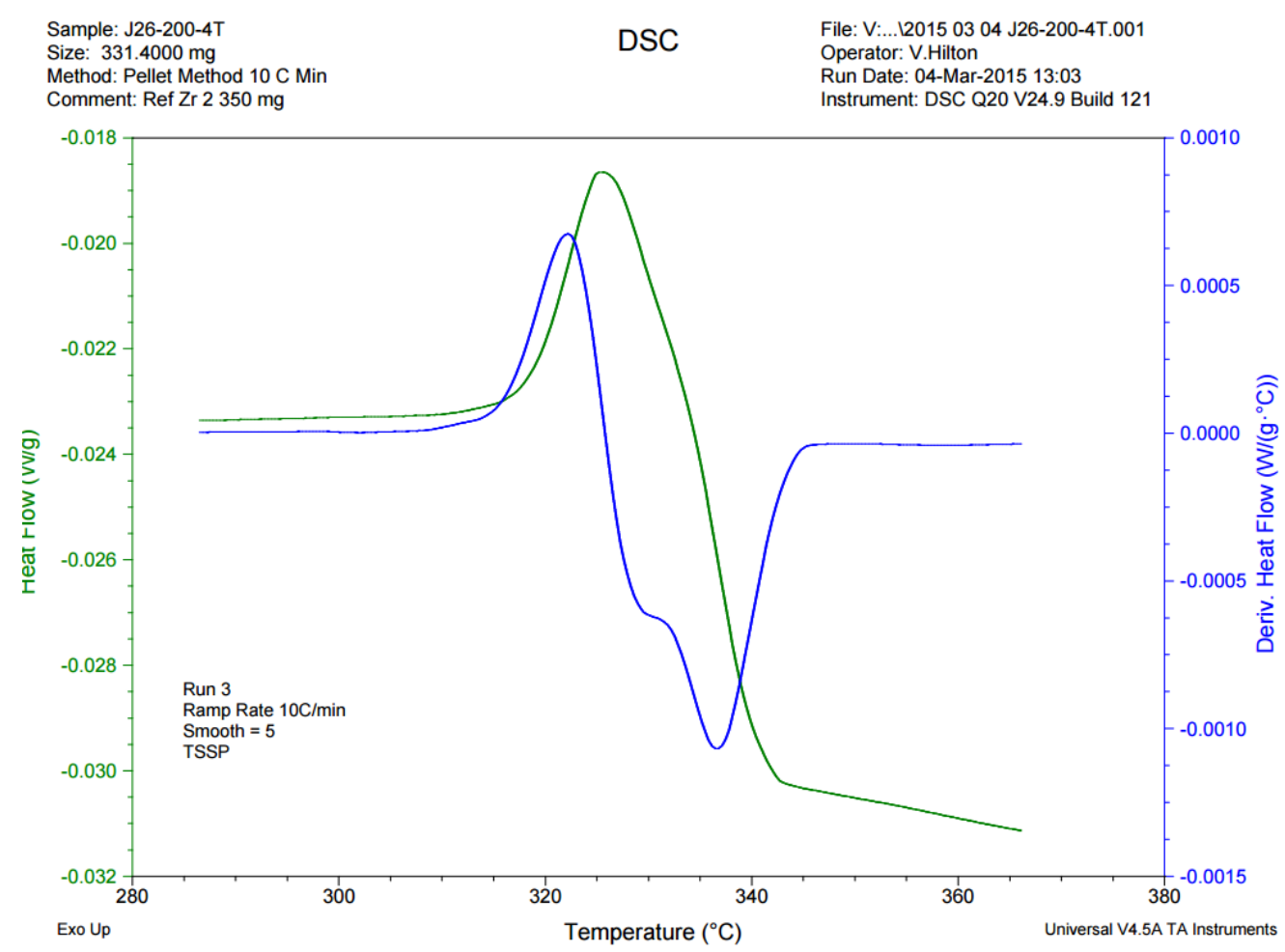

Figure 45: DSC cooling curve \#3 for sample J26-200-4T

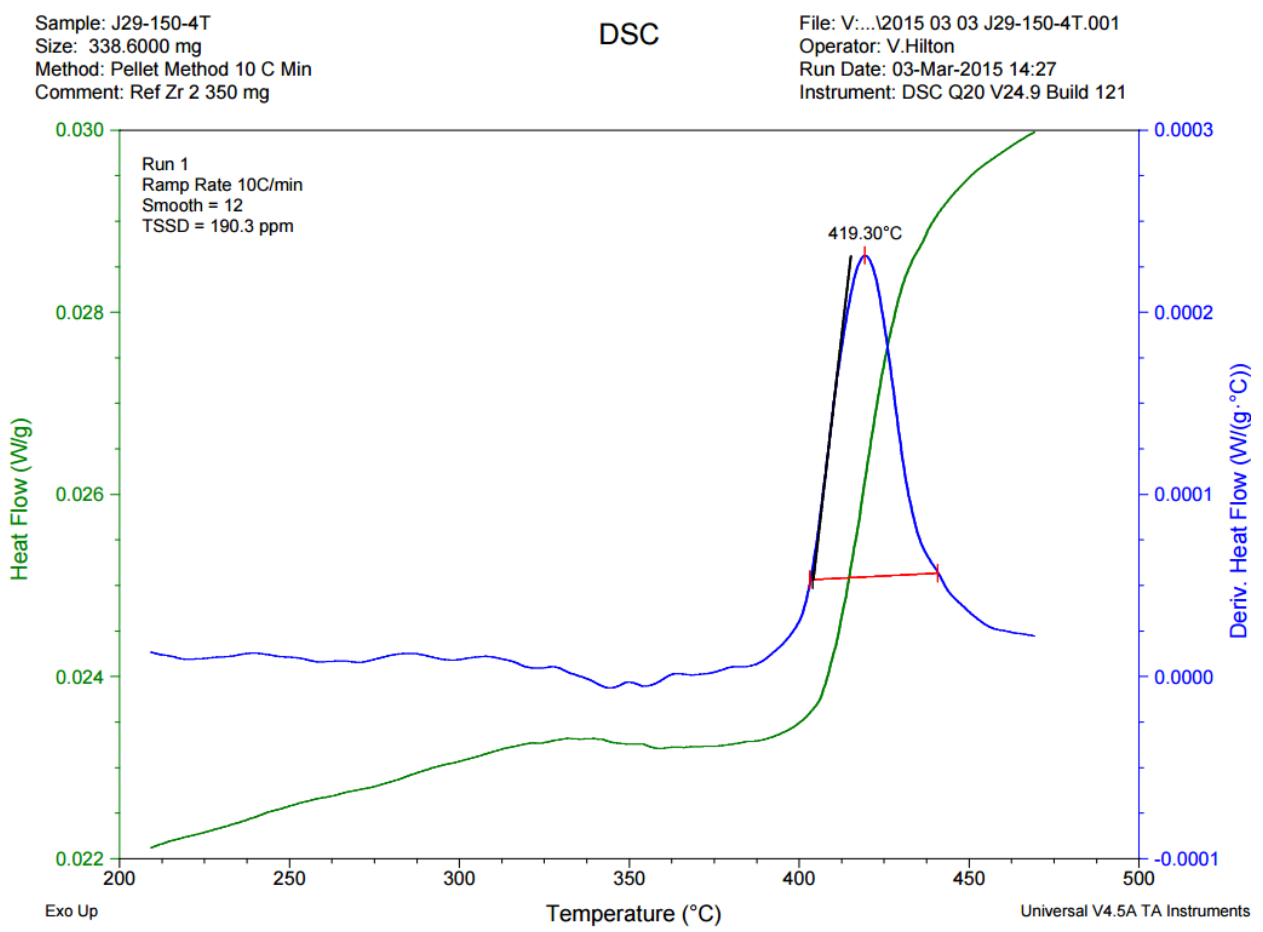

Figure 46: DSC heating curve \#1 for sample J29-150-4T 


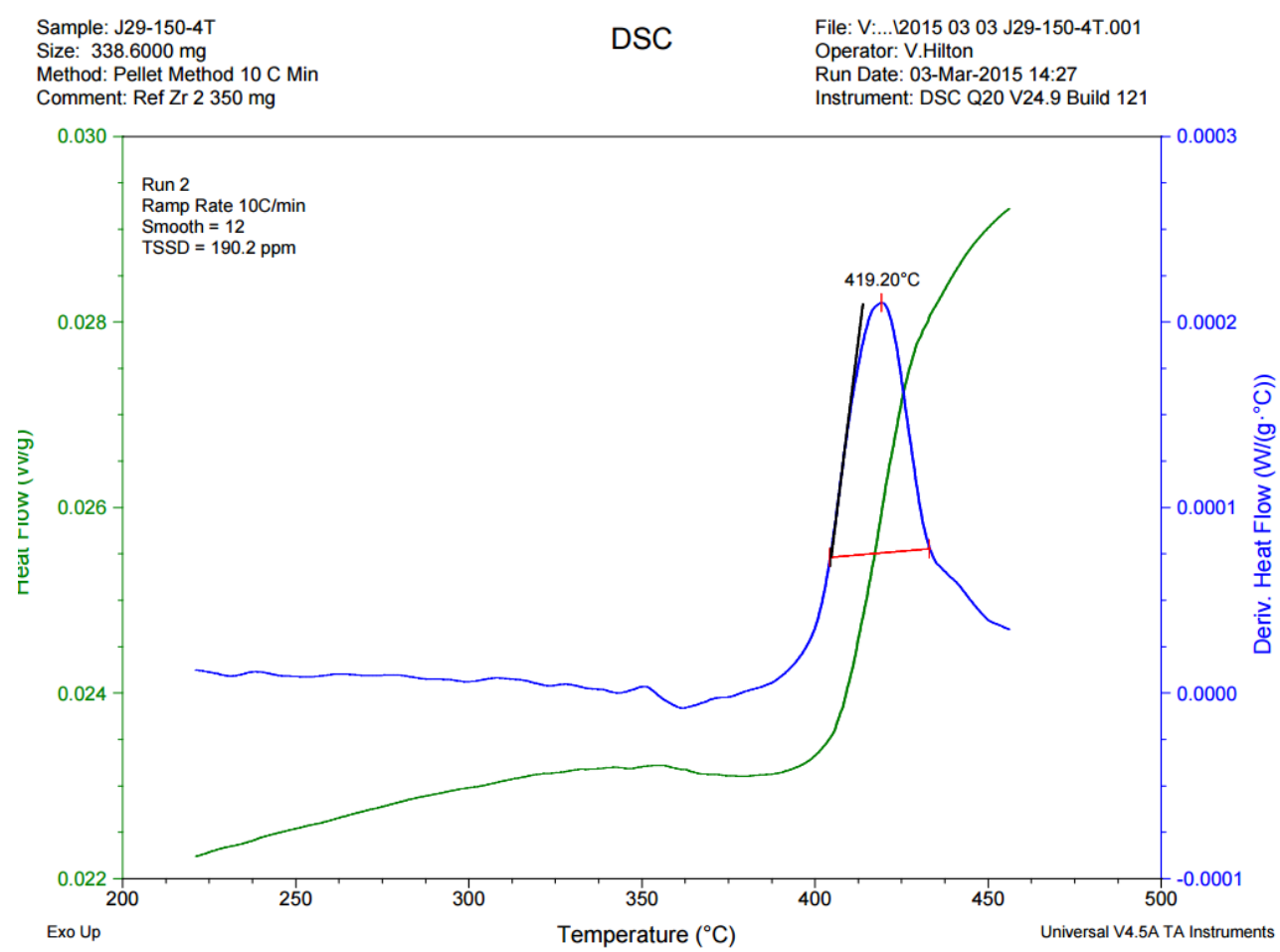

Figure 47: DSC heating curve \#2 for sample J29-150-4T

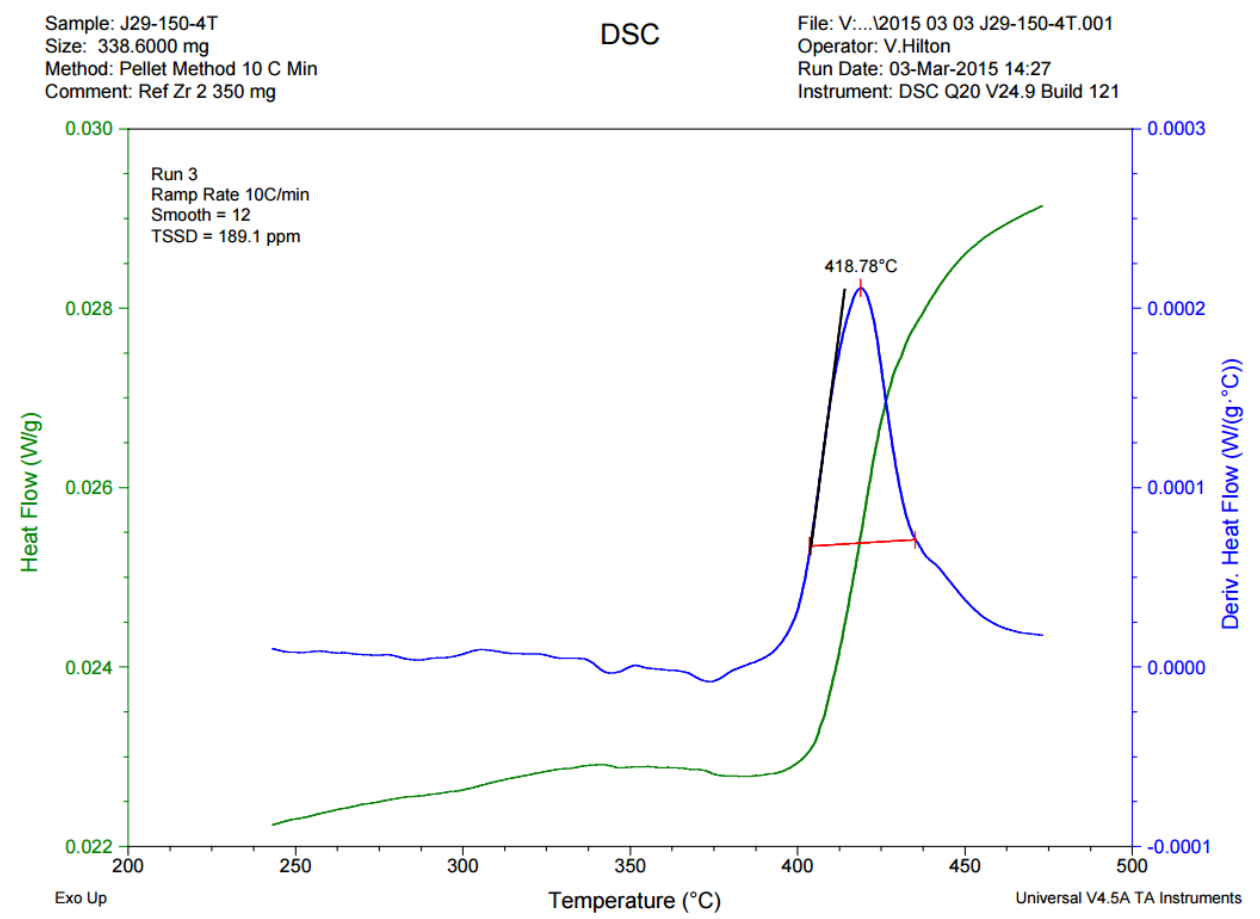

Figure 48: DSC heating curve \#3 for sample J29-150-4T 


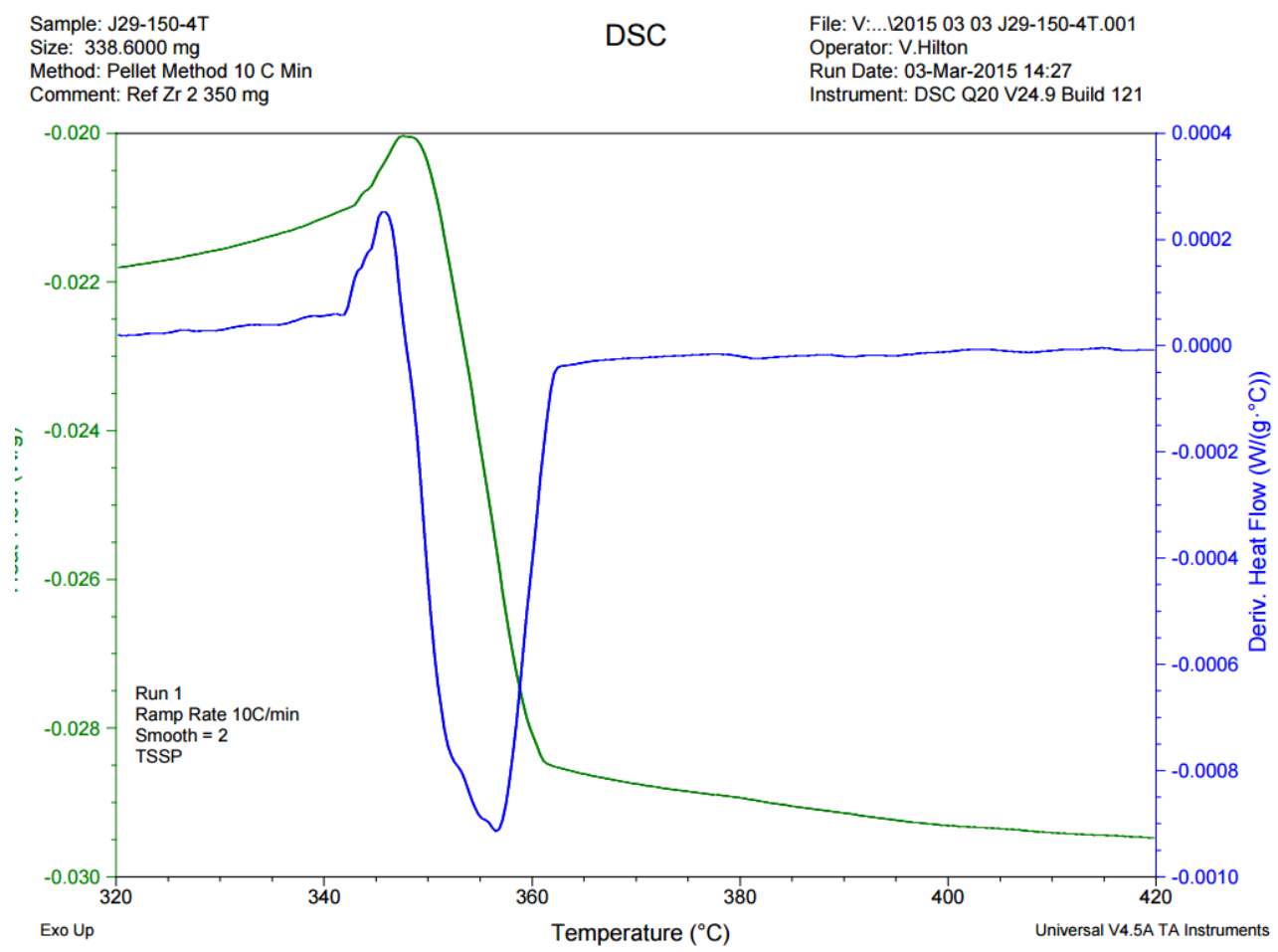

Figure 49: DSC cooling curve \#1 for sample J29-150-4T

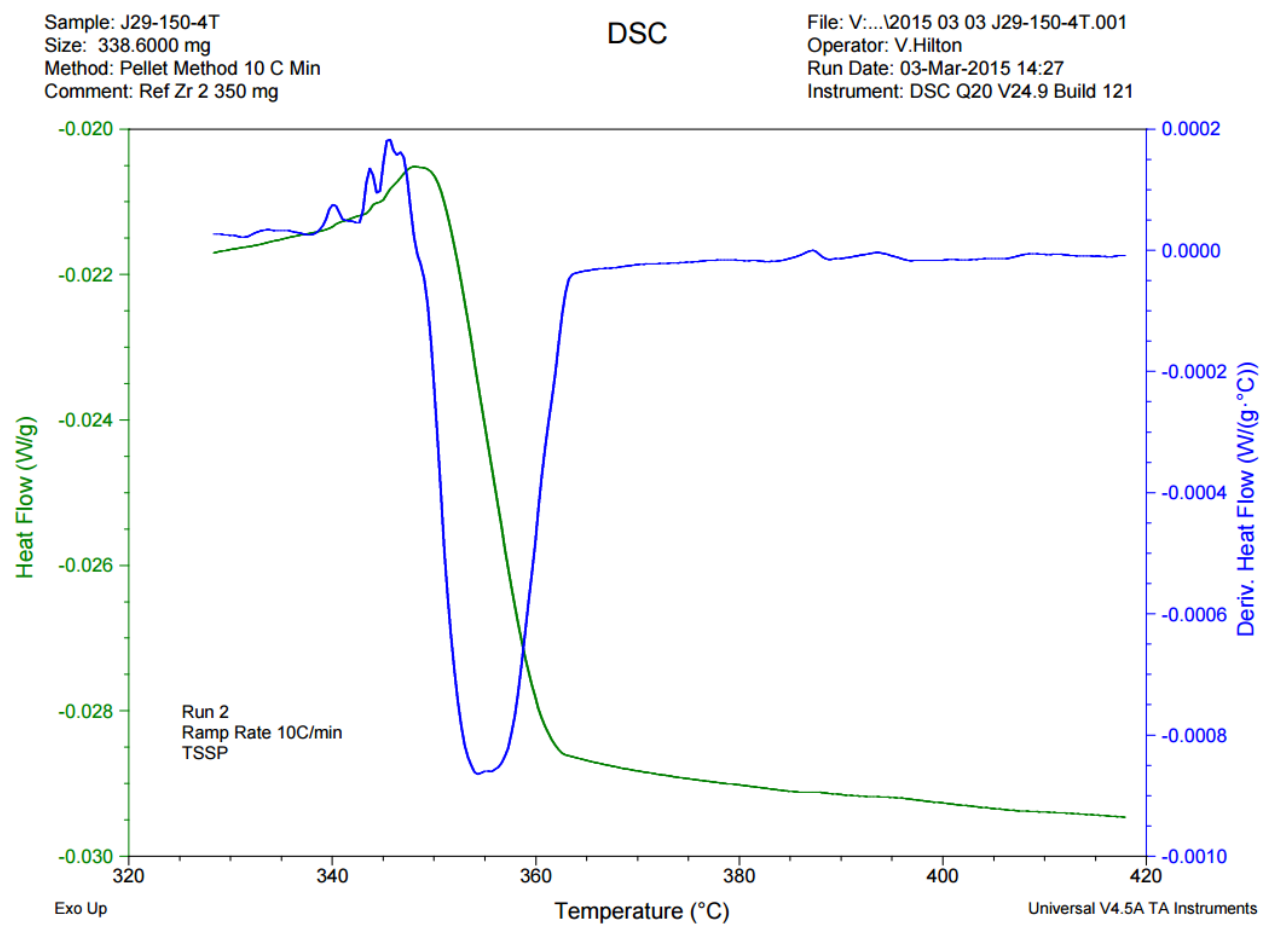

Figure 50: DSC cooling curve \#2 for sample J29-150-4T 


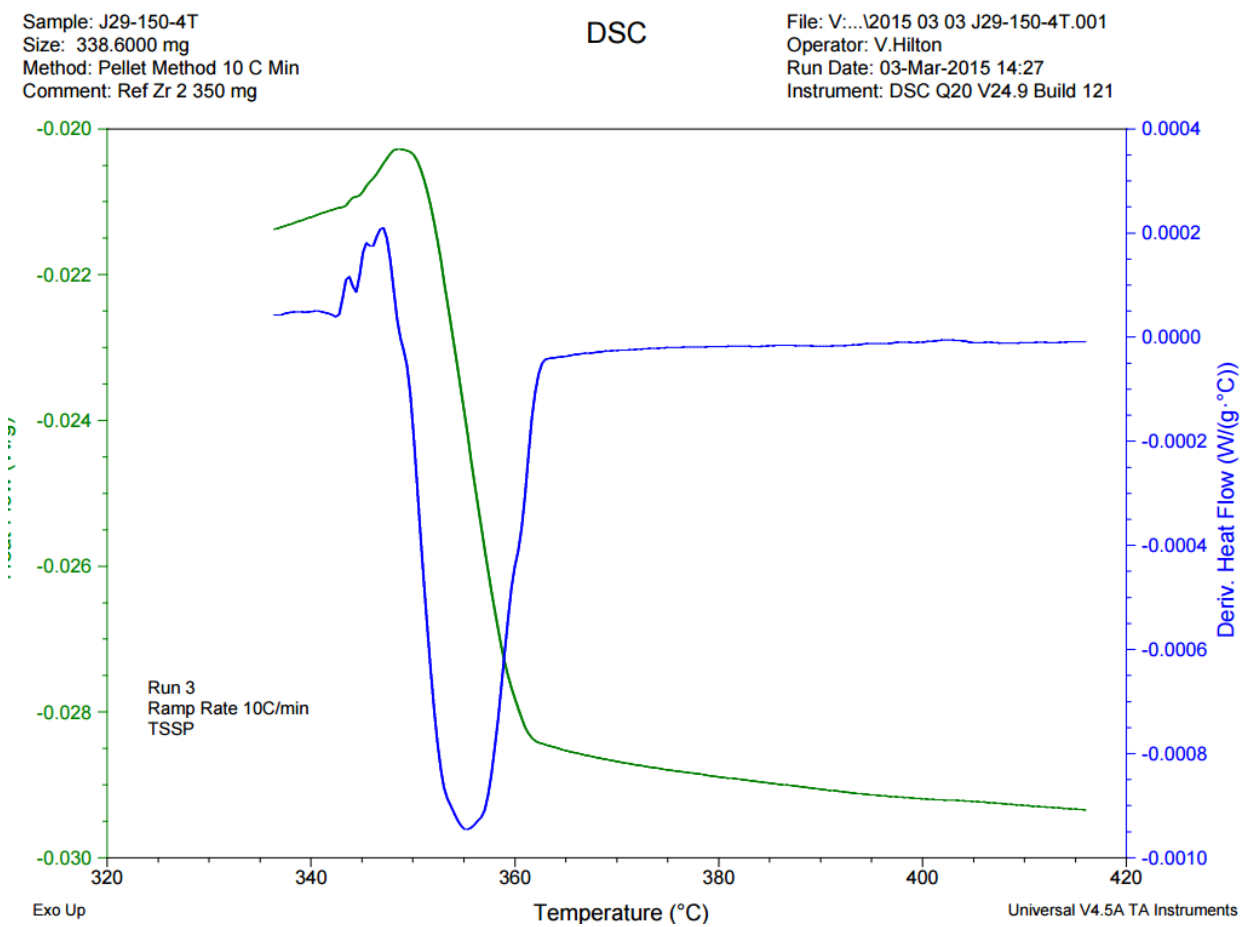

Figure 51: DSC cooling curve \#3 for sample J29-150-4T

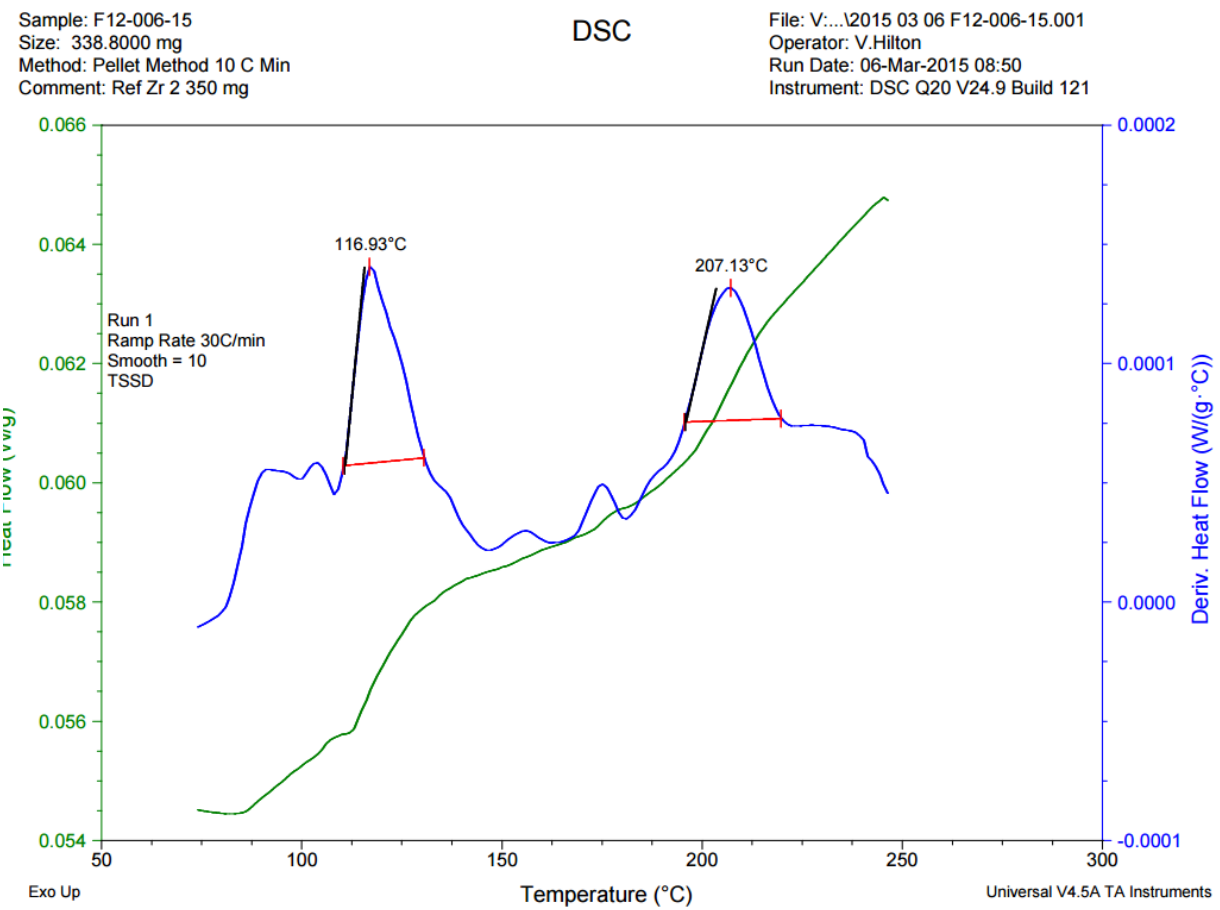

Figure 52: DSC heating curve \#1 for sample stock material 


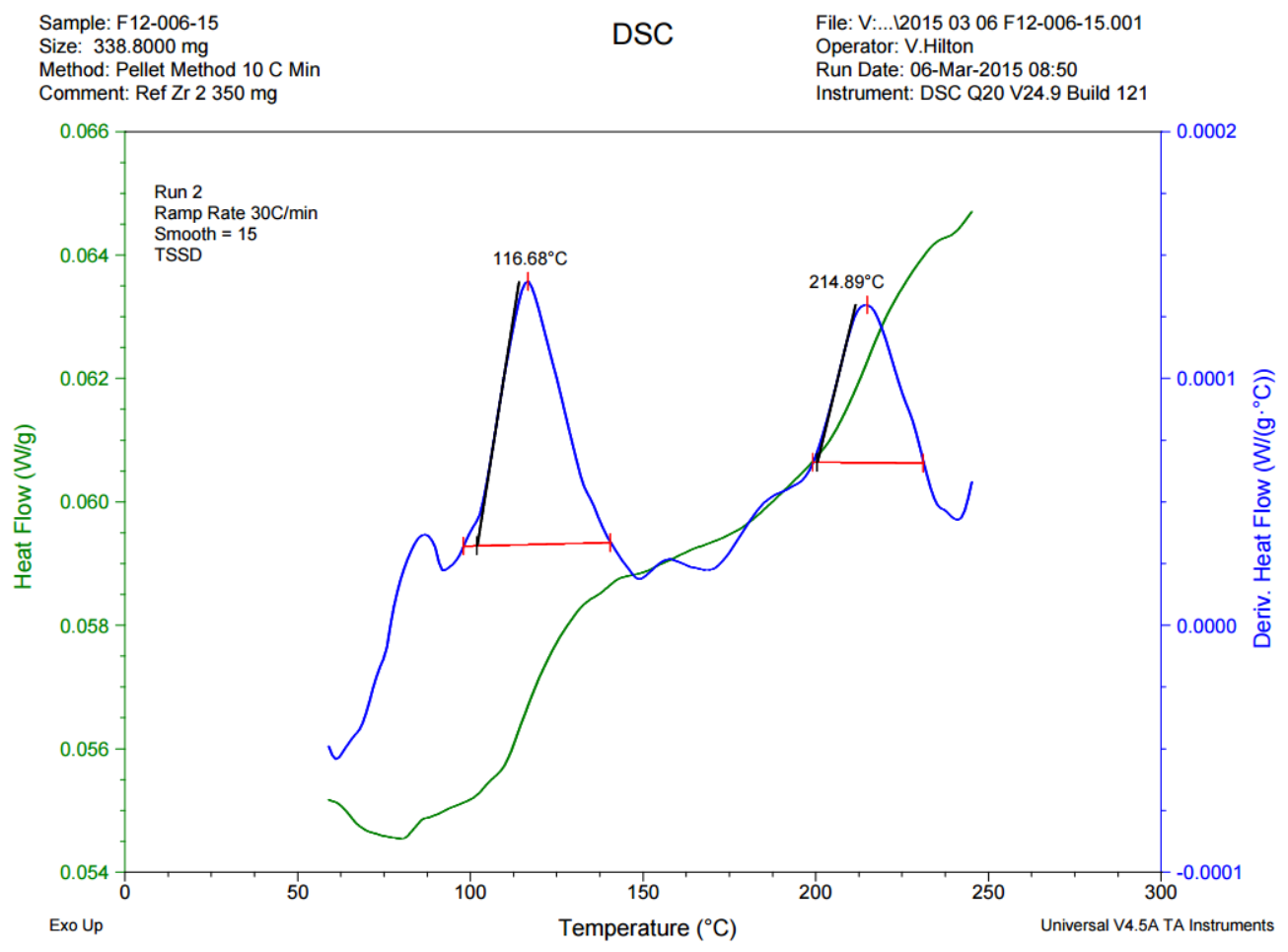

Figure 53: DSC heating curve \#2 for sample stock material

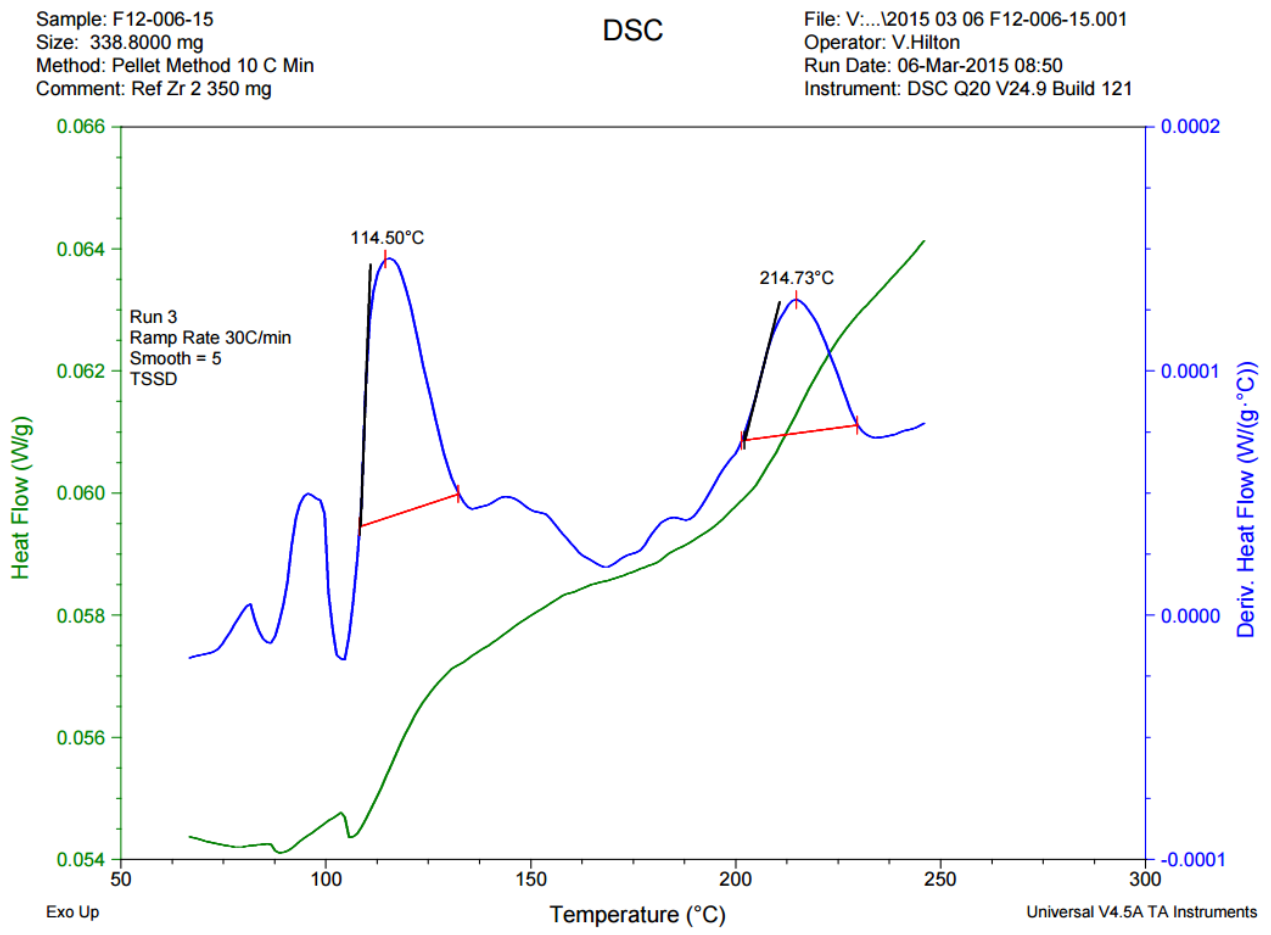

Figure 54: DSC heating curve \#3 for sample stock material 


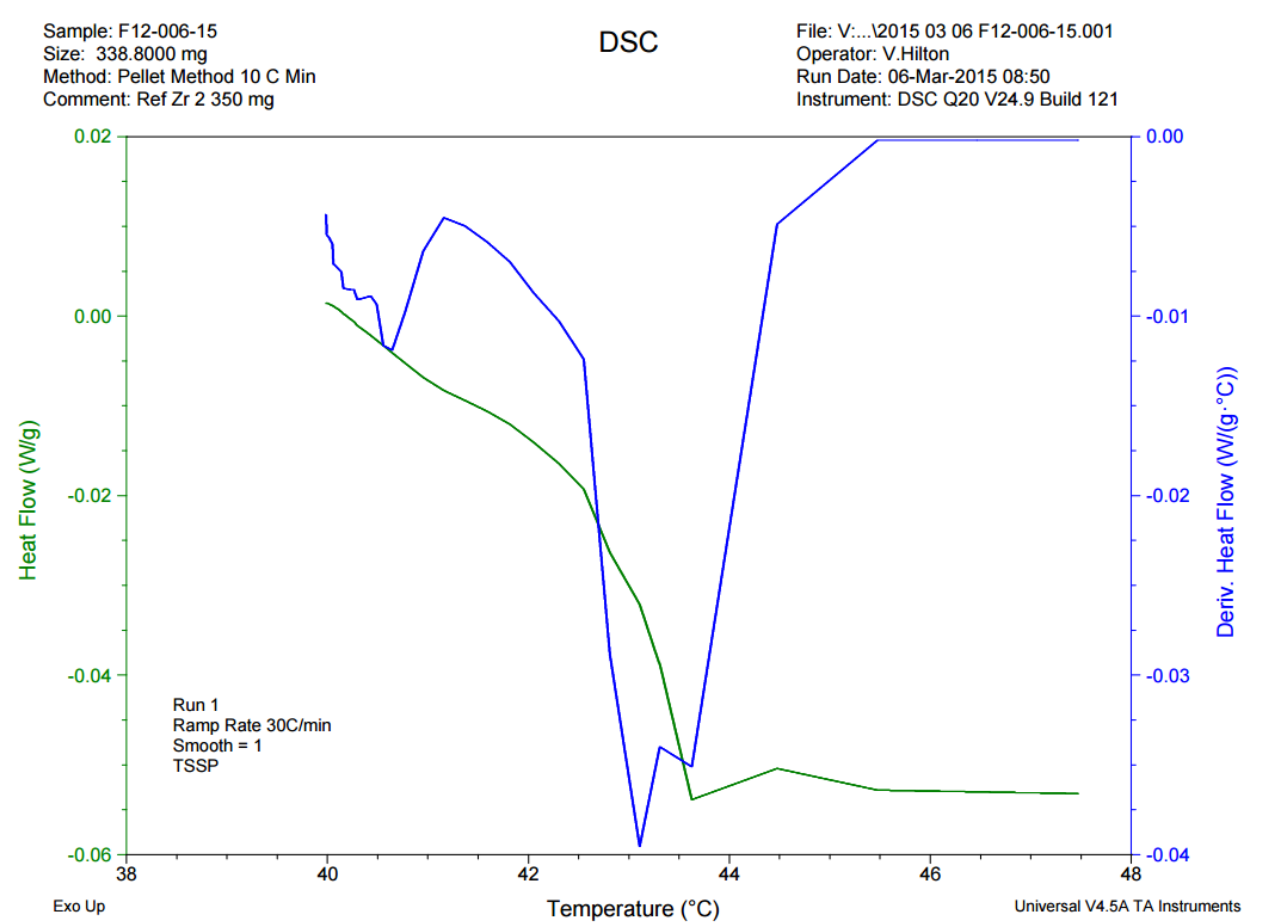

Figure 55: DSC cooling curve \#1 for sample stock material

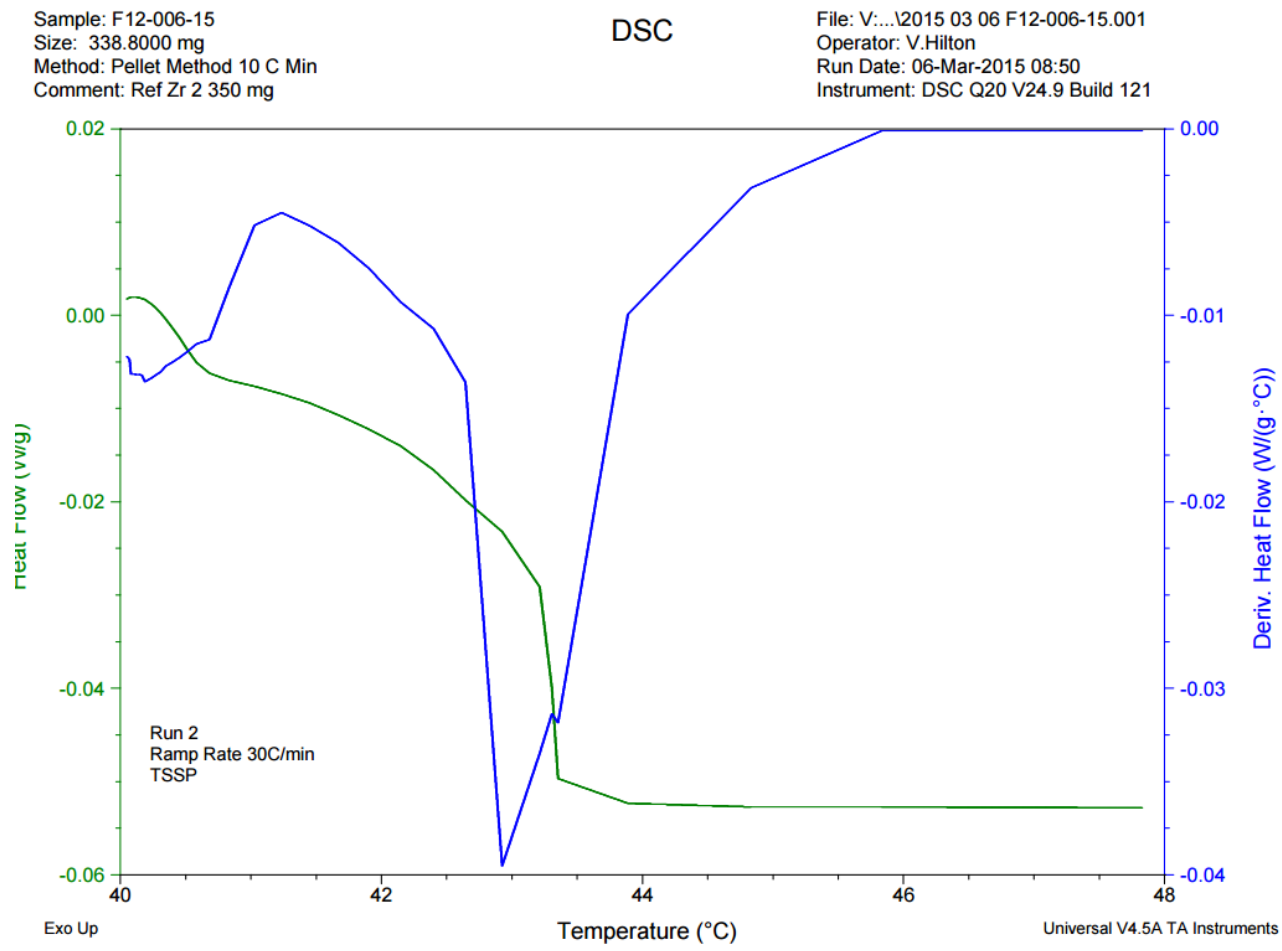

Figure 56: DSC cooling curve \#2 for sample stock material 


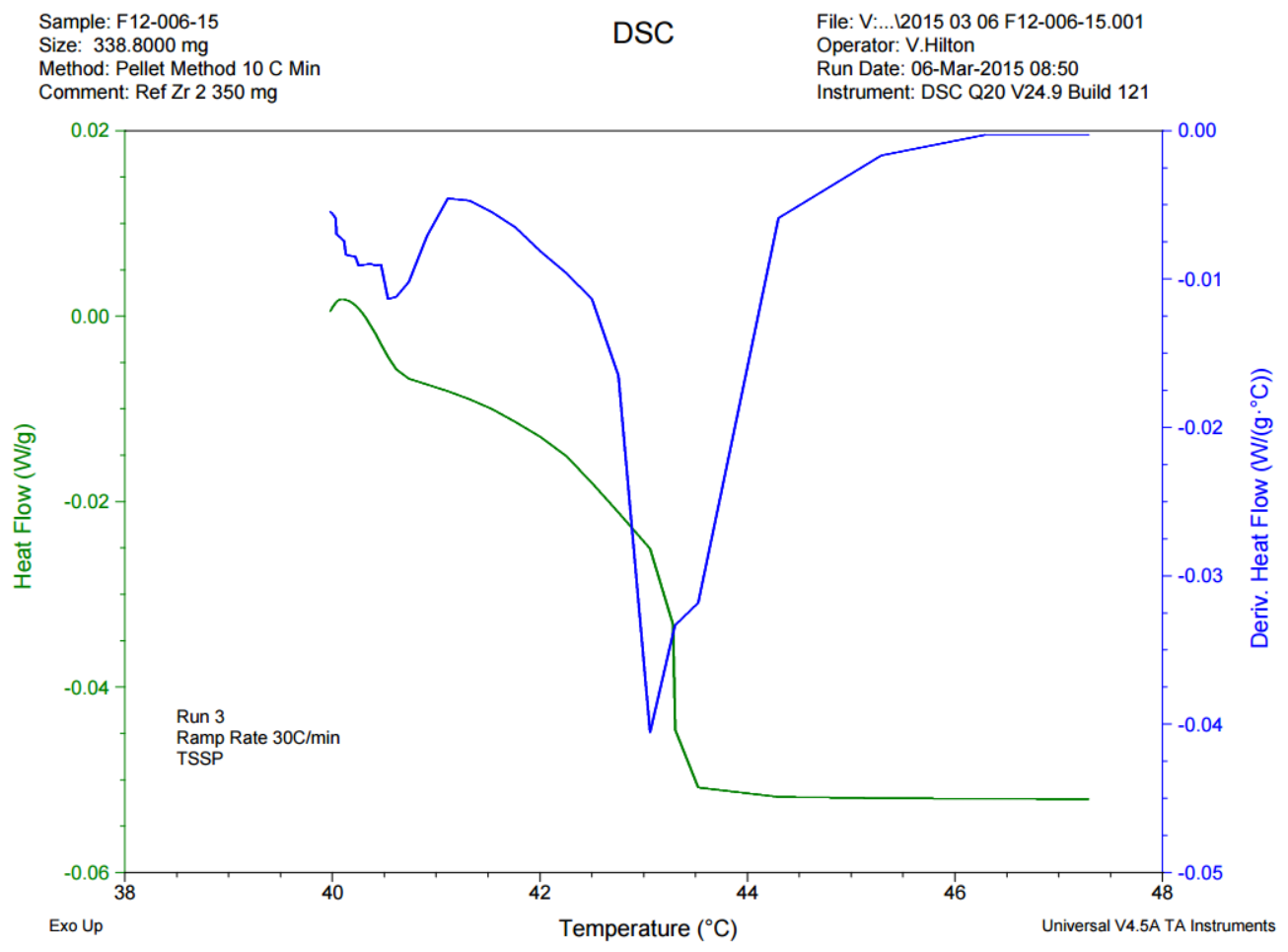

Figure 57: DSC cooling curve \#3 for sample stock material

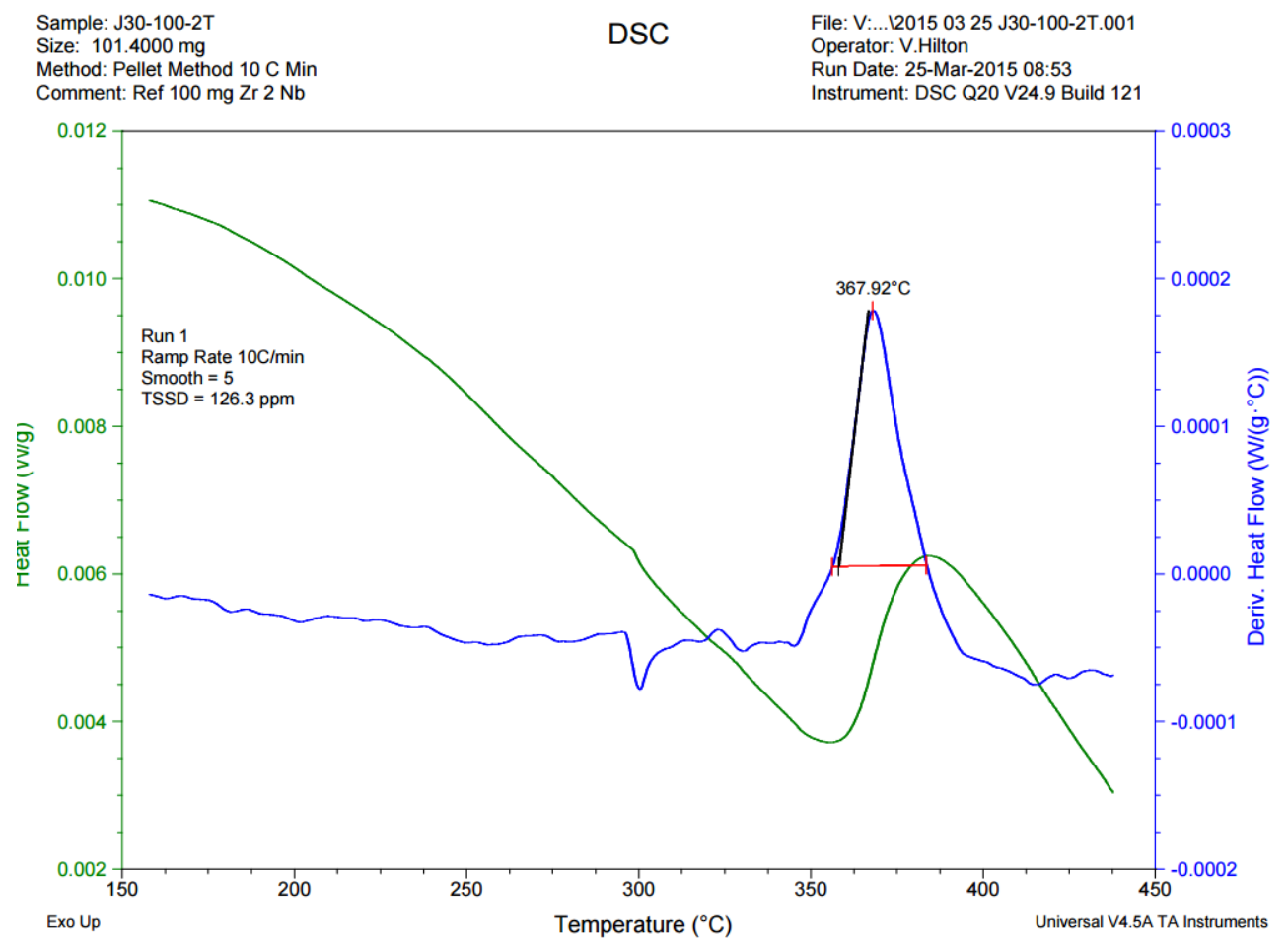

Figure 58: DSC heating curve \#1 for sample J30-100-2T 


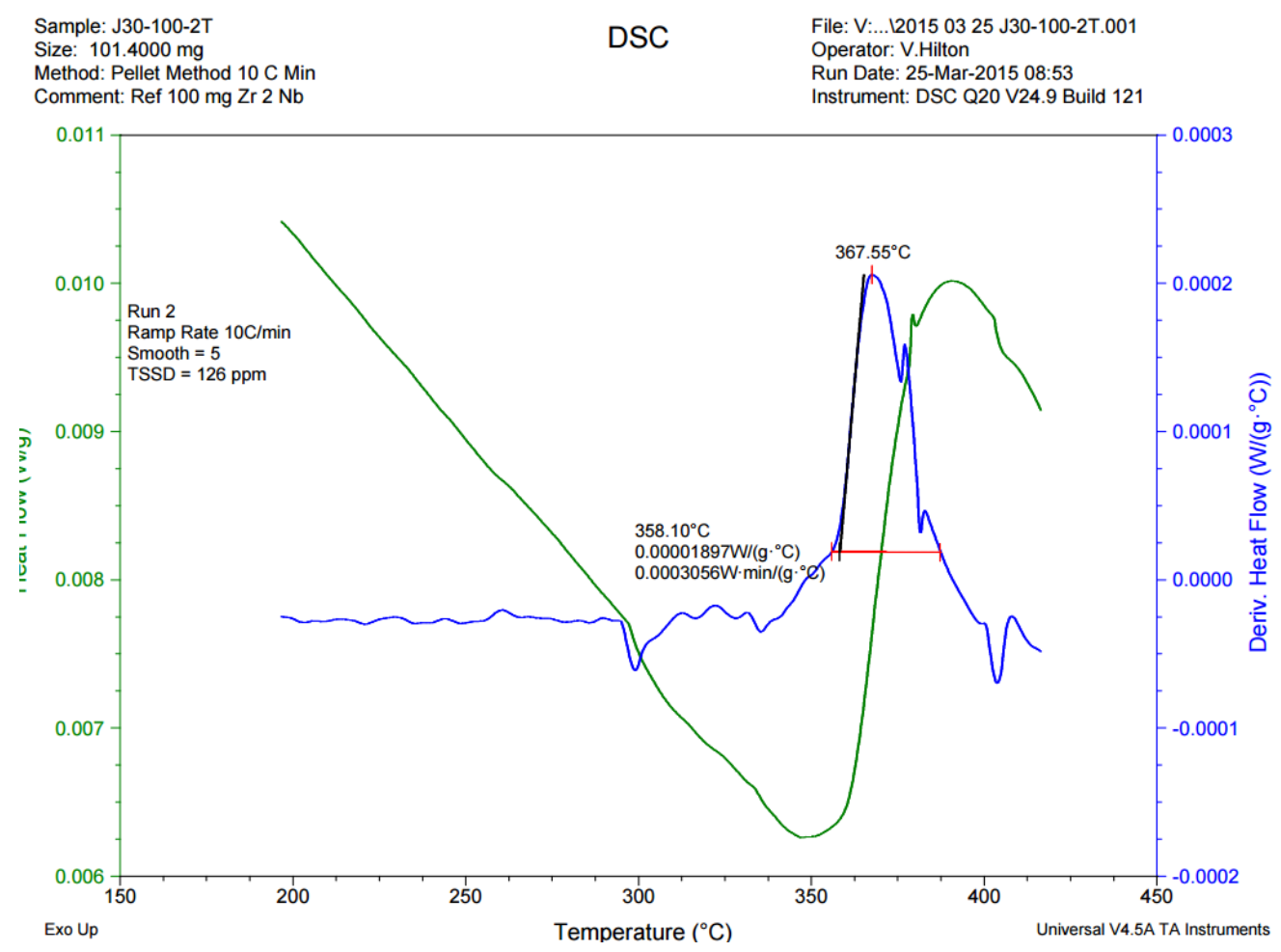

Figure 59: DSC heating curve \#2 for sample J30-100-2T

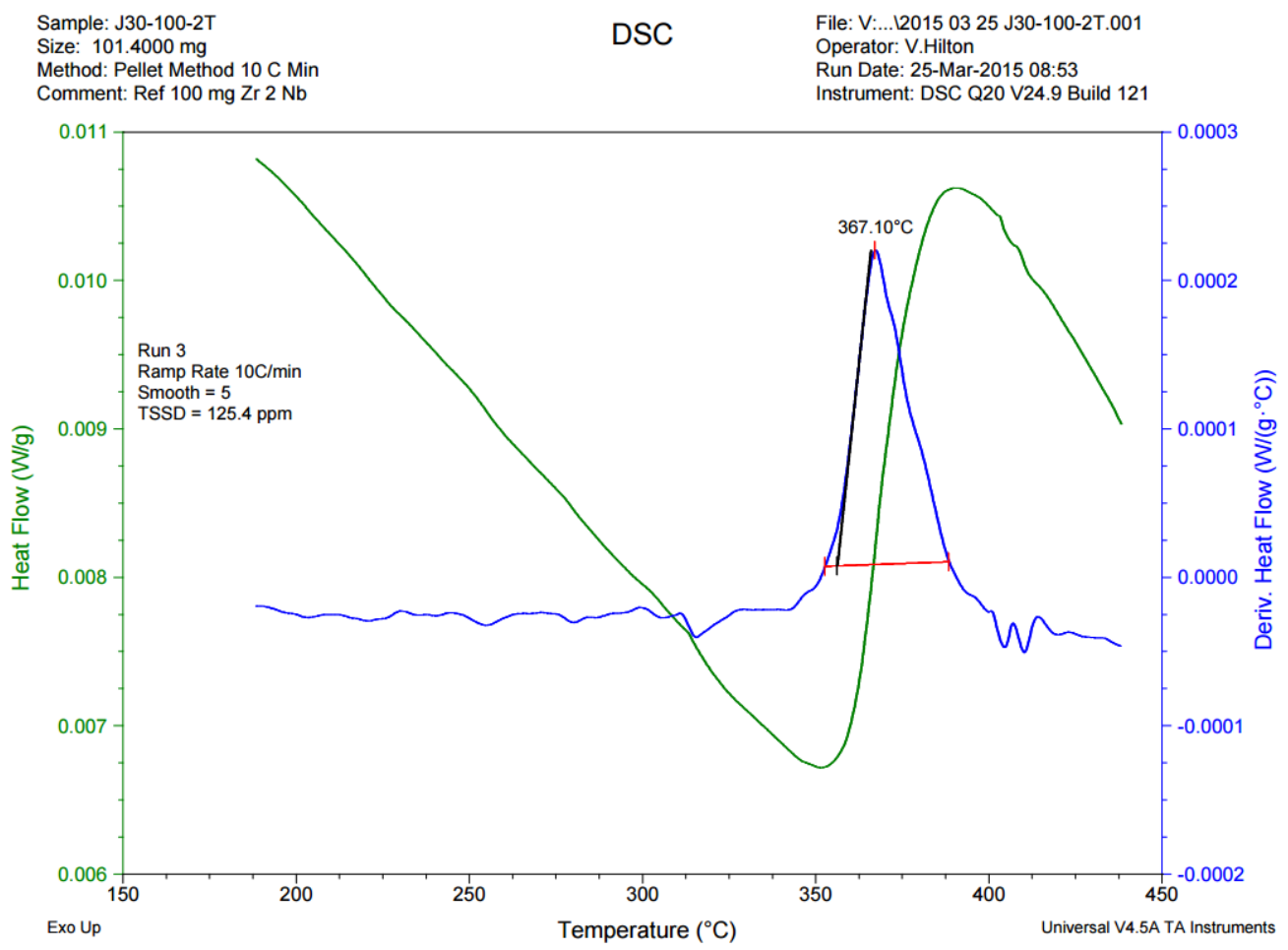

Figure 60: DSC heating curve \#3 for sample J30-100-2T 


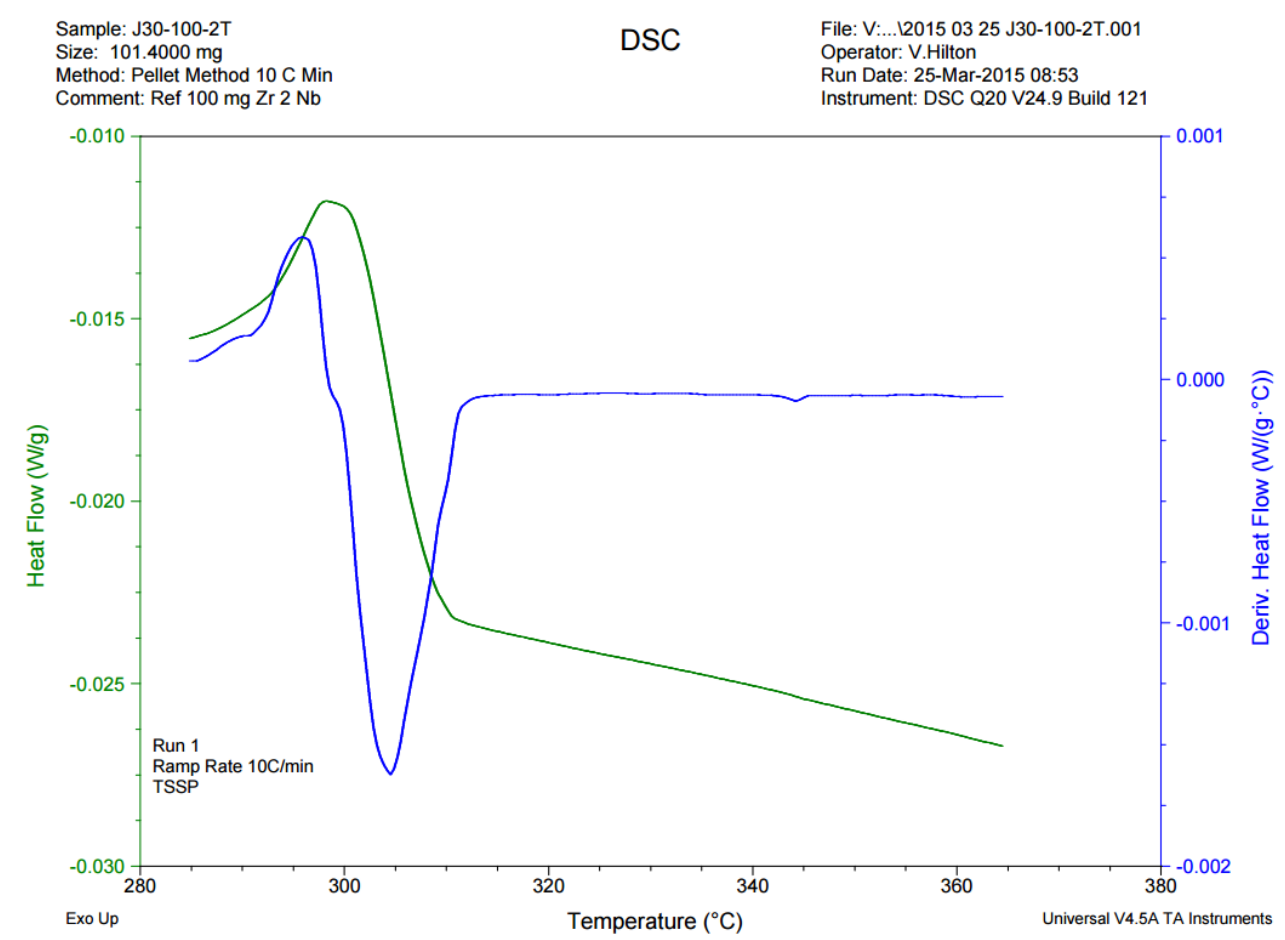

Figure 61: DSC cooling curve \#1 for sample J30-100-2T

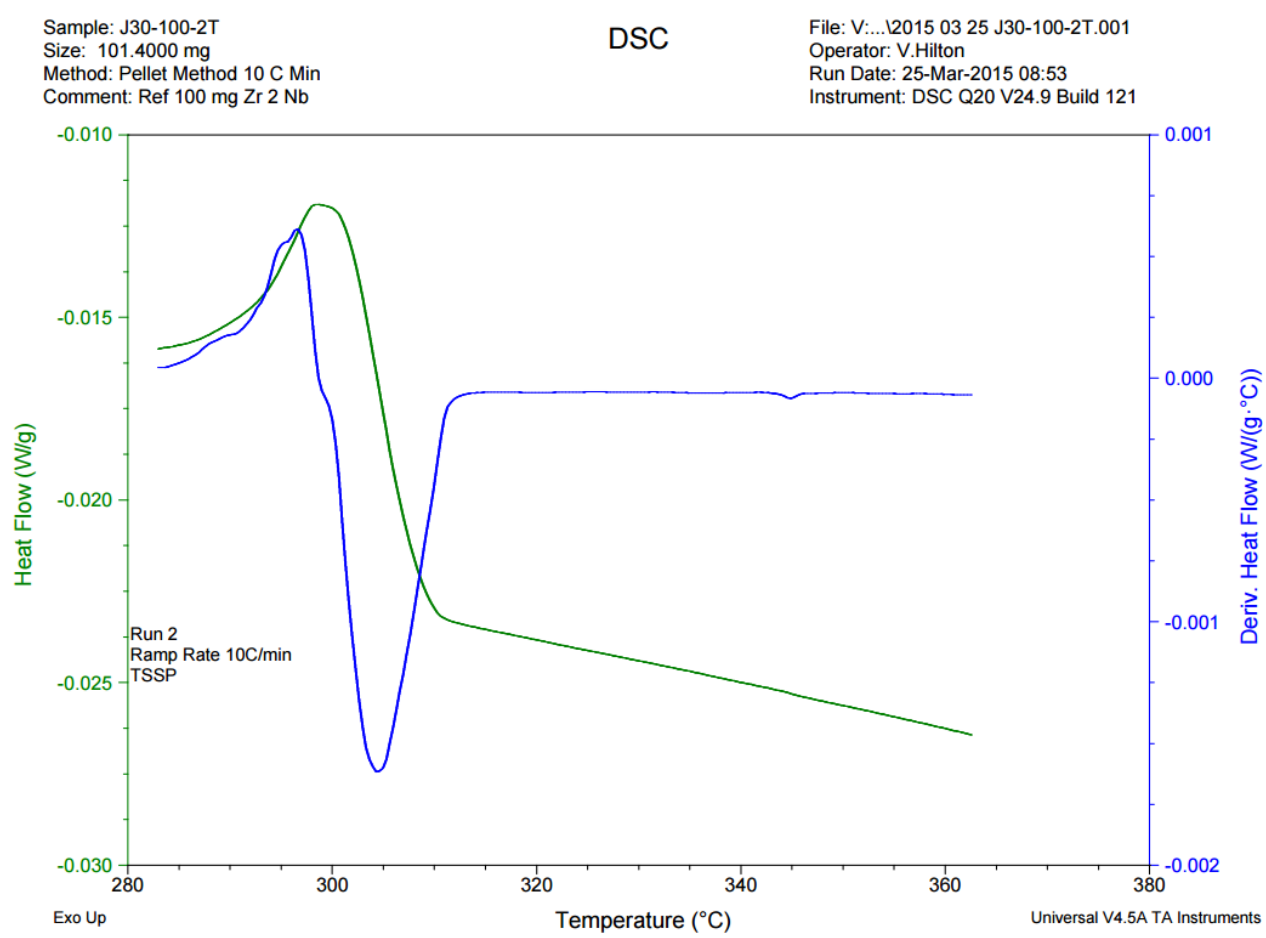

Figure 62: DSC cooling curve \#2 for sample J30-100-2T 


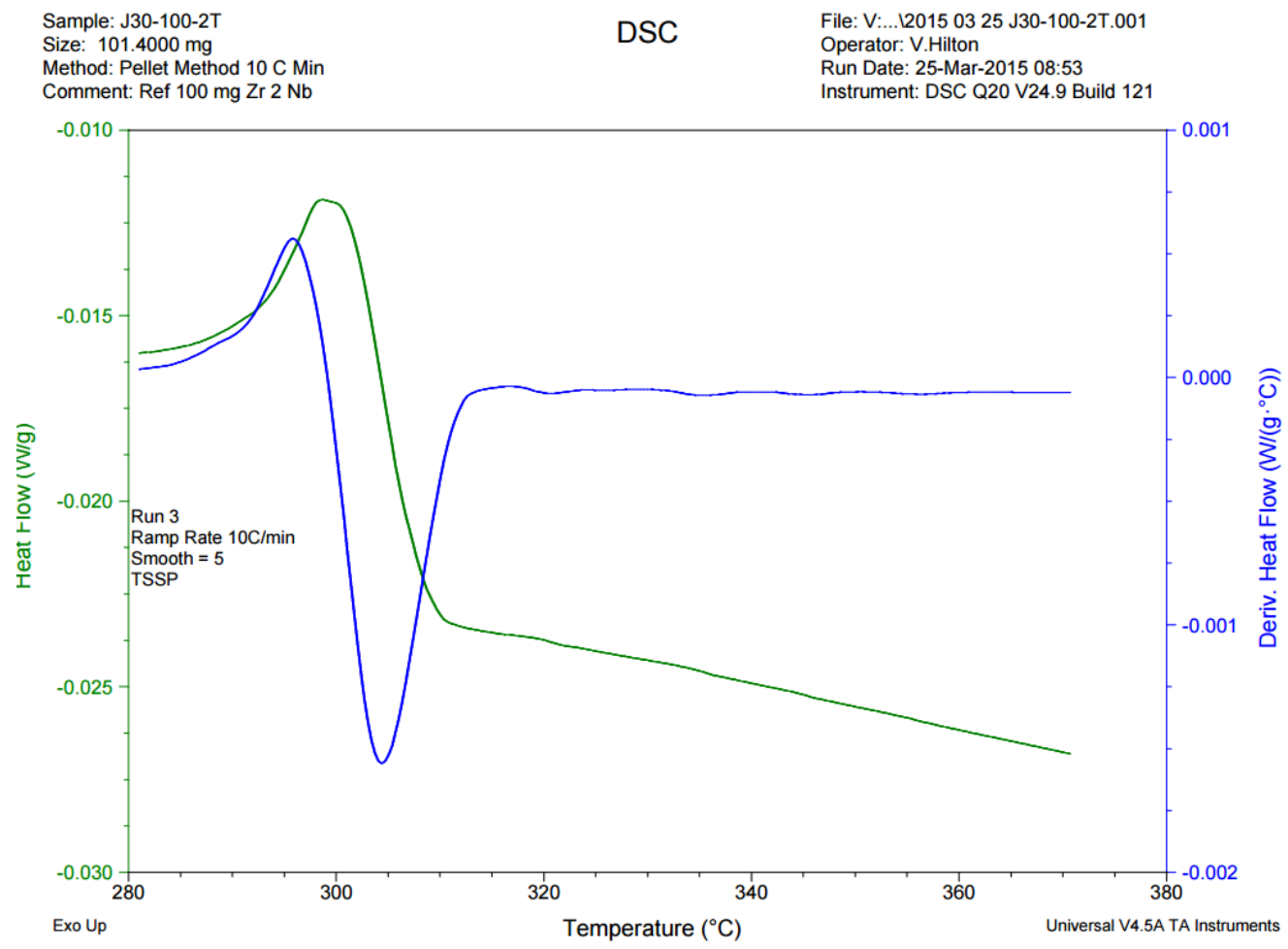

Figure 63: DSC cooling curve \#3 for sample J30-100-2T

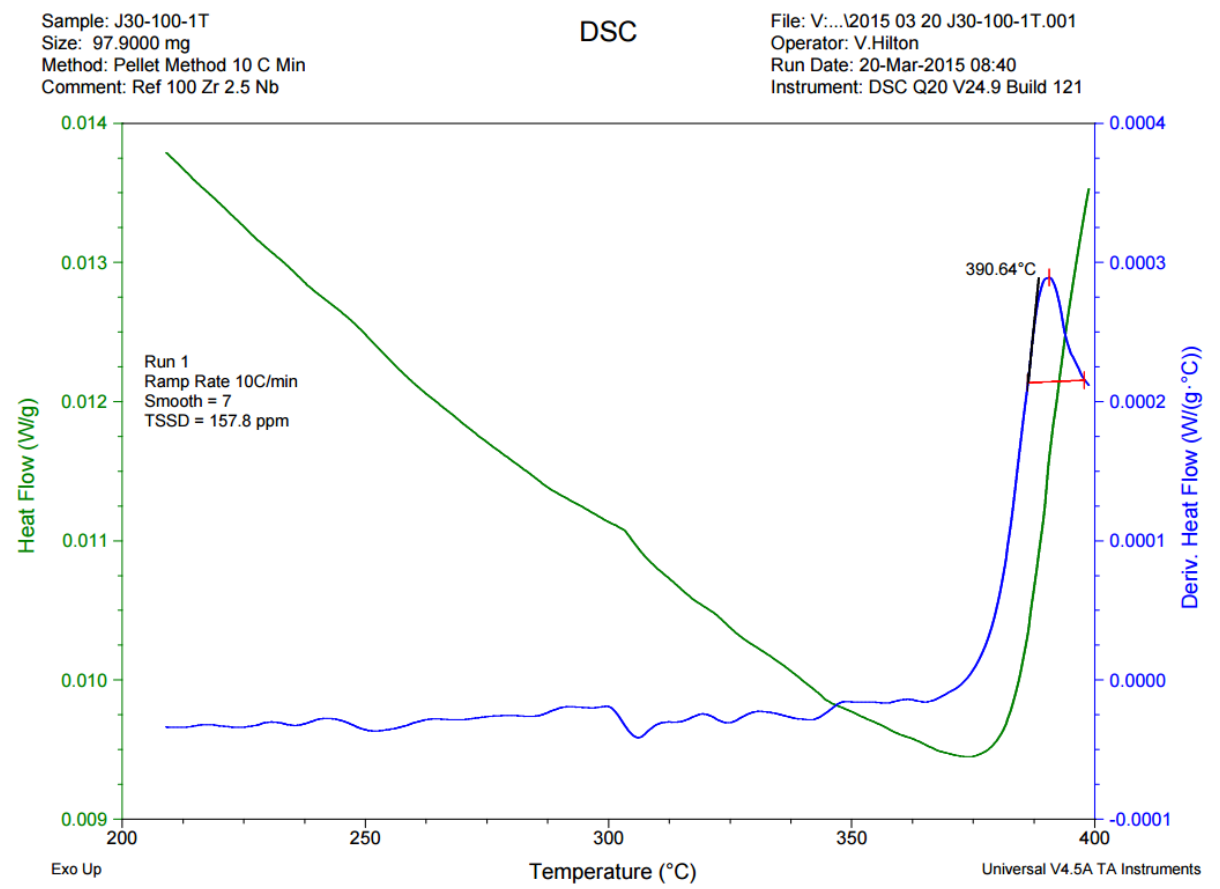

Figure 64: DSC heating curve \#1 for sample J30-100-1T 


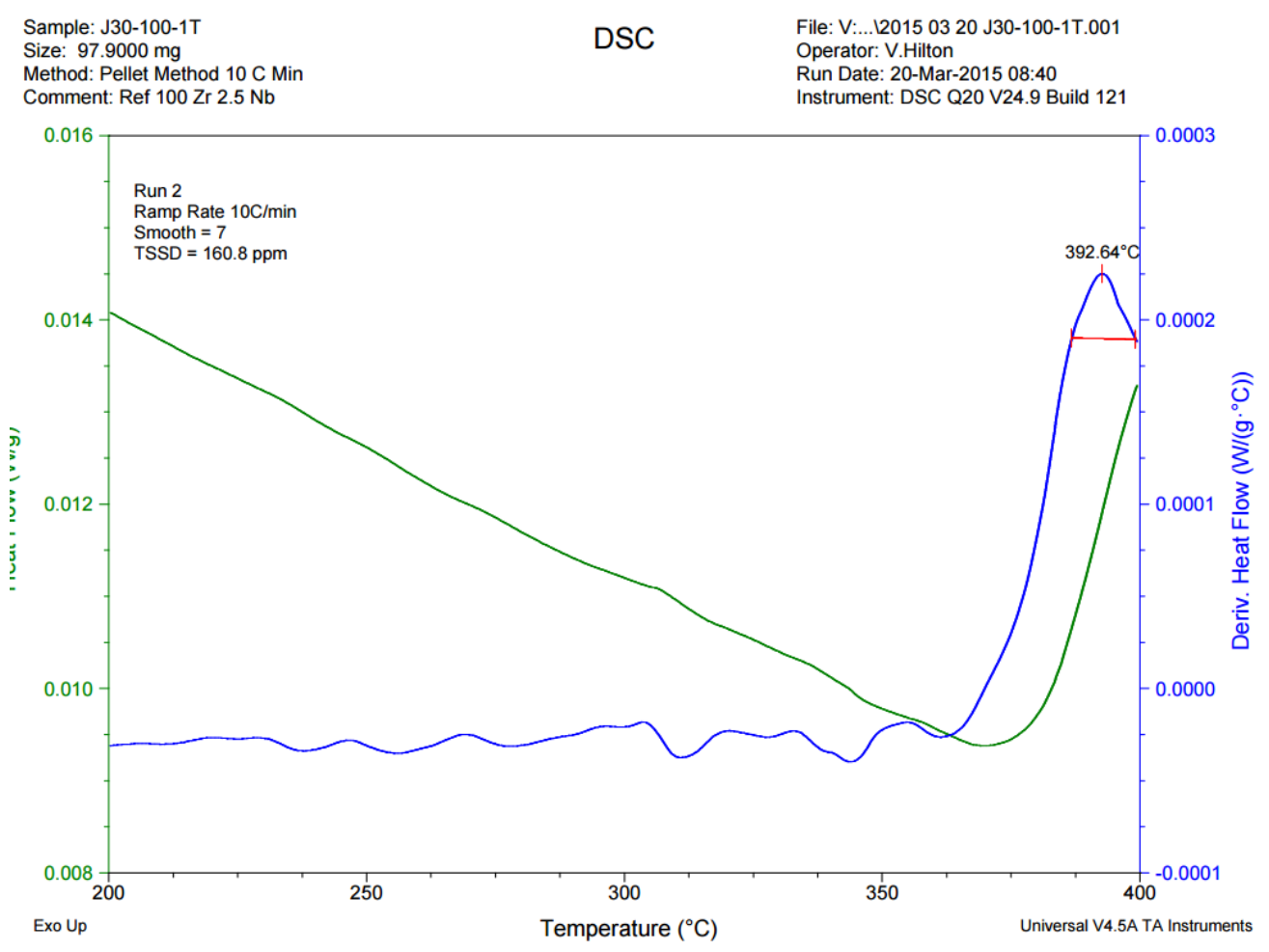

Figure 65: DSC heating curve \#2 for sample J30-100-1T

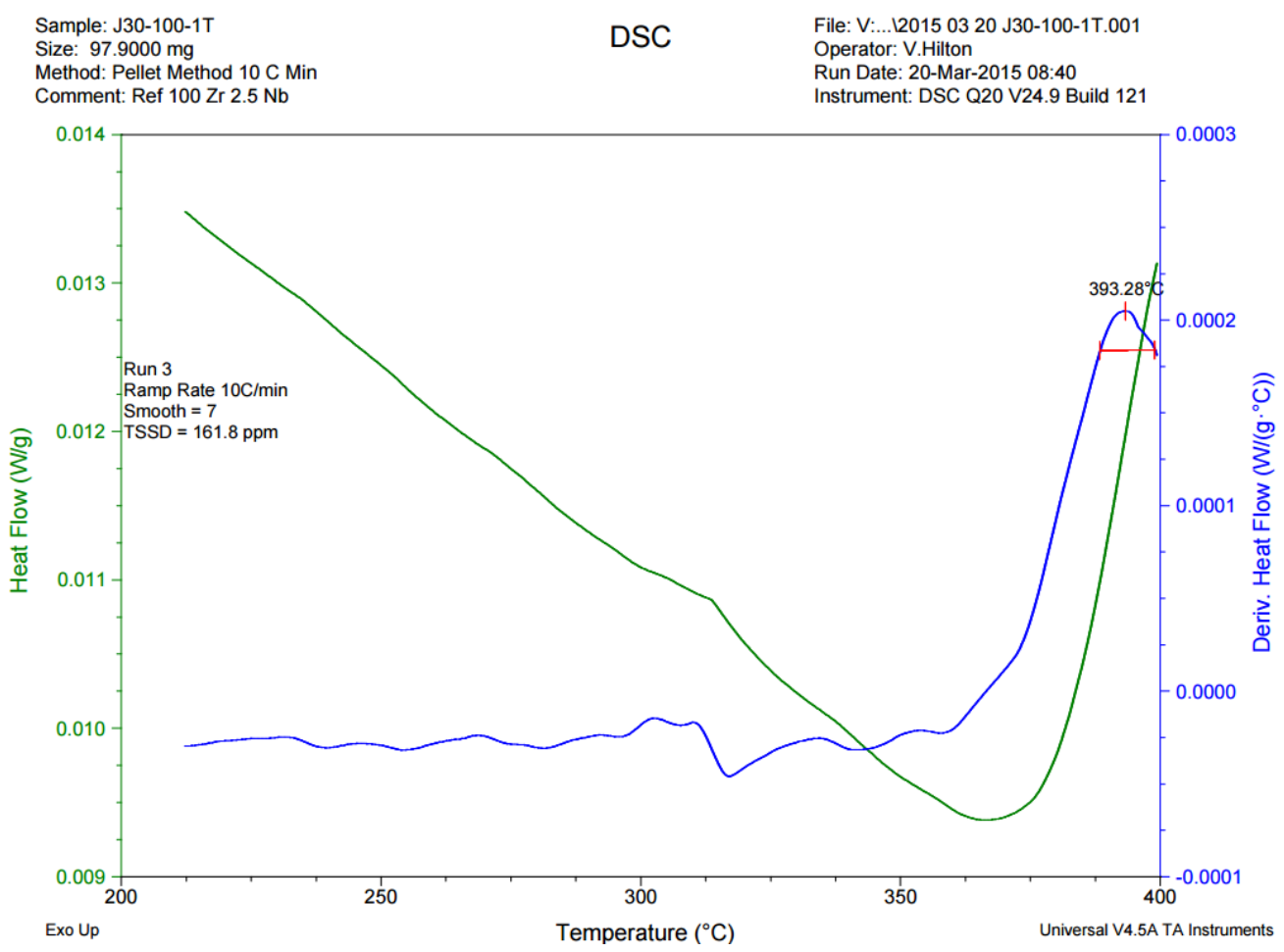

Figure 66: DSC heating curve \#3 for sample J30-100-1T 


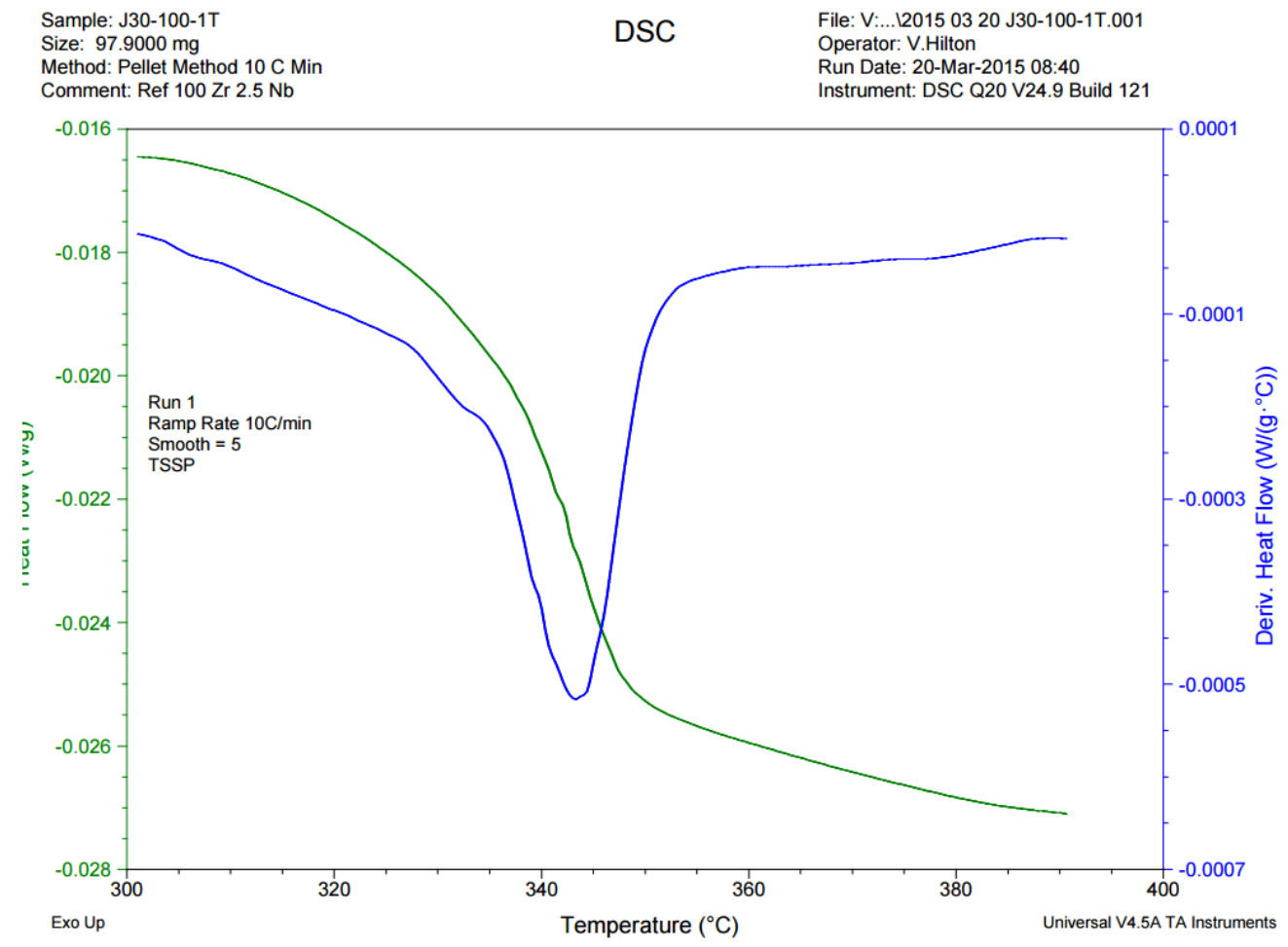

Figure 67: DSC cooling curve \#1 for sample J30-100-1T

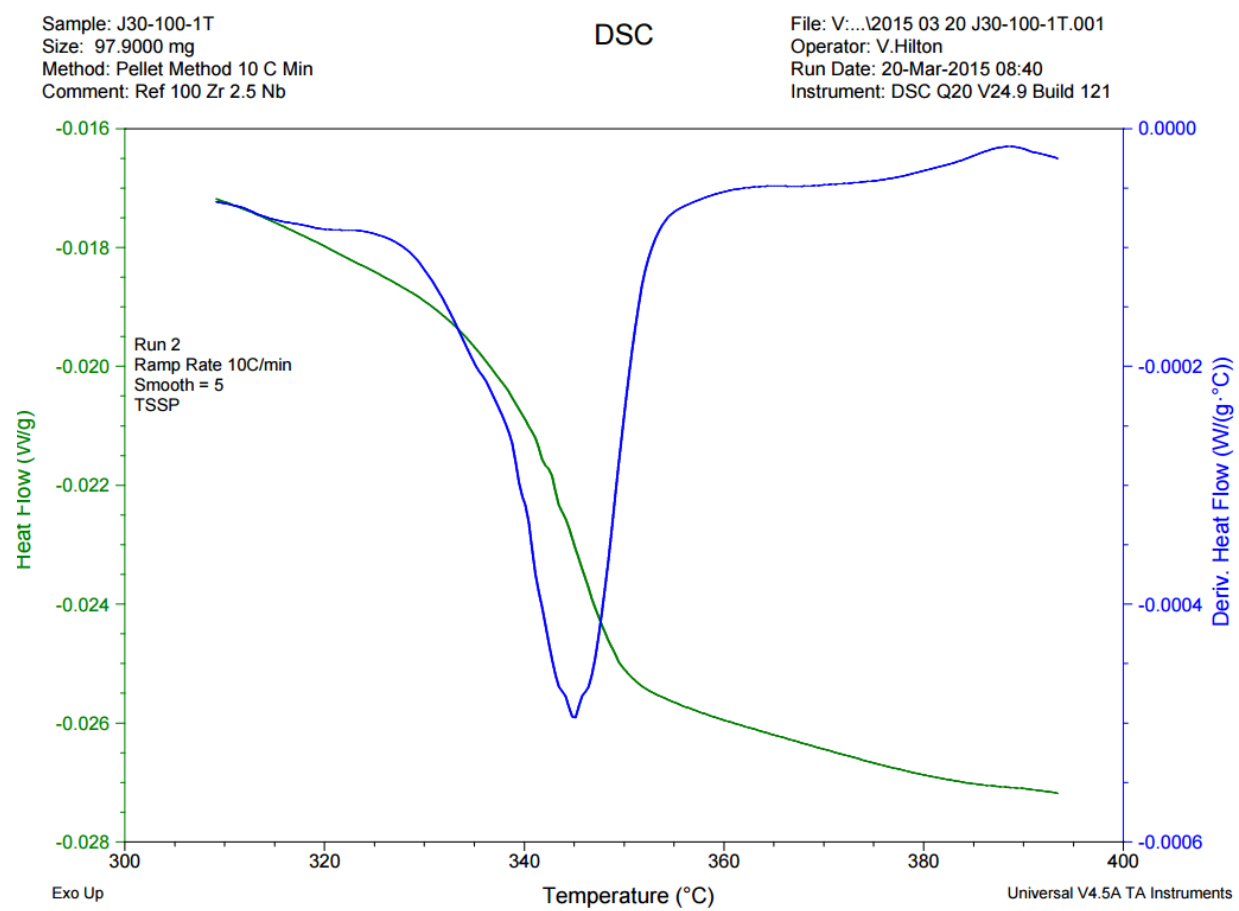

Figure 68: DSC cooling curve \#2 for sample J30-100-1T 


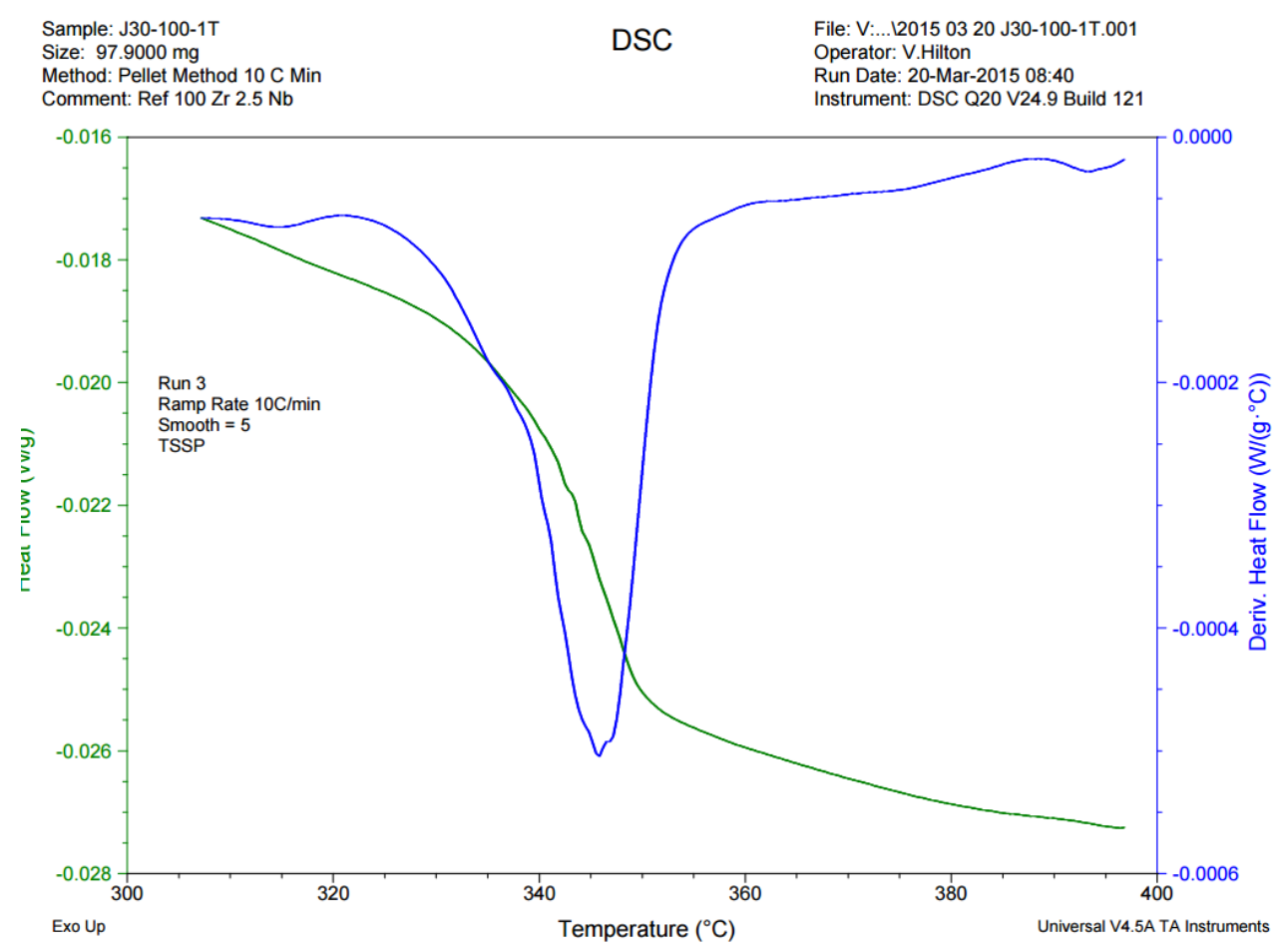

Figure 69: DSC cooling curve \#3 for sample J30-100-1T

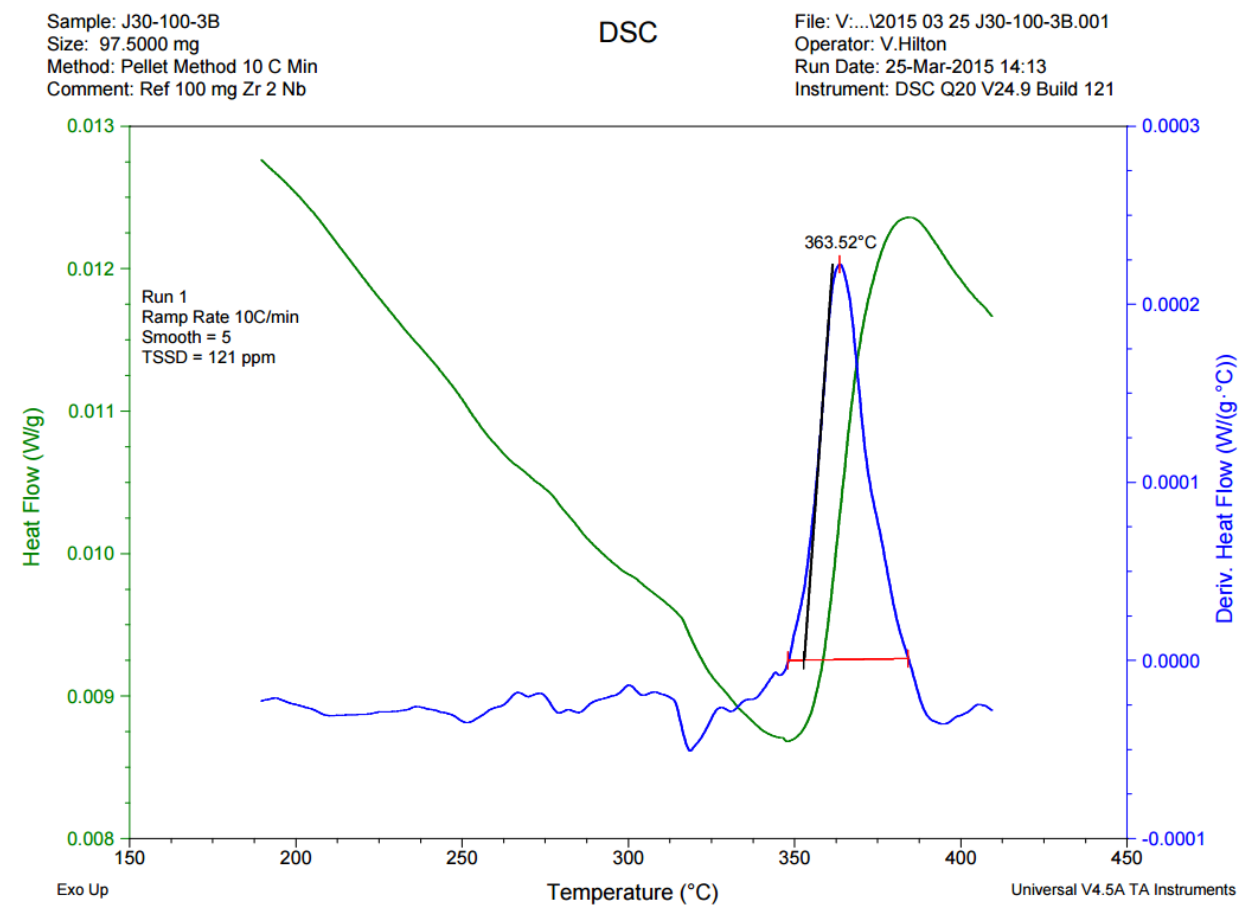

Figure 70: DSC heating curve \#1 for sample J30-100-3B 


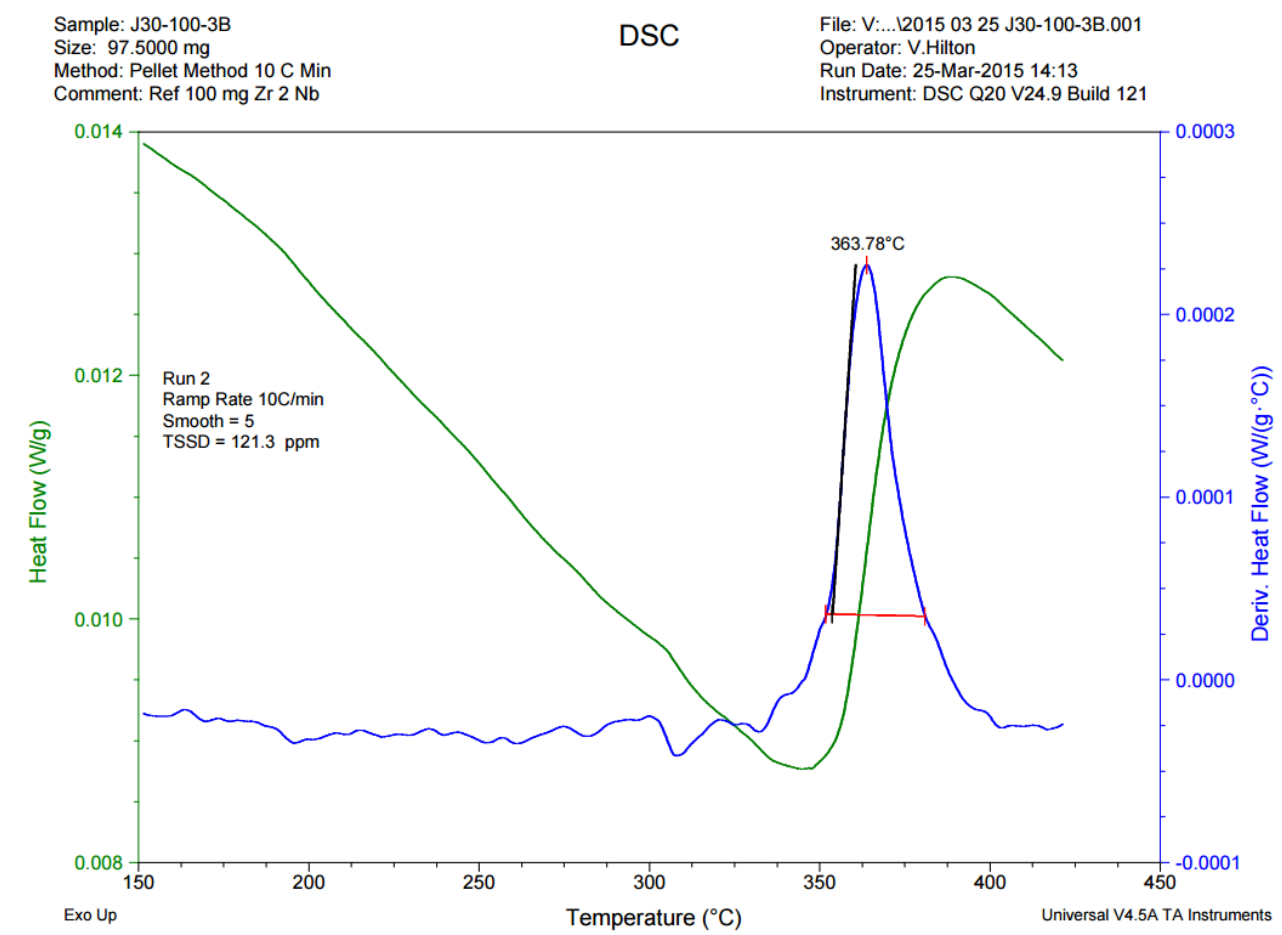

Figure 71: DSC heating curve \#2 for sample J30-100-3B

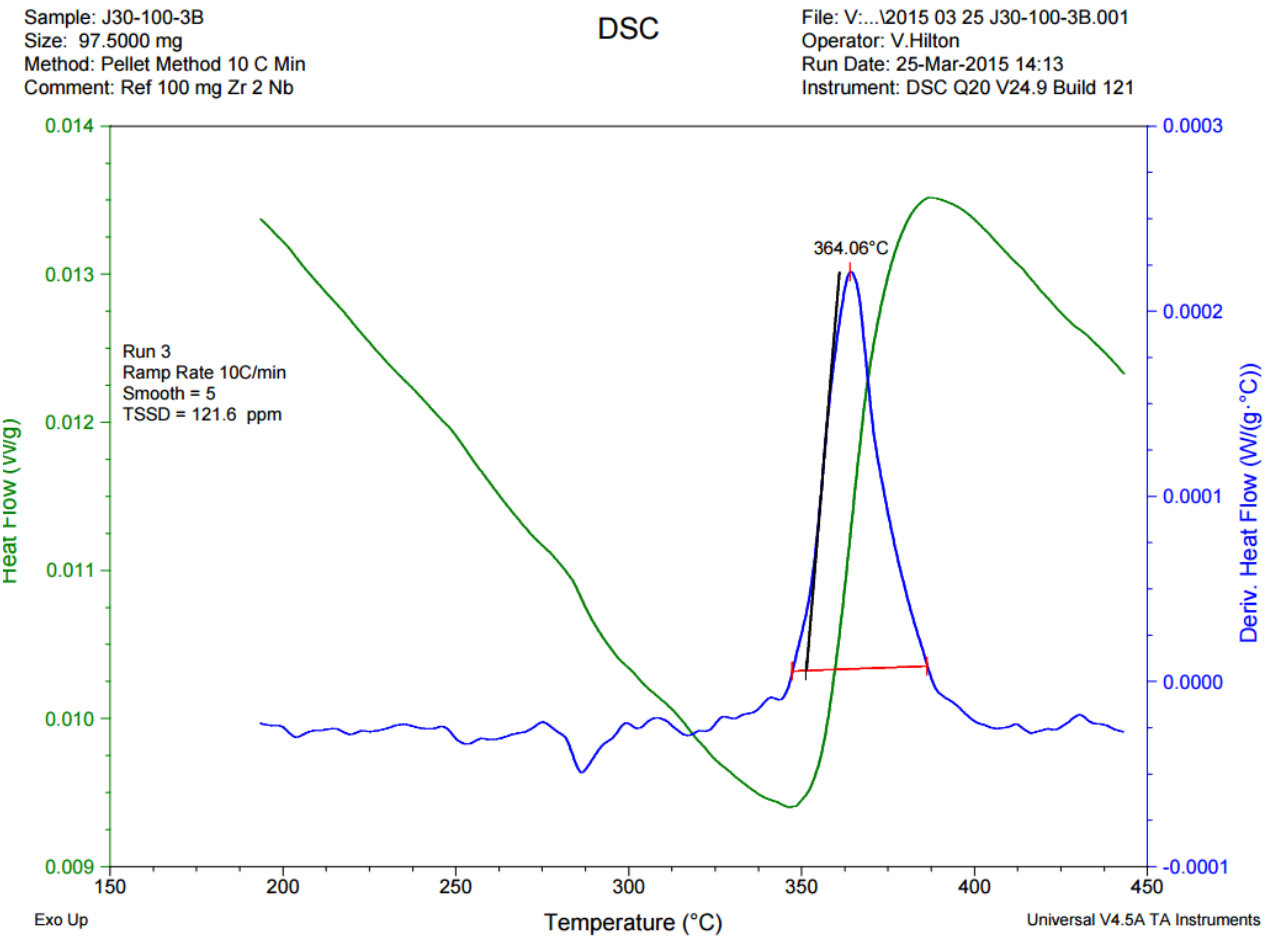

Figure 72: DSC heating curve \#3 for sample J30-100-3B 


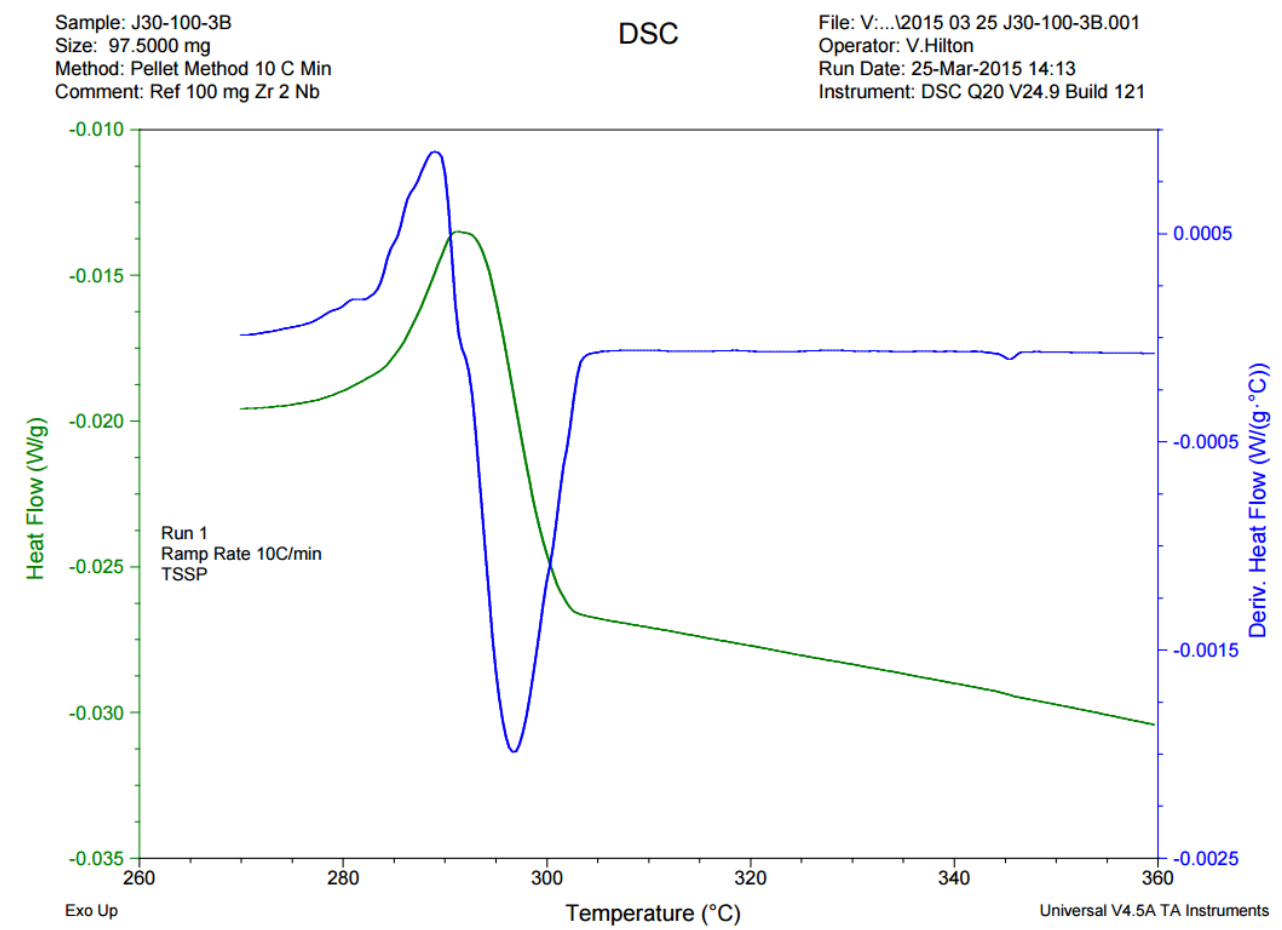

Figure 73: DSC cooling curve \#1 for sample J30-100-3B

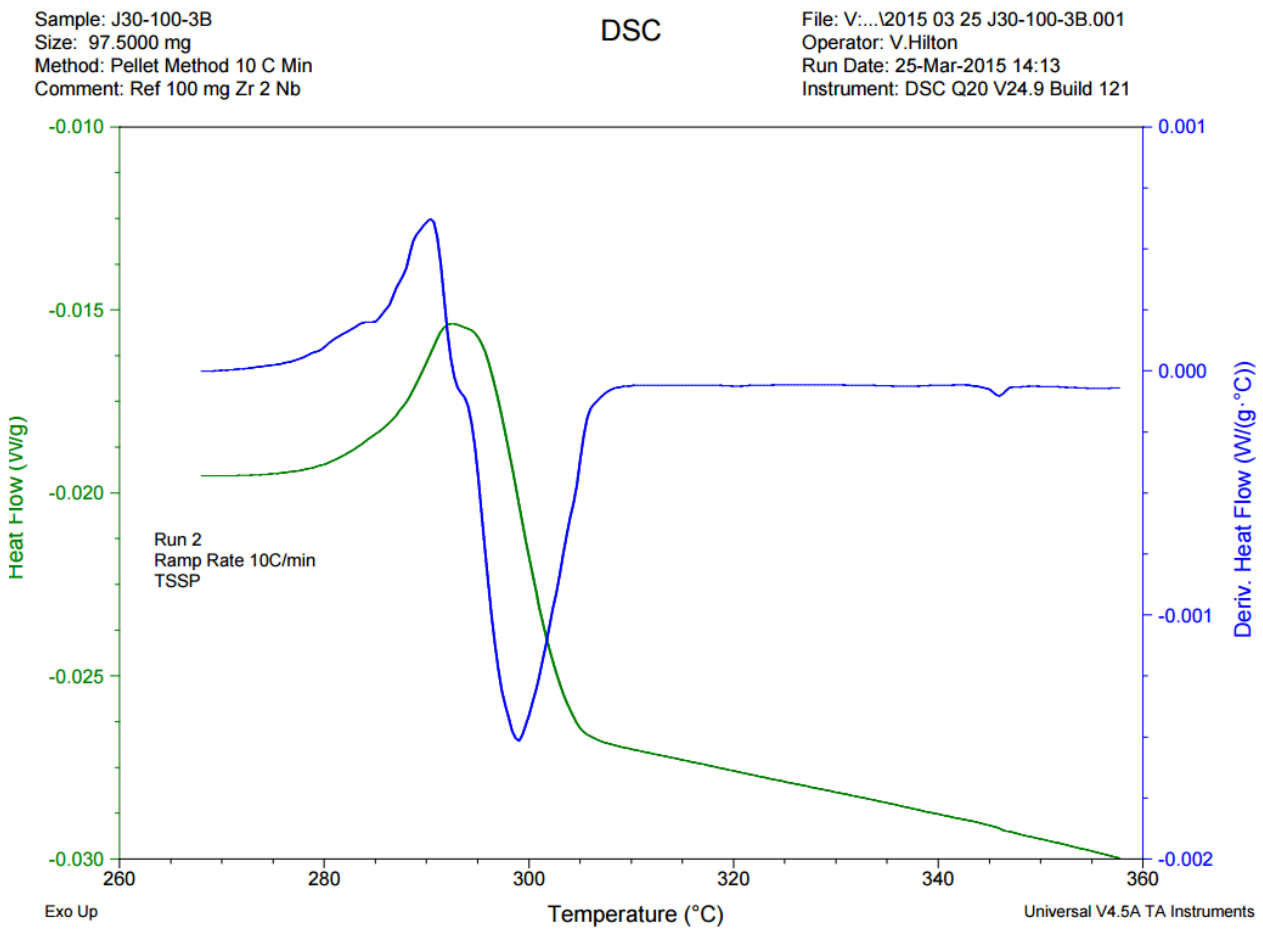

Figure 74: DSC cooling curve \#2 for sample J30-100-3B 


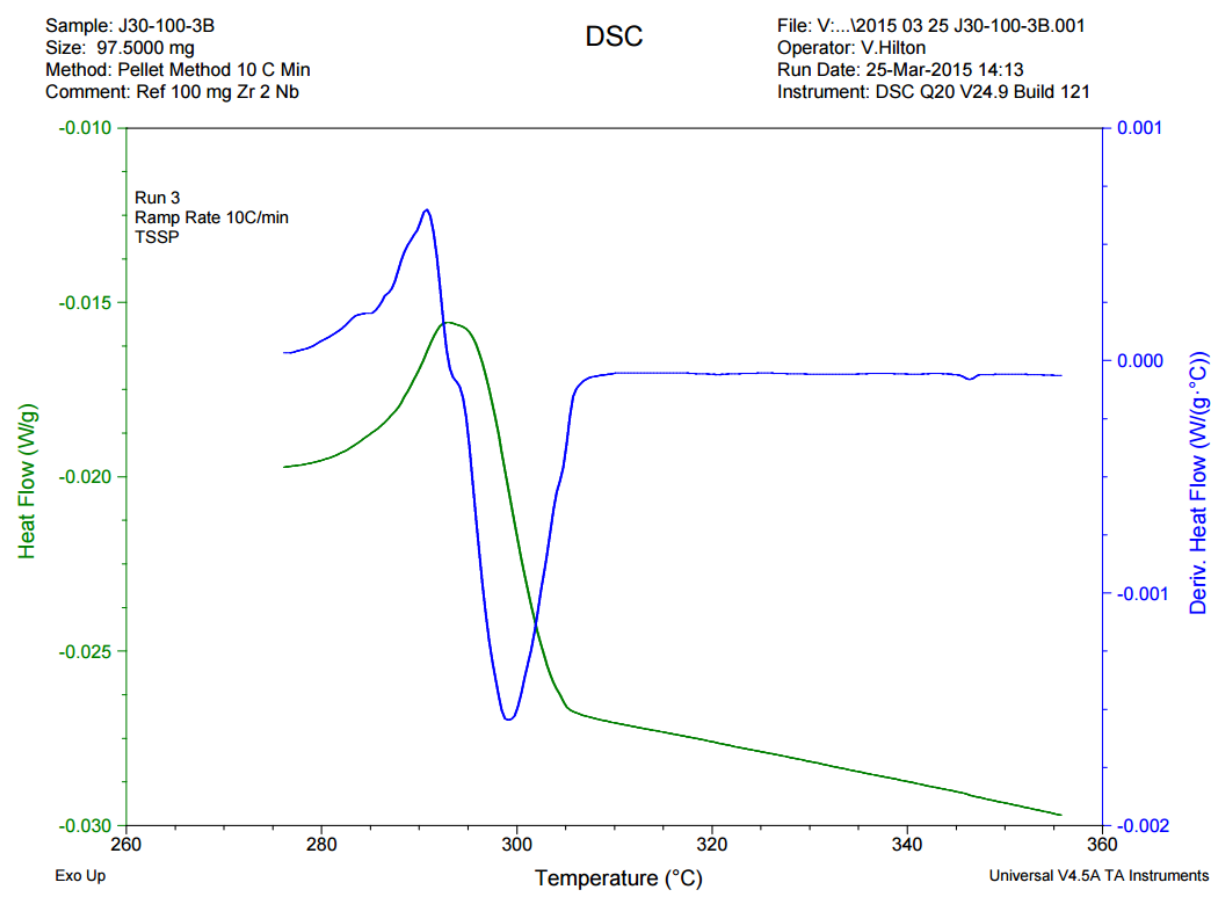

Figure 75: DSC cooling curve \#3 for sample J30-100-3B

S. Hanlon

AECL - OFFICIAL USE ONLY

TRAK \#148-127610-450-000

ACQA Request \#15139

ACQA Sample \#147826-147836

2015 Apr 07

Results

\begin{tabular}{|c|c|c|c|c|}
\hline ACQA\# & Sample Name & Mass (g) & Hydrogen (ppm) & Deuterium (ppm) \\
\hline 147826 & DFM Plate F FX-68 & 0.3728 & $62 \pm 3$ & $0.04 \pm 0.02$ \\
\hline 147827 & As-received DMF Plate Sample 1 & 0.2304 & $4 \pm 1$ & $<0.04$ \\
\hline 147828 & As-received DMF Plate Sample 2 & 0.1682 & $4 \pm 1$ & $<0.06$ \\
\hline 147829 & F12-006-1S & 0.3379 & $14 \pm 1$ & $<0.03$ \\
\hline 147830 & J29-150-4T & 0.3355 & $230 \pm 10$ & $0.09 \pm 0.04$ \\
\hline 147831 & F09-50-4T & 0.3118 & $72 \pm 4$ & $<0.03$ \\
\hline 147832 & J26-200-4T & 0.3297 & $200 \pm 10$ & $0.06 \pm 0.04$ \\
\hline 147833 & J26-200-5B & 0.3321 & $230 \pm 10$ & $0.09 \pm 0.04$ \\
\hline 147834 & J30-100-4T & 0.3333 & $168 \pm 9$ & $0.07 \pm 0.03$ \\
\hline 147835 & F08-20-4T & 0.3445 & $34 \pm 2$ & $<0.03$ \\
\hline 147836 & J30-100-5B & 0.3335 & $121 \pm 6$ & $<0.06$ \\
\hline
\end{tabular}

Figure 76: HVEMS data from CNL Chalk River for Sandwiched Hydride experiment 
Table 6: Zirconium Sandwiched Hydride Experimental Data ${ }^{12}$

\begin{tabular}{|c|c|c|c|c|c|c|}
\hline Sample & $\begin{array}{c}M \\
(\mathrm{mg})\end{array}$ & $\begin{array}{c}\text { Predicted } \\
\text { Concentration } \\
\text { (ppm) }\end{array}$ & $\begin{array}{c}\text { DSC } \\
\text { Measured } \\
\text { Concentration } \\
\text { (ppm) } \\
\end{array}$ & $\begin{array}{c}\text { HVEMS } \\
\text { Measured } \\
\text { Concentration } \\
(p p m)\end{array}$ & $\begin{array}{c}\text { DSC } \\
\text { Uncertainty } \\
\text { (ppm) }{ }^{13}\end{array}$ & $\begin{array}{l}\text { HVEMS } \\
\text { Uncertainty } \\
\text { (ppm) }^{14}\end{array}$ \\
\hline $\begin{array}{l}\text { F12- } \\
006-1 S\end{array}$ & 338.8 & 14 & 15 & 14 & 5 & 1 \\
\hline $\begin{array}{l}\text { J30- } \\
100-1 T\end{array}$ & 97.9 & 113 & 160 & N/A & 4 & N/A \\
\hline $\begin{array}{l}30- \\
100-2 T\end{array}$ & 101.4 & 113 & 126 & N/A & 4 & N/A \\
\hline $\begin{array}{l}\text { J30- } \\
100-3 B\end{array}$ & 95.4 & 113 & 121 & N/A & 4 & N/A \\
\hline $\begin{array}{l}\text { F08- } \\
20-4 \mathrm{~T}\end{array}$ & 346.0 & 35 & 33 & N/A & 5 & N/A \\
\hline $\begin{array}{l}\mathrm{J} 29- \\
150-4 \mathrm{~T}\end{array}$ & 338.6 & 162 & 190 & 230 & 10 & 10 \\
\hline $\begin{array}{l}\mathrm{J} 30- \\
100-4 \mathrm{~T}\end{array}$ & 335.6 & 113 & 147 & 168 & 10 & 9 \\
\hline $\begin{array}{l}\mathrm{J} 30- \\
100-5 \mathrm{~B}\end{array}$ & 336.5 & 113 & 116 & 121 & 5 & 6 \\
\hline $\begin{array}{l}\text { F09- } \\
50-4 \mathrm{~T}\end{array}$ & 315.2 & 66 & 65 & 72 & 4 & 4 \\
\hline $\begin{array}{l}\text { J26- } \\
200-4 T\end{array}$ & 331.4 & 207 & 165 & 200 & 10 & 10 \\
\hline $\begin{array}{l}J 26- \\
200-5 B\end{array}$ & 333.7 & 207 & N/A & 230 & N/A & 10 \\
\hline
\end{tabular}

${ }^{12} \mathrm{M}$ is the mass of the specimen punch in $\mathrm{mg}$. Predicted concentration is calculated using Equation 4.18. DSC measured concentration, and HVEMS measured concentration were determined at CNL Chalk River using the DSC or HVEMS techniques, respectively.

${ }^{13}$ DSC uncertainty was calculated from the standard error of concentrations determined from each heating trial, and t-table values corresponding to the $95 \%$ confidence interval.

${ }^{14}$ Uncertainties as reported by CNL Chalk River in Figure 76. 


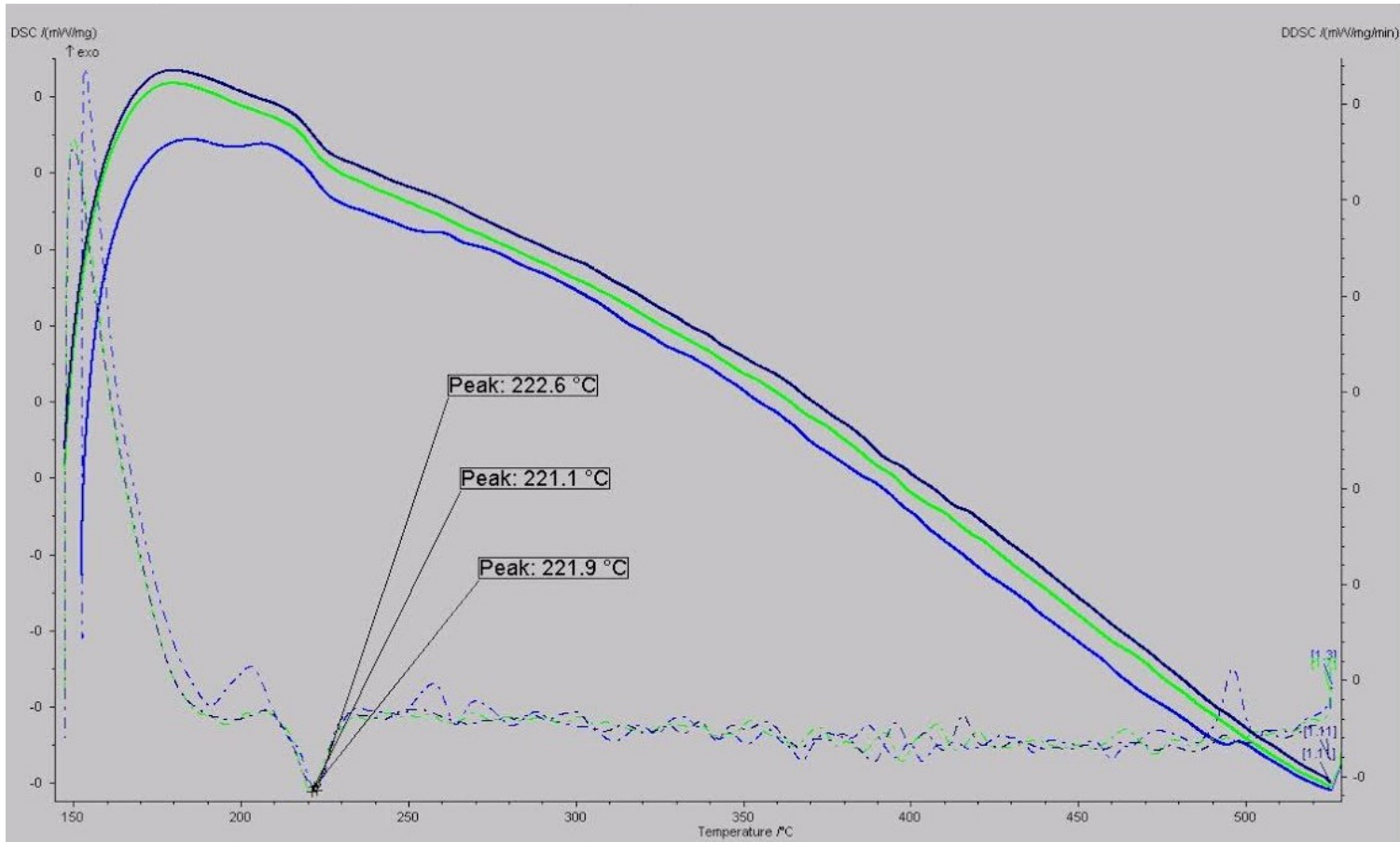

Figure 77: Heating run of a sheet of zirconium with no hydride powder. The TSSD maximum slope correspondes to $20 \mathrm{ppm}$. 


\section{D.2 Data for Copper-Shell Mechanical Hydrogen Ingress Experiment ${ }^{15}$}

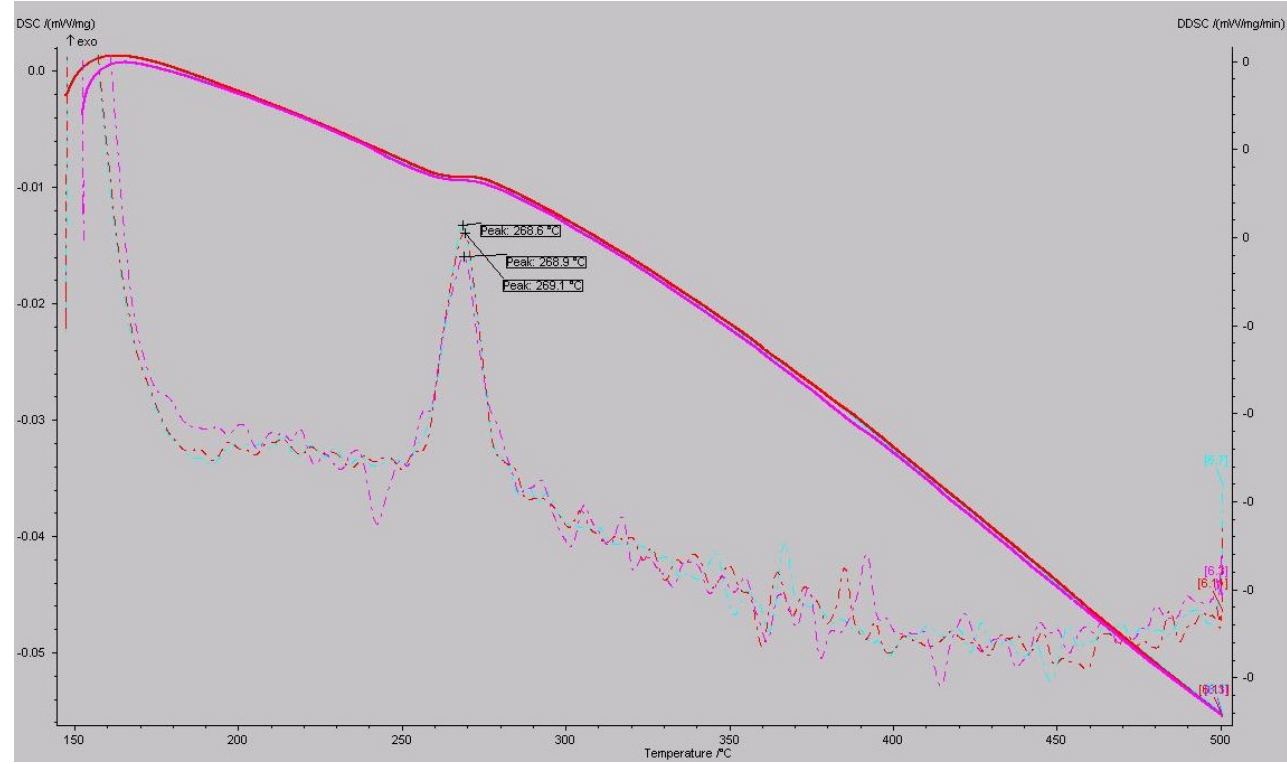

Figure 78: DSC heating curve for sample $\mathrm{Cu}-50$

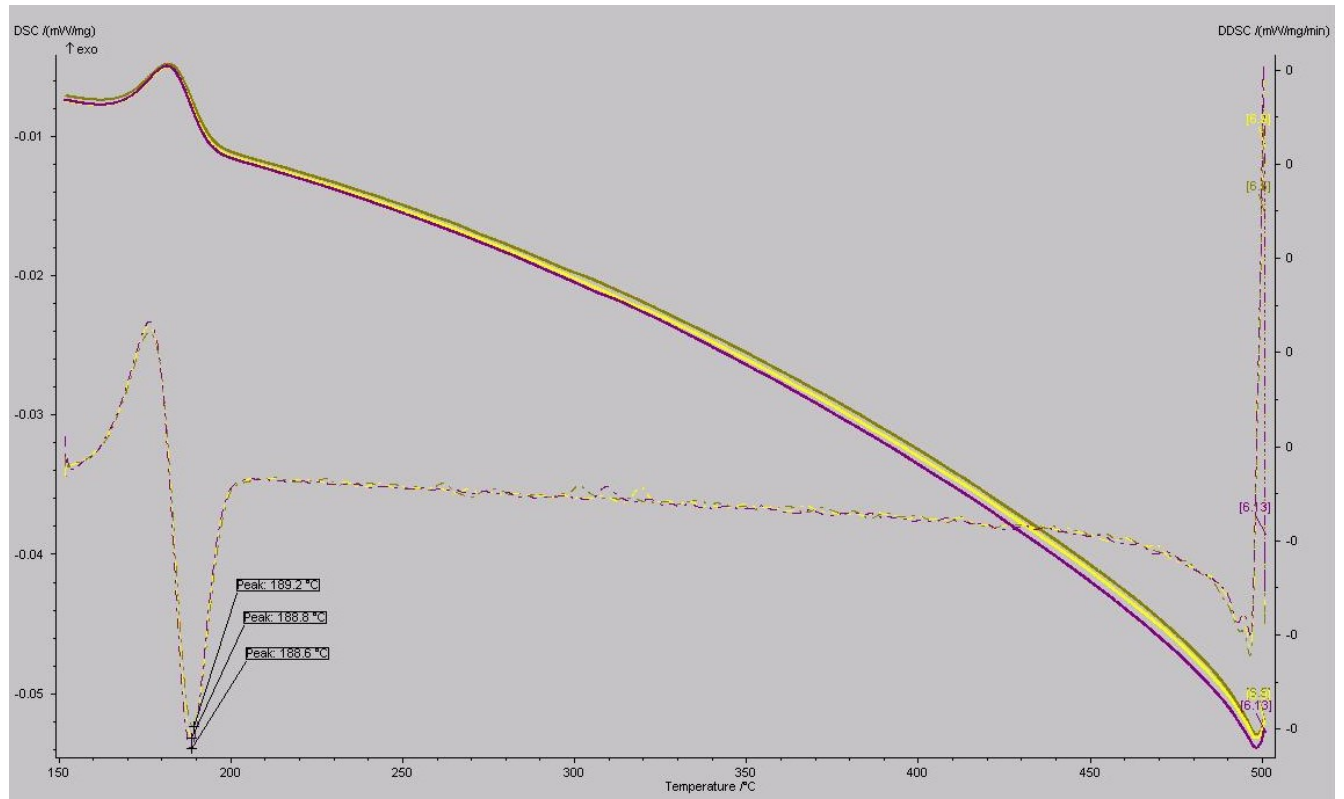

Figure 79: DSC cooling curve for sample $\mathrm{Cu}-50$

${ }^{15}$ Includes data from saturation experiment, and MH-DSC experiment, as these data were done using the CuSMH technique 


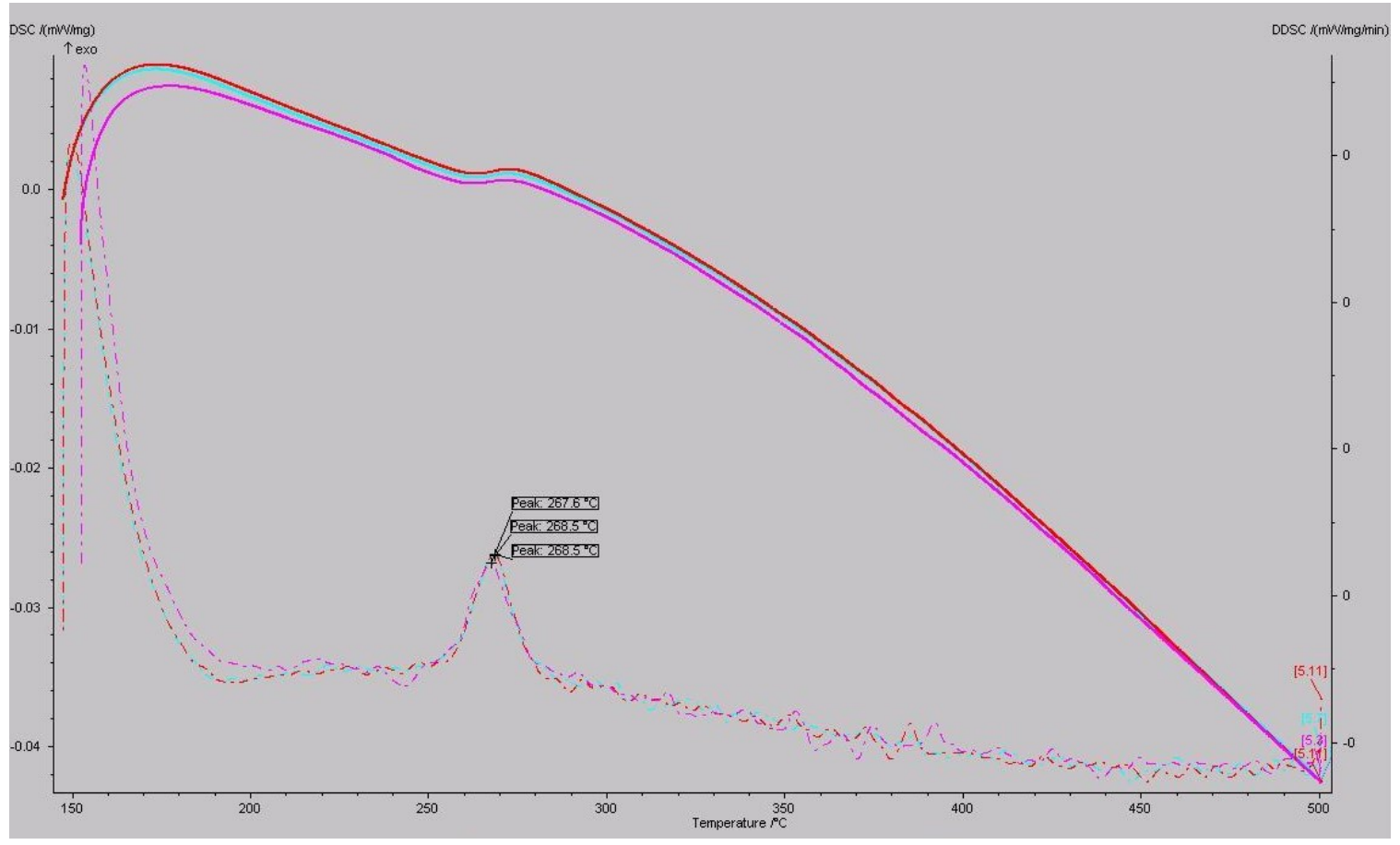

Figure 80: DSC heating curve for sample $\mathrm{Cu}-100$

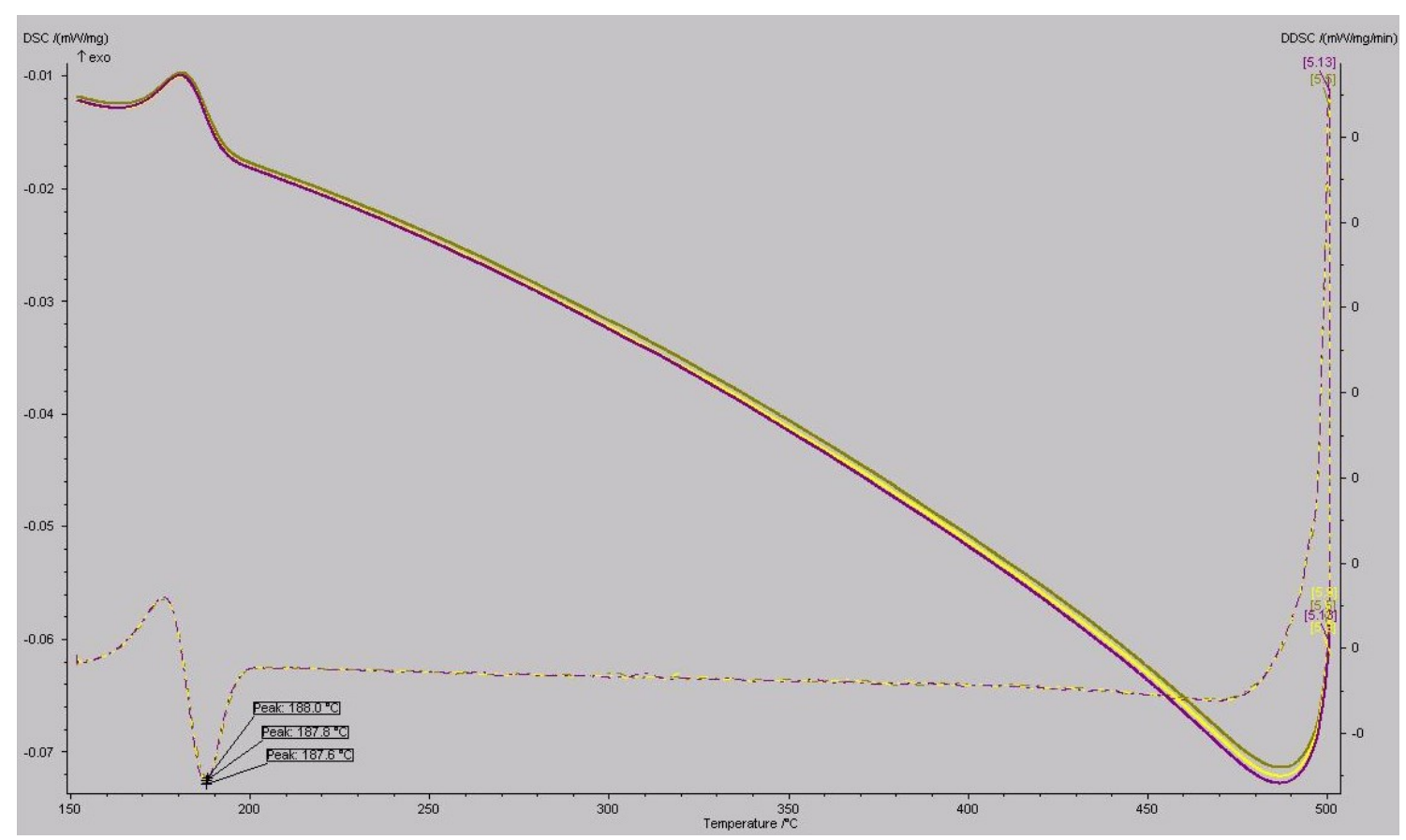

Figure 81: DSC cooling curve for sample Cu-100 


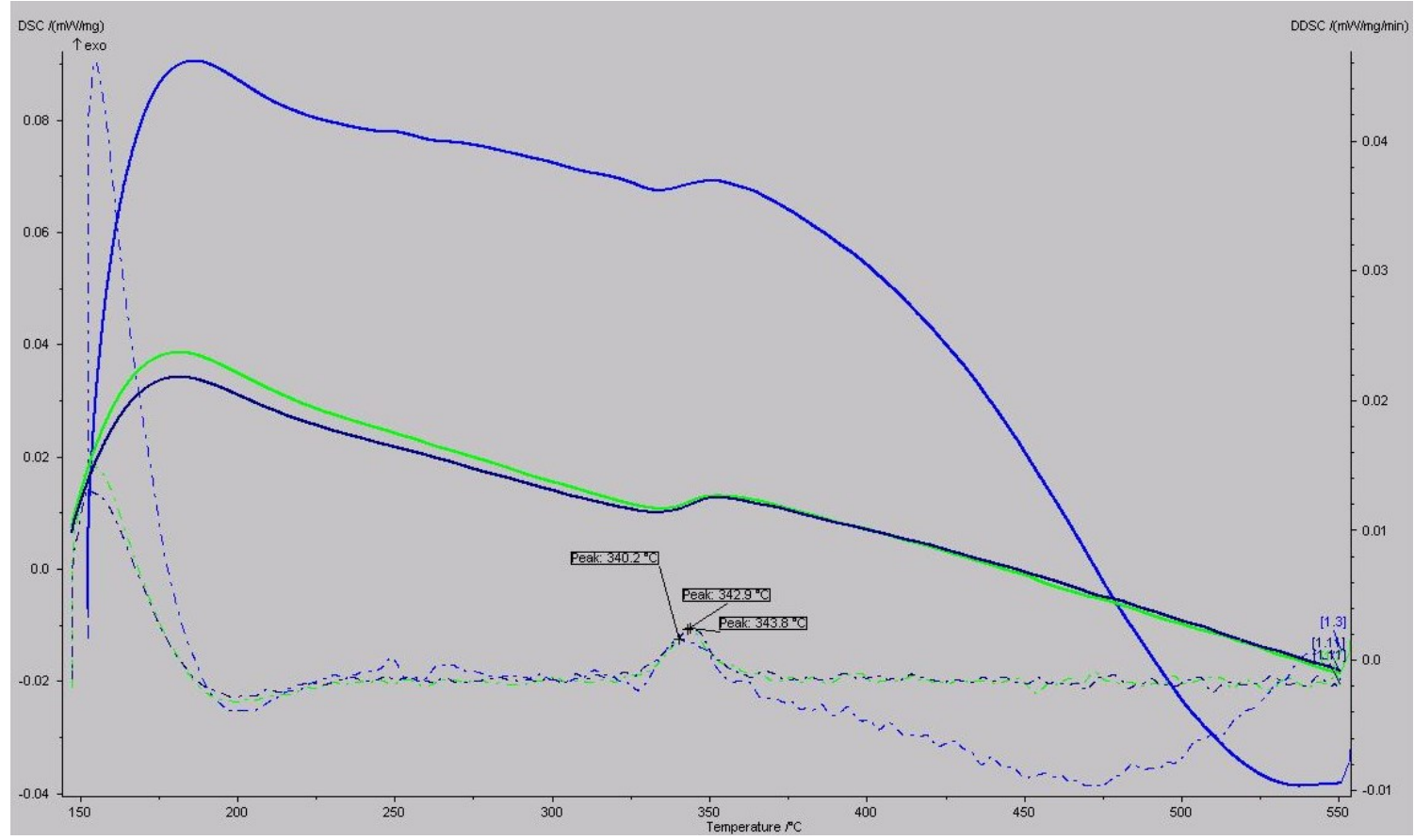

Figure 82: DSC heating curve from sample Cu-LT

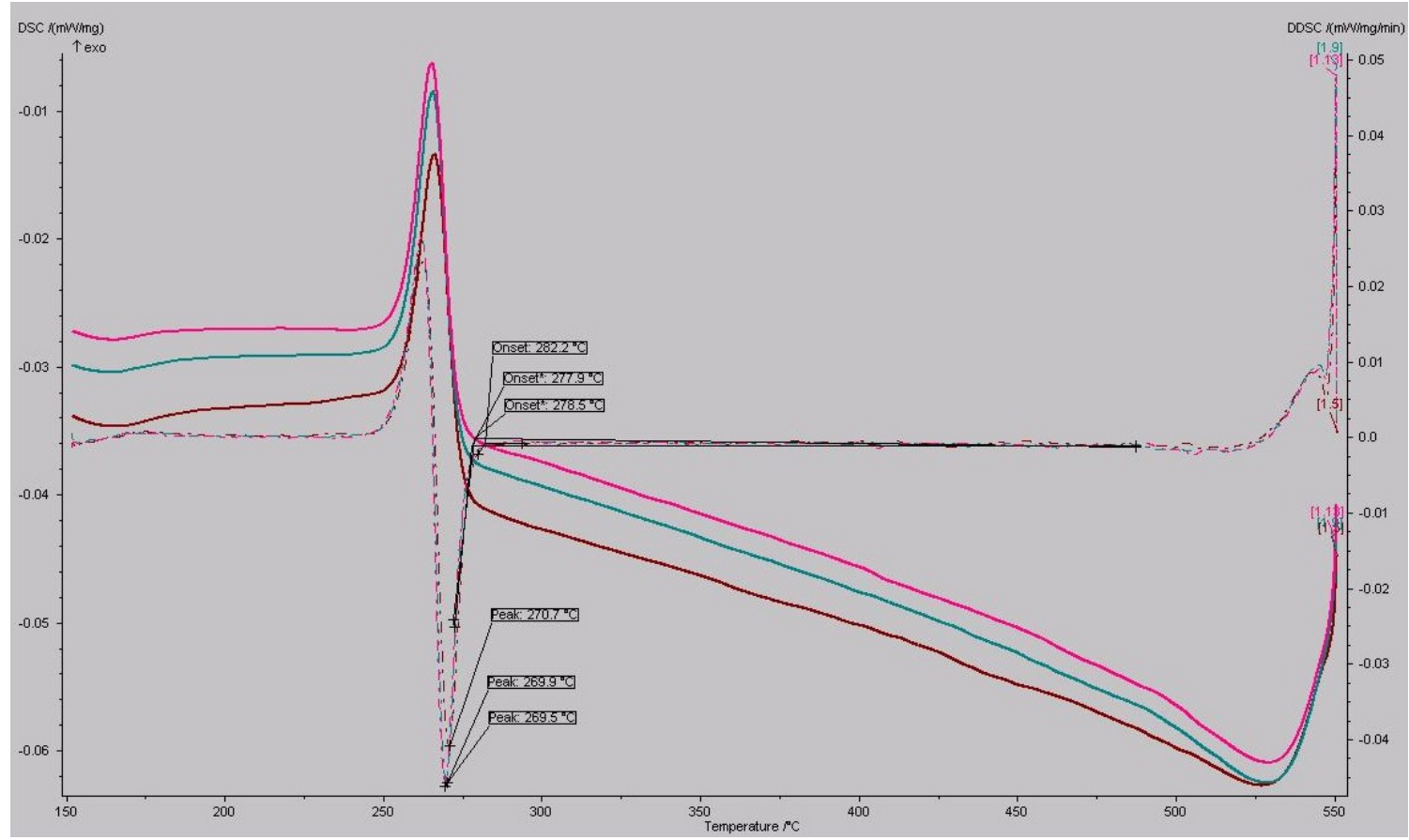

Figure 83: DSC cooling curve for sample Cu-LT 


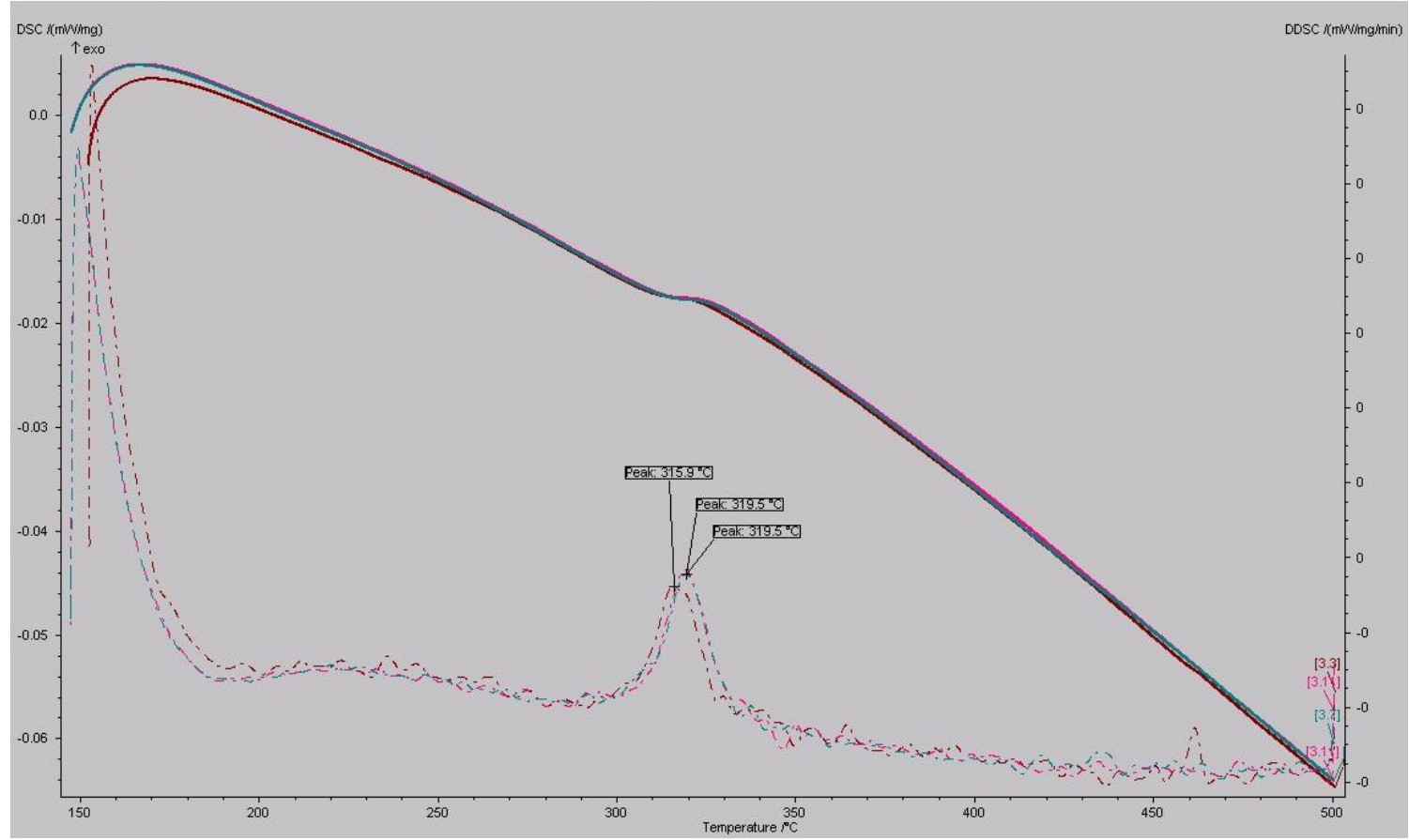

Figure 84: DSC heating curve for sample MH-DSC-1

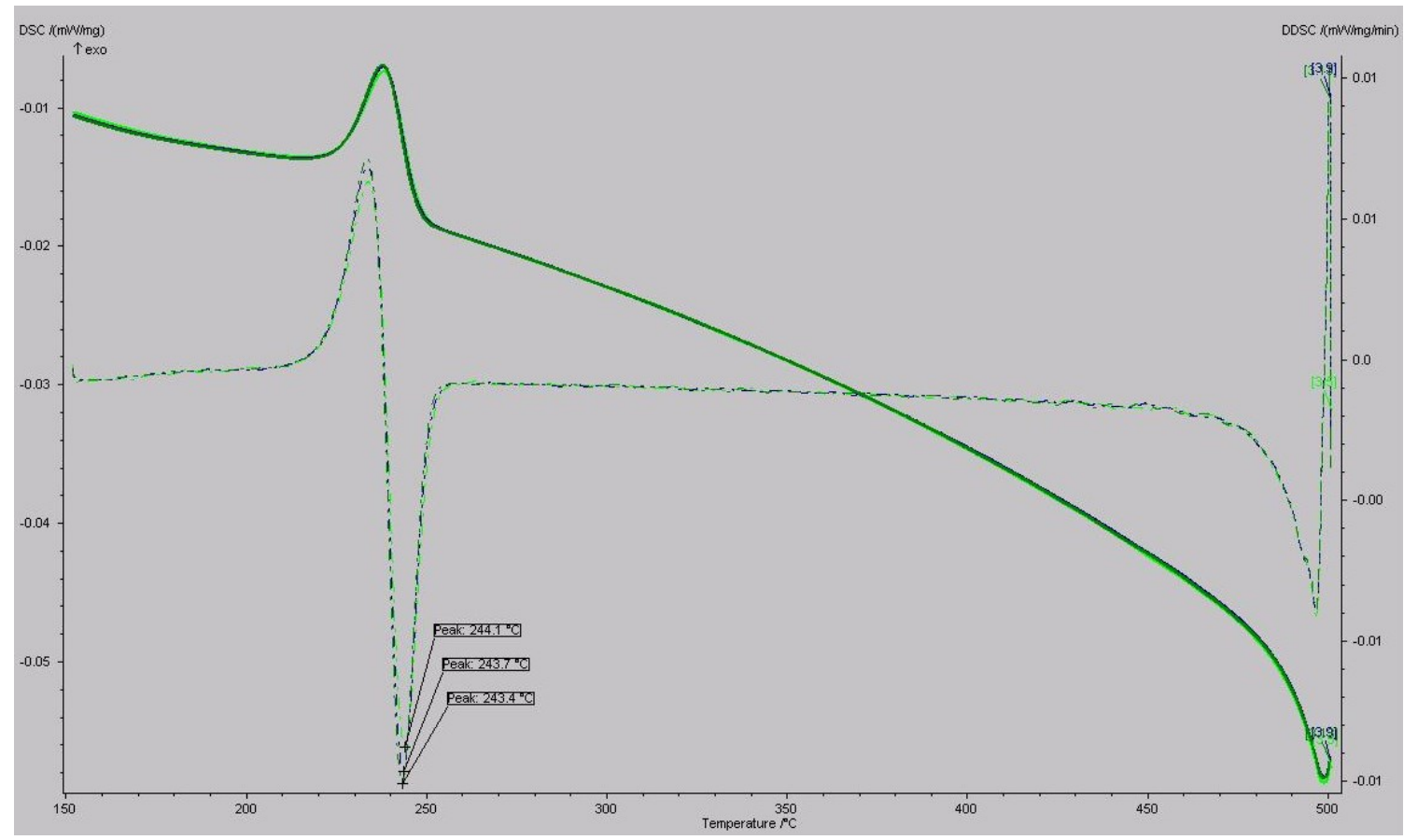

Figure 85: DSC cooling curve for sample MH-DSC-2 


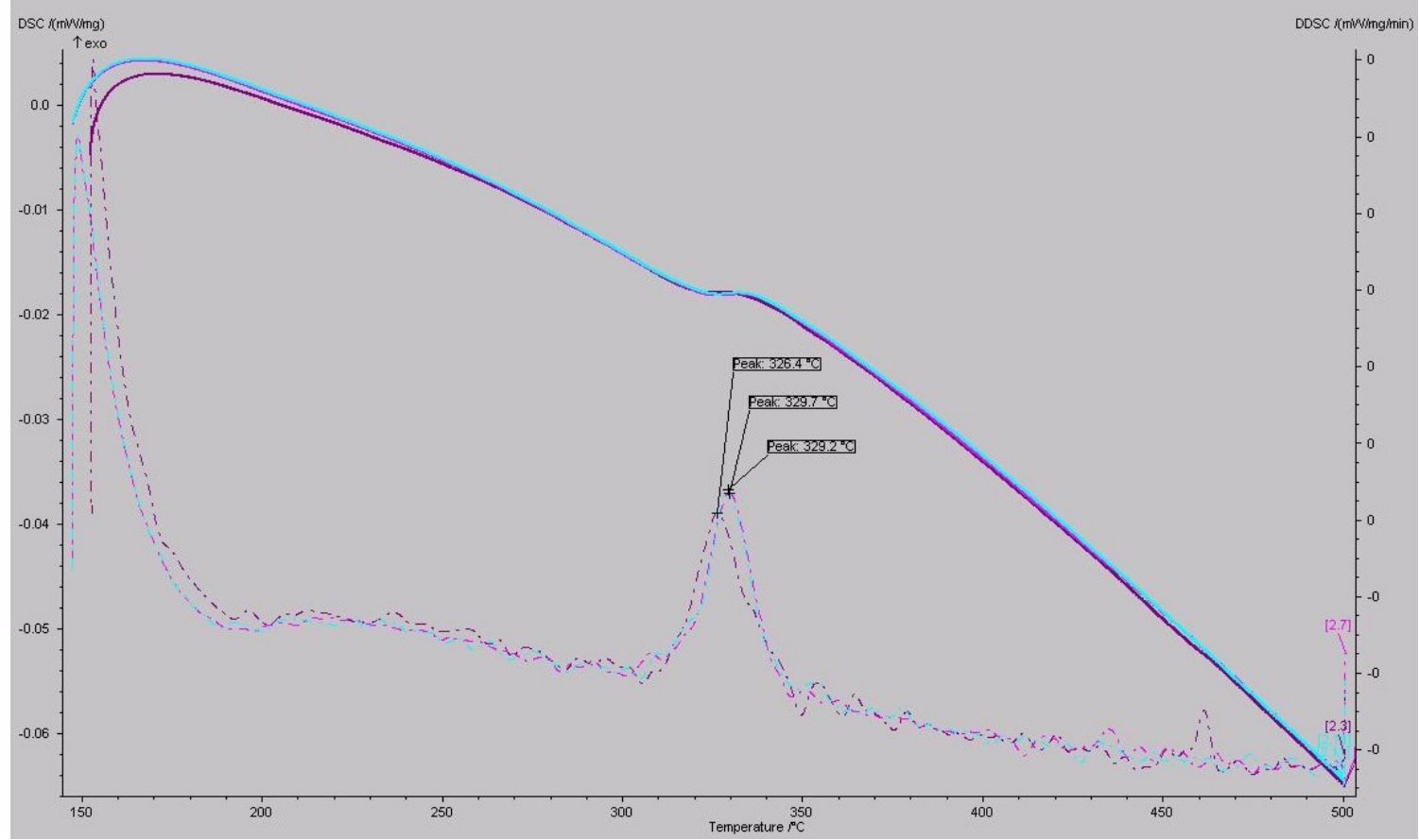

Figure 86: DSC heating curve for sample MH-DSC-2

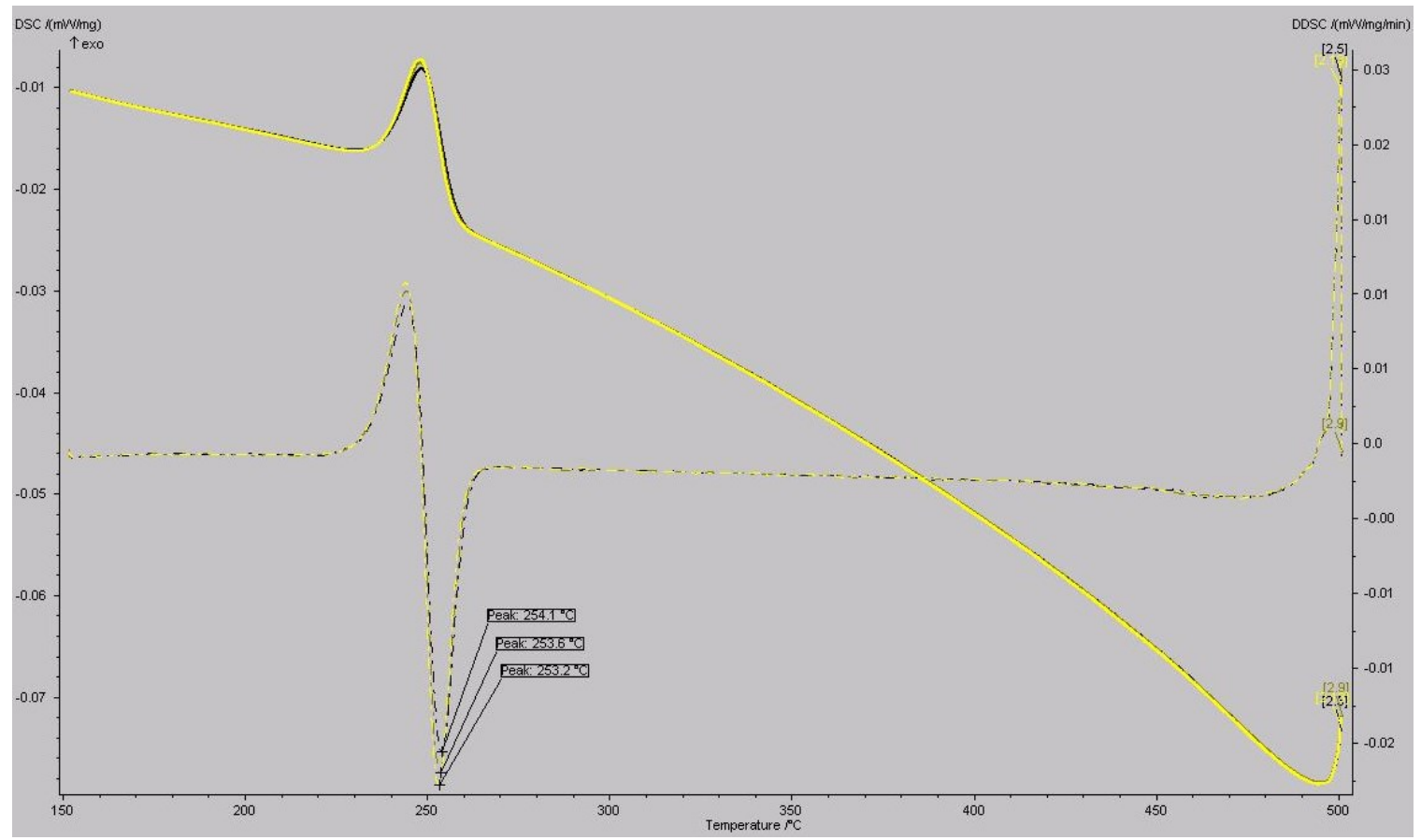

Figure 87: DSC cooling curve for sample MH-DSC-2 


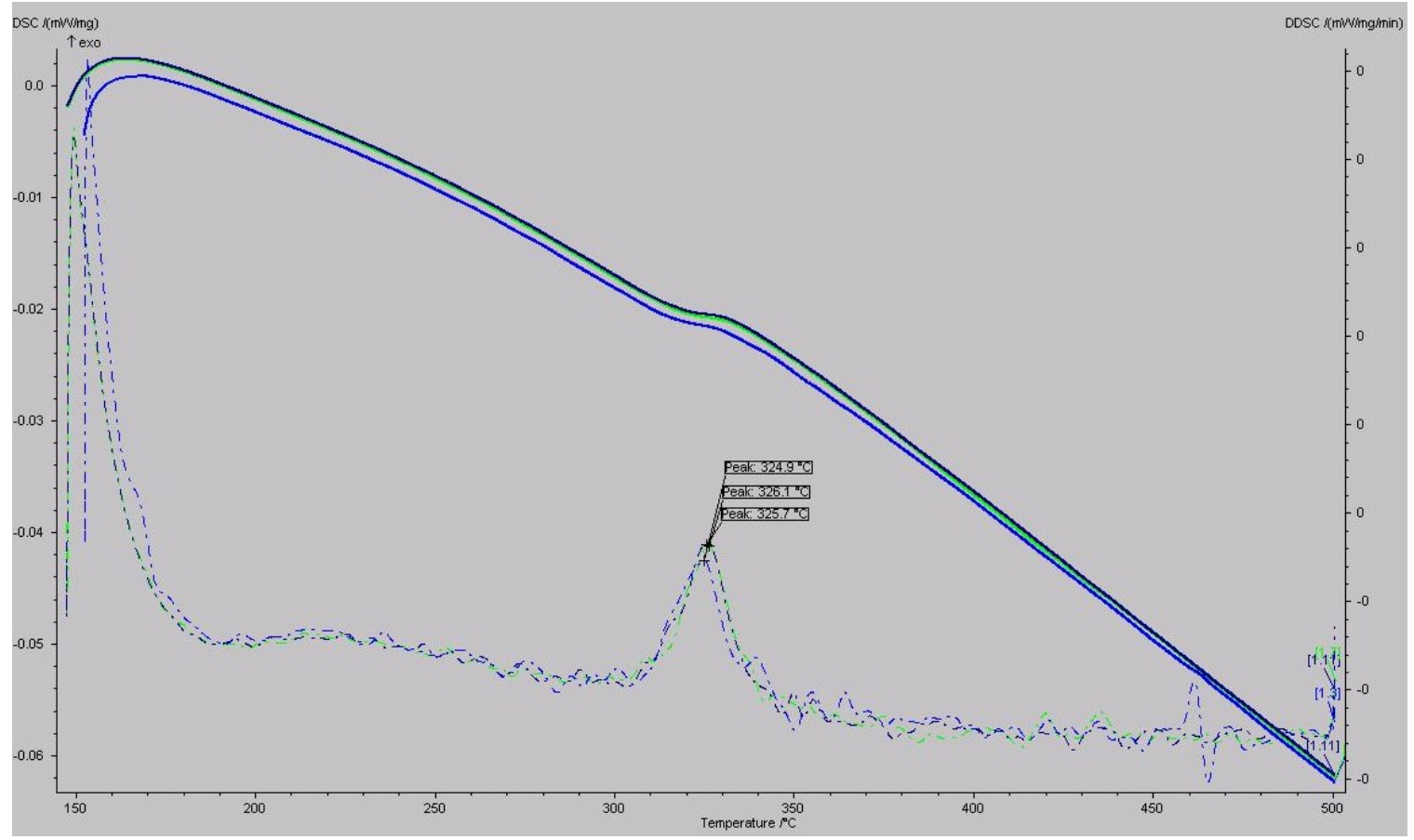

Figure 88: DSC heating curve for MH-DSC-3

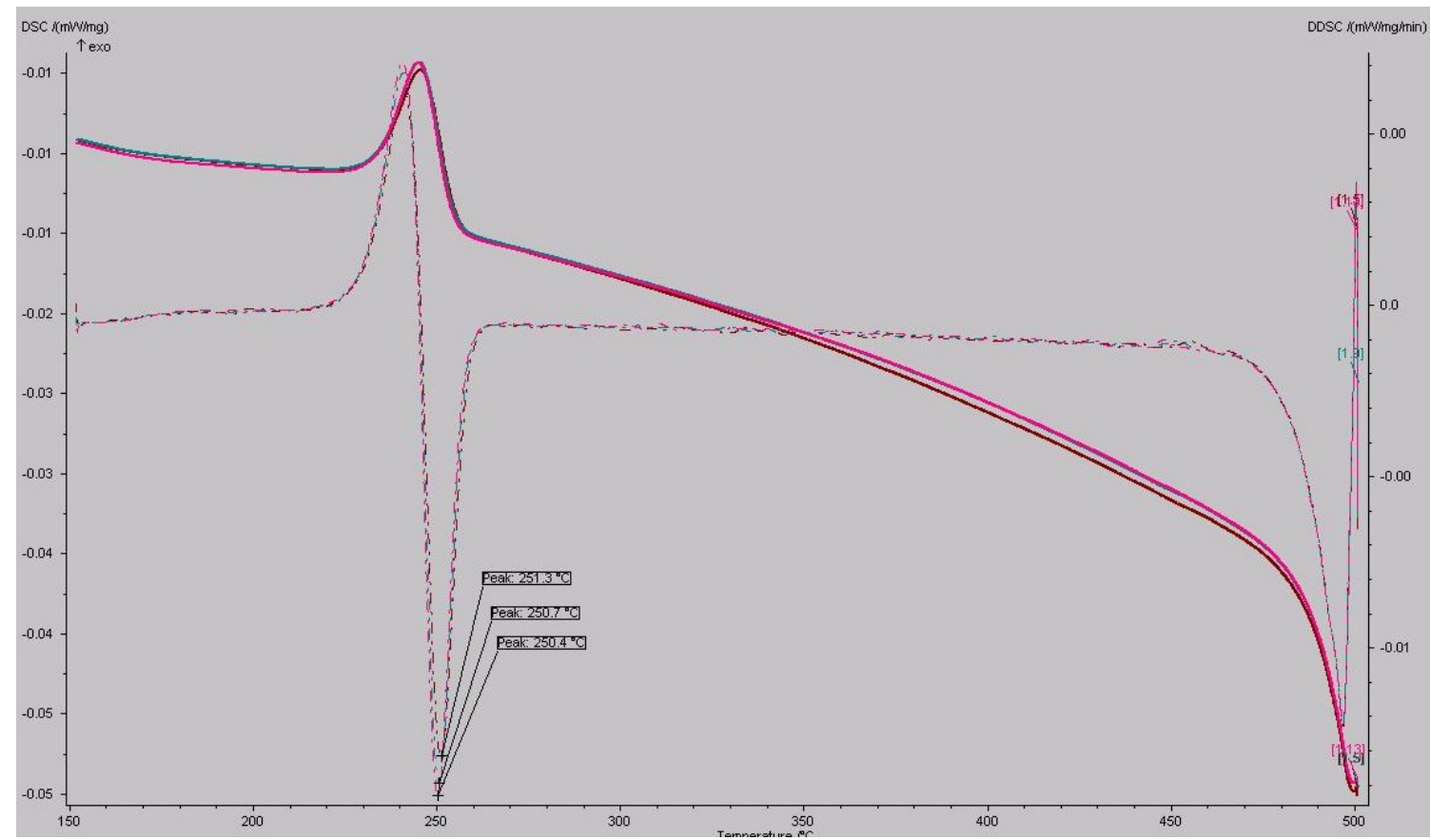

Figure 89: DSC cooling curve for sample MH-DSC-3 


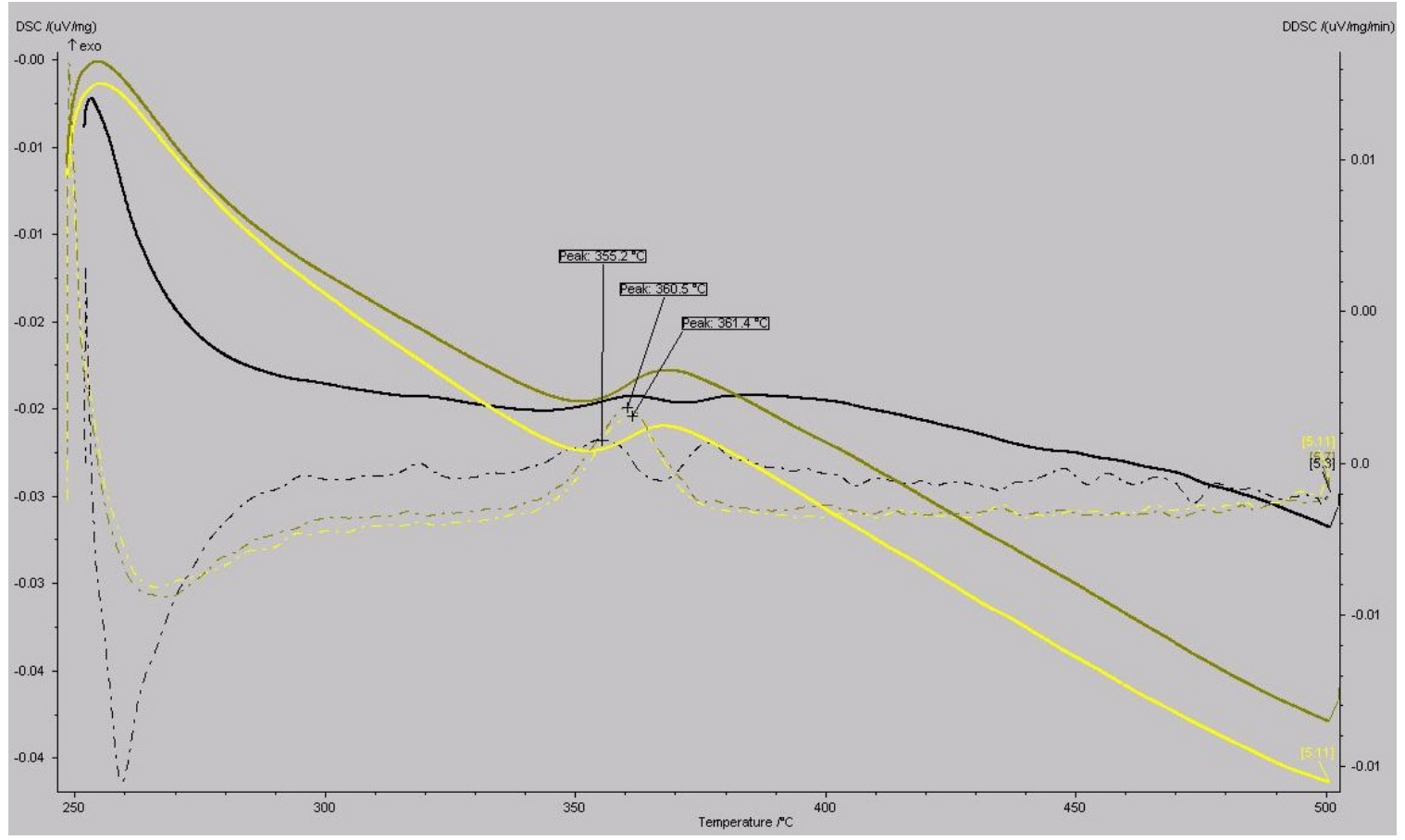

Figure 90: DSC heating curve of sample Sat2-B

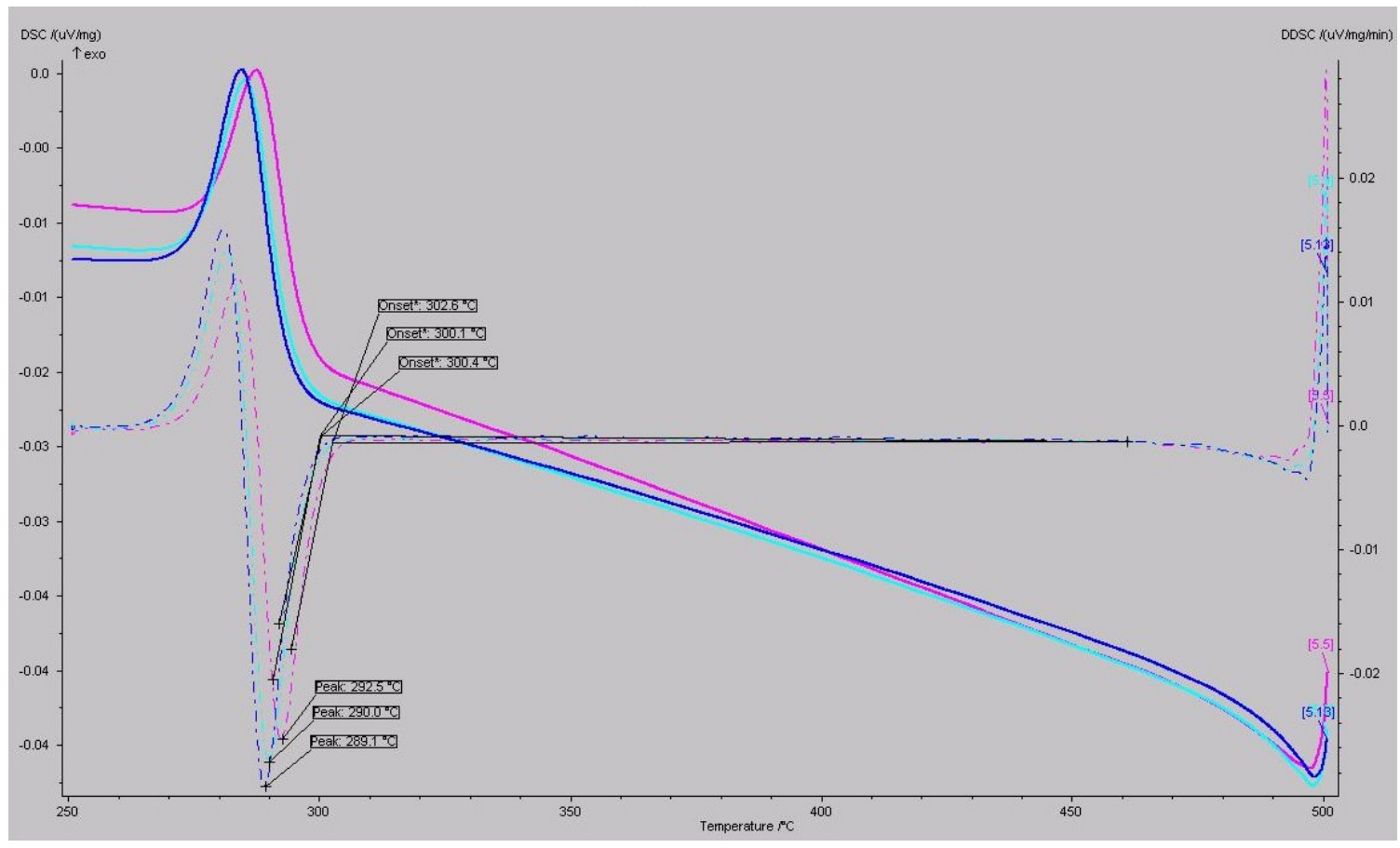

Figure 91: DSC cooling curve of sample Sat2-B 


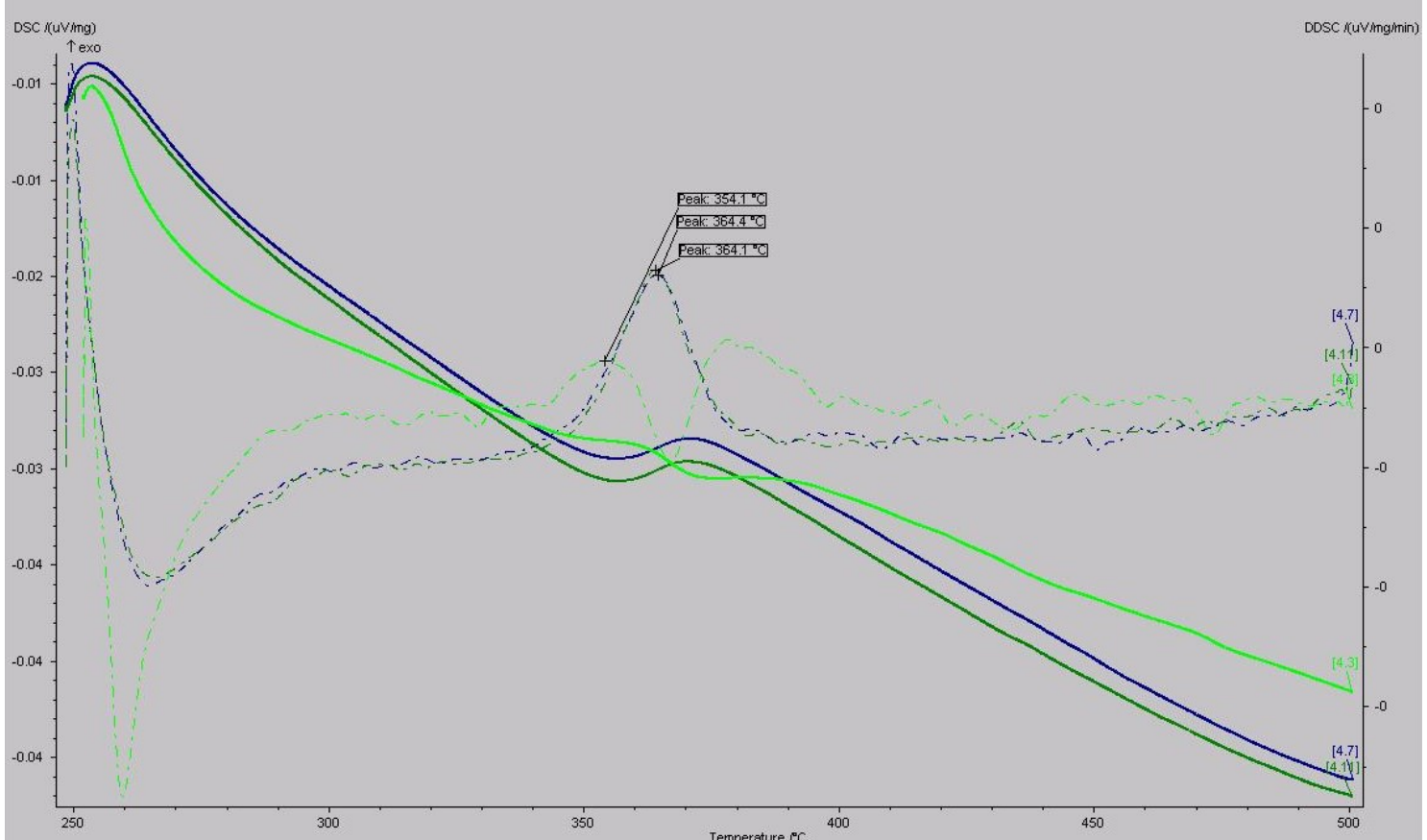

Figure 92: DSC heating curve of sample Sat2-M

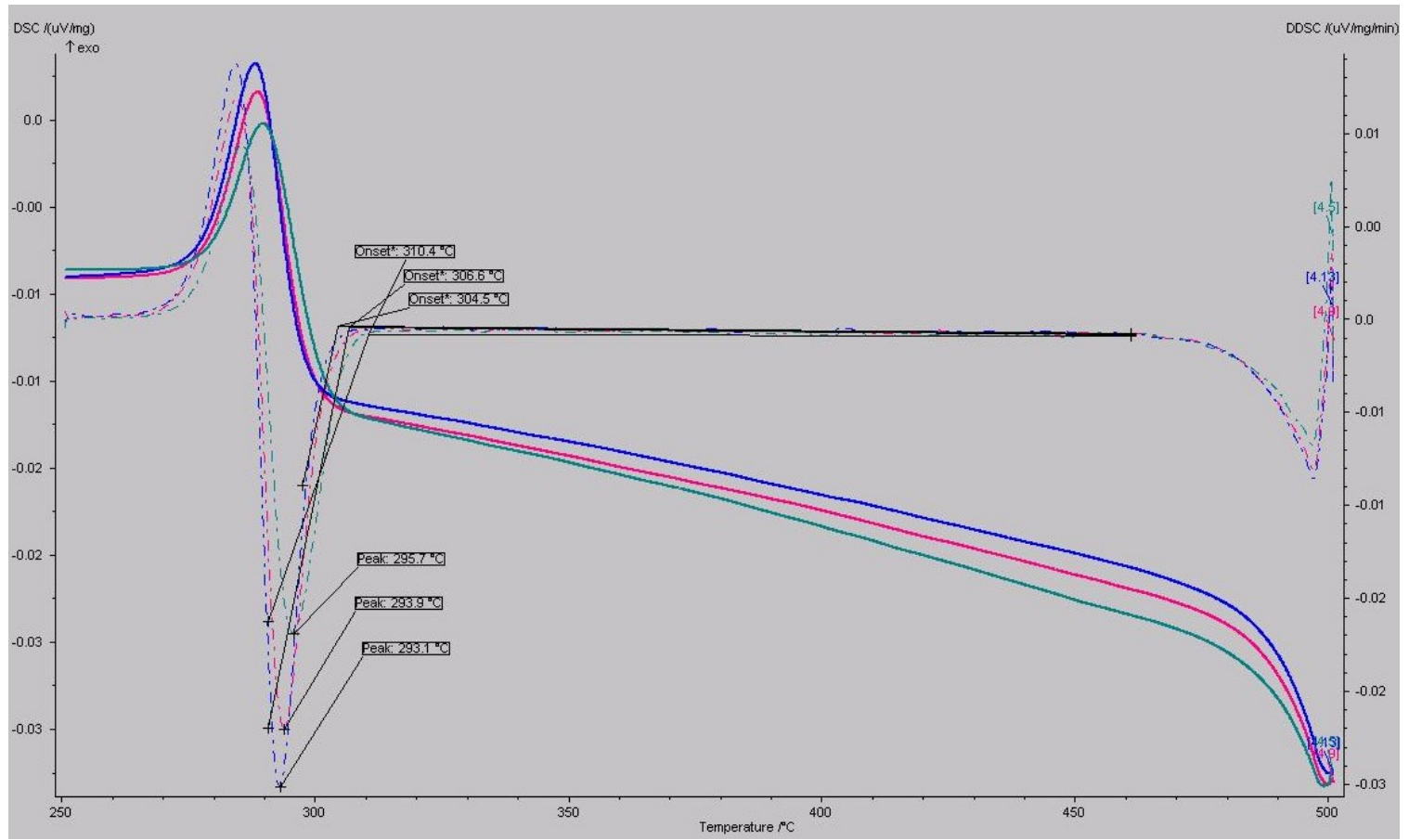

Figure 93: DSC cooling curve of sample Sat2-M 


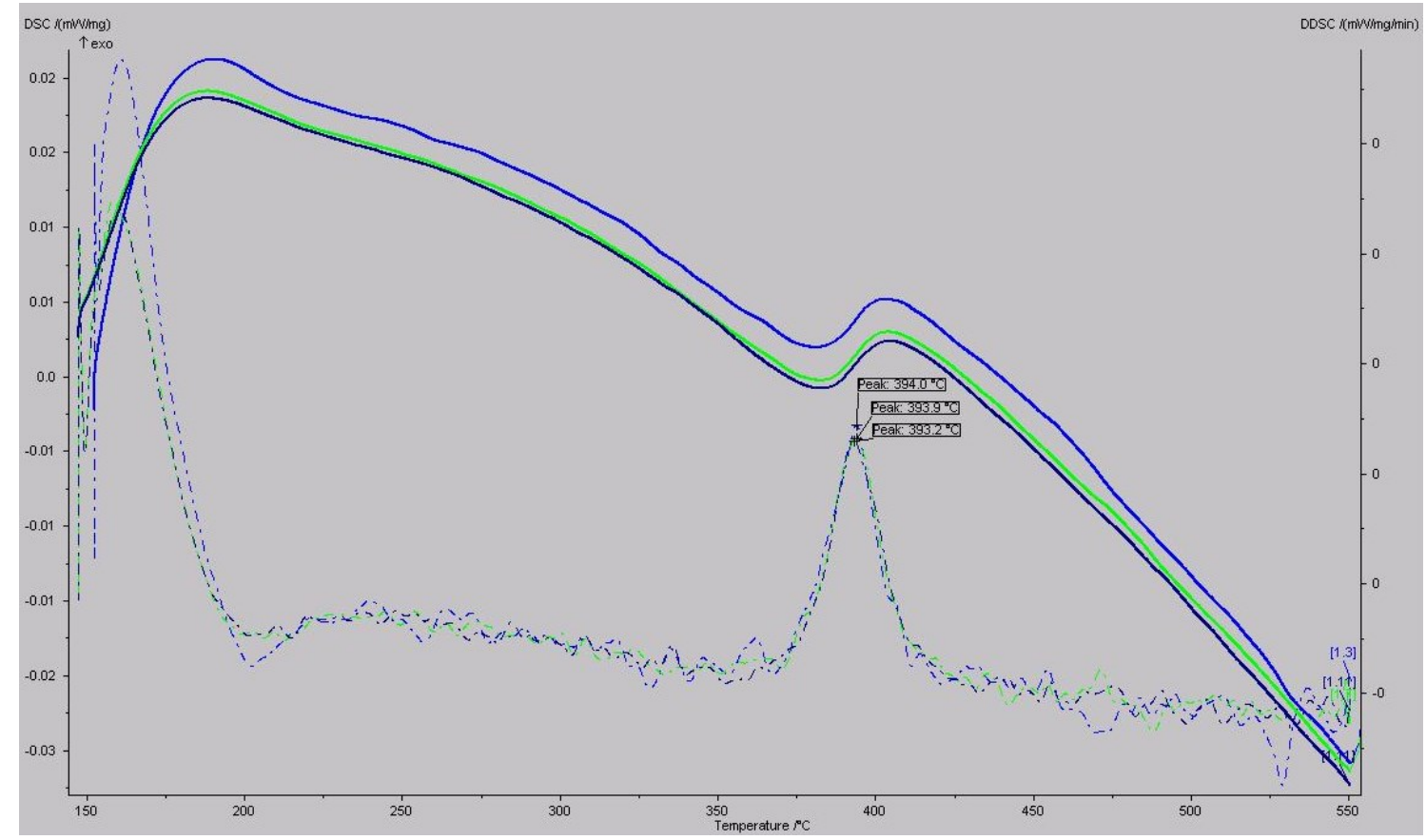

Figure 94: DSC heating curve of sample Sat2-T

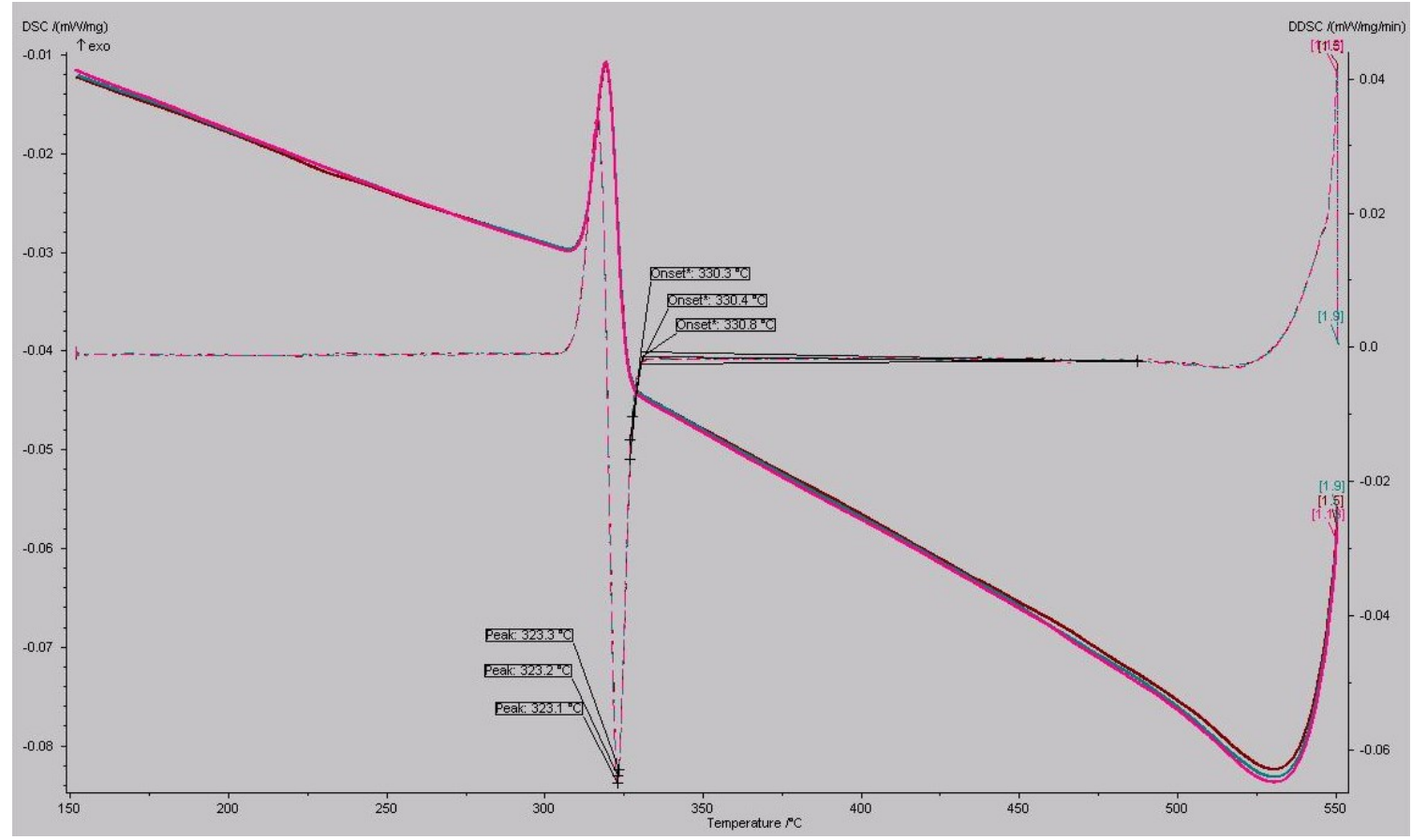

Figure 95: DSC cooling curve for sample Sat2-T 


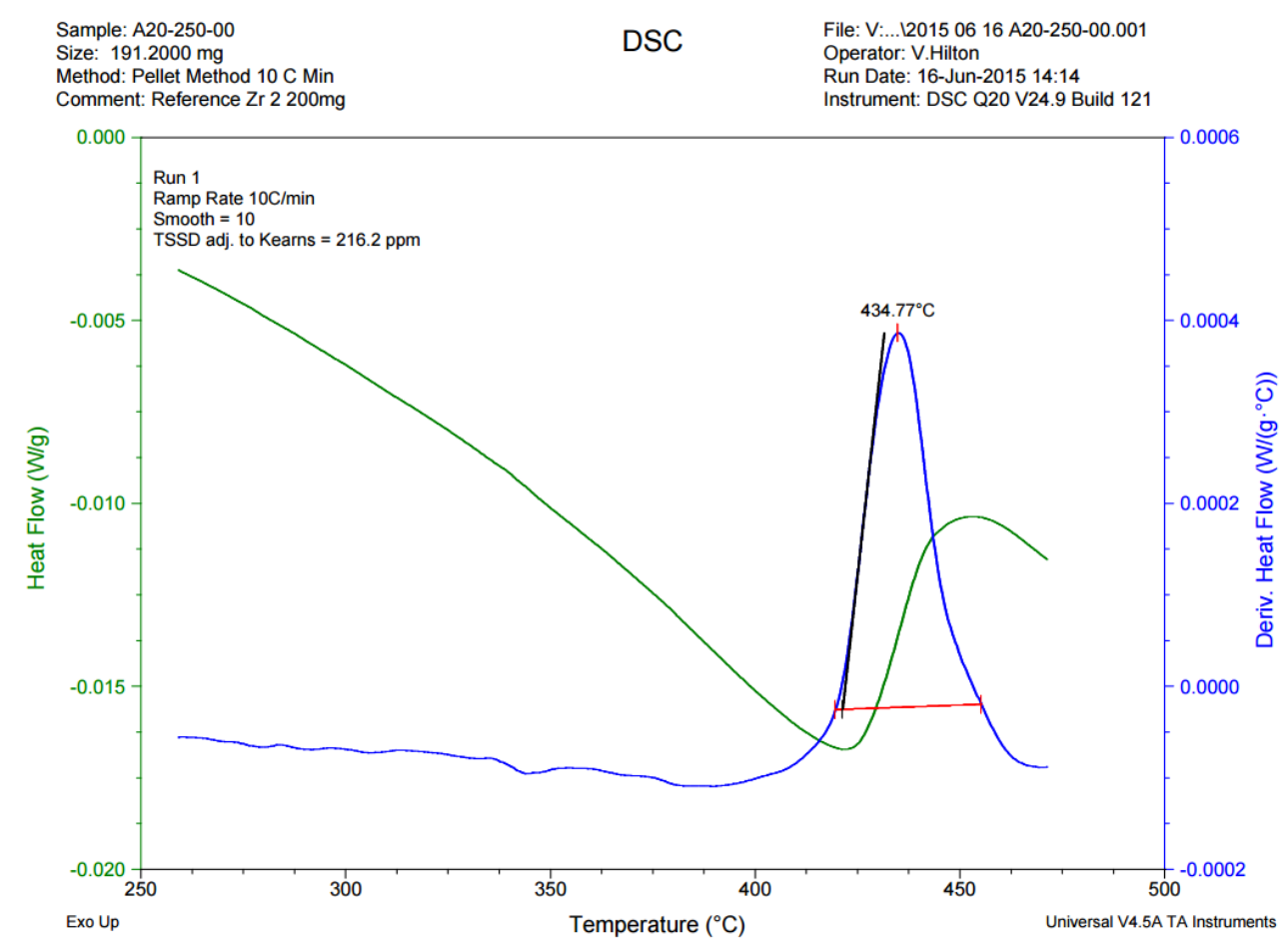

Figure 96: DSC heating curve \#1 for sample A20-250-00

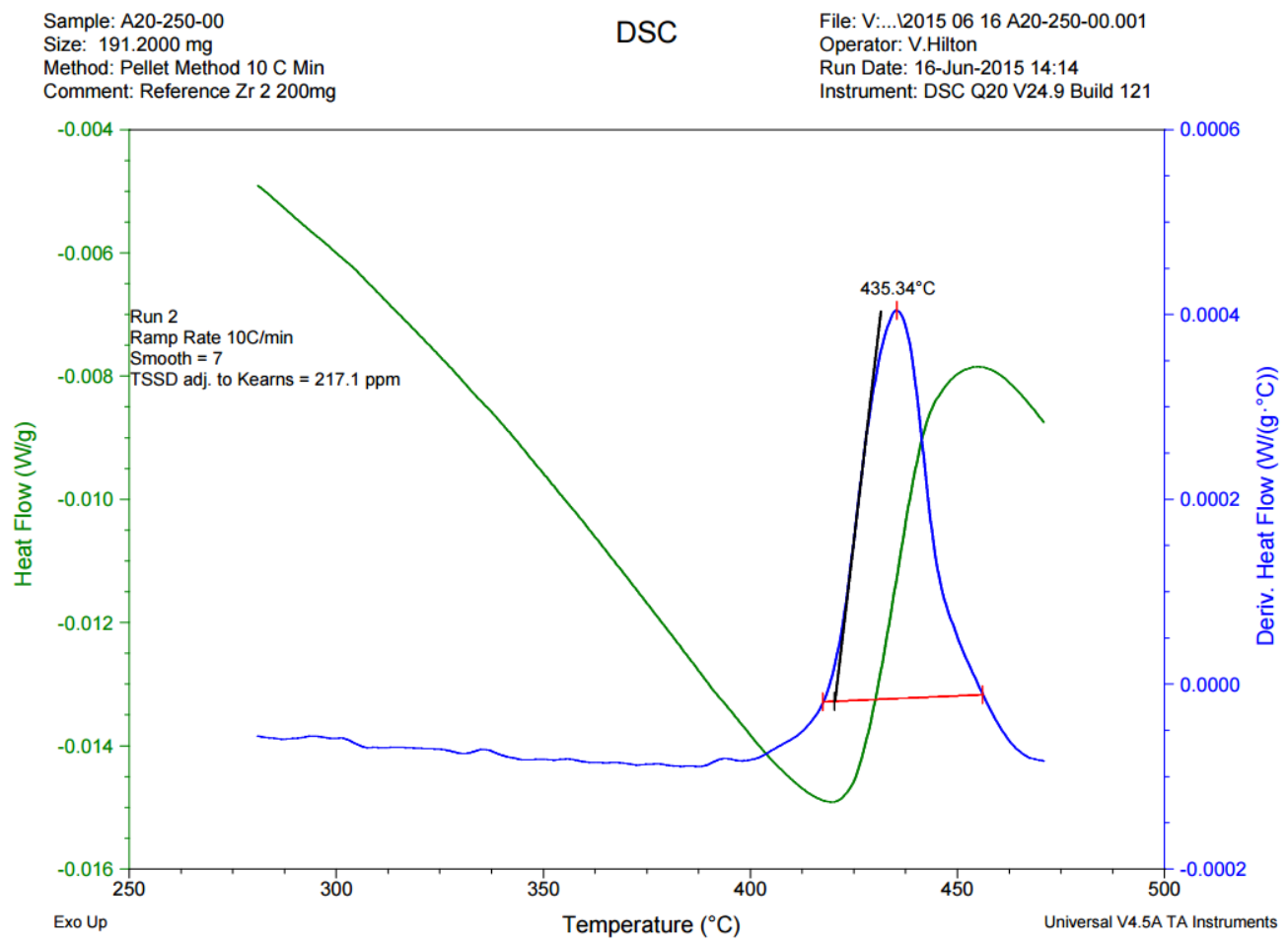

Figure 97: DSC heating curve \#2 for sample A20-250-00 


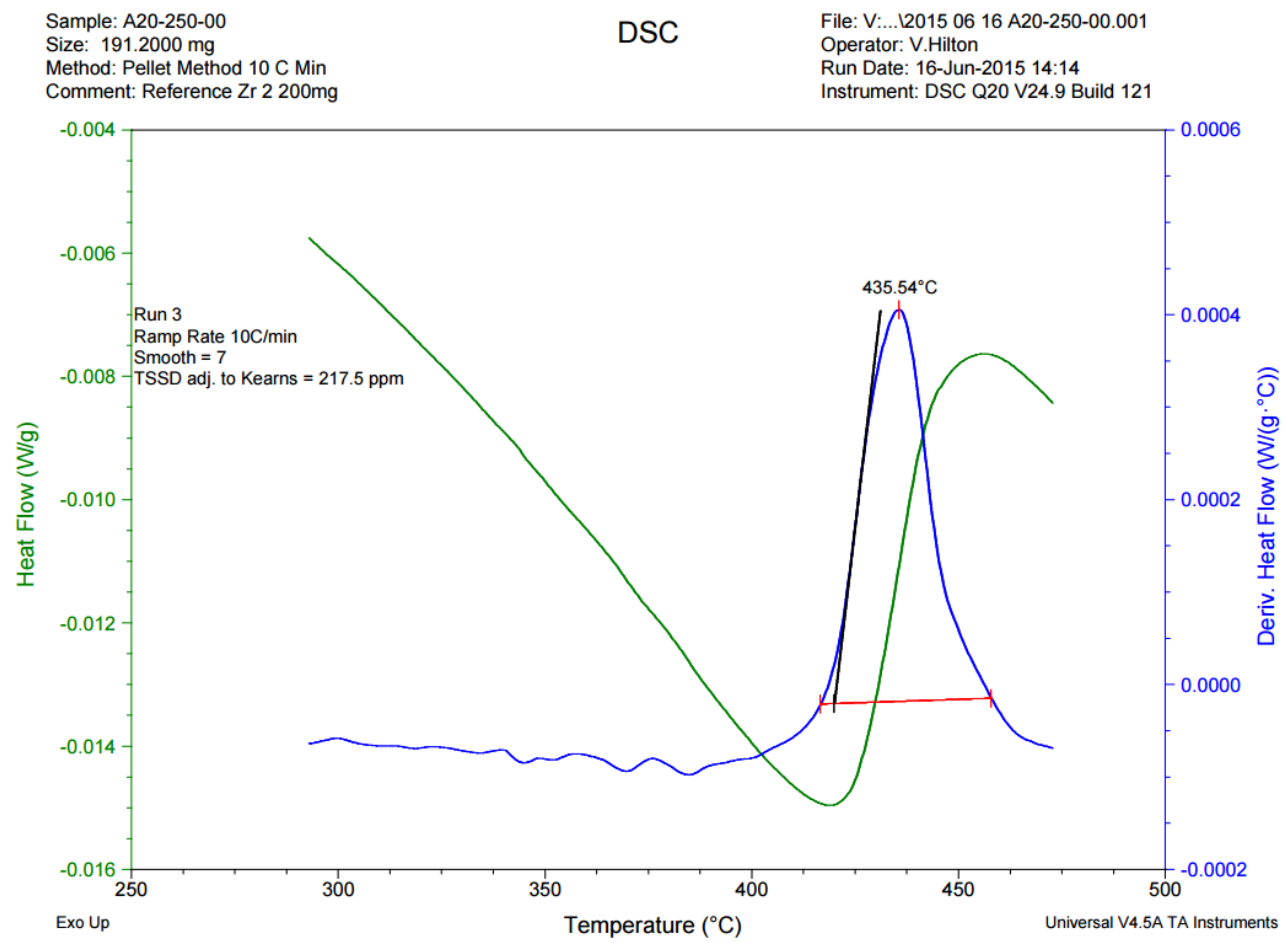

Figure 98: DSC heating curve \#3 for sample A20-250-00

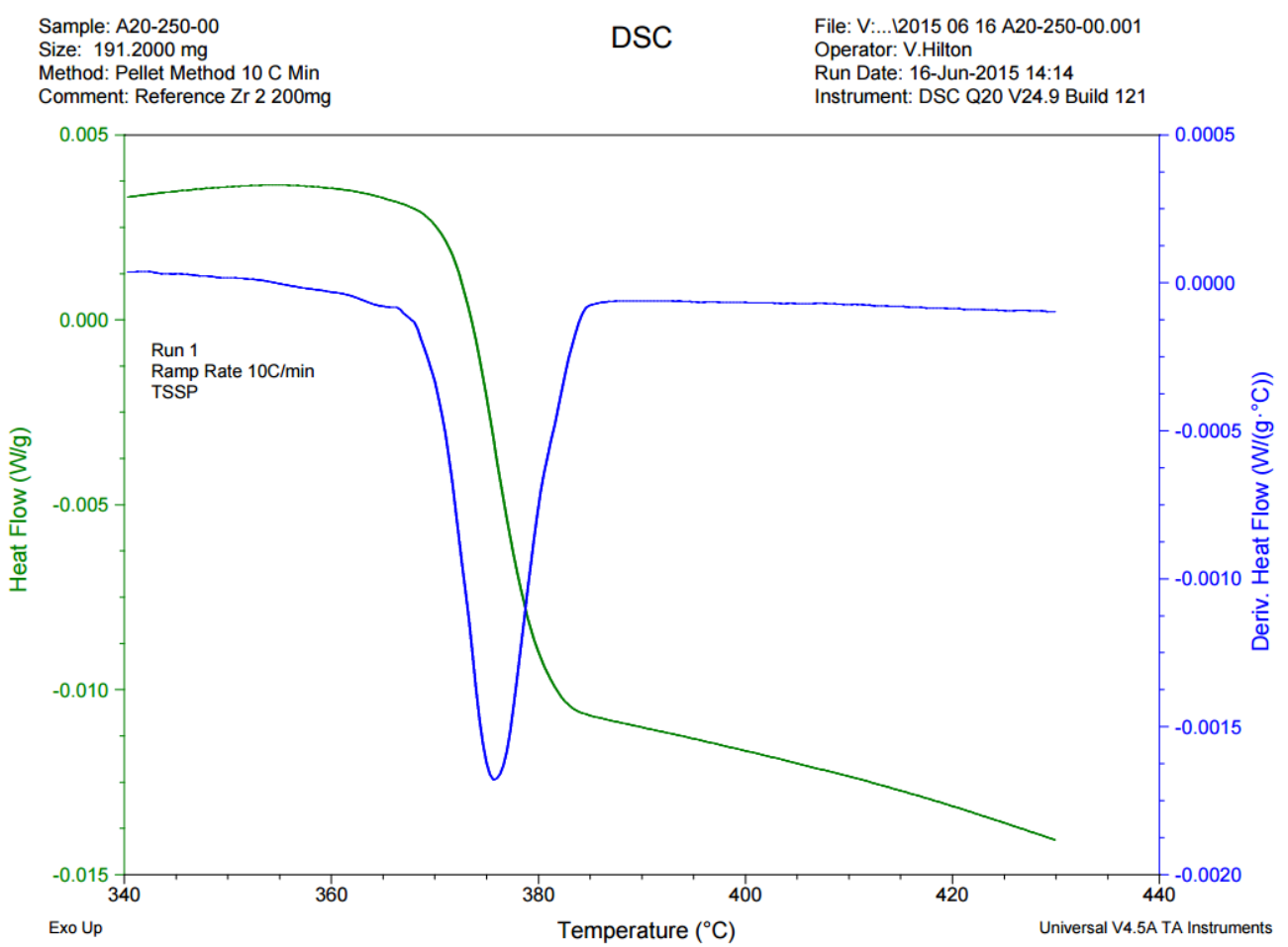

Figure 99: DSC cooling curve \#1 for sample A20-250-00 


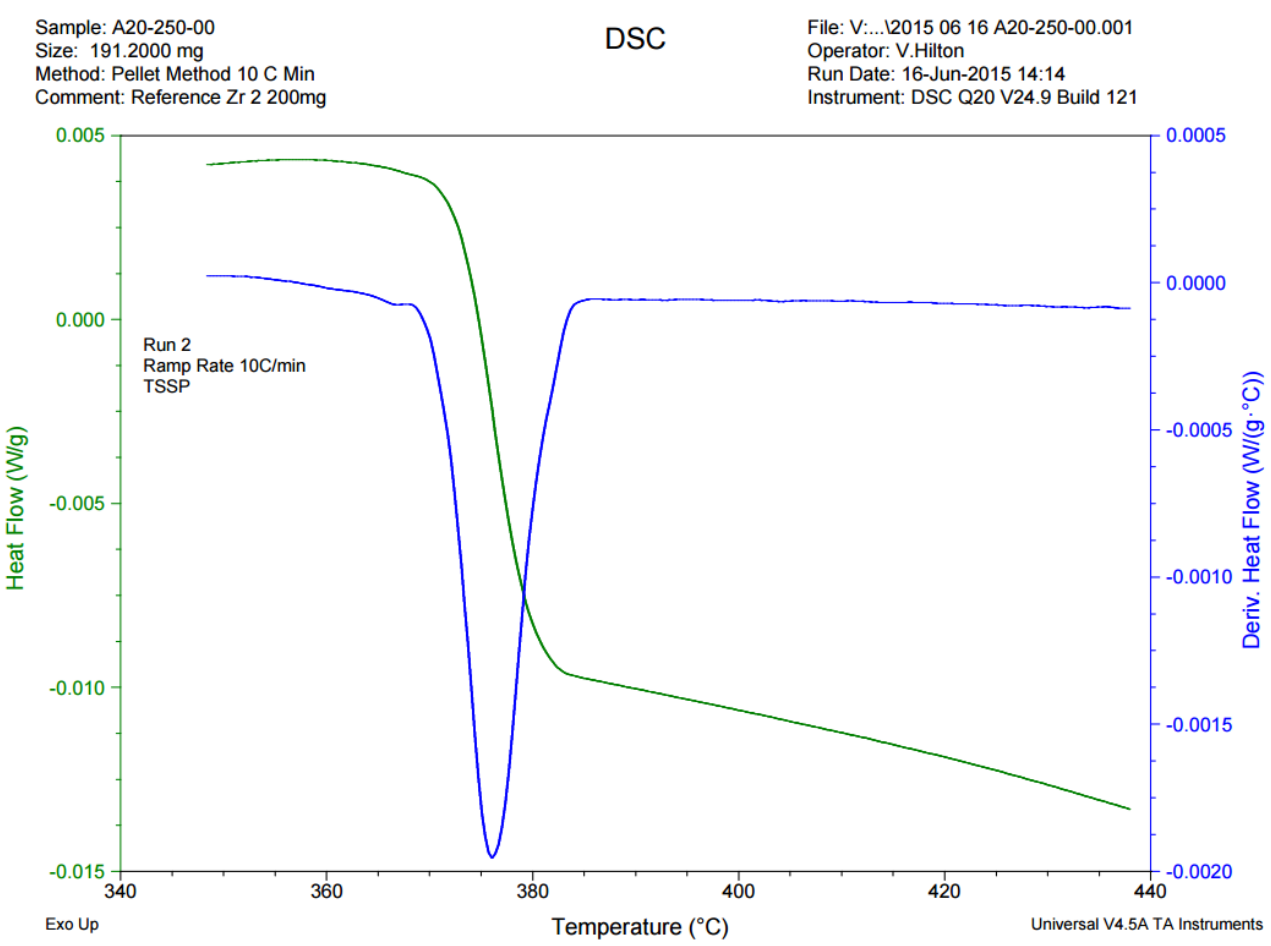

Figure 100: DSC cooling curve \#2 for sample A20-250-00

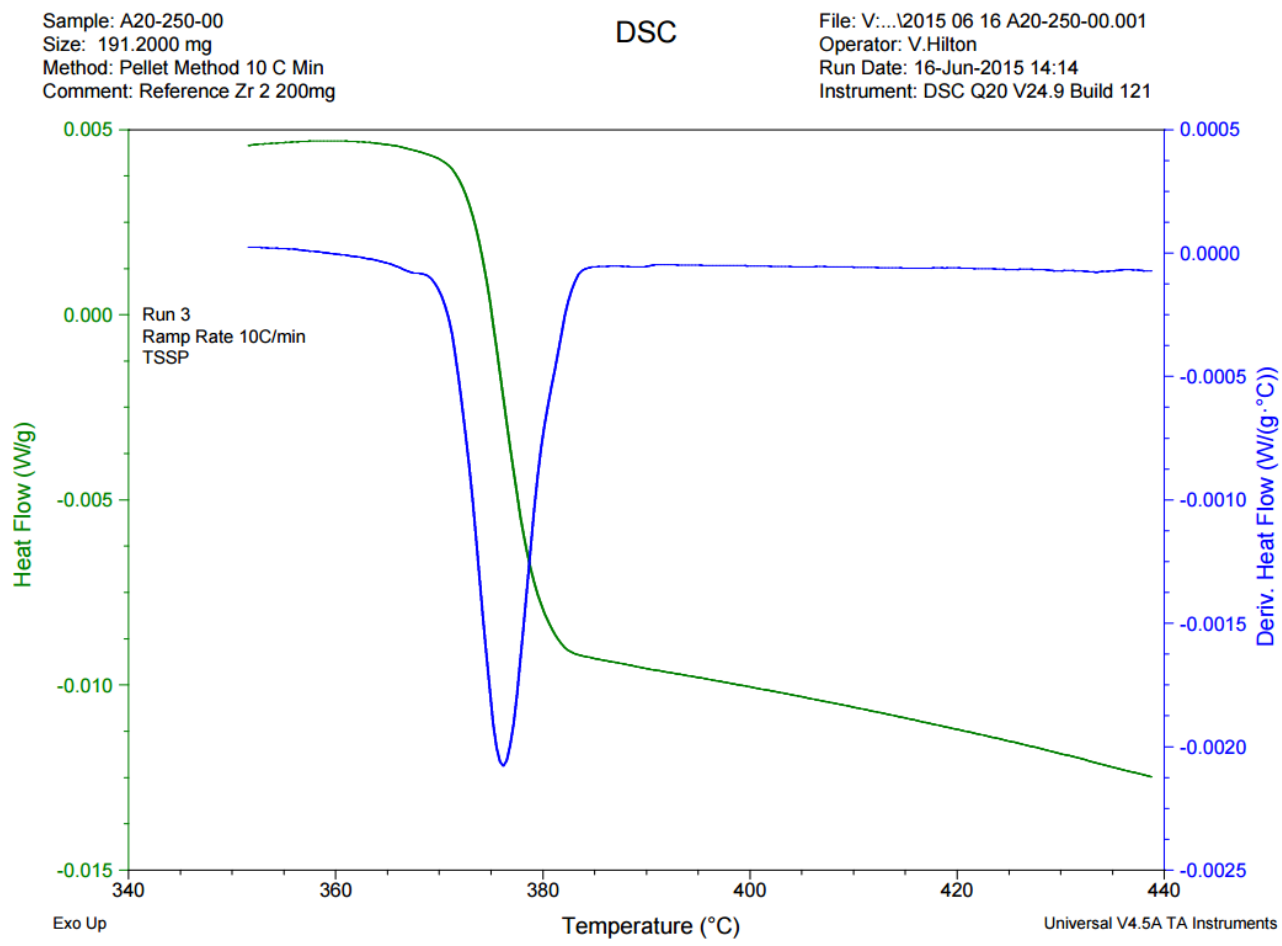

Figure 101: DSC cooling curve \#3 for sample A20-250-00 


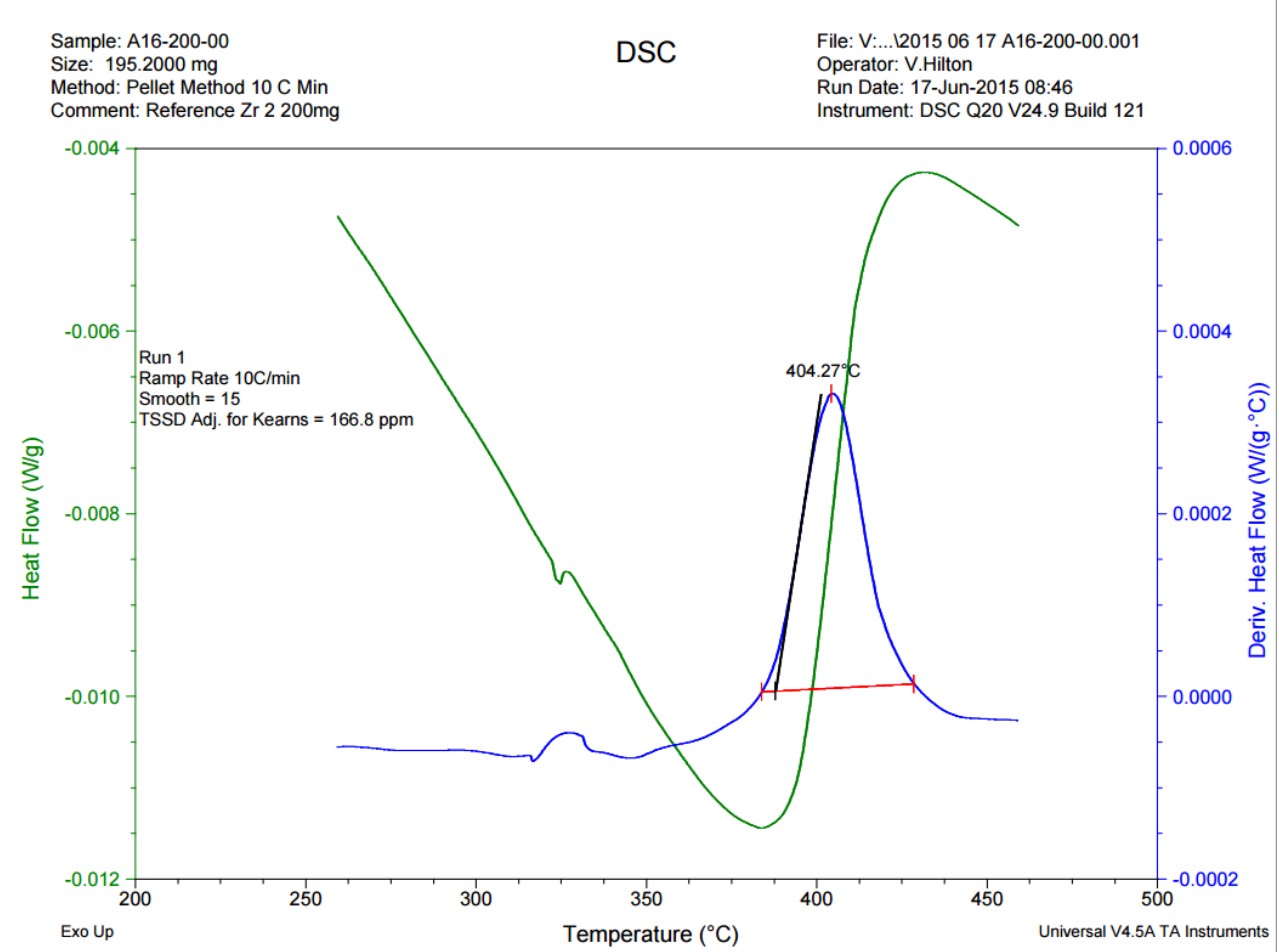

Figure 102: DSC heating curve \#1 for sample A16-200-00

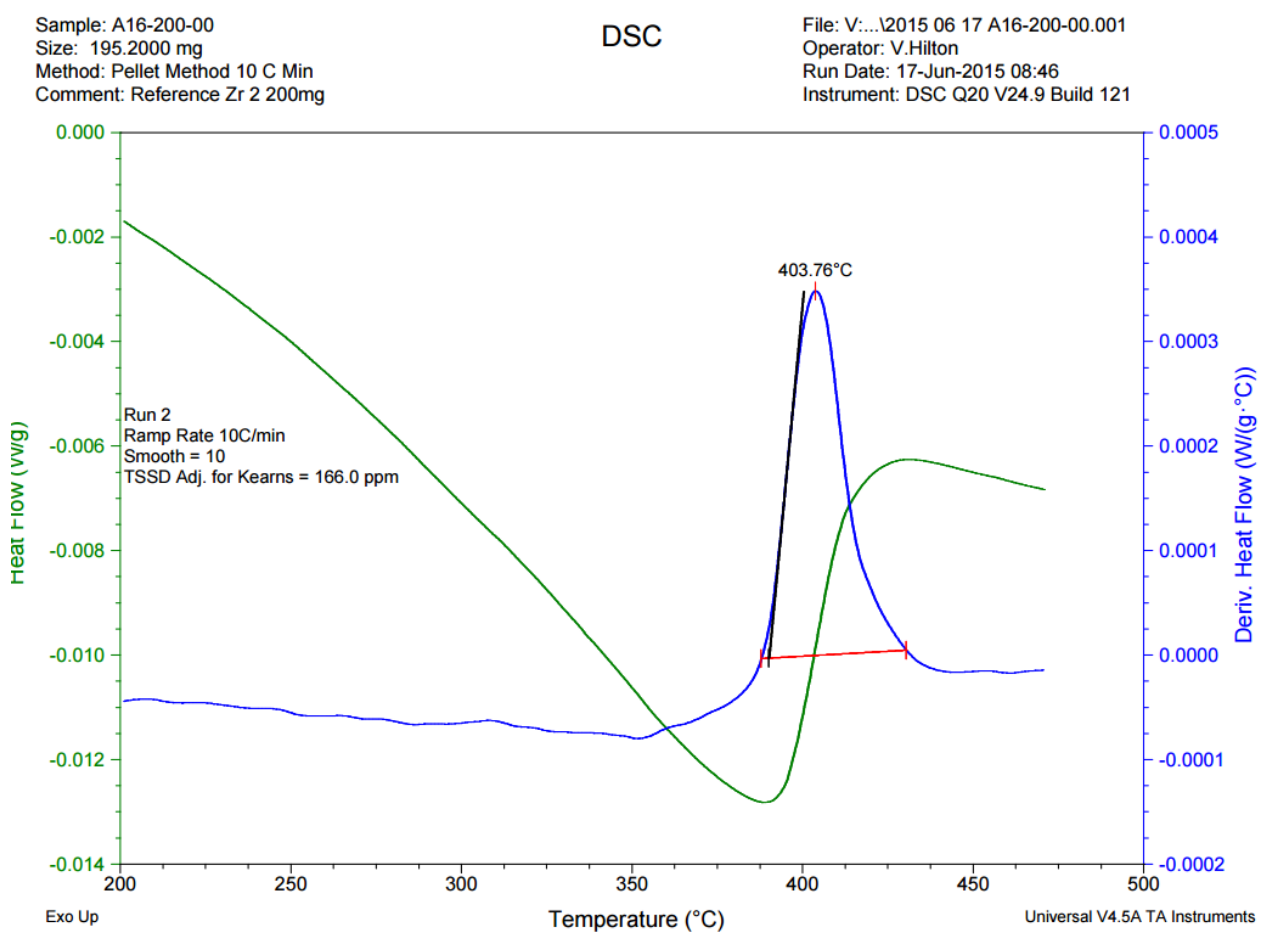

Figure 103: DSC heating curve \#2 for sample A16-200-00 


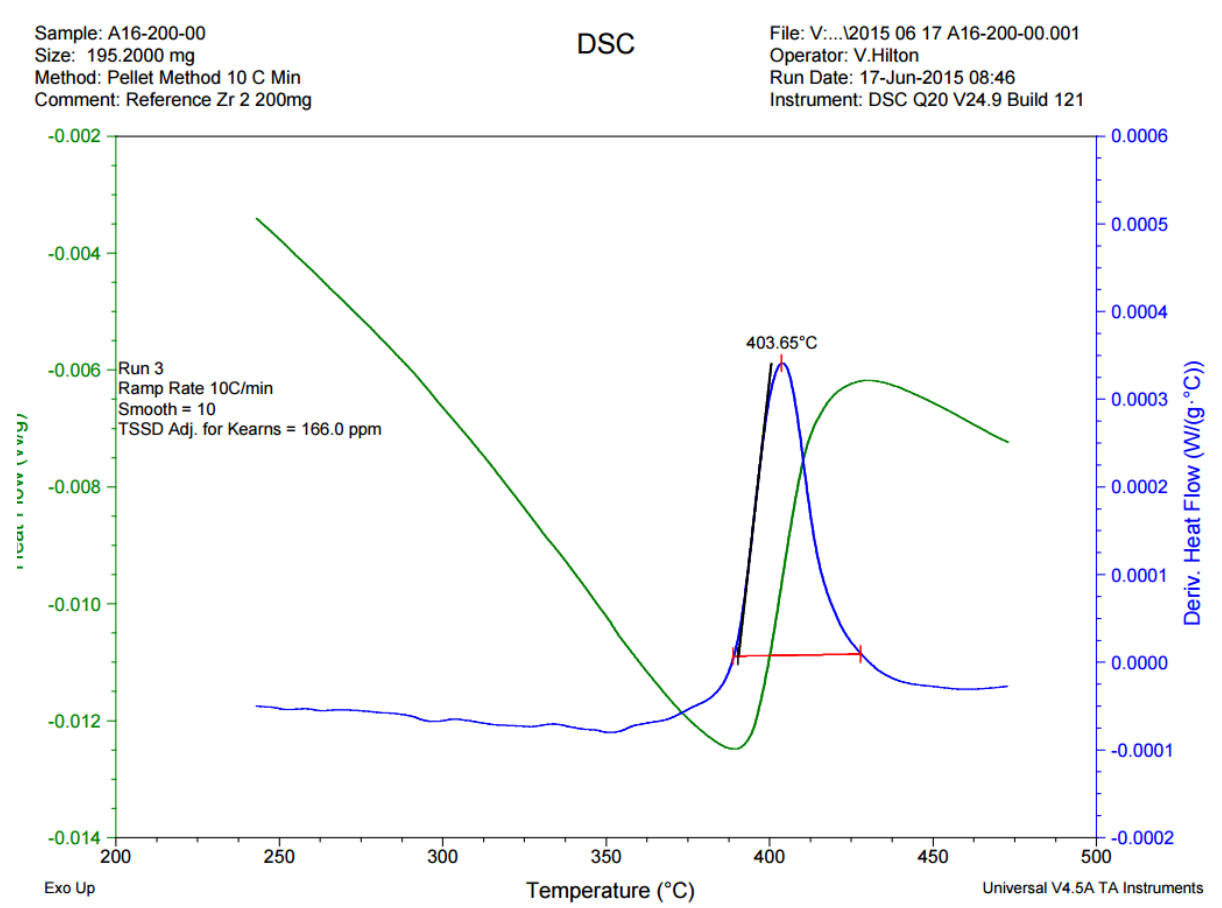

Figure 104: DSC heating curve \#3 for sample A16-200-00

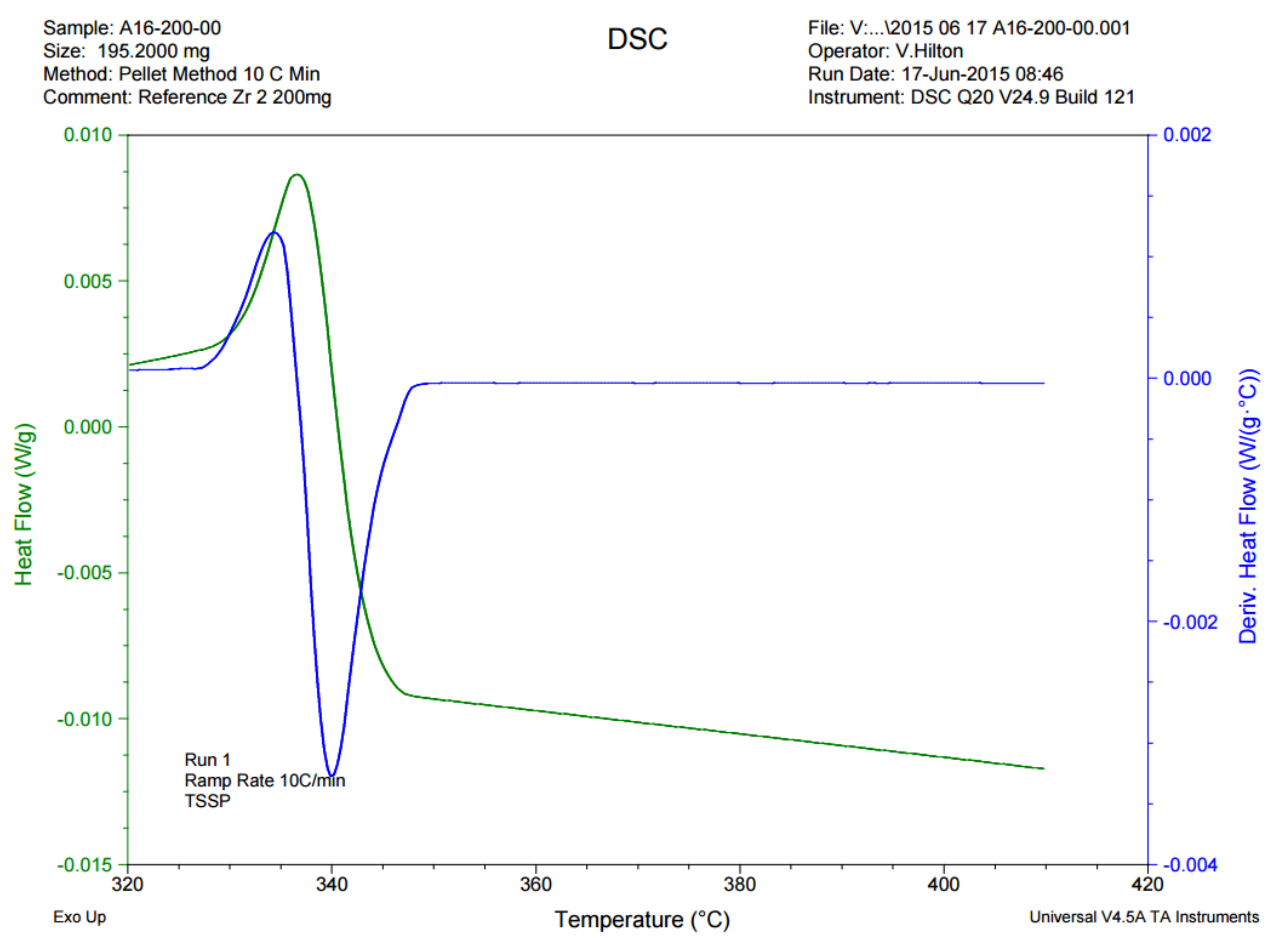

Figure 105: DSC cooling curve \#1 for sample A16-200-00 


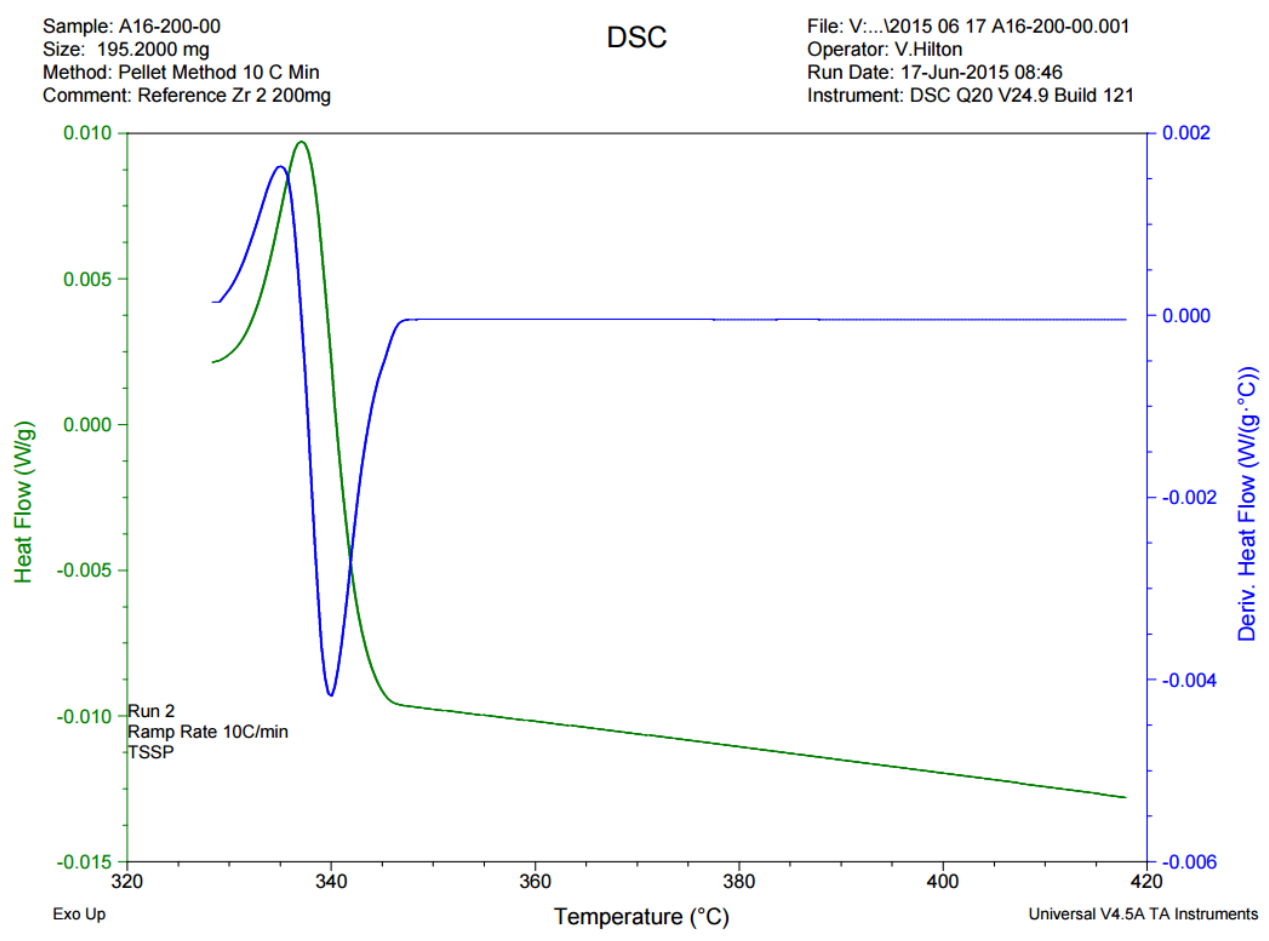

Figure 106: DSC cooling curve \#2 for sample A16-200-00

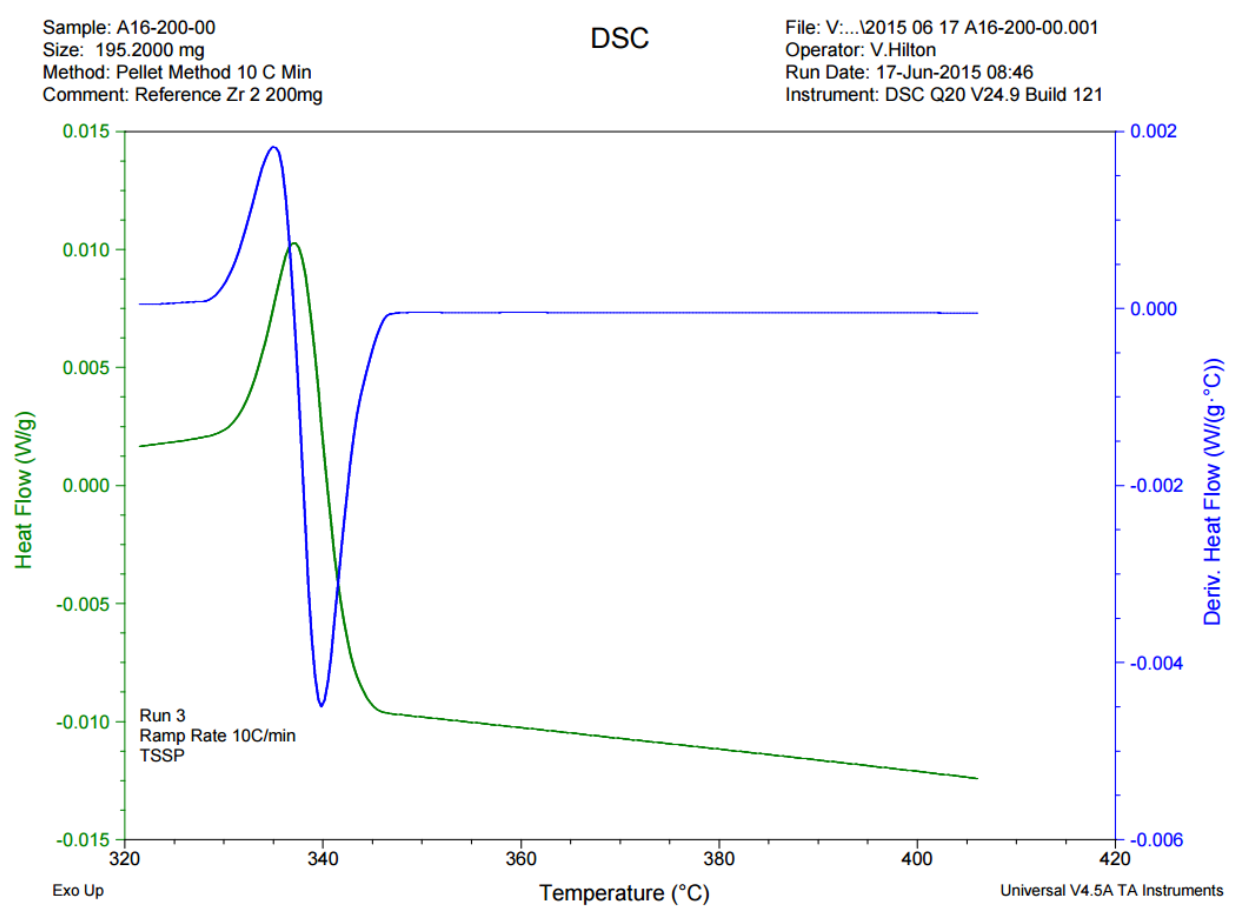

Figure 107: DSC cooling curve \#3 for sample A16-200-00 


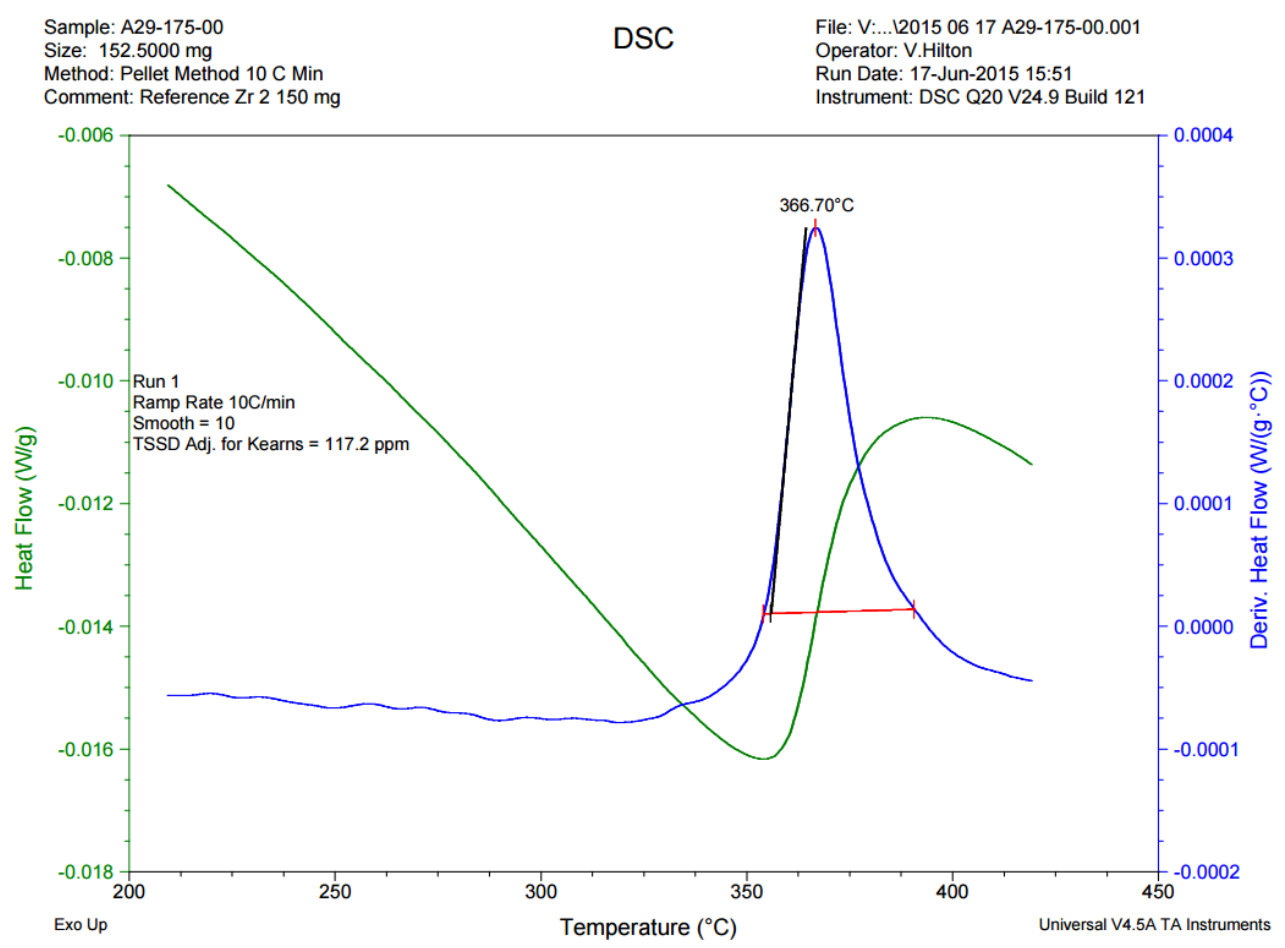

Figure 108: DSC heating curve \#1 for sample A29-175-00

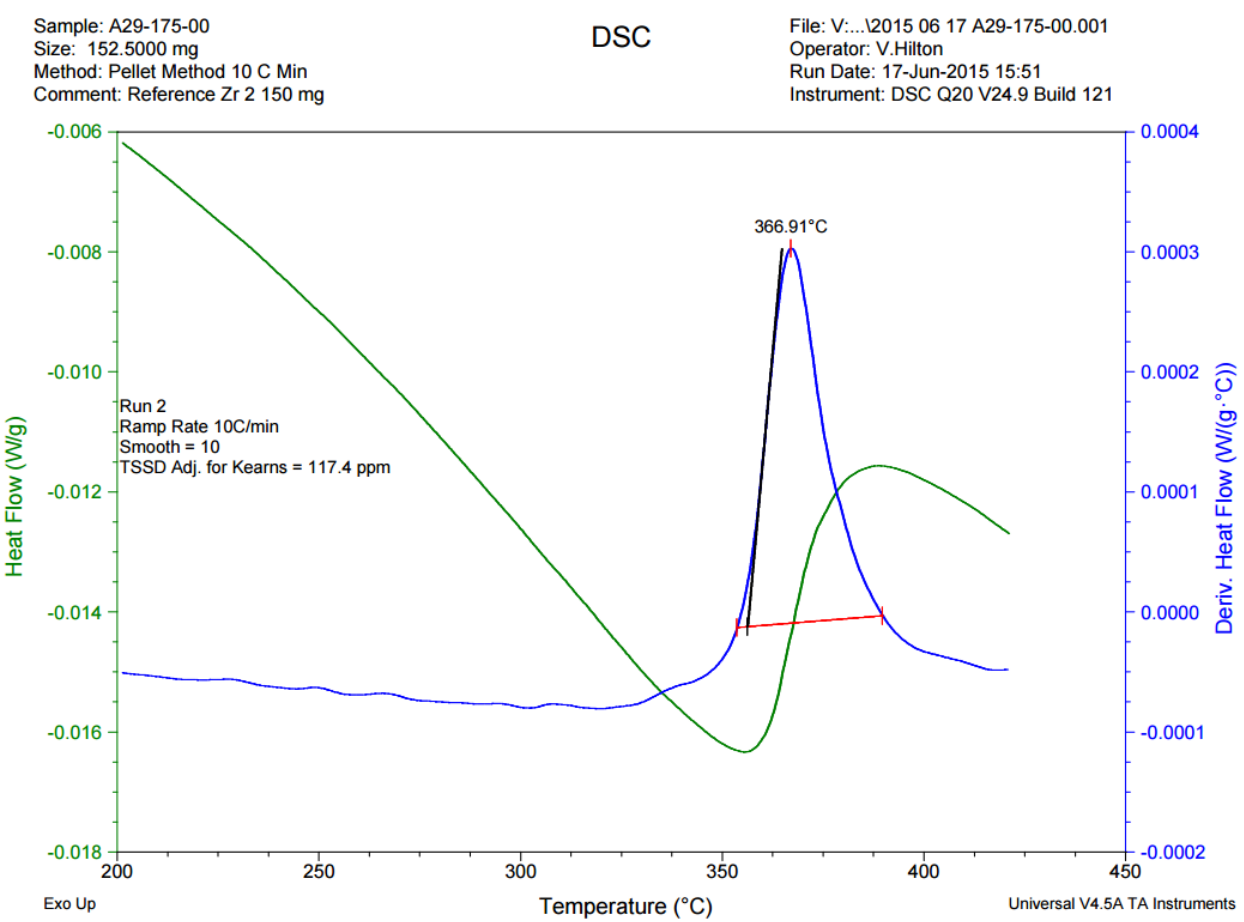

Figure 109: DSC heating curve \#2 for sample A29-175-00 


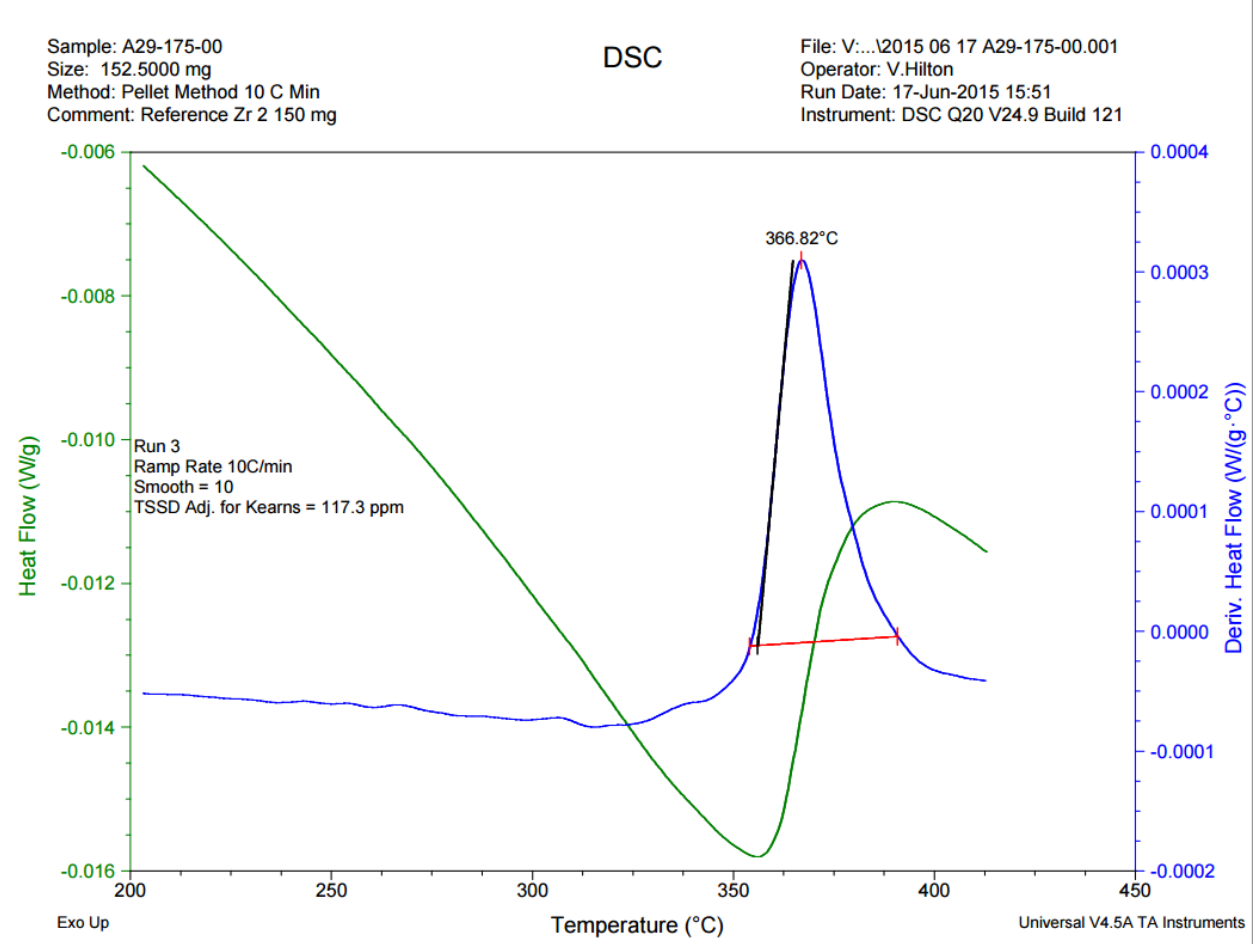

Figure 110: DSC heating curve \#3 for sample A29-175-00

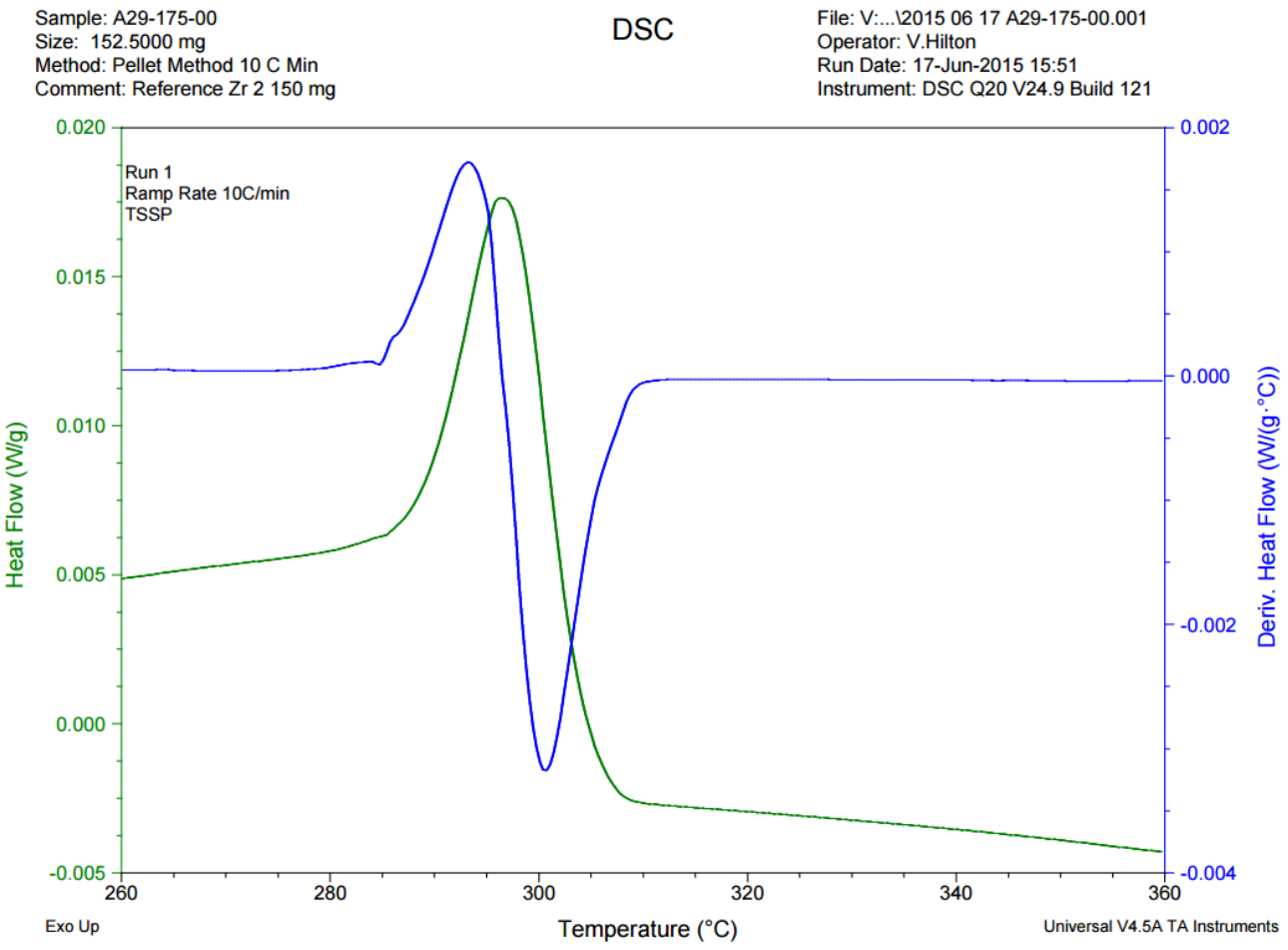

Figure 111: DSC cooling curve \#1 for sample A29-175-00 


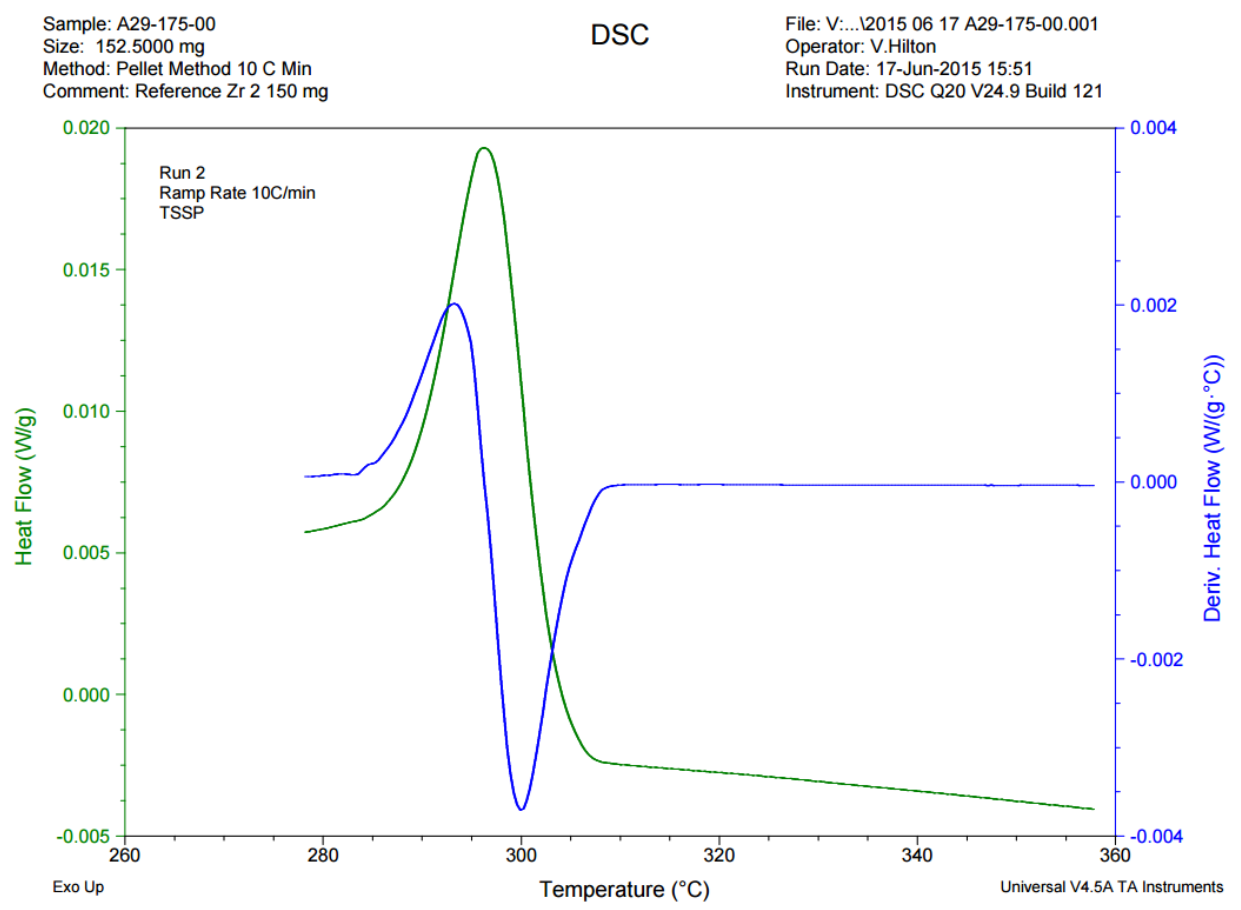

Figure 112: DSC cooling curve \#2 for sample A29-175-00

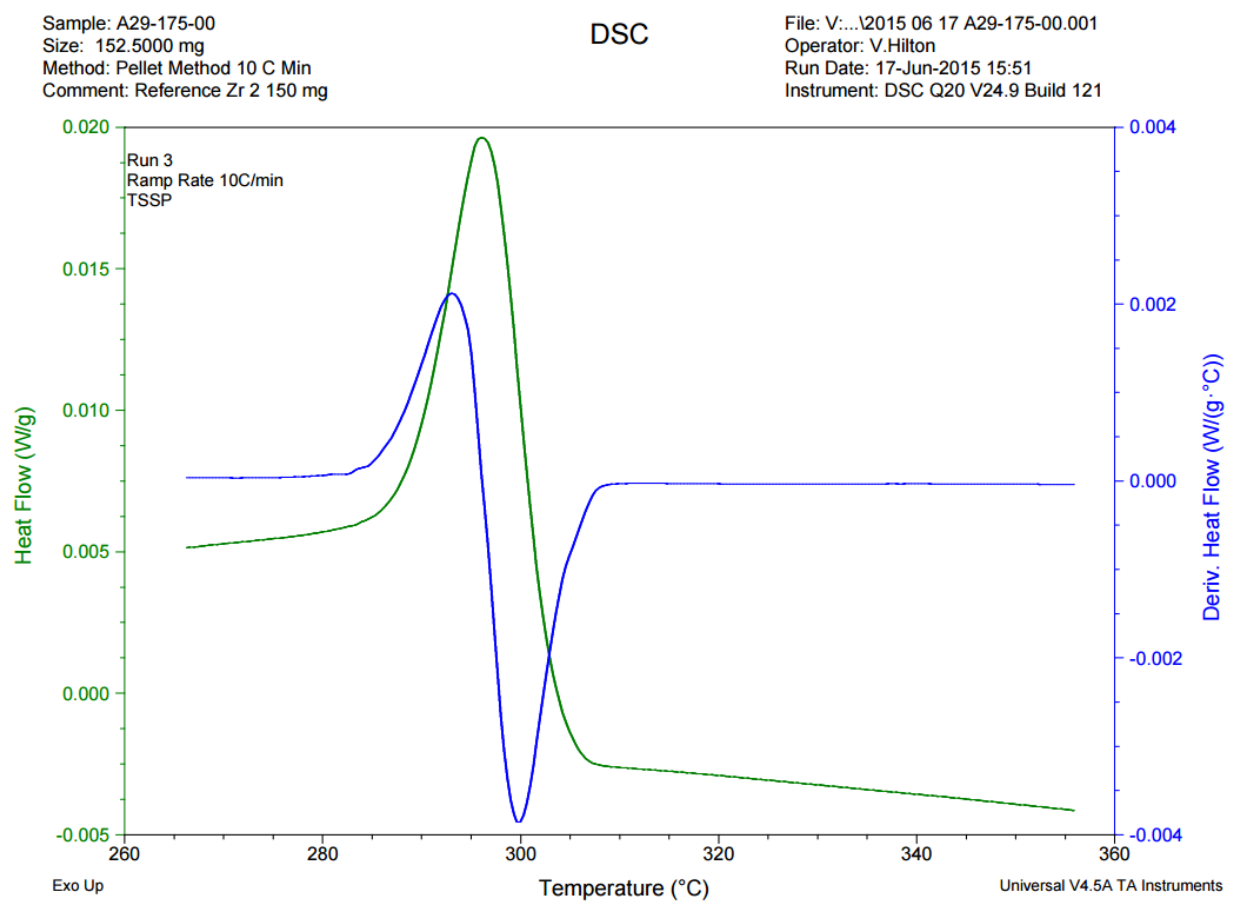

Figure 113: DSC cooling curve \#3 for sample A29-175-00 


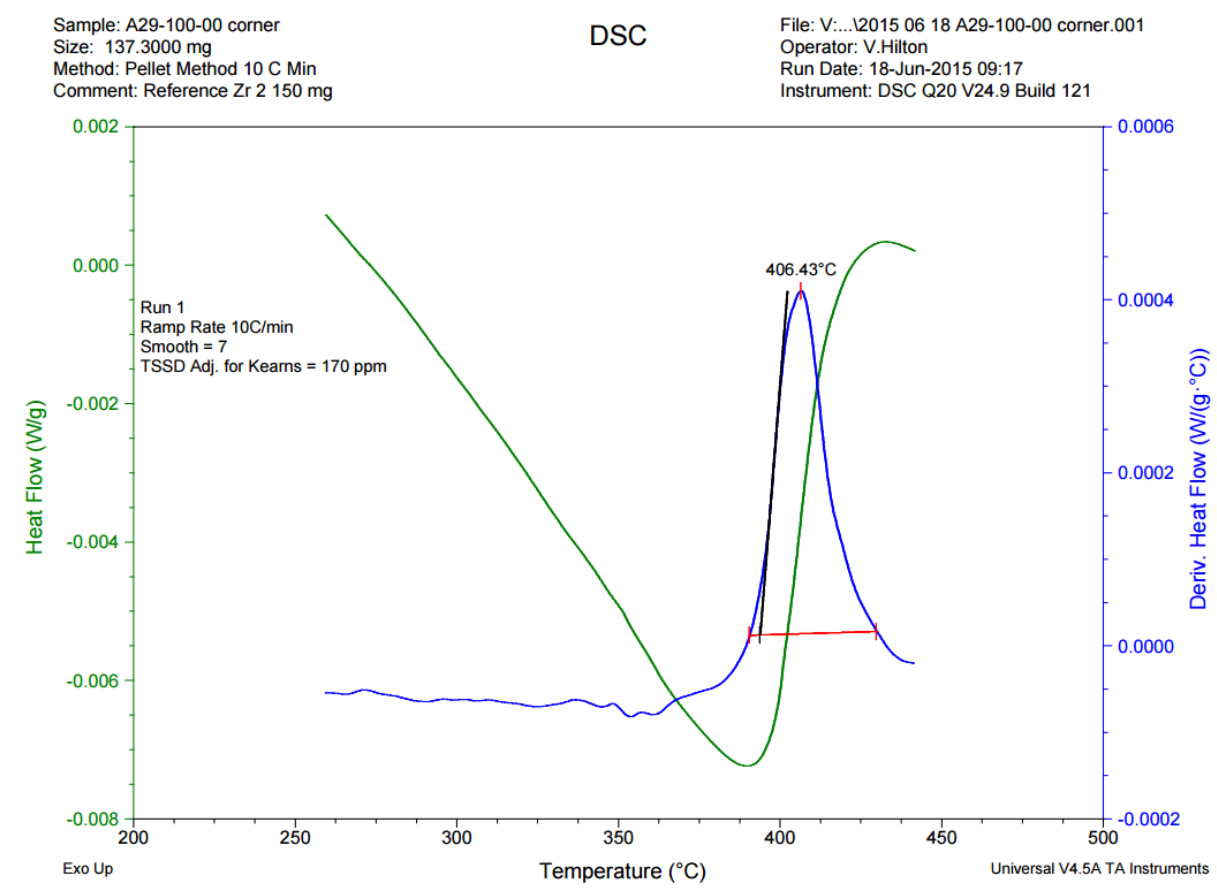

Figure 114: DSC heating curve \#1 for sample A29-100-00

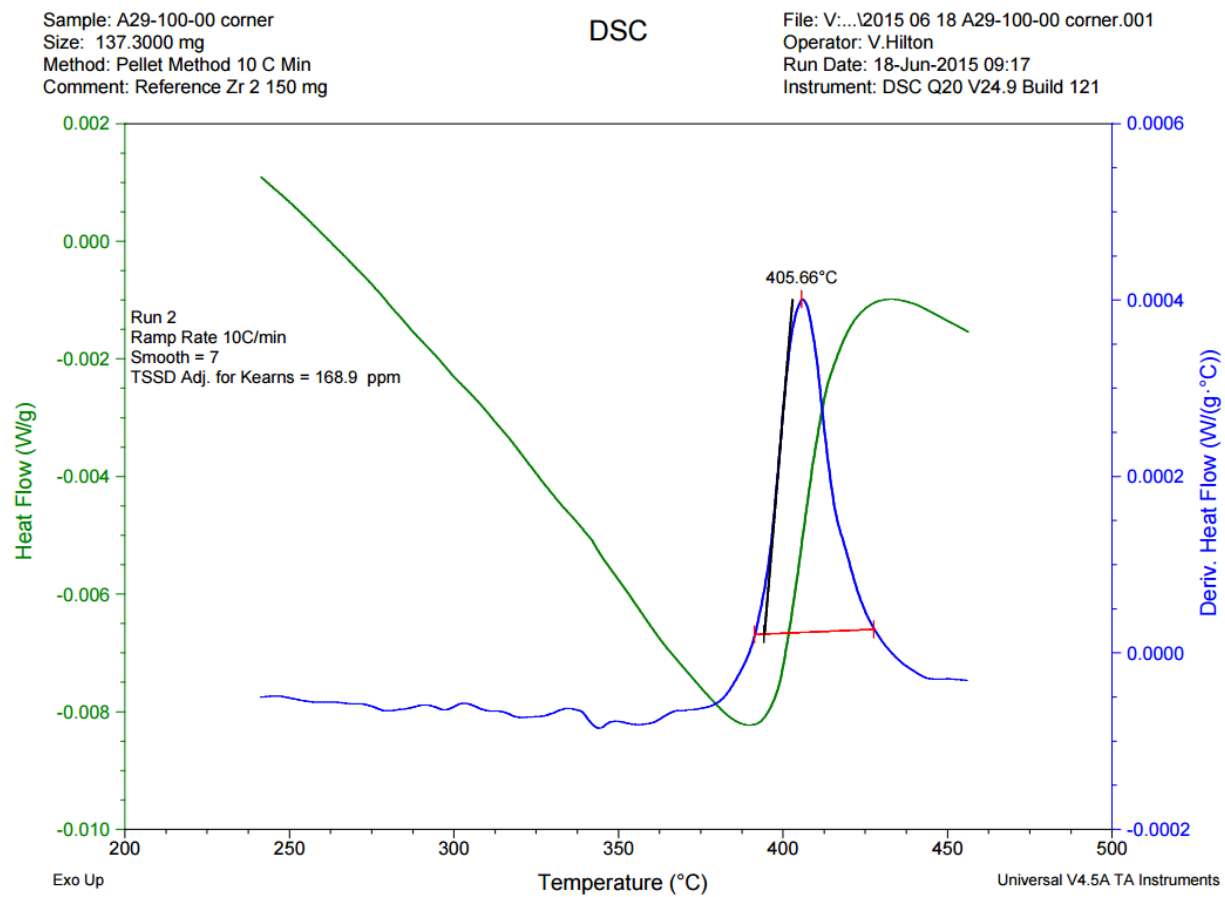

Figure 115: DSC heating curve \#2 for sample A29-100-00 


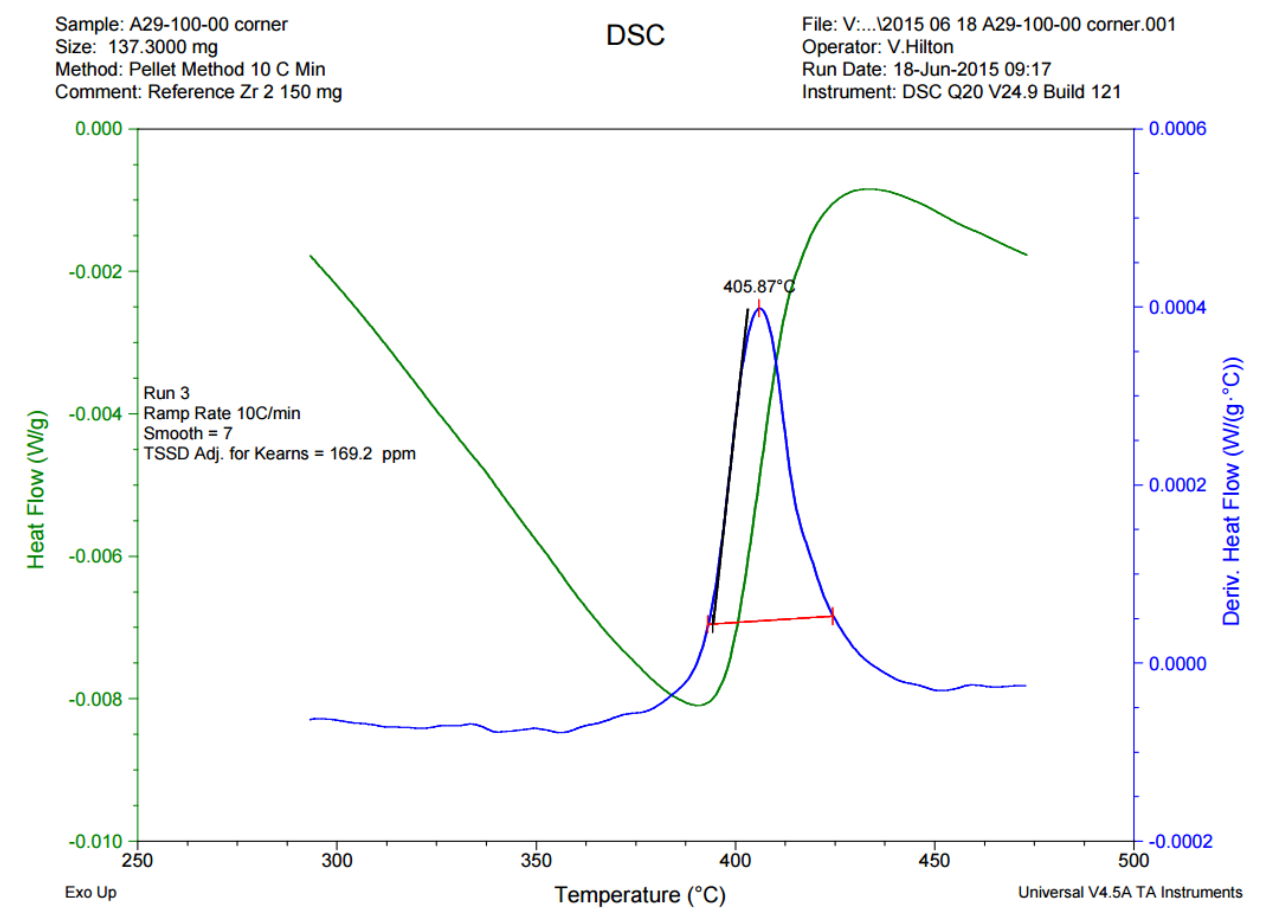

Figure 116: DSC heating curve \#3 for sample A29-100-00

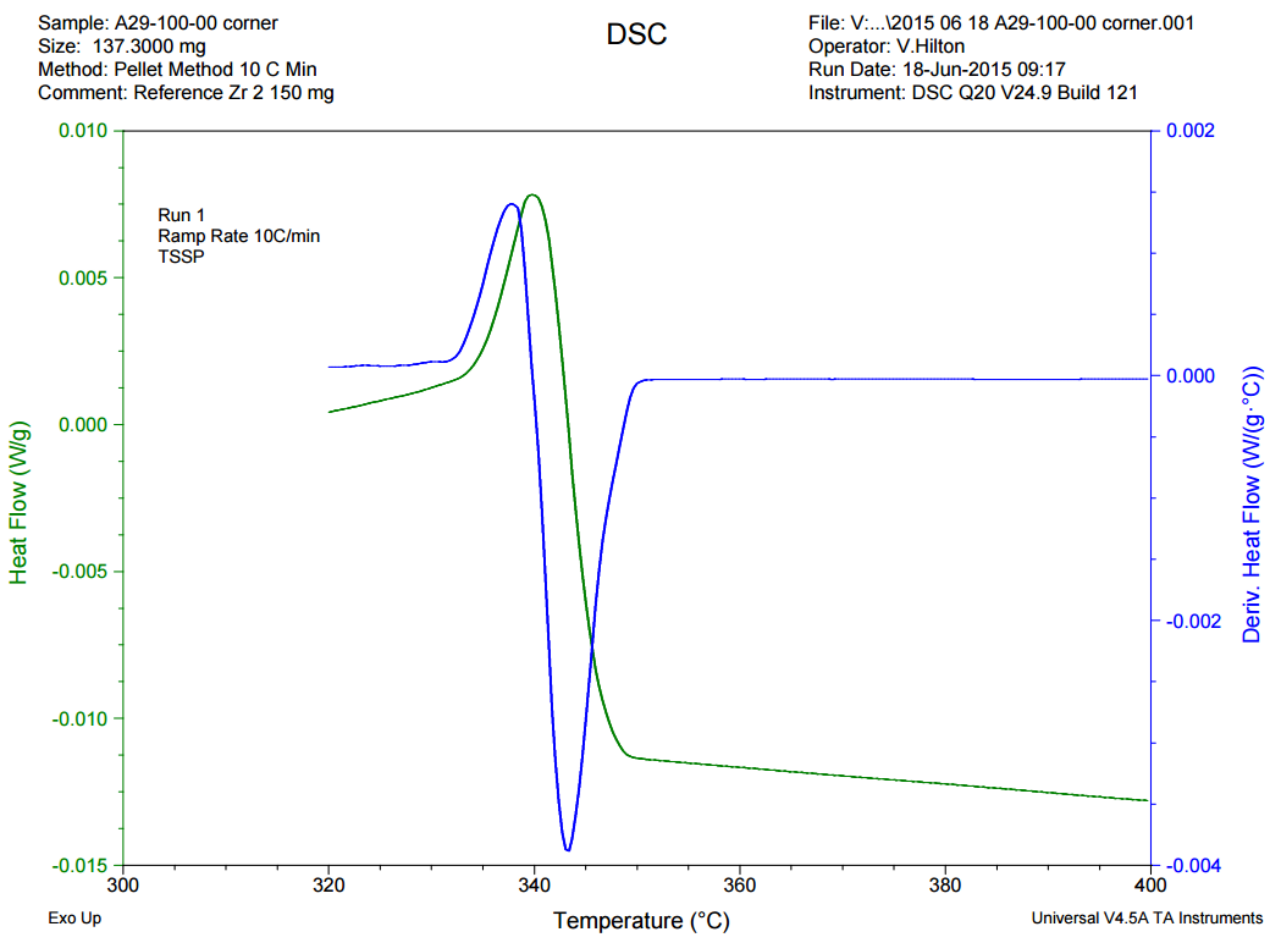

Figure 117: DSC cooling curve \#1 for sample A29-100-00 


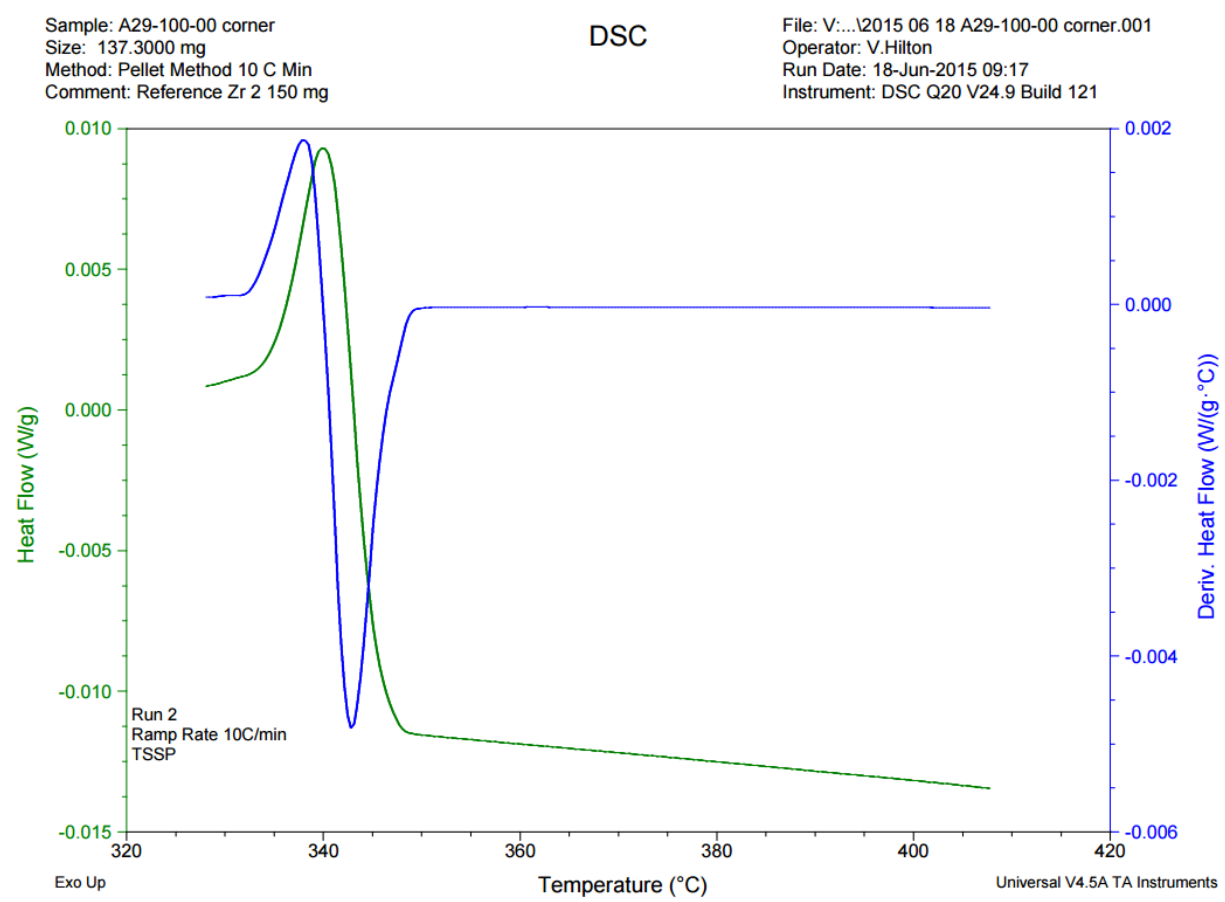

Figure 118: DSC cooling curve \#2 for sample A29-100-00

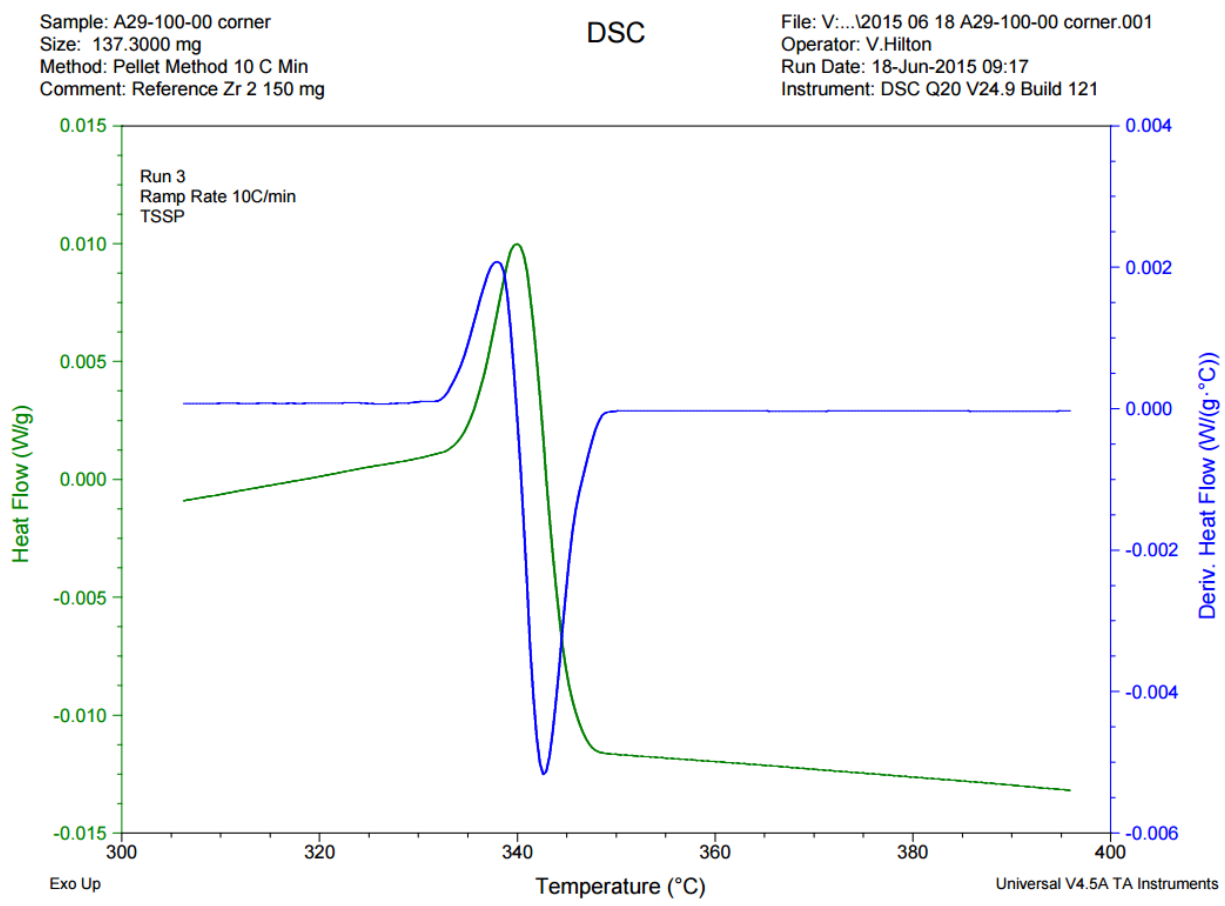

Figure 119: DSC cooling curve \#3 for sample A29-100-00 


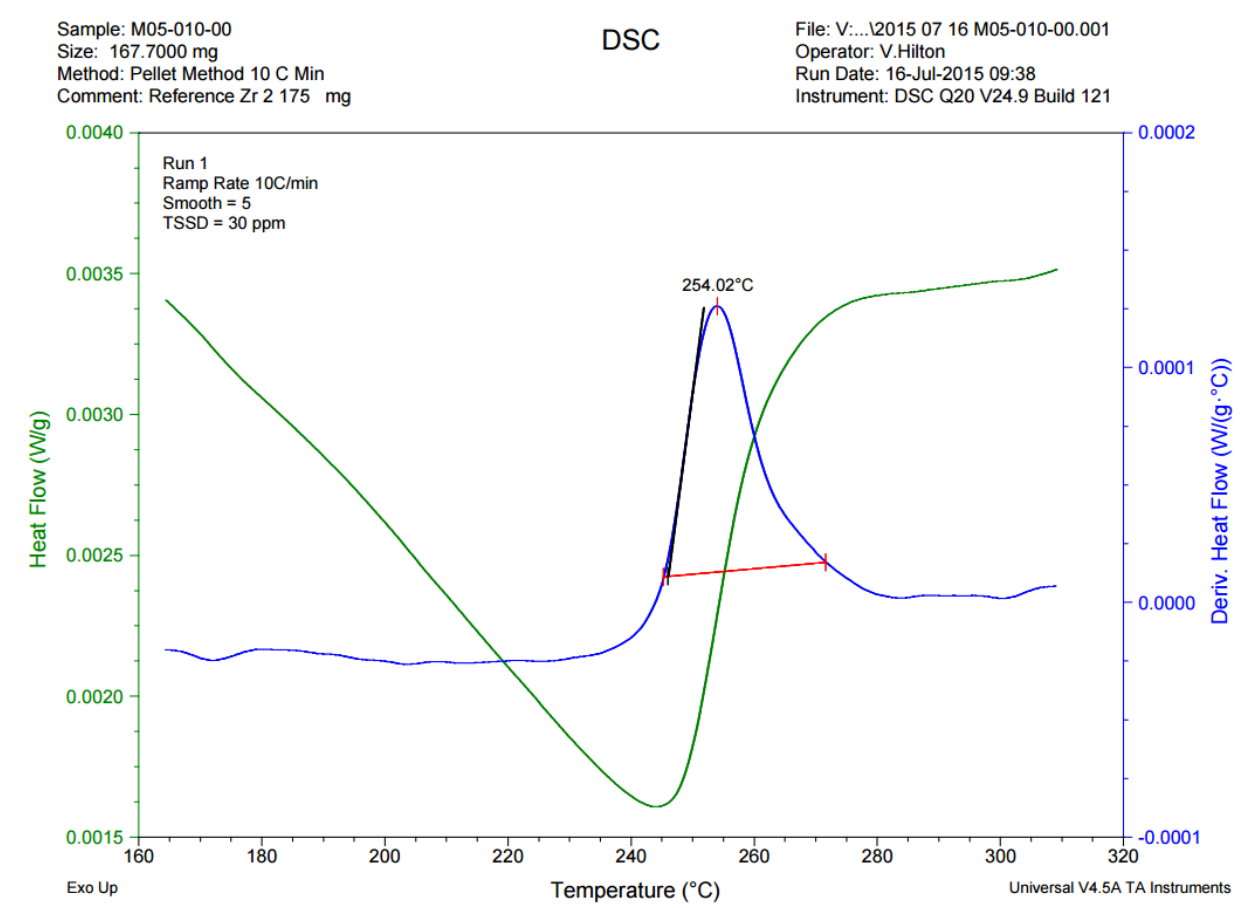

Figure 120: DSC heating curve \#1 for sample M05-010-00

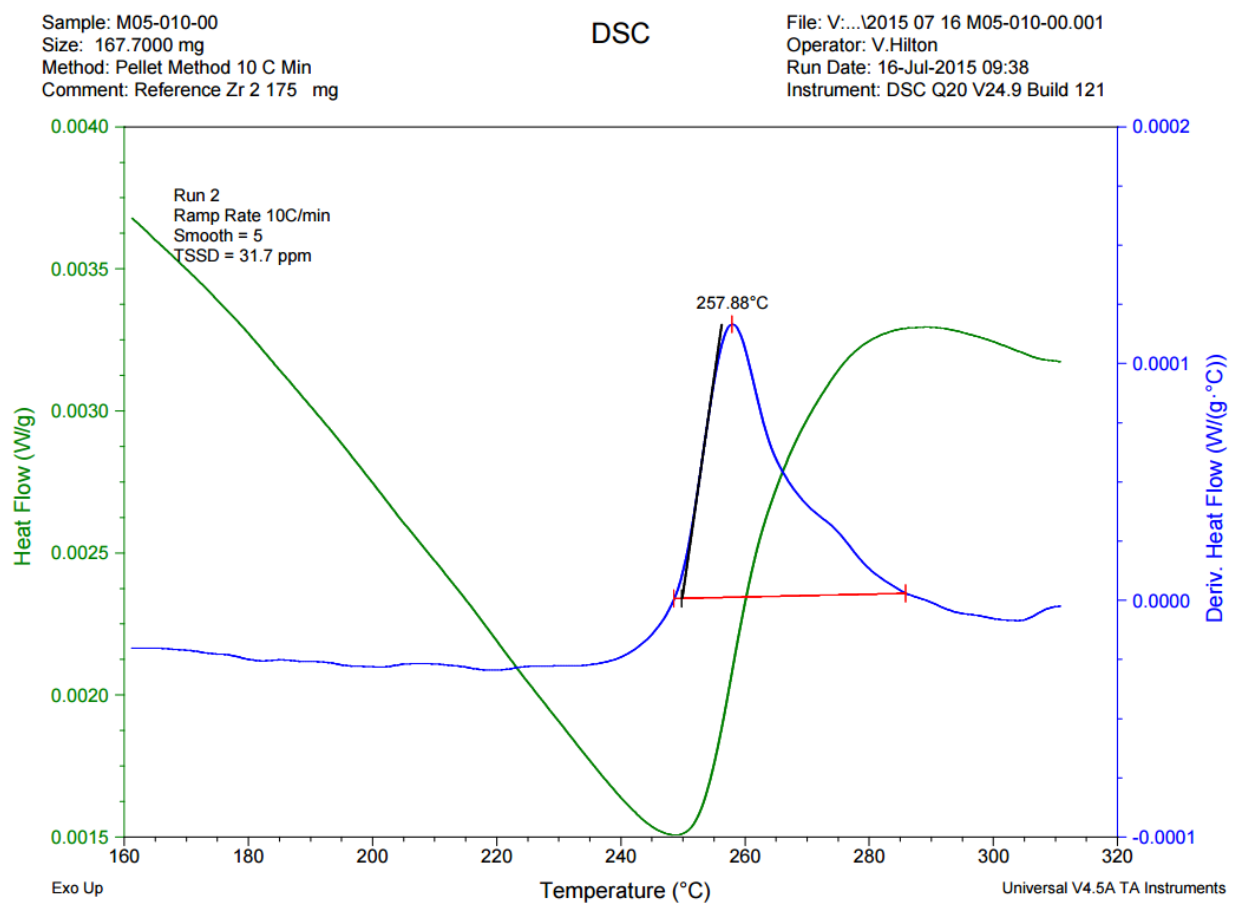

Figure 121: DSC heating curve \#2 for sample M05-010-00 


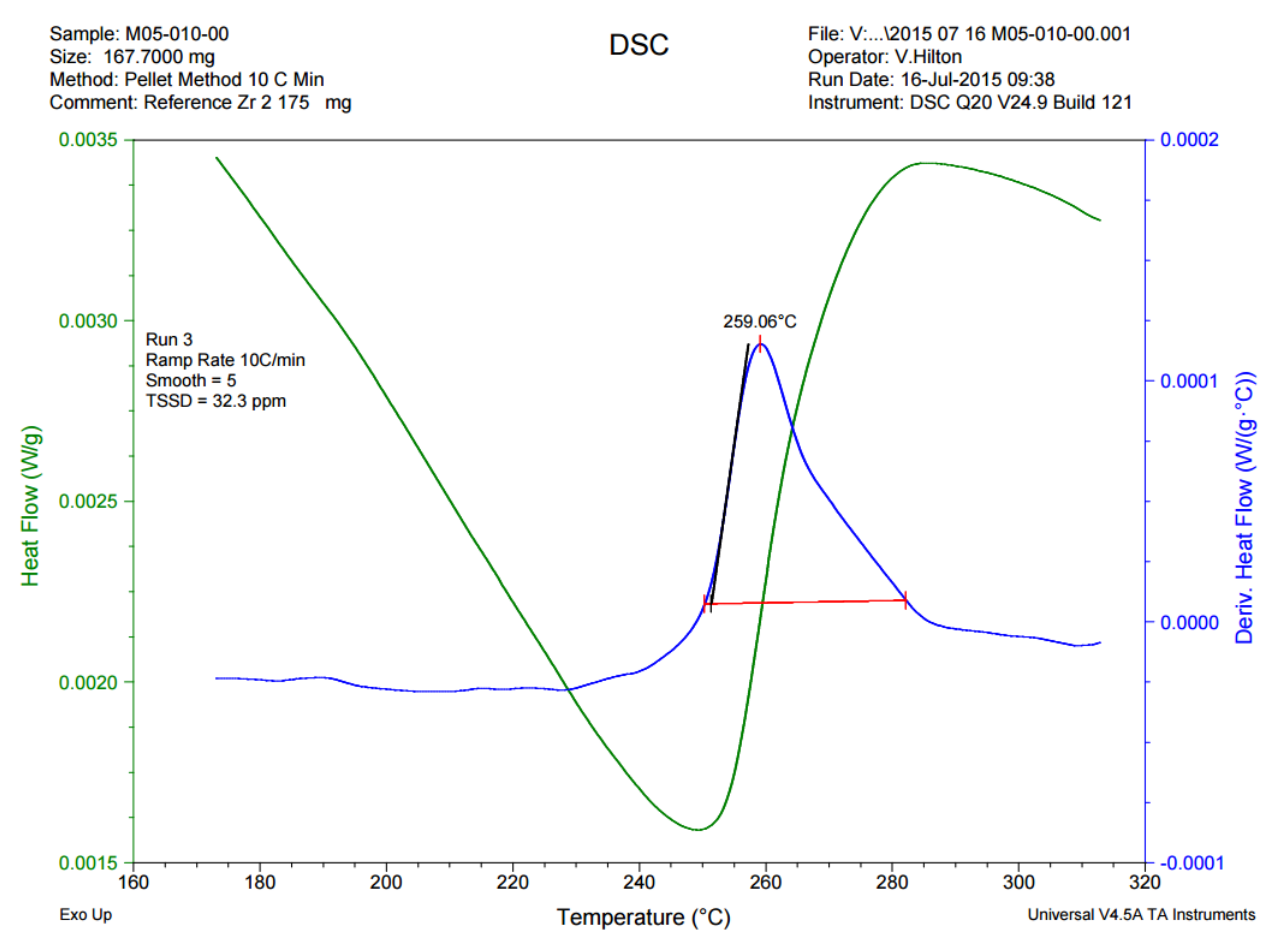

Figure 122: DSC heating curve \#3 for sample M05-010-00

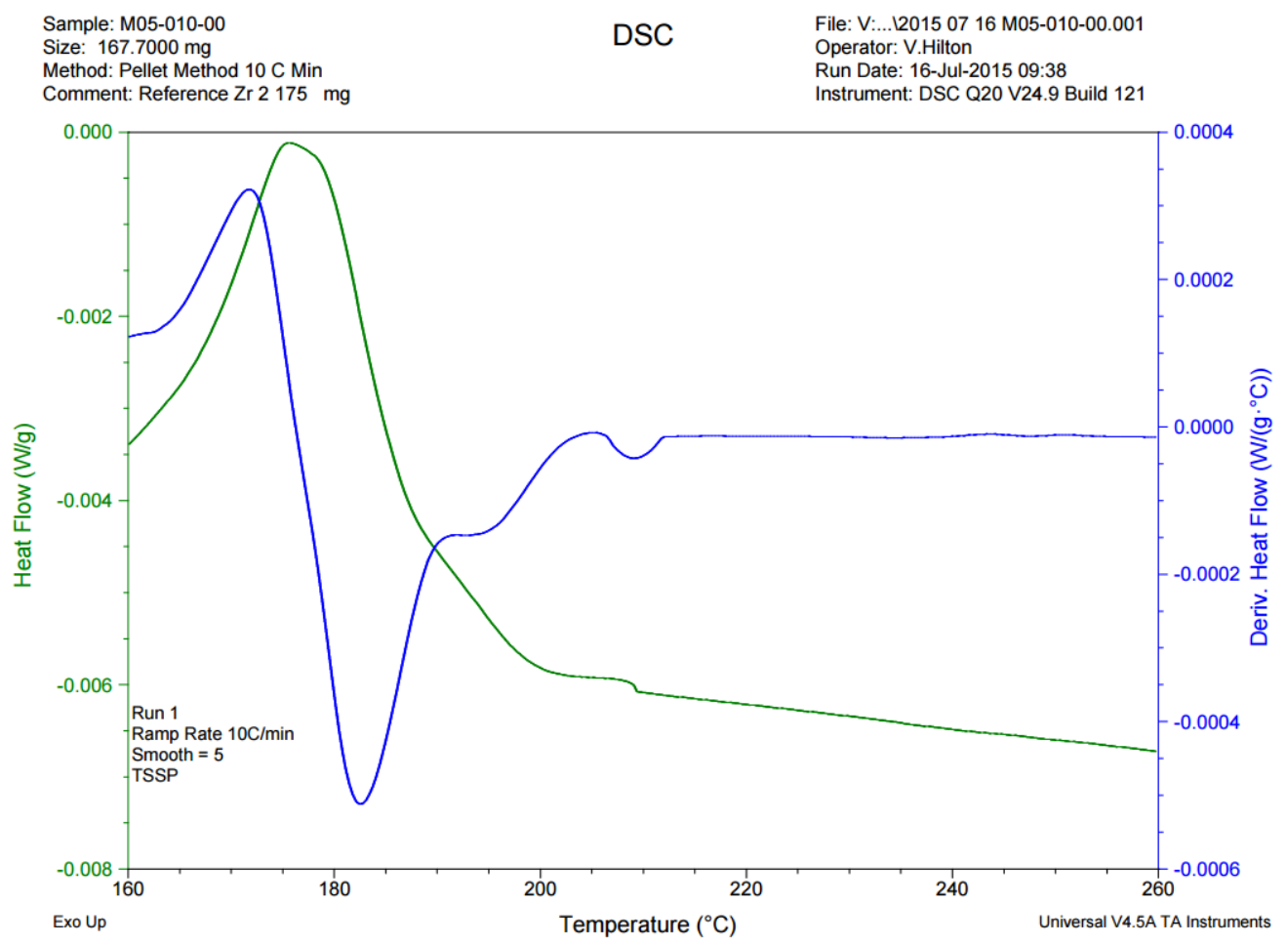

Figure 123: DSC cooling curve \#1 for sample M05-010-00 


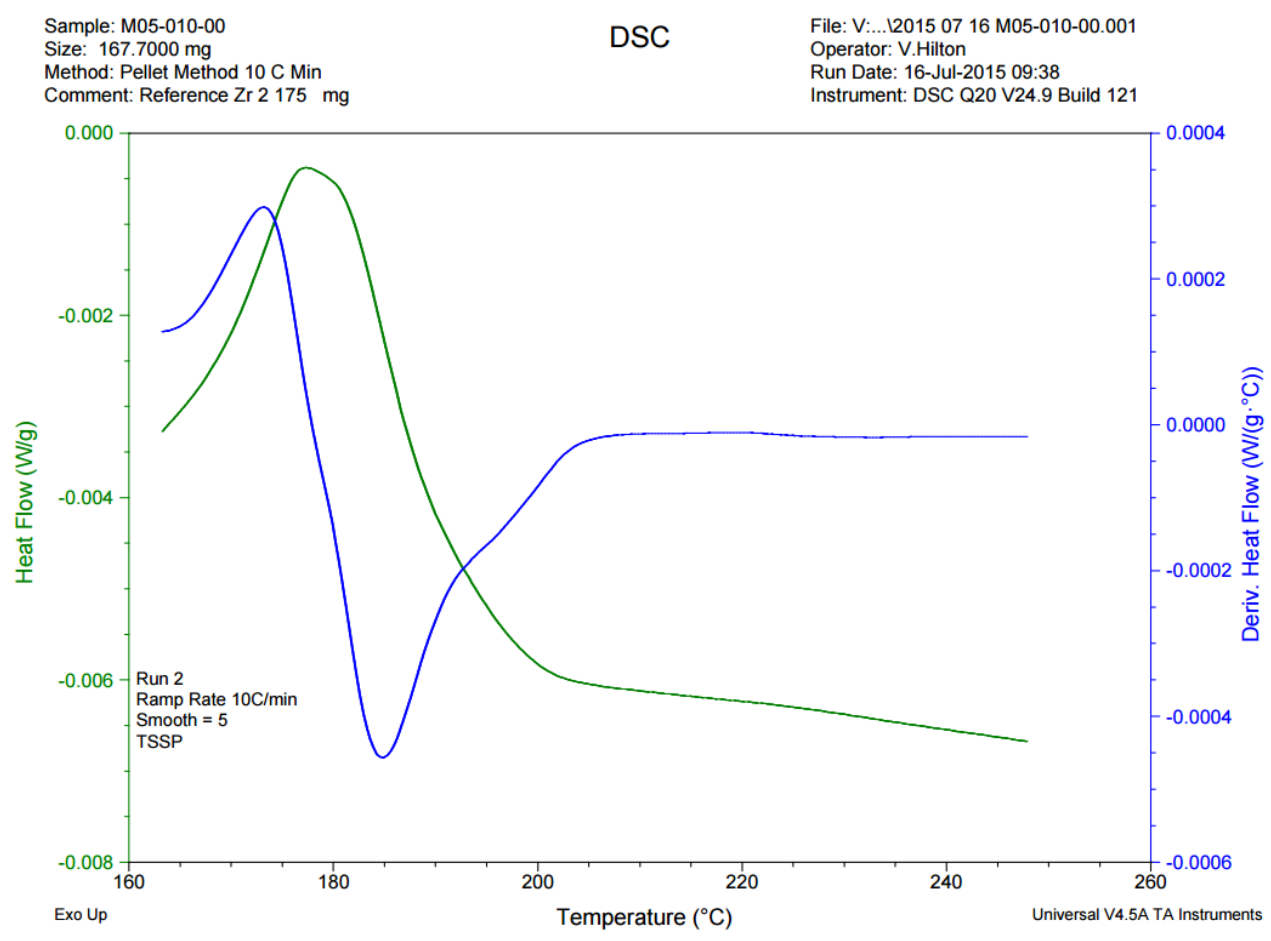

Figure 124: DSC cooling curve \#2 for sample M05-010-00

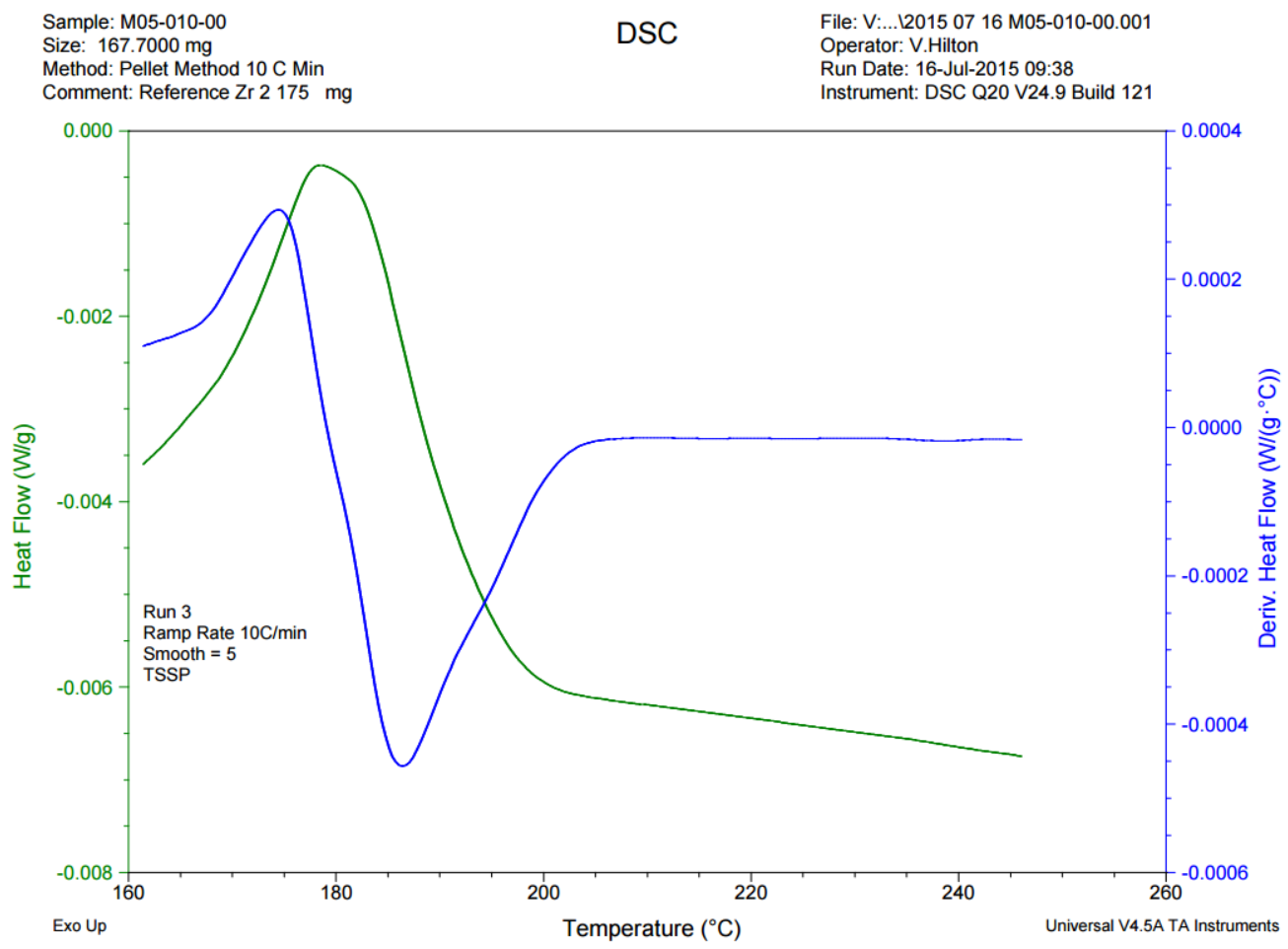

Figure 125: DSC cooling curve \#3 for sample M05-010-00 


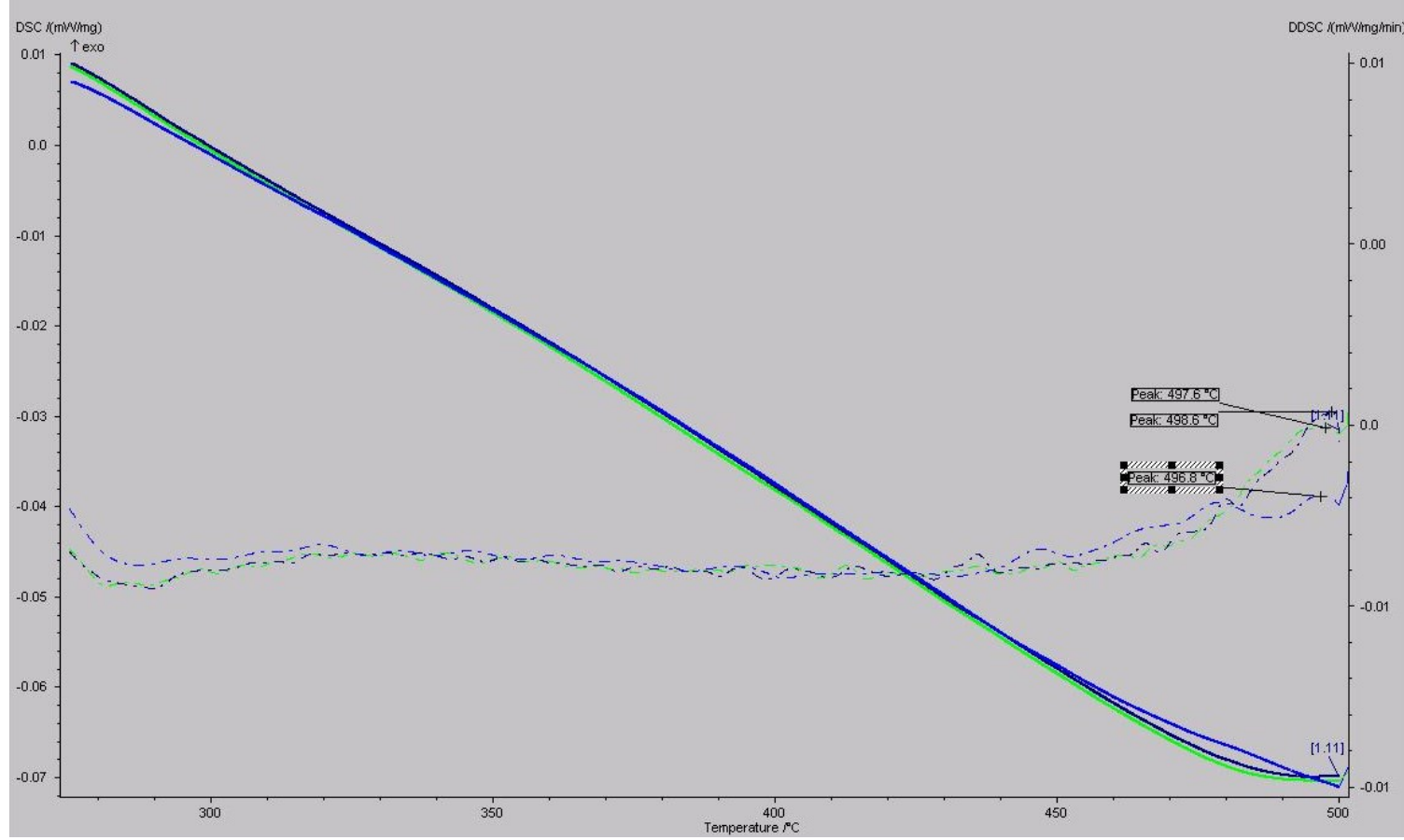

Figure 126: DSC heating curve of sample Sat1

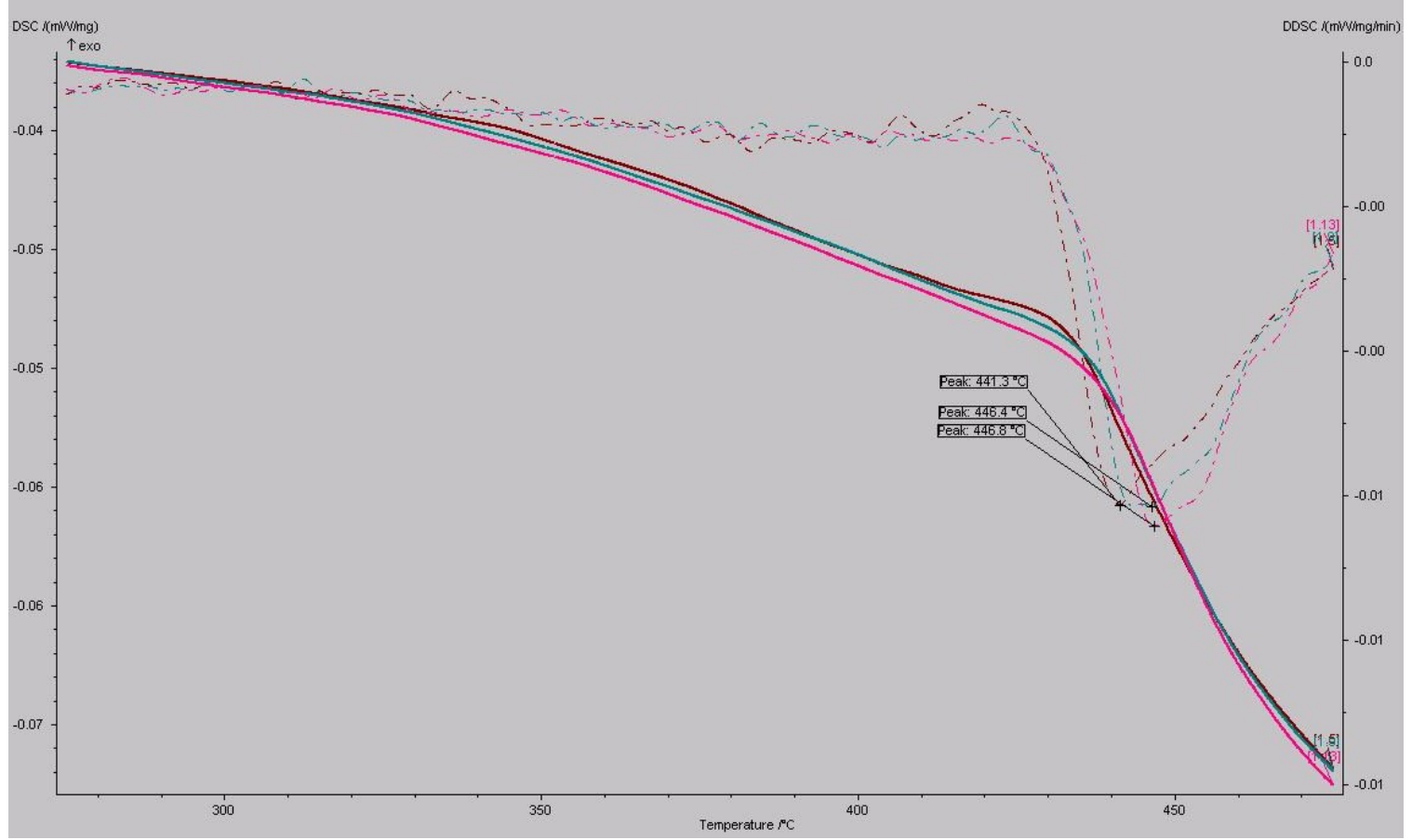

Figure 127: DSC cooling curve of sample Sat1 


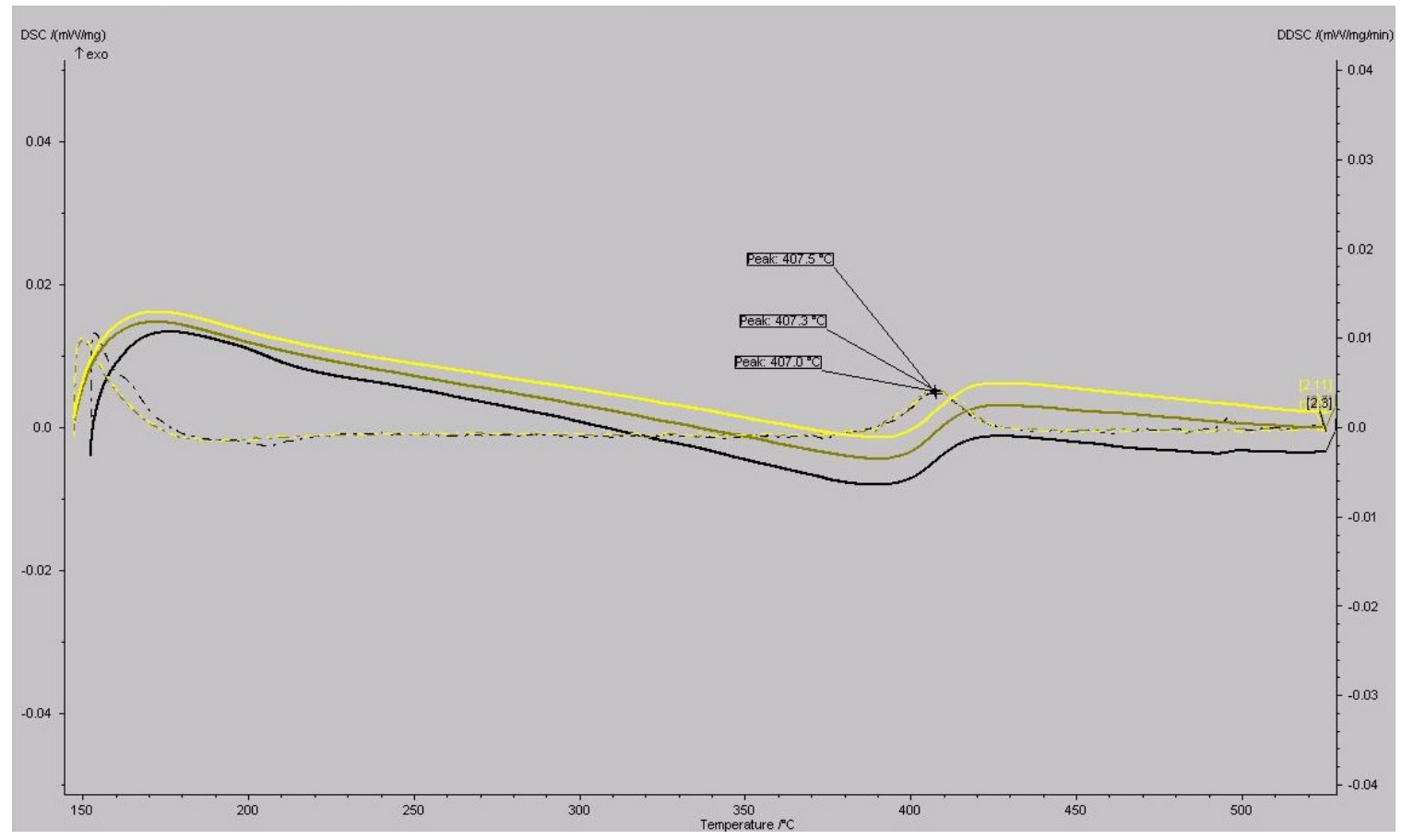

Figure 128: DSC heating curve of sample Sat3-B

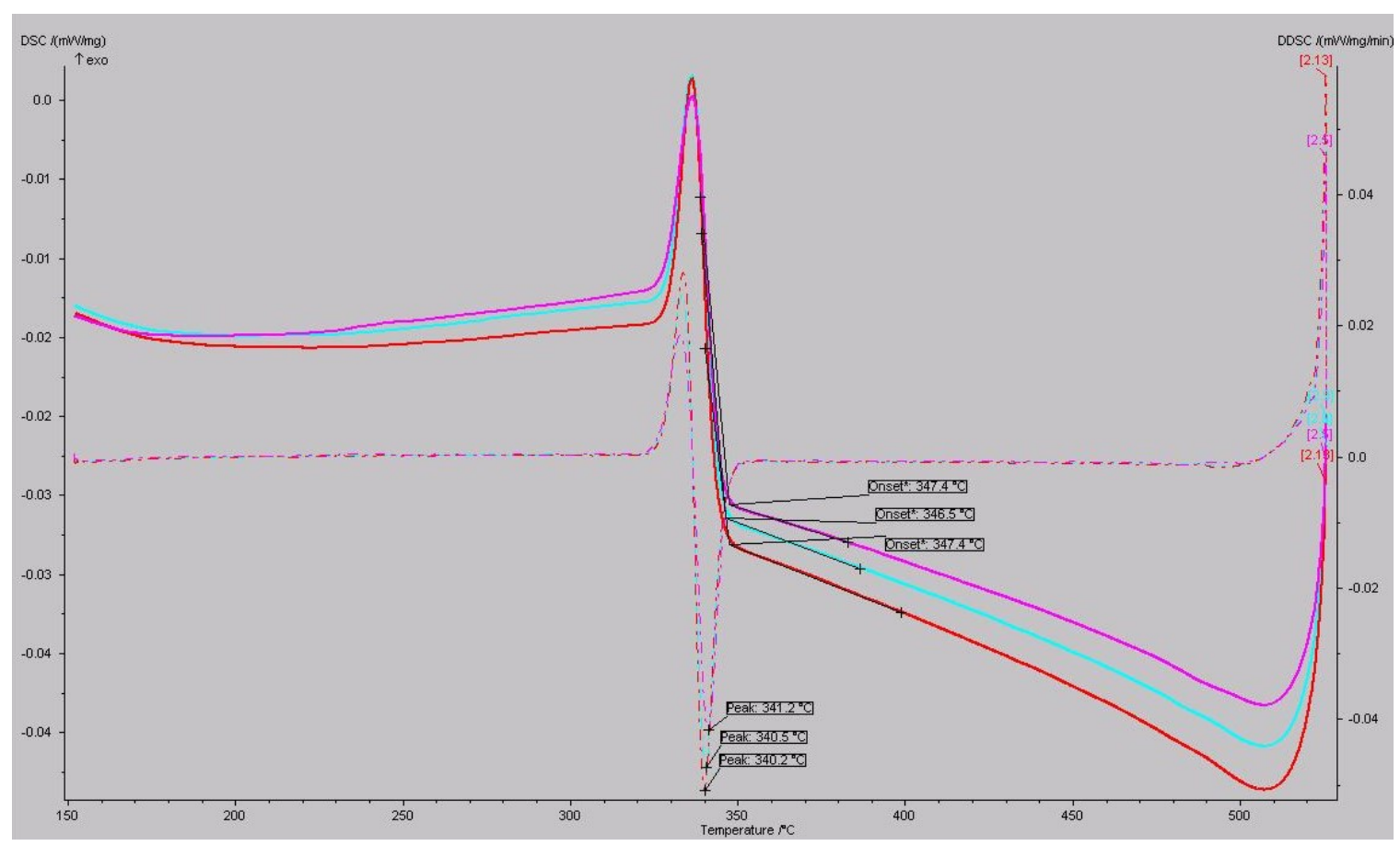

Figure 129: DSC cooling curve of sample Sat3-B 


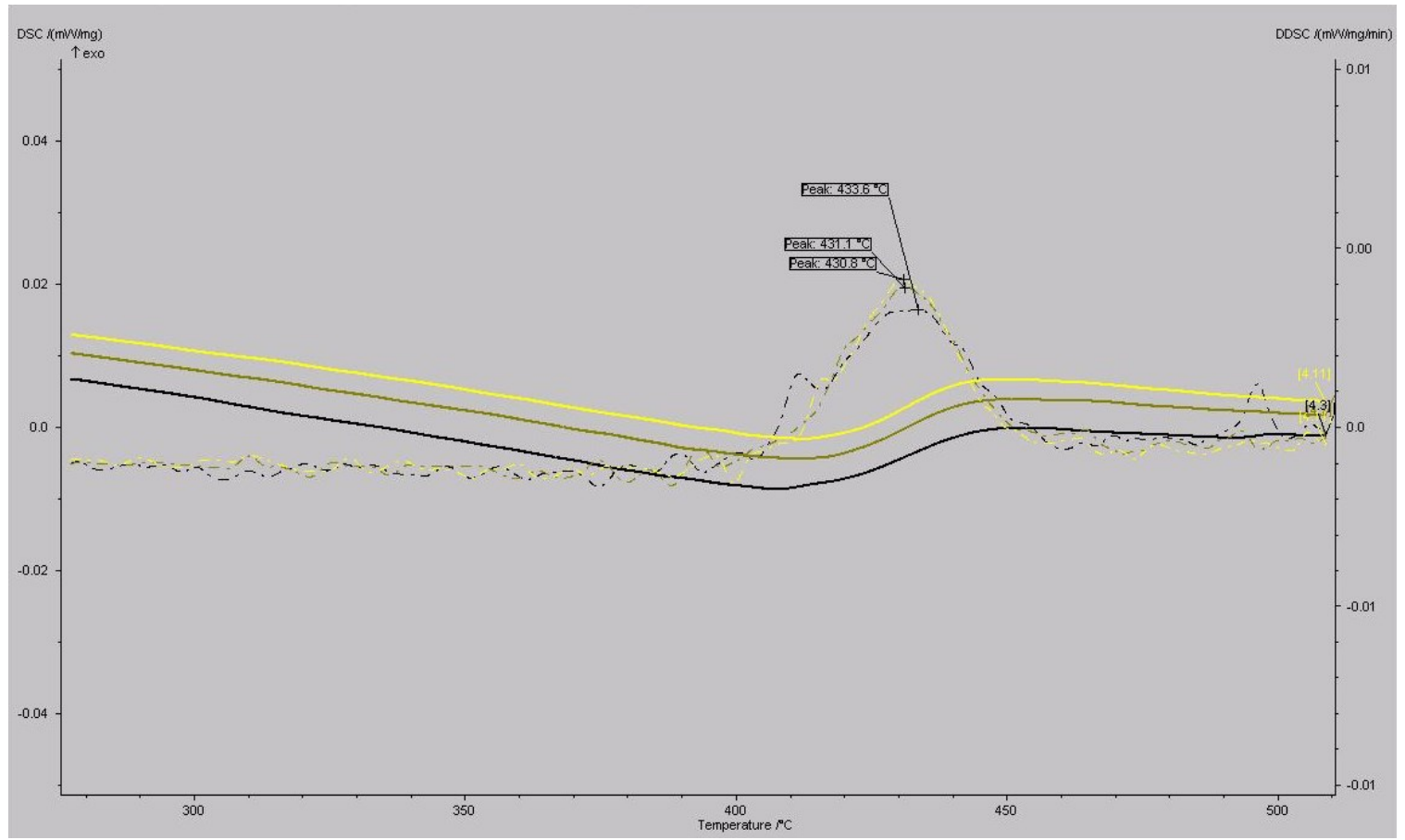

Figure 130: DSC heating curve of sample Sat3-M

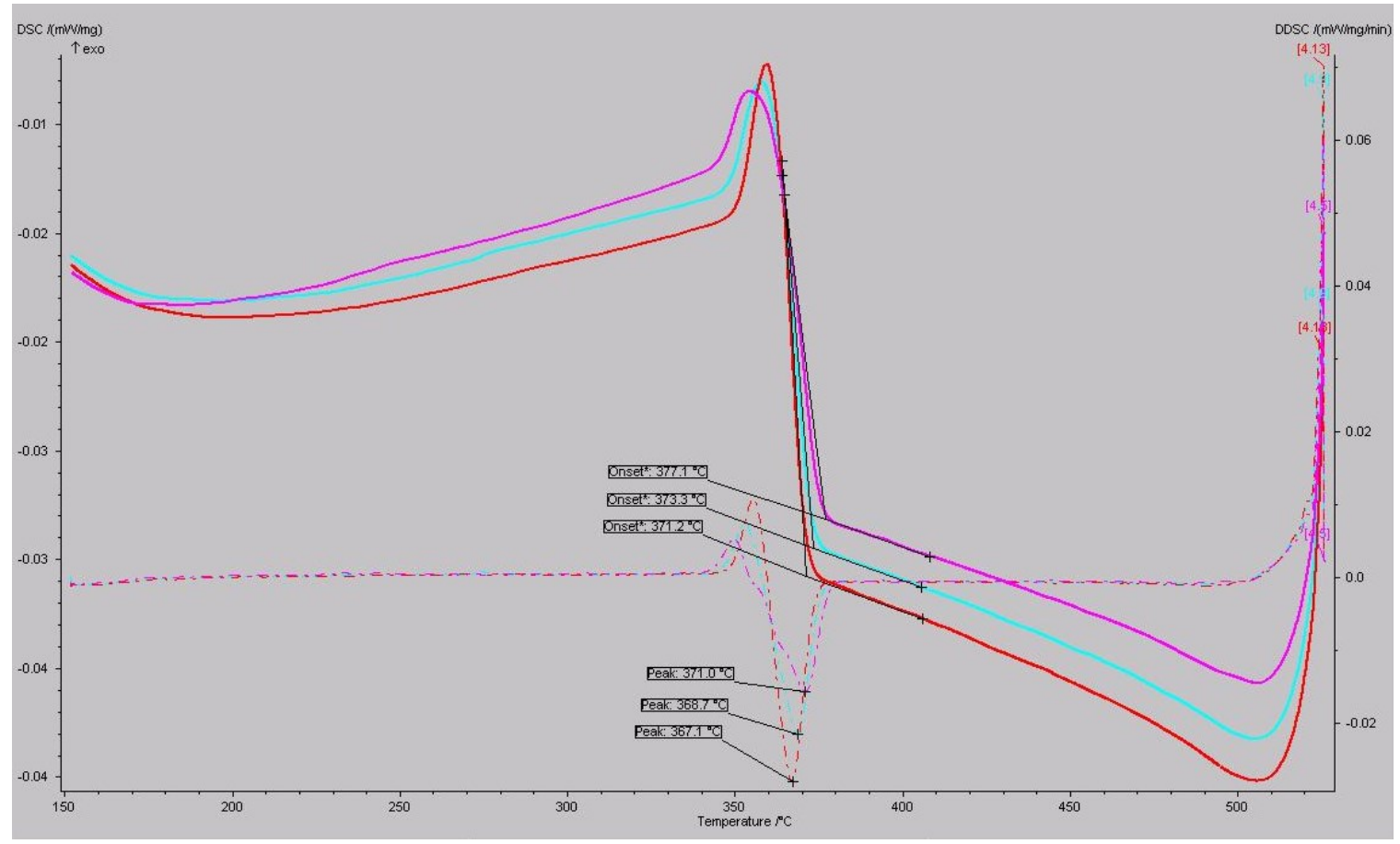

Figure 131: DSC cooling curve of sample Sat3-M 


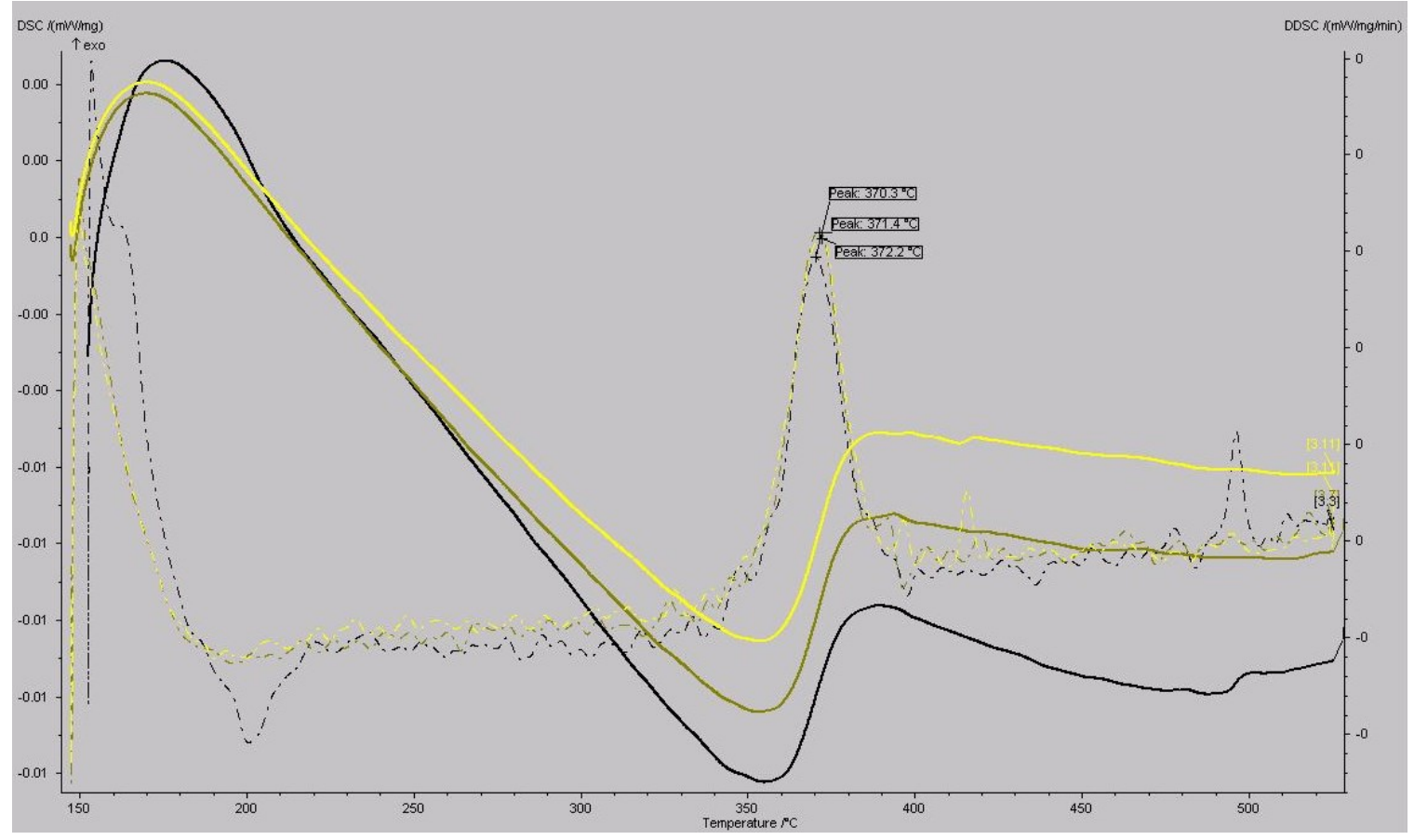

Figure 132: DSC heating curve of sample Sat3-T

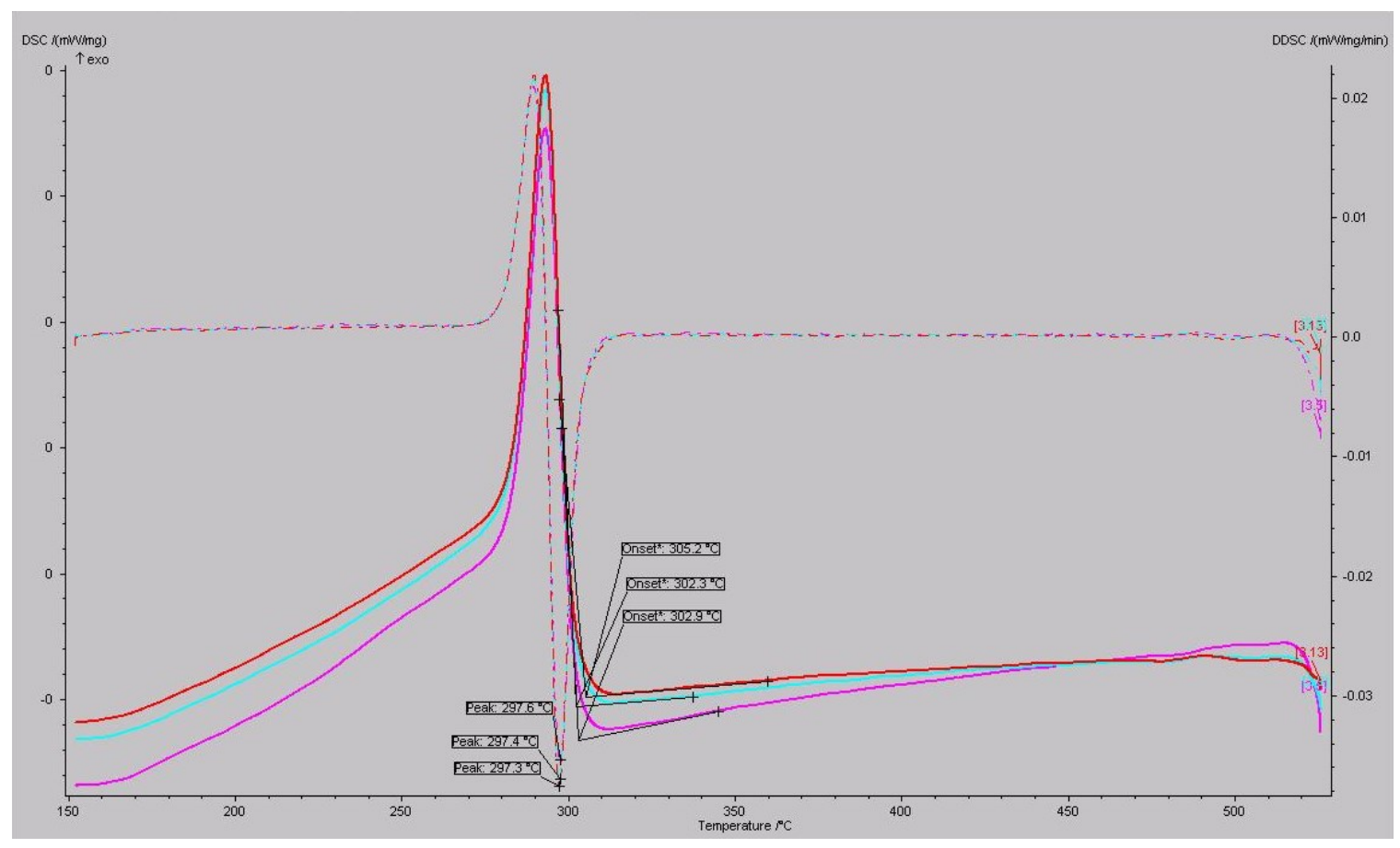

Figure 133: DSC cooling curve of sample Sat3-T 
Table 7: Copper-shell mechanical hydrogen ingress experimental data ${ }^{16}$

\begin{tabular}{|c|c|c|c|c|c|c|c|c|c|}
\hline Sample & Site & Ms (g) & $\begin{array}{c}\text { Mzrh2 } \\
\text { (g) }\end{array}$ & $\begin{array}{c}\mathrm{C}_{\mathrm{m}} \\
(\mathrm{ppm})\end{array}$ & $\mathbf{M C u}_{\text {(g) }}$ & $\begin{array}{c}\mathrm{C}_{\mathbf{p}} \\
(\mathrm{ppm})\end{array}$ & $\begin{array}{l}\text { Toven } \\
\left({ }^{\circ} \mathrm{C}\right)\end{array}$ & $\begin{array}{l}\text { Stress } \\
\text { (Mpa) }\end{array}$ & $\begin{array}{c}\mathbf{S}_{\mathbf{C u}} \\
(\mathbf{p p m})\end{array}$ \\
\hline $\begin{array}{c}\text { A16- } \\
\text { 200-00 }\end{array}$ & $\mathrm{CNL}$ & 3.5513 & 0.0331 & $\begin{array}{r}166.3 \\
\pm 5.0\end{array}$ & 65.2936 & $\begin{array}{l}173.0 \\
\pm 8.7\end{array}$ & 450.0 & 120. & 2.6 \\
\hline $\begin{array}{c}\text { A20- } \\
250-00\end{array}$ & $\mathrm{CNL}$ & 3.6710 & 0.0432 & $\begin{array}{r}216.9 \\
\pm 4.7\end{array}$ & 68.8353 & $\begin{array}{c}224.0 \\
\pm 11.2\end{array}$ & 450.0 & 120 & 2.6 \\
\hline $\begin{array}{c}\text { A20- } \\
175-00\end{array}$ & $\mathrm{CNL}$ & 3.5119 & 0.0198 & $\begin{array}{r}117.3 \\
\pm 5.2\end{array}$ & 39.6253 & $\begin{array}{l}114.0 \\
\pm 5.7\end{array}$ & 425.0 & 120 & 1.6 \\
\hline $\begin{array}{c}\text { A20- } \\
100- \\
\text { Centre }\end{array}$ & $\mathrm{CNL}$ & 3.7295 & 0.0324 & $\begin{array}{l}169.4 \\
\pm 4.9\end{array}$ & 56.1295 & $\begin{array}{l}173.0 \\
\pm 8.6\end{array}$ & 425.0 & 120 & 2.1 \\
\hline Sat-1 & $\mathrm{CU}$ & 0.9866 & 0.0478 & $\begin{array}{l}346.0 \\
\pm 4.4\end{array}$ & 224.6321 & $\begin{array}{l}366.0 \\
\pm 8.2\end{array}$ & 500.0 & 111 & 3.1 \\
\hline Sat-2T & $\mathrm{CU}$ & 0.8917 & 0.0074 & $\begin{array}{r}143.9 \\
\pm 5.1 \\
\end{array}$ & 52.6382 & $\begin{array}{r}131.0 \\
\pm 6.5 \\
\end{array}$ & 350.0 & 140 & 0.96 \\
\hline Sat-2M & $\mathrm{CU}$ & 1.0172 & 0.0072 & $\begin{array}{r}114.5 \\
\pm 5.3 \\
\end{array}$ & 61.4235 & $\begin{array}{r}103.0 \\
\pm 5.2 \\
\end{array}$ & 350.0 & 140 & 0.96 \\
\hline $\begin{array}{c}\text { CU- } \\
100-1\end{array}$ & $\mathrm{CU}$ & 3.4362 & 0.0162 & $\begin{array}{r}36.9 \\
\pm 6.2\end{array}$ & 152.6251 & $\begin{array}{r}34.0 \\
\pm 1.7\end{array}$ & 425.0 & 120 & 1.8 \\
\hline CU-50 & $\mathrm{CU}$ & 3.749 & 0.0082 & $\begin{array}{r}37.27 \\
\pm 6.2 \\
\end{array}$ & 48.6385 & $\begin{array}{c}37.3 \\
\pm \quad 1.9\end{array}$ & 425.0 & 120 & 1.8 \\
\hline Sat-2B & $\mathrm{CU}$ & 1.017 & 0.0068 & $\begin{array}{r}110.5 \\
\pm 5.3\end{array}$ & 50.1986 & $\begin{array}{l}106.0 \\
\pm 5.3\end{array}$ & 350.0 & 140 & 0.96 \\
\hline $\begin{array}{l}\text { A20- } \\
100- \\
\text { Side }\end{array}$ & $\mathrm{CNL}$ & 3.7300 & 0.0324 & $\begin{array}{l}167.4 \\
\pm 5.0\end{array}$ & 56.1295 & $\begin{array}{l}173.0 \\
\pm 8.6\end{array}$ & 425.0 & 120 & 1.8 \\
\hline $\begin{array}{c}\text { MH- } \\
\text { DSC-1 }\end{array}$ & $\mathrm{CU}$ & 3.1596 & 0.0128 & $\begin{array}{l}69.4 \\
\pm 5.7 \\
\end{array}$ & 56.3554 & $\begin{array}{r}71.4 \\
\pm 4.8 \\
\end{array}$ & 425.0 & 99 & 1.8 \\
\hline $\begin{array}{c}\text { MH- } \\
\text { DSC-2 }\end{array}$ & $\mathrm{CU}$ & 3.2869 & 0.0138 & $\begin{array}{r}78.3 \\
\pm 5.7 \\
\end{array}$ & 49.8975 & $\begin{array}{r}79.0 \\
\pm 3.6 \\
\end{array}$ & 425.0 & 99 & 1.8 \\
\hline $\begin{array}{c}\mathrm{MH}- \\
\mathrm{DSC}-3\end{array}$ & $\mathrm{CU}$ & 3.2552 & 0.0140 & $\begin{array}{r}75.6 \\
\pm 5.7\end{array}$ & 59.8655 & $\begin{array}{r}75.8 \\
+3.6\end{array}$ & 425.0 & 99 & 1.8 \\
\hline
\end{tabular}

\footnotetext{
${ }^{16}$ Site is the location where the hydrogen concentration was determined: Carleton University (CU), or CNL Chalk River (CNL). $\mathrm{M}_{\mathrm{s}}$ is the mass of the zirconium sample. $\mathrm{M}_{\mathrm{ZrH} 2}$ is the mass of zirconium hydride powder. $\mathrm{C}_{\mathrm{m}}$ is the determined hydrogen concentration using DSC. $\mathrm{M}_{\mathrm{Cu}}$ is the mass of copper used for the shell. $\mathrm{C}_{\mathrm{p}}$ is the predicted concentration from Equation 4.18. $\mathrm{T}_{\text {oven }}$ is the clamshell oven temperature used. Stress is the applied load in MPa, it is calculated as the MTS force divided by the copper shell area (this stress is equal to the hydrogen gas pressure). $\mathrm{S}_{\mathrm{Cu}}$ is the solubility of hydrogen in copper calculated from Equation 4.23. Unless otherwise indicated errors are in units of the least significant digit.
} 


\begin{tabular}{|c|c|c|c|c|c|c|c|c|c|}
\hline CU-LT & CU & 2.0496 & 0.0101 & $\begin{array}{c}90.3 \\
\pm 5.5\end{array}$ & 57.5839 & $\begin{array}{c}96.0 \\
\pm 4.8\end{array}$ & 322.0 & 145 & 1.1 \\
\hline $\begin{array}{c}\text { M05- } \\
10\end{array}$ & CNL & 3.4469 & 0.0023 & $\begin{array}{c}31.3 \\
\pm 6.3\end{array}$ & 42.0625 & $\begin{array}{c}5.9 \\
\pm 4.0\end{array}$ & 425.0 & 120 & N/A \\
\hline Sat3-T & CU & 1.7570 & 0.0154 & $\begin{array}{c}171.3 \\
\pm 5.2\end{array}$ & 58.8019 & $\begin{array}{c}169.8 \\
\pm 8.5\end{array}$ & 350.0 & 140 & 0.9 \\
\hline Sat3-M & $\mathrm{CU}$ & 2.0575 & 0.0216 & $\begin{array}{c}210.2 \\
\pm 4.8\end{array}$ & 58.4621 & $\begin{array}{c}211.4 \\
\pm 10.6\end{array}$ & 350.0 & 140 & 1.0 \\
\hline Sat3-B & $\mathrm{CU}$ & 1.6580 & 0.0129 & $\begin{array}{c}171.3 \\
\pm 4.9\end{array}$ & 57.2880 & $\begin{array}{c}147.8 \\
\pm 7.4\end{array}$ & 350.0 & 140 & 0.3 \\
\hline
\end{tabular}

